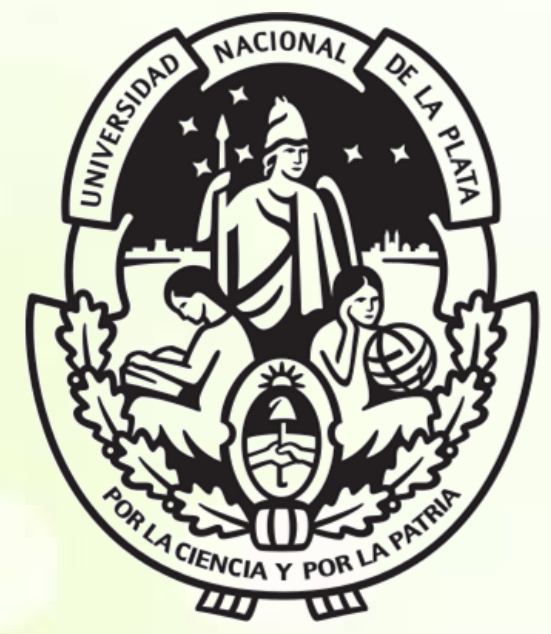

UNIVERSIDAD NACIONAL DE LA PLATA

FACULTAD DE CIENCIAS EXACTAS DEPARTAMENTO DE QUÍMICA

\title{
USO DE RESIDUOS ORGÁNICOS DOMICILIARIOS EN LA OBTENCIÓN DE MATERIALES ÚTILES DE INTERÉS AMBIENTAL Y NANOTECNOLÓGICO
}

Ing. Donaldo Fabio Mercado Castro

\section{Directores:}

Dra. Mónica C. González. Dra. Paula Careghato. 


\section{USO DE RESIDUOS ORGÁNICOS DOMICILIARIOS EN LA OBTENCIÓN DE MATERIALES ÚTILES DE INTERÉS AMBIENTAL Y NANOTECNOLÓGICO}

Ing. Quim. Donaldo Fabio Mercado Castro

2016

El presente trabajo de tesis para optar al grado de Doctor en Ciencias Exactas ha sido desarrollado en el Instituto de Investigaciones Fisicoquímicas Teóricas y Aplicadas - (INIFTA), Facultad de Ciencias Exactas, UNLP, bajo la dirección de la Dra. Mónica C. González y de la Dra. Paula Caregnato. 
A mi Padre y Madre, Los motores de mi vida. 


\section{Agradecimientos}

Mi experiencia en el doctorado comenzó mucho antes que la fecha en la que está registrada mi matrícula. Empezó el 27 de octubre de 2011, el día que salí desde Colombia hacia Argentina. Desde ese día han sido muchas de las personas y entidades que me apoyaron durante este trayecto, a las que les agradezco inmensamente.

A Argentina y a CONICET por financiarme los estudios de doctorado mediante la beca.

A mi directora Mónica, quien sin conocerme personalmente me apoyó desde el inicio de este proyecto. Quien me orientó tanto personal como profesionalmente durante todos estos años. Por darme la oportunidad de trabajar en lo que verdaderamente me apasiona.

A mi co-directora Paula, por la inmensa paciencia que me tuvo, por los consejos y por apoyarme en mis experimentos, por permitirme equivocarme y orientarme en el mundo de la ciencia.

A mi co-directora CONICET Cristina, por su calidez humana, consejos, favores, regaños. Por la confianza, por salirse de su zona de confort en la ciencia para que yo pudiera trabajar en lo que me gusta, por el empuje, el apoyo. Por haberme introducido al mundo de la ciencia.

A Daniel Martiré por estar siempre pendiente de todos en el grupo. Por sus consejos y buena disposición a ayudar.

A María Laura Dell' Arciprete por abrirme, literalmente, las puertas de la oficina y del laboratorio. Por intentar ayudarme en mi fallido intento de integrarme. Por los consejos y por escucharme las veces que más lo necesitaba. Por el apoyo en los muchísimos experimentos que hicimos juntos.

A Luciano Carlos por los consejos tanto en índole personal como profesional. Por el apoyo y la confianza. Por mostrarme que la parte social en la ciencia es un factor sumamente importante.

A Cristian Lillo, sin el cual mi estadía en Argentina hubiese sido muchísimo más complicada y difícil. Por la calidez humana y mostrarme el significado de lo que es una persona totalmente desinteresada.

A JuanJo Romero por la buena onda. Por las charlas, por los experimentos que planteamos juntos. Por siempre estar dispuesto en seguirme en las locuras que se me ocurrían. 
A María Laura Dittler. A pesar del percance que tuvimos me diste una palabra de aliento y me prestaste tu hombro en uno de los momentos más difíciles de mi vida.

A los demás integrantes del grupo, Hernán, Gabriela, Valeria, Belén, Francisca, Damián y Joaquín por las sonrisas, charlas y todo el tiempo tan ameno que pasamos juntos.

Al Dr. Aldo Rupert por el apoyo en las medidas de XPS.

Al Dr. Francisco H. Sánchez por el apoyo y orientación en las medidas de magnetismo.

Al Dr. Marcelo Ceolín por el apoyo en la realización y análisis de las medidas de SAXS.

A las Dras. Alessandra Bianco-Prevot y Giuliana Magnacca por su apoyo durante mis estadías en Torino. Por guiarme y apoyarme durante todo ese tiempo. Por las charlas y sonrisas, por la calidez humana. A la Dra. Mery Malandrino por su apoyo en las medidas de ICP y por siempre tener una sonrisa para mí.

A la Dra. Paola Avetta y al Dr. Juan Gomis por ayudarme a entender el mundo de los SBO.

Al Dr. Antonio Arques por guiarme durante mi estadía en España. Por las recomendaciones. Por las charlas y orientaciones tanto a nivel científico como personal.

A Sara Ballesteros por las sonrisas, por el apoyo tanto científico como personal. Quien, a pesar de la distancia, sigue siendo una excelente amiga.

A todo el personal del INIFTA quienes facilitaron el apoyo de esta tesis.

A las autoridades de la Facultad de Cs. Exactas de la UNLP y del INIFTA por haberme permitido trabajar y aprender en las instalaciones.

Y por último, pero desde el fondo de mi corazón:

A mi papá, este sueño quizá era más tuyo que mío. Te agradezco enormemente el haberme dado tu vida para que sea quien soy. Por enseñarme, por permitir que me equivocara por mi bien, por hacerme crecer como persona y explicarme cómo funciona el mundo, por confiar en mí. Por todo tu amor y entrega. Me hubiera encantado alzar mi rostro el día de la sustentación y verte viéndome de la forma con la que lo hacías. Espero estés orgulloso de mi como siempre lo decías.

A mi madre, el ser que más amo en la vida, gracias por mostrarme que hay que seguir adelante, aunque la vida te golpee una y mil veces. Por ser la mujer fuerte e inquebrantable que eres. Por apoyarme y quererme. Por tus 
sacrificios. Por enseñarme lo que es verdaderamente importante en la vida y por apoyarme en todo lo que he hecho a pesar de no estar de acuerdo.

A mis hermanos, con quienes a pesar de ser tan diferentes nos apoyamos y amamos.

A mis Tíos y primos por mostrarme que, a pesar de las diferencias, la familia es un grupo incondicional.

A John, por todo el tiempo compartido. Las experiencias vividas. Por apoyarme, soportarme, orientarme, aconsejarme. Por ayudarme a crecer socialmente. Por Sakura y Neko. Por ser de las personas que dejan huella en tu vida.

A Juan, mi amigo-hermano. Por todas las experiencias vividas, por los consejos y favores. Por su hospitalidad durante mis innumerables visitas a Medellín. Por su amistad incondicional.

A Diana Henao, mi amiga-hermana. Por estar siempre conmigo, por su preocupación y amistad. Quien a pesar de la distancia nunca permitió que dejáramos de hablar.

A mis amigos, Eduart, Sebas, Adriana, Mauricio, por el apoyo y los consejos. Quienes, a pesar de la distancia, desacuerdos y/o momentos difíciles siempre me alegraron la existencia. 


\section{Contenido}

Capítulo 1:Introducción y objetivos .12

1.1. Sustancias tipo húmicas obtenidas de residuos agroindustriales - Caso de los SBO en la región Piamonte, Italia.

1.1.1. Obtención de los SBO .14

1.1.2.ComposiciónQuímica de los SBO. 15

1.1.3. Uso de los CVT230 como fotosensibilizadores y como auxiliares en la degradación tipo Fenton de contaminantes orgánicos.

1.2. Biorefinería - Aprovechamiento de Biomasa para obtención de productos de interés.

1.2.1. Otros residuos de interés.

1.2.1.1. Yerba Mate (Ilexparaguariensis) - De bebida tipo infusión a fuente de aplicaciones tecnológicas.

1.2.1.2. Cascara de Naranja - Residuo potencialmente útil. .18

1.3. Nanomateriales y Nanotecnología - La tecnología del futuro. .18

1.3.1. Síntesis "verde" de nanopartículas y sus ventajas ante la síntesis convencional.

1.4. Casos específicos de estudio.

1.4.1. Metales pesados en agua - Casos del $\mathrm{Cu}$ y $\mathrm{Pb}$. .20

1.4.2. Contaminación de cuerpos de Agua con colorantes - Caso de Medellín, Colombia y la industria textil.

1.4.3. Hidrocarburos aromáticos policíclicos (PAH) en cuerpos de agua Donde los tratamientos biológicos no son suficiente.

1.4.4.Aguas residuales agroindustriales - Caso del Flusilasol, Fungicida de última generación. 
1.5. Posibles campos de aplicación de los residuos considerados.

1.5.1. Fotoquímica de las Sustancias Tipo Húmicas - Analogía con los SBO.

1.5.2. Sistema de degradación de contaminantes orgánicos por medio de tratamientos tipo Fenton.

1.5.3.Uso de los SBO y el extracto hidrosoluble de la Yerba Mate como plantilla en la síntesis de nanopartículas.

1.5.4. Remediación de cuerpos de agua mediante la adsorción - Uso de superficies para la depuración.

1.6. Objetivos

1.7. Referenciasbibliográficas.

Capítulo 2:Materiales y métodos .32

2.1.Métodos.

2.1.1. Métodos de fotolisis.

2.1.1.1. Fotolisis Continua.

2.1.2. Métodos de Fluorescencia. .36

2.1.2.1. Fluorescencia en estado estacionario. .36

2.1.2.2 Fluorescencia resuelta en el tiempo.

2.1.3. Análisis Computacional (Bilineal).......................................38

2.1.4. Identificación y cuantificación de moléculas en solución. .38

2.1.4.1. Espectrometría de Masas. .38

2.1.4.2. Espectroscopia UV-VIS. .39 
2.1.4.3. Determinación indirecta de Producción de OxígenoMolecular Singulete $\mathrm{O}_{2}\left({ }^{1} \Delta_{g}\right)$ - Consumo de Oxigeno MolecularDisuelto $\mathrm{O}_{2}\left({ }^{3} \Sigma_{g}\right)$. 40

2.1.4.4. Determinación indirecta de Producción Anión Radical Superóxido $\mathrm{O}_{2} \cdots$

2.1.4.5. Determinación de Carbono Orgánico Total (TOC). .42

2.1.4.6. Espectroscopiaóptica de emisión (ICP-AES).

2.1.5.1. Determinación de distribución de Tamaños de partículas Microscopio Electrónico de Transmisión (TEM)

2.1.5.2. Espectroscopia Infrarroja (IR) .43

2.1.5.3. Análisis Termogravimétrico (TGA) .45

2.1.5.4. Dynamic Light Scattering (DLS). .45

2.1.5.5. Movilidad Electroforéticay Potencial de Carga Cero. .46

2.1.5.6. Área Superficial Especifica. .46

2.1.5.7. Difracción de Rayos X (XRD). 47

2.1.5.8. Dispersión de Rayos $X$ a bajo ángulo - SAXS .48

2.1.5.9. Espectroscopia de fotoelectrones emitidos por Rayos $X(X P S)$.

2.1.5.10. Caracterización de propiedades magnéticas. .50

2.1.6. Tratamiento matemático de las isotermas de adsorción. .52

2.2. Materiales. .53

2.2.1. Equipo de Agua MilliQ. .53

2.2.2. Balanza. .54

2.2.3. Medición de $\mathrm{pH}$. .54

2.2.4. Reactivos. .54 
Capítulo 3: Estudio de diferentes aplicaciones ambientales de los SBO en la remediación de cuerpos de aguas contaminados.

3.1. Materiales y métodos.

3.1.1. Preparación de las soluciones y cuantificaciónde Pireno, AM y Flusilasol.

3.2. Resultados y análisis. .58

3.2.1. Propiedades de los SBO. .58

3.2.1.1. Fotoestabilidad de los SBO. .60

3.2.1.2. Interacción del Pyr y del AM con los SBO. .62

3.2.2. Degradación fotoasistida de Pireno y Azul de Metileno. .65

3.2.3. Degradación del Flusilasol mediante procesos del tipo fenton tipo fenton usando a los SBO como agentes complejantes de Fe.

3.2.3.1. Elucidación del mecanismo inicial de degradación del Flusilasol mediado por los radicales oxidantes. .68

3.3. Conclusiones. .74

3.4. Referencias bibliográficas. .75

Capítulo 4: Uso de los SBO como plantilla de síntesis de nanocompositos de Hidroxiapatita/Óxidos de Hierro - Estudio de las propiedades mejoradas de estos nanomateriales para la adsorción de $\mathrm{Cu}^{+2}$ y $\mathrm{Pb}^{+2}$ en sistemas acuosos. .78

4.1. Materiales y métodos. .79

4.1.1. Síntesis de las nanopartículas. .79

4.1.2. Ensayos de adsorción de $\mathrm{Cu}^{+2}$ y $\mathrm{Pb}^{+2}$ sobre las nanopartículas en solución acuosa. 80 
4.2. Resultados y análisis.

4.2.1. Caracterización de las nanopartículas.

4.2.2. Ensayos de adsorción ......................................................91

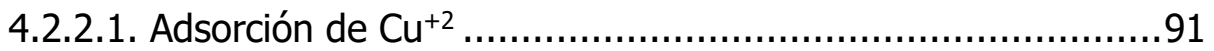

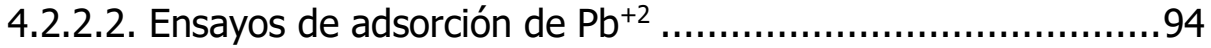

4.2.2.3. Caracterización de partículas con $\mathrm{Pb}^{2+}$ adsorbido. ...............96

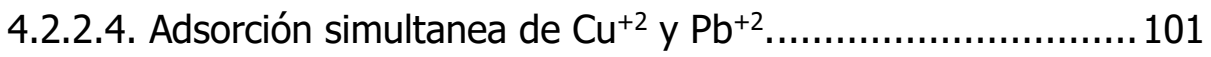

4.3. Conclusiones. .................................................................. 103

4.4. Referencias Bibliográficas. ................................................. 104

Capítulo 5: Uso de residuos orgánicos domiciliarios para la obtención de diferentes nanomateriales.

5.1. Materiales y métodos. 108

5.1.1 Síntesis de las nanopartículas. 108

5.2. Resultados y análisis. 109

5.2.1. Nanopartículas de Ag.. 109

5.2.2. Nanopartículas de $\mathrm{Fe}_{3} \mathrm{O}_{4}$.

5.2.3. Nanopartículas de C. 123

5.2.4. Nanopartículas de $\mathrm{SiO}_{2}$. 125

5.3. Conclusiones. 128

5.4. Referencias bibliográficas 129 
Capítulo 6: Estudio de las propiedades y aplicaciones de algunos nanomateriales obtenidosusando residuos domiciliarios.

6.1. Caracterización magnética de las nanopartículas de $\mathrm{Fe}_{3} \mathrm{O}_{4}$ con diferentes recubrimientos de extracto de YM.

6.1.1.Materiales y Métodos.

6.1.2. Resultados y análisis.

6.2. Adsorción de Azul de Metileno sobre las nanopartículas de $\mathrm{Fe}_{3} \mathrm{O}_{4}$ recubiertas con extracto de YM.

6.2.1. Materiales y Métodos. 140

6.2.2. Resultados y análisis 140

6.3. Ensayos de degradación de azul de metileno mediante la formación catalizada de $\mathrm{SO}_{4}{ }^{-}$por las nanopartículas de $\mathrm{Fe}_{3} \mathrm{O}_{4}$. 144

6.3.1. Métodos experimentales 144

6.3.2.Resultados 144

6.4. Caracterización Fotoquímica de las diferentes $\mathrm{NpC}$ 149

6.4.3. Ensayos de generación de especies reactivas. 161

6.3. Conclusiones. 165

6.4. Referencias bibliográficas. 166

Capítulo 7: Conclusiones Generales. 169 


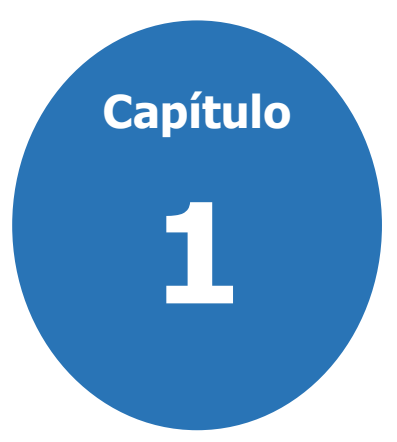

\section{Introducción y objetivos ¿Qué estamos investigando?, ¿Por qué lo hacemos?}

En las últimas décadas se ha generado un intenso debate social en torno a las prácticas industriales y de manufactura que atentan contra el medio ambiente. A raíz de esta problemática, diversas ramas del conocimiento han direccionado sus objetivos para generar soluciones sustentables frente a temas como el tratamiento de residuos y la optimización energética de procesos productivos, entre otros.

Desde las ciencias básicas surgió una rama del conocimiento denominada química verde que posteriormente abriría paso a la creación de la ingeniería verde, esta última más ligada al desarrollo tecnológico [1], [2]. Ambas disciplinas, unidas transversalmente por objetivos comunes, pretenden entre otras tareas, la reducción significativa (producción cero) de subproductos no deseados que se generan en los procesos productivos e industriales.

Otra corriente denominada economía ecológica que aúna [3] a las ciencias de la administración con la termodinámica, sostiene que la generación de residuos es inherente a los procesos productivos. De este modo, desde un enfoque técnico-administrativo se propone el aprovechamiento de los productos residuales teniendo en cuenta su uso como materia prima para otros procesos[4]. Estos procesos pueden incluso estar por fuera del circuito productivo inicial, generando así beneficios económicos y sociales adicionales.

Siguiendo estas directrices, durante la extensión de este trabajo se trató de dar valor agregado a algunos residuos domiciliarios, utilizándolos para el estudio de procesos y síntesis de materiales con énfasis en aplicaciones de remediación de cuerpos de aguas contaminados. 


\subsection{Sustancias tipo húmicas obtenidas de residuos domiciliarios - Caso de los SBO en la región Piamonte, Italia.}

Dentro del conjunto de los residuos domiciliarios se pueden agrupar un sin número de sustancias y desechos de toda índole provenientes del uso humano en el día a día. La fracción orgánica de estos residuos es una mezcla compleja de moléculas orgánicas entre las que resaltan los carbohidratos, la lignina, las proteínas, los lípidos y otras biomoléculas.

Actualmente, esta fracción se aprovecha para la producción de energía eléctrica o térmica. Sin embargo, estas tecnologías poseen un rendimiento bajo debido a la baja conversión de la biomasa a biogás. Como alternativa se han generado propuestas para desarrollar otros procesos que involucren el uso eficiente de la biomasa[5].

En este marco, el proyecto EnvironBOS de la unión europea, conformado por grupos de investigación de Italia, España, Brasil y Argentina, ha utilizado la fracción orgánica resultante de la digestión aeróbica y anaeróbica de los residuos verdes domiciliarios denominada Sustancias Bio-Orgánicas (SBO) con el fin de evaluar sus posibles aplicaciones tecnológicas.

Debido a la gran diversidad de compuestos presentes en los desechos previos a su tratamiento y a la mineralización parcial que tiene lugar en los procesos de biodegradación, es imposible otorgar una única estructura molecular a estos compuestos[6]. Se ha comprobado que el comportamiento fisicoquímico de los SBO es comparable al de las sustancias húmicas[5], [6]. En las figuras 1.1 y 1.2 se muestra la apariencia física de esos compuestos y la formula molecular virtual atribuida a los mismos.

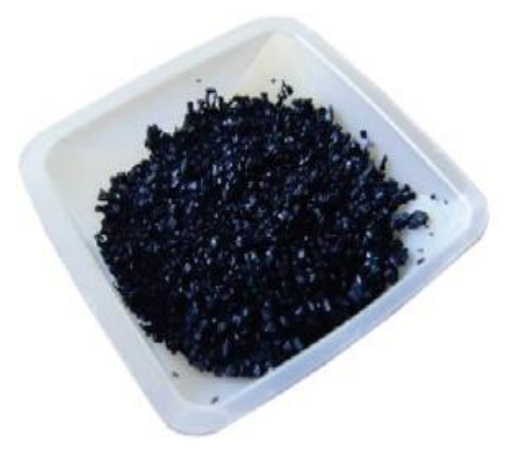

Fig. 1.1 - Estructura típica de los SBO.

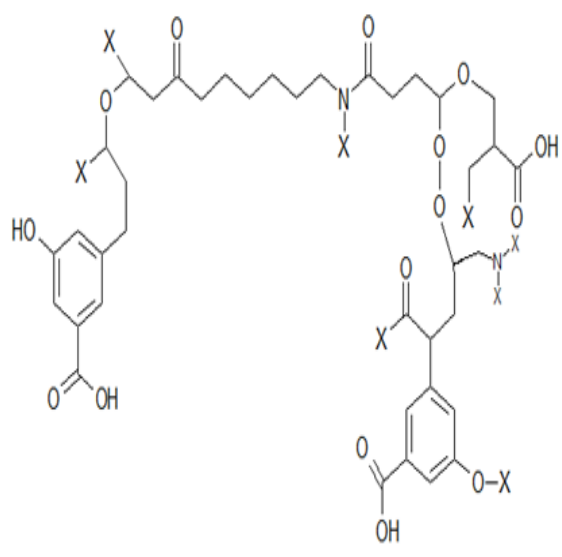

Fig. 1.2 - Estructura molecular virtual de los SBO CVT230.

Existen diferentes tipos de SBO dependiendo de 3 factores principales:

- El tipo de tratamiento biológico, sea este aeróbico o anaeróbico. 
- El origen de los desechos; es decir, si son de origen rural, doméstico o industrial, ya que esto determina la composición química de partida.

- El tiempo de biodegradación, que determina el grado de conversión de la materia orgánica original.

Para enmarcar la importancia de estos 3 factores, a los diversos tipos de SBO se les concede un nombre a partir de las condiciones bajo las que se obtuvo. Para el caso específico del SBO considerado en este trabajo se aplicó, durante 230 días, un tratamiento aeróbico al compost conformado por residuos urbanos verdes conteniendo restos de comida, hojas, ramas de árboles, entre otros, suministrados por ACEA Pinerolese S.p.a. A dicho SBO se le asigna el nombre de CVT230.

\subsubsection{Obtención de los SBO.}

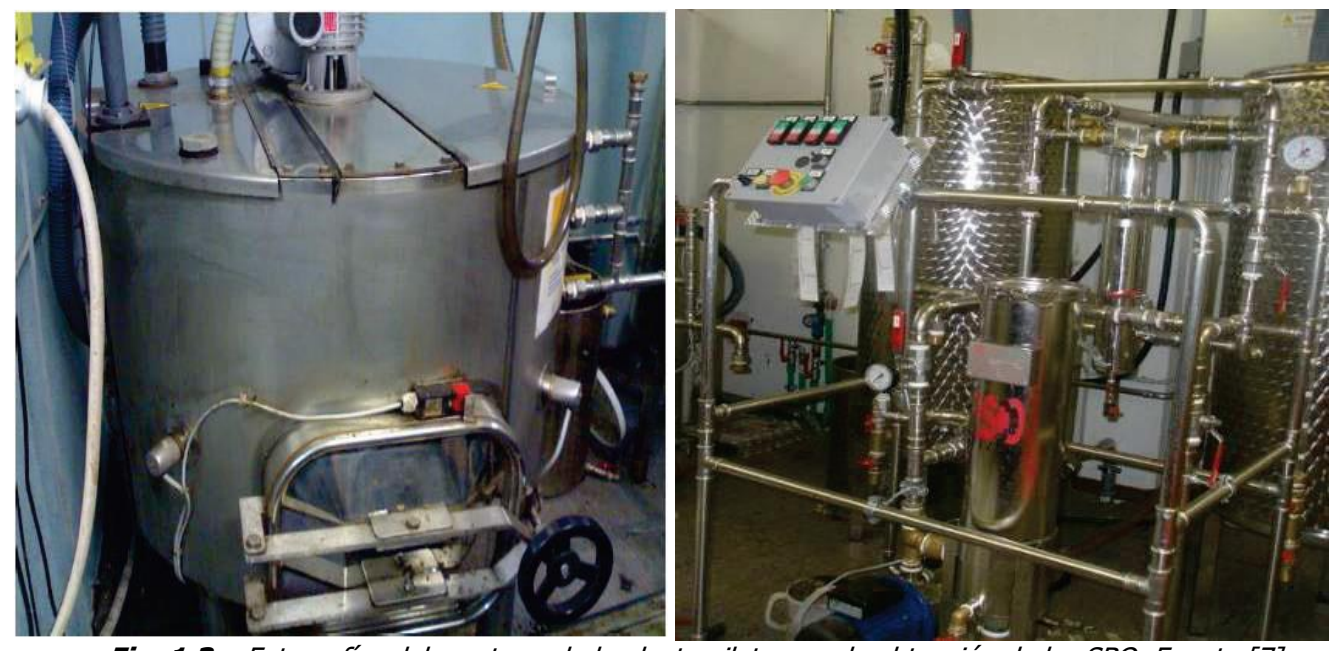

Fig. 1.3 - Fotografías del reactor y de la planta piloto para la obtención de los SBO. Fuente [7].

El proceso se inicia con la recolección de los residuos. Posterior a ello se someten los residuos al proceso de degradación (aeróbico o anaeróbico) durante un tiempo determinado donde se obtiene un compost en el caso de una biodegradación aeróbica 0 un digestato cuando se emplea una digestión anaeróbica. Las sustancias orgánicas son separadas de la biomasa en un reactor de tanque agitado de acero inoxidable con soluciones acuosas de $\mathrm{KOH}$ en una relación 1:4 en gramos de biomasa/volumen de líquido a una temperatura de $65^{\circ} \mathrm{C}$.Se utilizan hidróxidos en este paso del proceso para promover la ruptura de barreras celulares de los microorganismos. Con ello se produce la liberación espontanea del contenido orgánico que estos poseen, tales como proteínas, carbohidratos, y lípidos que son la materia prima utilizada para dar lugar a la formación de los SBO. La condición operacional óptima para el reactor utilizado corresponde a $300 \mathrm{~L}$ de agua y $75 \mathrm{~kg}$ de biomasa solida con un $\mathrm{pH}$ de operación inicial de 11. El tiempo de reacción es de 4 horas. Pasado ese tiempo se dejan decantar los sólidos por un periodo mayor a 12 horas. Una vez transcurrido ese periodo, la solución sobrenadante se bombea a una centrifuga donde se somete a $9000 \mathrm{rpm}$ para separar la solución de los sólidos sedimentables aún presentes. Posterior a ello, la solución remanente se bombea a un mezclador donde se le adiciona $\mathrm{HCl} \circ \mathrm{H}_{2} \mathrm{SO}_{4}$ hasta $\mathrm{pH}<1.5$. Dicha 
solución es llevada a un molino tipo Ball Mill donde se seca y se deja sedimentar para obtener sólidos con una distribución de tamaño de partícula homogénea.

Debido a la gran variedad de compuestos que son sometidos a una oxidación no selectiva al ser tratados con ácidos, el sólido final obtenido es una mezcla de compuestos de diferente naturaleza química. Por lo anterior los SBO presentan propiedades análogas con las sustancias húmicas.

\subsubsection{Composición Química de los SBO CVT 230.}

El grupo de investigación Italiano del proyecto EnvironBOS se encargó de caracterizar fisicoquímicamente los SBO CVT 230. Como primera instancia se realizó una caracterización básica de la composición de esta materia orgánica. En la Tabla 1.1 se muestran datos ya reportados sobre la caracterización química de los SBO-CVT230 [6], [8]:

\begin{tabular}{|c|c|c|c|c|}
\hline \%Hum & \%Cen & \%SV & \%C & \%N \\
\hline 6.8 & 31.0 & $69.0-72.1$ & $38.25 \pm 0.04$ & $4.01 \pm 0.01$ \\
\hline
\end{tabular}

Tabla 1.1 - Composición CVT230: Agua (\%Hum), Cenizas (\%Cen), Sustancias Volátiles (\%SV) y porcentajes másicos $(\mathrm{m} / \mathrm{m})$ referidos a peso seco. Fuente [8]

Se evidencia una gran cantidad de cenizas presentes en el CVT230, que surtiría un afecto adverso para el uso de estos materiales en el tratamiento de aguas contaminadas, por lo que se requeriría eliminar estas cenizas del material previo a su uso. La relación $\mathrm{C} / \mathrm{N}$ es un parametro de importancia en la química de aguas ya que hace referencia a la posibilidad de mejorar la eutrofización de las aguas naturales [9]mediante el uso de estos compuestos. En el caso específico del CVT230 esta relación es de 9.54, valor que presentaría un elevado grado de cadenas carbonadas disponibles para la desnitrificación del cuerpo acuoso.

De igual manera se hicieron estudios de caracterización de grupos funcionales y de sus concentraciones relativas, los resultados obtenidos se pueden visualizar en la tabla 1.2 a continuación:

\begin{tabular}{|c|c|c|c|c|c|c|c|c|c|c|}
\hline Af & Ph & OMe & CON & NR & OR & PhOY & OCO & COOH & PhOH & COC \\
\hline 0.37 & 0.13 & 0.00 & 0.01 & 0.07 & 0.14 & 0.12 & 0.04 & 0.12 & 0.05 & 0.05 \\
\hline
\end{tabular}

Tabla 1.2 - Composición relativa de tipos de Carbono y grupos funcionales referidos a fracción molar de Carbono Orgánico Total. Af (C. Alifático), Ph (C. Aromático), OMe (C. Metoxi-), CON (C. Amida), NR (C. Amina), OR (C. Alcoxi-), Phoy(C. Fenóxico-), OCO (C. Anomerico), COOH (C. Carboxilico), PhOH(C. Fenólico), $\operatorname{coc}$ (C. Cetona). Fuente [7]

Estos resultados indican una abundancia relativa de carbonos aromáticos menor respecto de los alifáticos, C Alifático $/$ C Aromático $=2.85$, evidenciando un bajo grado de condensación aromática. Esta relación indica que solo una fracción de la materia orgánica podría presentar actividad fotoquímica de interés para su uso como fotosensibilizadores en la degradación de contaminantes en sistemas acuosos, ya que al haber mayor abundancia de $\mathrm{C}$ alifáticos las longitudes de onda de la luz utilizada para irradiar tenderán a ser menores que las esperadas para un sistema con alta abundancia de $\mathrm{C}$ aromáticos. 
En estos compuestos coexisten dos fracciones de materia orgánica: una de tipo húmica $(80 \% \mathrm{~m} / \mathrm{m})$ que precipita a $\mathrm{pH}<2.0$, y otra de tipo fúlvica $(20 \%$ $\mathrm{m} / \mathrm{m}$ ) soluble en todo el rango de $\mathrm{pH}$.

Además, se cuantificó la presencia de metales en el residuo inorgánico obtenido posterior a la calcinación. La concentración de algunos de los elementos más relevantes se muestra en la tabla 1.3:

\begin{tabular}{|c|c|c|c|c|c|c|c|c|c|c|c|}
\hline Si & Fe & Al & Mg & Ca & $\mathbf{K}$ & Na & Hg & Zn* & Cr* & Pb* & Ni* \\
\hline 0.37 & 0.13 & 0.49 & 1.13 & 6.07 & 3.59 & 0.16 & 0.15 & 256 & 19 & 85 & 92 \\
\pm & \pm & \pm & \pm & \pm & \pm & \pm & \pm & \pm & \pm & \pm & \pm \\
0.01 & 0.04 & 0.04 & 0.06 & 0.38 & 0.21 & 0.01 & 0.02 & 1 & 1 & 1 & 1 \\
\hline
\end{tabular}

Tabla 1.3 - Composición de metales en el SBO CVT230 en \% $(\mathrm{m} / \mathrm{m})$ o * en ppm referido a peso seco de sólido. Fuente [7].

De los datos expuestos en la tabla, se puede apreciar que el CVT230 posee alrededor de un $12 \%$ del peso total en metales. Resalta además, la presencia de $\mathrm{Hg}$ y $\mathrm{Pb}$ en el sólido, la que deberá controlarse en el uso directo de esta sustancias en aplicaciones ambientales debido a la toxicidad de estos elementos. Sin embargo, durante el desarrollo de este trabajo de tesis las concentraciones de SBO utilizadas para los ensayos de fotosensibilización son tales que las concentraciones de estos metales se encuentran por debajo del límite máximo permitido.

\subsubsection{Uso de los CVT230 como fotosensibilizadores y como auxiliares en la degradación tipo Fenton de contaminantes orgánicos.}

Durante el desarrollo del proyecto EnvironBOS se estudió la factibilidad técnica de diferentes aplicaciones de los SBO, algunas de las cuales se muestran en la Figura 1.4.

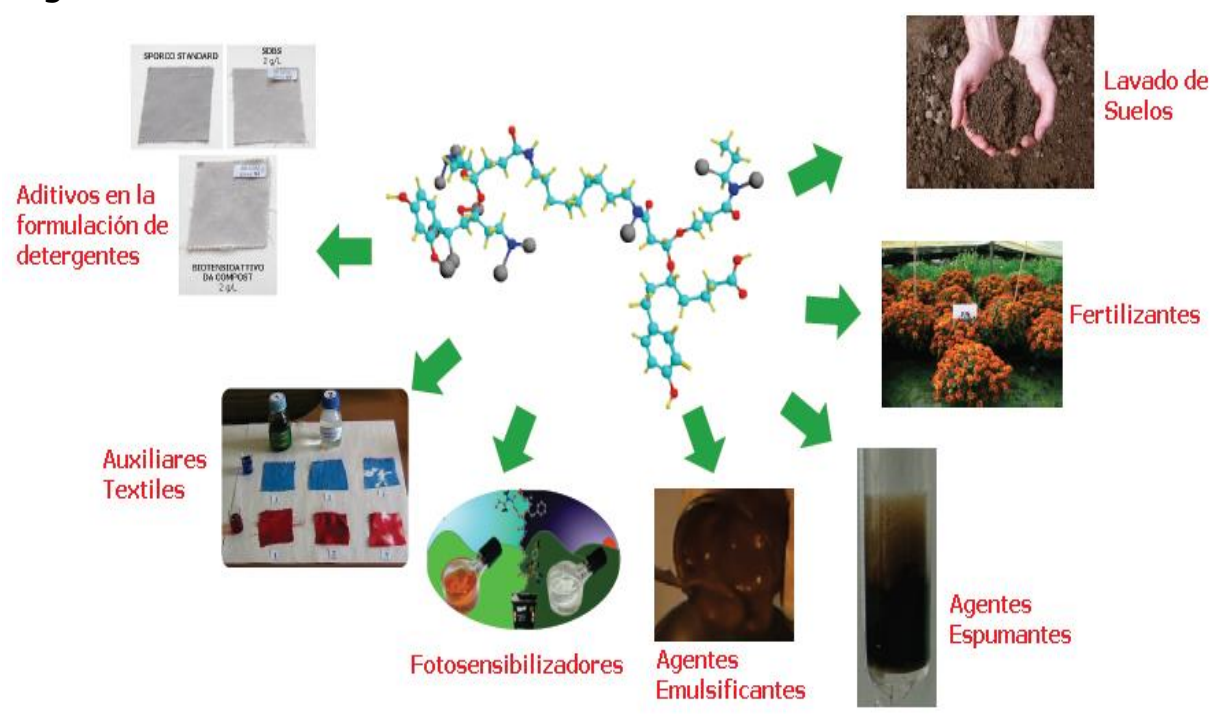

Fig. 1.4 - Algunas de las aplicaciones estudiadas de los SBO durante el proyecto EnvironBOS. Fuente[7]. 
En este trabajo se investigó la capacidad de los CVT230 de fotosensibilizar la degradación de moléculas orgánicas en fase acuosa y su uso como agentes estabilizantes de $\mathrm{Fe}^{+3}$ en solución para promover degradación por vía Fenton. Además, se utilizaron como plantilla de síntesis de diferentes nanopartículas para mejorar la eficiencia de las mismas en procesos de adsorción.

\subsection{Biorefinería - Aprovechamiento de Biomasa para obtención de productos de interés.}

Al grupo de procesos basados en la conversión de Biomasa mediante el uso de tecnologías biológicas, químicas y/o físicas para la producción de energía, combustibles, materiales, productos químicos, entre otros, se le da el nombre de Biorefinerias [10]. Este término es comparable en la industria convencional a las refinerías de petróleos, en las cuales se utiliza el crudo para la obtención de múltiples productos. Ambas están basadas en la optimización del uso de la materia prima. Sin embargo, esta última ha sido fuertemente criticada debido a la alta toxicidad de sus desechos y baja biodegradabilidad de la mayoría de sus productos. Por ello la Biorefinería, la versión "verde" de las refinerías convencionales, ha adquirido gran interés debido a su versatilidad, dado que permite el aprovechamiento de la biomasa residual de procesos para la obtención de productos de interés. Se otorga así, valor agregado a los antiguos productos residuales de procesos optimizados tecnológica y económicamente.

Es válido mencionar, que el proceso de los SBO encajaría en primera instancia como un proceso de Biorefinería, en el cual se utiliza la Biomasa residual del proceso de degradación biológica de diversos residuos domiciliarios para la obtención de materia orgánica.

Durante el desarrollo experimental de esta tesis, hacemos una primera aproximación sobre lo que sería una Biorefinería usando como materia prima la Yerba Mate comercial para la obtención de nanomateriales de diversa naturaleza con diferentes campos de aplicación. Por otro lado, se usó la cascara de naranja como matriz para la obtención de una de las partículas de Carbono.

\subsubsection{Otros residuos de interés.}

\subsubsection{Yerba Mate (I/ex paraguariensis) - De bebida tipo} infusión a fuente de aplicaciones tecnológicas.

La yerba mate es un árbol nativo de la selva paranaense ubicada entre Argentina, Paraguay y Brasil. La hoja de este árbol es procesada, molida y empacada para ser comercializada. Se usa típicamente para hacer bebidas tipo infusiones de gran aceptación en la región. Actualmente el mercado de la Yerba Mate es un mercado en expansión y con proyección de crecimiento, llegando a producir según datos oficiales un poco más de 40 Millones de USD al año[11]. 
La presentación de la Yerba Mate tal cual se vende para su consumo se muestra en la figura 1.5. En la forma tradicional la infusión de mate se prepara poniendo en contacto la yerba con agua a aproximadamente $70^{\circ} \mathrm{C}$ permitiendo el contacto por corto tiempo y posterior bebida del agua de extracción, permaneciendo el sólido para varias corridas. La infusión es rica en carbohidratos, vitaminas, cafeína, proteínas, polifenoles, flavonoides, entre otros [12], [13]. Mientras que el residuo sólido posee alto contenido de lignina, celulosa y hemicelulosa.

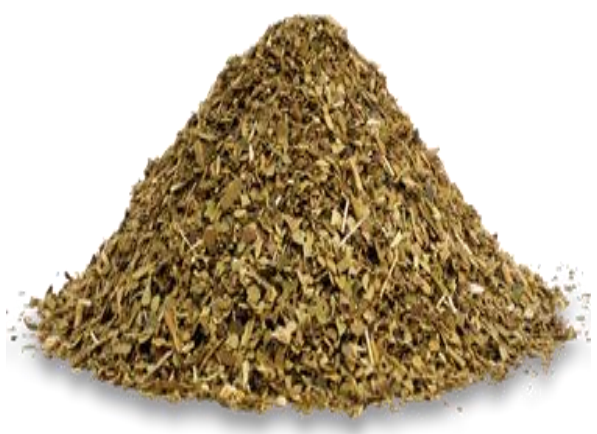

Fig. 1.5 - Presentación típica de la Yerba Mate comercial. Fuente: [11].
Como se mencionó anteriormente, en este trabajo se utiliza la Yerba Mate como matriz para la obtención de diferentes nanopartículas. Lo anterior se vio motivado debido a la creciente expansión de este mercado y del aumento de la demanda por parte de la comunidad argentina y global en general, lo que conlleva a un aumento del residuo sólido producido.

\subsubsection{Cascara de Naranja - Residuo potencialmente útil.}

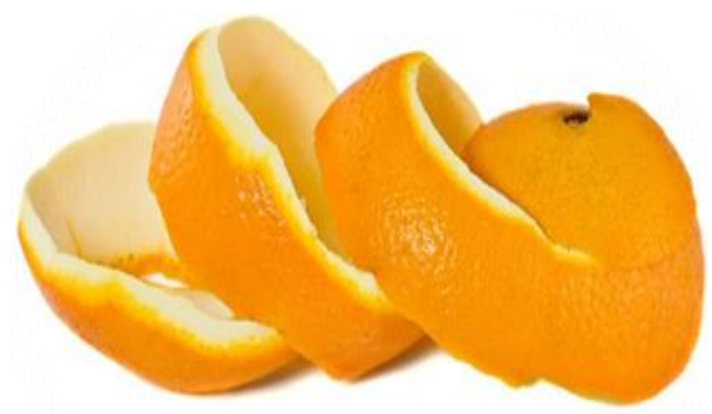

Fig. 1.6 - Cascara de naranja típica.
El mercado de naranjas solo en Estados Unidos de América mueve alrededor de 7 mil toneladas anual y está proyectado el aumento de la demanda durante las próximas décadas, por lo que este es un mercado en expansión y en crecimiento.

El consumo típico de las naranjas conlleva al desprendimiento de la corteza (cascara) y aprovechamiento por diferentes medios de la pulpa, sin embargo en la mayoría de los casos la cascara es considerada un desecho. No obstante, esta posee un alto contenido de ácido cítrico, proteínas, vitaminas, aminoácidos, etc. [14]. Por ello es necesaria la búsqueda de alternativas de aprovechamiento de este residuo.

En este trabajo utilizamos la cascara de naranja para el uso de nanopartículas de Carbono.

\subsection{Nanomateriales y Nanotecnología - La tecnología del futuro.}

La nanotecnología es el estudio, comprensión, manipulación, síntesis y aplicación de materiales con al menos una de sus dimensiones del tamaño del orden de los nanómetros (la mil millonésima parte de un metro) y hasta centenas 
de nanómetros. Originalmente, la nanotecnología se refería solamente a la construcción de materiales átomo a átomo mediante lo que se denomina procesos bottom-up. En la actualidad la nanotecnología incorpora también las estructuras generadas a partir de materiales de mayor tamaño al cual se le van reduciendo las dimensiones por diferentes métodos, procesos conocidos como top-down.

En la escala del nanómetro la relación área/volumen de los materiales es varios órdenes de magnitud más grande que la de sus homólogos macroscópicos. Además, la reducción del tamaño a estas magnitudes afecta las propiedades mecánicas, térmicas y catalíticas de los materiales. Por esta razón y debido a que posibilita el diseño y desarrollo de procesos y productos específicos para cada problemática, se considera que la nanotecnología puede aportar a la solución de diversos problemas medioambientales.

\subsubsection{Síntesis "verde" de nanopartículas y sus ventajas ante la síntesis convencional.}

Los métodos convencionales de obtención de nanomateriales pueden producir subproductos tóxicos o de difícil remediación, por lo que actualmente se está estudiando las ventajas y desventajas del uso de productos alternativos para la obtención de los mismos. Este es el caso del aprovechamiento de biomasas vegetales. Para ello se han utilizado extractos acuosos de los mismos e incluso directamente la misma matriz sólida para la obtención de los materiales deseados.

En este trabajo se hace uso de la yerba mate comercial marca "El Playadito" lote de producción 45-03, como auxiliar de síntesis o fuente directa para la obtención de diferentes nanopartículas. También se usó la Cascara de Naranja residual para la obtención de Nanopartículas de C.

\subsection{Casos específicos de estudio.}

La contaminación puede ser definida como la introducción de sustancias indeseadas en el ambiente [15]. A pesar de que existen fuentes de contaminación derivadas de la misma actividad natural, tal como la proveniente de las erupciones volcánicas, la actividad intrínseca del ser humano es un foco importante de contaminación. Desde la revolución industrial, una gran variedad de industrias, entre ellas la química, farmacéutica, agrícola, alimenticia, salud, energética, textil, construcción, electrónica, cosmética, han contaminado cuerpos de agua, el aire y gran variedad de suelos con sustancias de todo tipo, desde biodegradables a recalcitrantes, orgánicas e inorgánicas. Algunas de estas sustancias se han ido acumulando en la biota produciendo desbalances en ecosistemas específicos.

Muchas industrias se encuentran hoy en una etapa sin precedentes de evolución y adaptación rápida. La demanda social sobre la toma de conciencia respecto a la contaminación ambiental las obliga a la modificación y el rediseño 
de sus procesos, aumentando su eficiencia global, disminuyendo la cantidad de residuos generados y utilizando los que se produzcan [2], [15]-[17].

El agua es el recurso natural más importante desde el punto de vista de la sustentabilidad de la vida y para el desarrollo de tecnologías, ya que la mayoría de las industrias la utilizan en su cadena de operación [18]. Por ello, los cuerpos de agua son focos por excelencia de recepción de contaminación independientemente del origen de la misma [2], [15].Las características fisicoquímicas de los cuerpos de agua contaminadas dependen del uso que se ha dado, sin embargo entre la clasificación de las aguas contaminadas cabe resaltar las siguientes:

1. Aguas urbanas contaminadas: Normalmente con alto contenido de carga orgánica, detergentes, residuos de artículos de cuidado personal, desechos alimentarios e incluso se han detectado en pequeñas trazas los denominados contaminantes emergentes, entre los que se encuentran residuos farmacéuticos no regulados y hormonas [19].

2. Aguas industriales contaminadas: Son las de mayor divergencia en su caracterización, debido que dependen fuertemente de la industria de origen, siendo posible así la presencia de metales pesados, alto contenido de carga orgánica, colorantes, surfactantes, compuestos poliaromáticos, sustancias inorgánicas, entre otras [15].

3. Aguas contaminadas de la industria agrícola: Frecuentemente con residuos de fertilizantes, fungicidas, hormonas, antibióticos e incluso metales pesados [2], [15], [20].

Como se puede vislumbrar de manera general en la información anterior, existe una gran variedad de tipos de compuestos a tratar en la problemática de remediación de cuerpos de agua. Cada tipo de compuesto requiere tratamientos específicos intrínsecos a su naturaleza química y de las características fisicoquímicas del agua en el que se encuentra [18]. Por ello se hace necesario el desarrollo de diferentes procesos y/o materiales capaces de tratar las diversas clases de compuestos químicos.

\subsubsection{Metales pesados en agua - Casos del Cu y Pb.}

El caso de contaminación de cuerpos de aguas por metales pesados es de gran controversia para la sociedad en general y de mucho estudio para la comunidad científica debido a la gran toxicidad que presentan estos elementos, no solo para la hidrosfera si no para la biosfera en general [21]. El foco de inicio de propagación de la contaminación de metales pesados puede ser principalmente debido al funcionamiento de motores de combustión que usan combustibles fósiles [21] o por actividades industriales [22].

La presencia de metales pesados en aguas puede causar diversos efectos adversos en la salud de humanos, animales y plantas, dependiendo de la concentración y el tiempo de exposición al que es sometido el sujeto [22]. 
Específicamente hablando, el Cobre (Cu) es un elemento comúnmente encontrado en el medio ambiente en concentraciones de 24 - 55 ppm en la corteza terrestre. Sin embargo, estos límites se han elevado debido a la actividad humana e industrial como la refinería de petróleo y la producción de cemento. En concentraciones pequeñas, el $\mathrm{Cu}$ es un oligoelemento esencial para gran parte de los organismos vivos, de allí su alta tendencia a ser bioacumulado. Por otro lado una exposición por largos período de tiempo a elevadas concentraciones de $\mathrm{Cu}$ puede conllevar problemas en la salud debido a las propiedades redox que posee este elemento. Por ello se hace necesario la eliminación del $\mathrm{Cu}$ de los cuerpos de agua antes de su disposición final [23].

Por su lado, la contaminación por Plomo $\mathbf{( P b ) h a ~ r e c i b i d o ~ g r a n ~ a t e n c i o ́ n ~}$ debido al uso exhaustivo que se le da a este elemento, la alta toxicidad del mismo y los altos costos de los procesos de remediación [24].

A lo largo de la historia se han desarrollado gran número de procesos para la remoción de metales de cuerpos de aguas, tales como la precipitación química, la filtración, extracción con solventes, intercambio iónico, y adsorción, todas con diferentes requerimientos tecnológicos, costo y eficiencia global [22]. Sin embargo, los procesos de adsorción han tenido un alto grado de aceptación debido a su simplicidad y baja relación costo/beneficio [23].

Debido a lo anterior, durante el desarrollo de la parte experimental de este trabajo se estudió el proceso de adsorción de estos dos metales sobre algunos de los materiales sintetizados.

\subsubsection{Contaminación de cuerpos de Agua con colorantes - Caso de Medellín, Colombia y la industria textil.}

A pesar de ser percibidos a simple vista, existen casos como el de la fotografía en la Fig. 1.7 que evidencian que la contaminación por colorantes en cuerpos de aguas es un caso real. Estos, además de suponer una contaminación visual, al estar presentes en cuerpos hídricos en altas concentraciones como en la fotografía, aumentan la carga orgánica, $\mathrm{DQO}$ y $\mathrm{DBO}_{5}$ del agua, disminuyendo consigo la concentración de oxígeno soluble en la misma. A lo anterior se le suma la posibilidad de reaccionar con otros compuestos presentes en el agua, bioacumularse en la biota presente o reaccionar por vías fotoquímicas dando lugar a nuevas sustancias químicas que podrían ser incluso más tóxicas que la inicial. Por eso, se hace necesario evaluar procesos de remoción y/o degradación de colorantes presentes en aguas. 


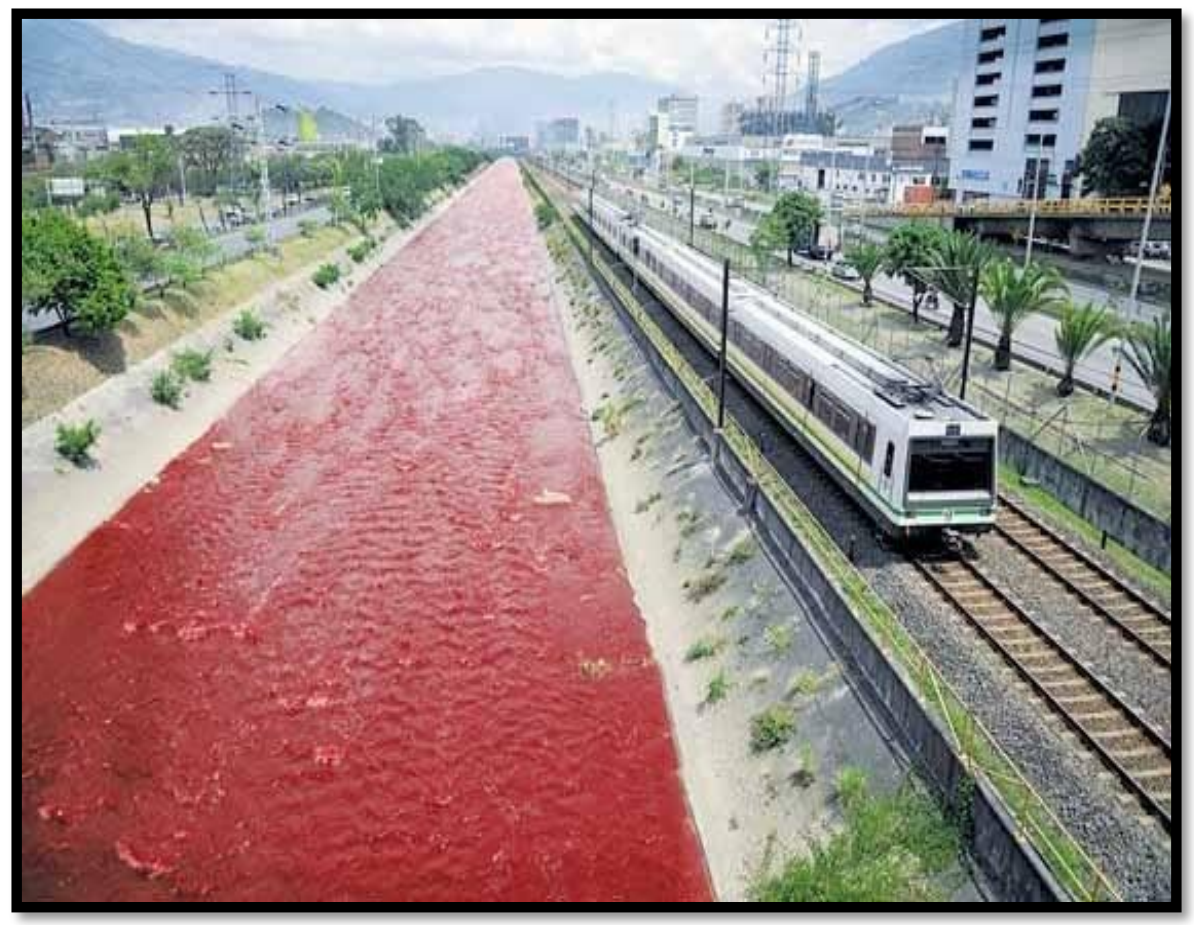

Fig. 1.7 - Fotografía del Río Medellín, Colombia teñido con un colorante el 25 de Enero 2013. Fuente: [25]

Durante este trabajo de tesis se utiliza el Azul de Metileno (ADM) como colorante modelo para evaluar la eficiencia de diversos procesos para la remediación de aguas contaminadas.

\subsubsection{Hidrocarburos aromáticos policíclicos (PAH) en cuerpos de agua - Donde los tratamientos biológicos no son suficiente. \\ El tratamiento biológico de degradación de contaminantes involucra} técnicas bien establecidas que suelen ser las más eficientes y económicas. Sin embargo, cuando los contaminantes son muy tóxicos y persistentes, los procesos biológicos pierden efectividad. En esos casos, un acercamiento útil consiste en pre-tratar las aguas contaminadas con tecnologías de oxidación avanzadas (AOP) capaces de degradar los contaminantes a sustancias de menor toxicidad y el posterior tratamiento biológico de los desechos remanentes[26].Entre estos compuestos resistentes a los tratamientos biológicos, se encuentran los hidrocarburos aromáticos policíclicos (PAH). Estos presentan un alto grado de toxicidad, son carcinogénicos y potencialmente mutagénicos. Su biodegradación está limitada por su baja solubilidad y por su lenta disolución en agua. La adición de surfactantes aumenta la concentración de los PAH hidrofóbicos en la fase acuosa solubilizándolos o formando emulsiones. Este aumento mejora la bioaccesibilidad de los PAH, los que en presencia de surfactantes debieran ver acelerada su biodegradación[27].

El Pireno fue el PAH utilizado en los test durante el desarrollo de la parte experimental de este trabajo, debido a que presenta fluorescencia fuertemente dependiente de la polaridad que lo hace sumamente apto para seguir el incremento de la solubilidad por agregado de algún surfactante[28]. Se plantea 
evaluar de esta forma, la capacidad surfactante de los residuos orgánicos solubles y la capacidad de los mismos de promover la degradación fotoquímica del PAH.

\subsubsection{Aguas residuales agroindustriales - Caso del Flusilasol,} Fungicida de última generación.

El reemplazo del $\mathrm{C}$ por $\mathrm{Si}$ en ciertos insecticidas no afecta su eficiencia en el uso agroindustrial. Sin embargo, se propone que estos insecticidas se degradan con mayor facilidad, por lo que resultarían menos perjudiciales para el medio ambiente. En los últimos años se han desarrollado compuestos orgánicos de silicio de uso comercial como el Flusilasol, fungicida con propiedades activas similares al del triazol OMS 3055.

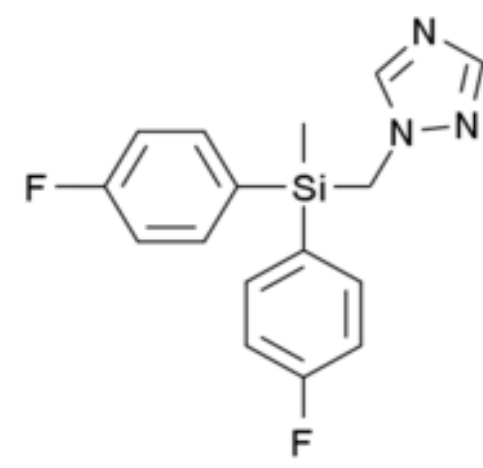

Fig. 1.8 - Formula molecular del Flusilasol.

La fórmula molecular de este compuesto se visualiza en la figura 1.8. Se utilizó este fungicida para evaluar su degradación por diferentes vías que involucran el uso de SBO y se trató de elucidar su mecanismo de degradación inicial utilizando diferentes especies reactivas ya que en bibliografía no se encontró información sobre las vías de su mineralización.

A manera de resumen, con base en lo anteriormente discutido, uno de los ejes primordiales sobre los que se fundamenta este trabajo es el estudio de la eficiencia de diferentes procesos que emplean SBO para la remediación de aguas contaminadas con:

- Metales pesados (Cu y $\mathrm{Pb})$.

- Colorantes (Azul de Metileno).

- PAH (Pireno).

- Agroquímicos (Flusilasol).

\subsection{Posibles campos de aplicación de los residuos considerados.}

\subsubsection{Fotoquímica de las Sustancias Tipo Húmicas - Analogía con Ios SBO.}

Todas las moléculas poseen un estado energético fundamental que corresponde a la distribución electrónica de menor energía termodinámicamente posible. A partir de este estado, las moléculas pueden absorber energía para 
hacer migrar un electrón hacia estados de mayor energía dando lugar a la formación de estados electrónicamente excitados. Uno de los procesos típicos de excitación de las moléculas es mediante la absorción de un fotón típicamente de la región Uv/Vis del espectro electromagnético [29]. Debido a que estos estados excitados no son termodinámicamente estables, tienden a regresar al estado fundamental después de un lapso de tiempo de $10^{-3}-10^{-12} \mathrm{~s}$. Dicho período está caracterizado por el tiempo de vida $(\boldsymbol{\tau})$ que es el tiempo requerido para que el número de moléculas inicialmente excitadas caiga a una fracción 1/e de su valor original. El tiempo de vida es característico de cada estado excitado y del medio que circunda a las moléculas.

Todas las moléculas orgánicas presentan dos configuraciones básicas en cuanto a la configuración de sus estados excitados. En la primera los dos electrones más externos tienen números cuánticos de espín opuesto o antiparalelo, denominándose estado excitado singulete, mientras que un estado energético triplete corresponde cuando tienen números cuánticos de espín iguales. Comúnmente, el estado fundamental de la mayoría de las moléculas orgánicas suele tener carácter singulete $\left(\mathrm{S}_{0}\right)$, mientras que los estados excitados pueden ser $\mathrm{S}_{1} \circ \mathrm{T}_{1}$.

Normalmente, una molécula podría absorber un fotón de luz de longitud de onda adecuada para alcanzar cualquiera de sus estados excitados, sin embargo, las reglas de la mecánica cuántica establecen que, en ciertos casos, la probabilidad de absorción de un fotón para producir la excitación hacia algún estado especifico podría ser muy baja e incluso nula. Entonces para poblar el estado excitado es necesario que tenga lugar un proceso de transferencia energética, en lugar de una absorción de fotones.

La fotosensibilización se basa en la absorción de fotones del estado fundamental de una molécula, llamada fotosensibilizador, para generar el estado excitado de la misma. Dicho estado sería capaz de transferir su exceso energético, a otra molécula presente en el medio circundante. Esta nueva molécula excitada, puede reaccionar con otras especies circundantes en el medio durante su tiempo de vida, dando lugar a la formación de productos de reacción o regresando al estado fundamental tras la liberación del exceso de energía. El uso de la fotosensibilización para la producción de especies reactivas mediante energía solar permite el desarrollo de nuevas tecnologías fotoquímicas limpias y basadas en energías renovables, aplicables a la remediación de aguas.

Las Sustancias Húmicas (SH) contienen una red de cadenas alifáticas y aromáticas con una gran variedad de grupos funcionales oxigenados (carboxílicos, fenoles, alcoholes, cetona, quinona, etc.) y su fotoquímica ha sido ampliamente estudiada ya que son la fracción más abundante de la materia orgánica disuelta en cuerpos de aguas naturales. A partir del proceso de absorción de fotones Uv/Vis desde el estado fundamental $S_{0}$ se da lugar a la formación del estado $S_{1}$ y a partir de este se da a la formación del estado $T_{1}$. Estos últimos estados son de larga vida y por ende son capaces de reaccionar con otras moléculas orgánicas ( $\mathrm{RH})$ o con el estado fundamental de la misma molécula y con el oxígeno molecular dando lugar a la formación de especies reactivas [9]. 
La Figura 1.9 muestra un esquema combinado de la excitación por vía fotoquímica de las $\mathrm{SH}$ a la formación del estado $S_{1}$ y posterior formación por entrecruzamiento de sistemas al estado $T_{1}$. A partir de ese estado se pueden formar por varias vías estados excitados del oxígeno molecular y especies reactivas del oxígeno de los cuales solo se muestran algunos. Las especies reactivas de oxígeno presentan un alto poder oxidante y pueden reaccionar químicamente con las moléculas orgánicas circundantes dando lugar a la formación de productos oxidados. Algunas de ellas son:

$$
\begin{array}{ll}
\text { - } & \text { Oxígeno Singlete }\left(\mathrm{O}_{2}\left({ }^{1} \Delta_{\mathrm{g}}\right)\right)[30] \\
\text { - } & \text { Radicales alquilperoxido }\left(\mathrm{RO}_{2}\right)[31] \\
\text { - } & \text { Radicales Hidroxilo }(\mathrm{HO} \cdot)[31] \\
& \text { Radicales anión superóxido }\left(\mathrm{O}_{2^{-}}\right) \text {[32] }
\end{array}
$$

En la misma figura también se muestra la posibilidad de excitación de una segunda molécula orgánica $(\mathrm{RH})$ mediante el mecanismo de transferencia de energía del estado triplete de las $\mathrm{SH}$, es decir, que estas últimas actúan como fotosensibilizadores de la excitación de la molécula orgánica. A partir de allí es posible que este estado excitado $\left({ }^{3} \mathrm{RH}^{*}\right)$ reaccione por diferentes vías que conllevan a la degradación de este compuesto.

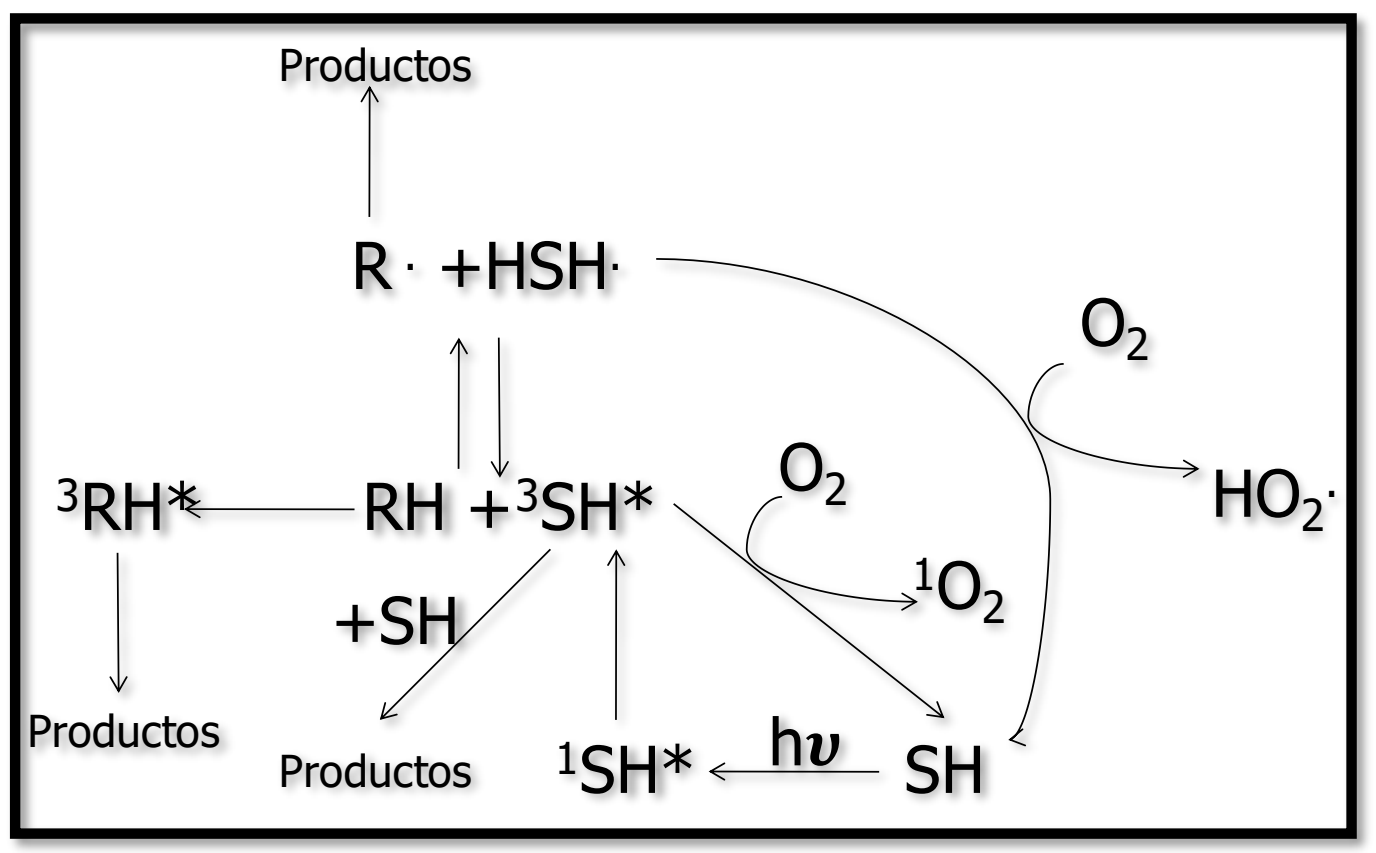

Fig. 1.9 - Esquema combinado de la excitación de Sustancias Húmicas y degradación de una molécula orgánica por vía sensibilizadora o reacción directa con los estados excitados de las SH.

La eficiencia de la degradación de la molécula orgánica $(\mathrm{RH})$ depende entre otras cosas, de la facilidad de producción de estados tripletes por parte del fotosensibilizador y de la transferencia de energía entre los estados $\left({ }^{3} \mathrm{SH}^{*}\right)$ y $\mathrm{RH}$ y de las constantes cinéticas de reactividad de todas las reacciones posibles. 
Los objetivos de este trabajo contemplan el estudio del sistema de degradación de Azul de Metileno y Pireno mediante la fotosensibilización por los SBO utilizando fuentes de luz mono y poli-cromáticas.

\subsubsection{Sistema de degradación de contaminantes orgánicos por medio de tratamientos tipo Fenton. \\ El peróxido de hidrogeno $\mathrm{H}_{2} \mathrm{O}_{2}$ es un agente oxidante fuerte $\left(\varepsilon_{\mathrm{pH}=0}^{\mathrm{O}}=1.80\right.$} $\mathrm{V}$ y $\varepsilon^{\mathrm{O}}{ }_{\mathrm{pH}=14}=0.87 \mathrm{~V}$ ). A pesar de ello, la oxidación iniciada térmicamente debida a este compuesto no es efectiva debido a las bajas velocidades de reacción a concentraciones de $\mathrm{H}_{2} \mathrm{O}_{2}$ razonables, no excesivamente altas.

De allí que se usan sales de hierro para favorecer la formación de $\mathrm{HO}$, que es la segunda especie más reactiva, después del átomo de Flúor $\left(\varepsilon_{\mathrm{HO}^{\circ}}{ }^{0}=\right.$ $2.80 \mathrm{~V})$, capaz de producir la mineralización de una gran cantidad de moléculas orgánicas [33], [34]. Los mecanismos de degradación típicos por tratamiento con HO conllevan a la extracción de átomos de $H$, la adición a enlaces insaturados[34] y a reacciones de transferencia de carga.

La ecuación química global de la reacción fenton es:

$$
2 \mathrm{Fe}^{+2}+\mathrm{H}_{2} \mathrm{O}_{2}+2 \mathrm{H}^{+} \rightarrow 2 \mathrm{Fe}^{+3}+2 \mathrm{H}_{2} \mathrm{O}
$$

Sin embargo el mecanismo de iniciación de la reacción en ausencia de moléculas orgánicas es el siguiente[33], [34]:
(1) $\mathrm{Fe}^{+2}+\mathrm{H}_{2} \mathrm{O}_{2} \rightarrow \mathrm{Fe}^{+3}+\mathrm{HO}+\mathrm{OH}^{-}$
(2) $\mathrm{Fe}^{+2}+\mathrm{HO} \rightarrow \mathrm{OH}^{-}+\mathrm{Fe}^{+3}$
(3) $\mathrm{Fe}^{+3}+\mathrm{H}_{2} \mathrm{O}_{2} \leftrightarrow \mathrm{Fe}-\mathrm{OOH}^{+2}+\mathrm{H}^{+}$
(4) $\mathrm{Fe}-\mathrm{OOH}^{+2} \rightarrow \mathrm{HO}_{2}+\mathrm{Fe}^{+2}$
(5) $\mathrm{Fe}^{+2}+\mathrm{HO}_{2} \rightarrow \mathrm{Fe}^{+3}+\mathrm{HO}_{2}^{-}$
(6) $\mathrm{Fe}^{+3}+\mathrm{HO}_{2} \rightarrow \mathrm{Fe}^{+2}+\mathrm{O}_{2}+\mathrm{H}^{+}$
(7) $\mathrm{HO}+\mathrm{H}_{2} \mathrm{O}_{2} \rightarrow \mathrm{H}_{2} \mathrm{O}+\mathrm{HO}_{2}$.

$\mathrm{k}_{1} \approx 70 \mathrm{M}^{-1} \mathrm{~s}^{-1}$

$\mathrm{k}_{2}=3.2 \times 10^{8} \mathrm{M}^{-1} \mathrm{~s}^{-1}$

$\mathrm{k}_{3} \approx(0.001-0.01) \mathrm{M}^{-1} \mathrm{~s}^{-1}$

$\mathrm{k}_{5}=1.3 \times 10^{6} \mathrm{M}^{-1} \mathrm{~s}^{-1}$ a pH 3.0

$\mathrm{k}_{6}<2 \times 10^{3} \mathrm{M}^{-1} \mathrm{~s}^{-1}$ a pH 3.0

$\mathrm{k}_{7}=3.3 \times 10^{7} \mathrm{M}^{-1} \mathrm{~s}^{-1}$

Al introducir moléculas orgánicas al sistema $(\mathrm{RH})$ estas pueden reaccionar con el radical hidroxilo para dar radicales orgánicos que inician a su vez una serie de reacciones que llevan a la mineralización de los reactivos de partida de la siguiente manera:

$$
\begin{aligned}
& \text { (8) } \mathrm{RH}+\mathrm{HO} \rightarrow \mathrm{H}_{2} \mathrm{O}+\mathrm{R} \cdot \quad \mathrm{k}_{8}>10^{8} \mathrm{M}^{-1} \mathrm{~S}^{-1} \\
& \text { (9) } \mathrm{R} \cdot+\mathrm{H}_{2} \mathrm{O}_{2} \rightarrow \mathrm{ROH}+\mathrm{HO} \cdot \\
& \text { (10) } \mathrm{R} \cdot+\mathrm{O}_{2} \rightarrow \mathrm{ROO} \\
& \text { (11) } \mathrm{R} \cdot+\mathrm{Fe}^{+3} \rightarrow \mathrm{R}^{+}+\mathrm{Fe}^{+2} \\
& \text { (12) } \mathrm{R} \cdot+\mathrm{Fe}^{+2} \rightarrow \mathrm{R}^{-}+\mathrm{Fe}^{+3} \\
& \text { (13) } 2 \mathrm{R} \cdot \rightarrow \mathrm{R}-\mathrm{R}
\end{aligned}
$$

Por lo anterior es posible mencionar que la introducción de moléculas orgánicas al sistema evita la posterior descomposición del $\mathrm{H}_{2} \mathrm{O}_{2}$ mediante la reacción con el $\mathrm{HO}$ - dado que la constante $\mathrm{k}_{8}>\mathrm{k}_{7}$. 
Referente a la aparición del $\mathrm{Fe}^{+3}$ en el sistema se requiere su reducción para dar lugar a la formación de $\mathrm{Fe}^{+2}$ y continuar el proceso de degradación. Por lo que se han planteado varios métodos de reducción entre los que resalta la vía fotoquímica: $\mathrm{Fe}^{+3} \stackrel{h v}{\rightarrow} \mathrm{Fe}^{+2}$ con luz entre 290 - $400 \mathrm{~nm}$ [35]. Incluso es posible el uso de irradiación por encima de $400 \mathrm{~nm}$ ya que el ion férrico posee una pequeña cola de absorción en esa región.

El pH de operación óptimo para el fenton convencional es 2 - 4 debido a que a $\mathrm{pH}<2$ la cinética se ve afectada debido a la formación de $\mathrm{H}^{+}$y la reacción de estos con el peróxido de hidrogeno, mientras que a $\mathrm{pH}>4$ la velocidad disminuye debido a la formación de complejos hidroxo-ferricos. Debido a ello el proceso fenton es más eficiente a $\mathrm{pH} \sim 3.0$ donde $\mathrm{el} \mathrm{Fe}^{+3}$ es una especie soluble [34].

Sin embargo, debido a los costos y consecuencias ambientales de acidificar los cuerpos de aguas a tratar, el uso de $\mathrm{pH}<5.0$ no es recomendable. Por ello se propuso el uso de agentes quelantes del $\mathrm{Fe}^{+3}$ para permitir su uso a pH neutro. En este sentido, las Sustancias Húmicas logran un aumento de la eficiencia del proceso bajo estas condiciones de $\mathrm{pH}$ [16], [33], [34]. De igual forma se han estudiado procesos fenton en sistemas heterogéneos donde el Fe utilizado en la reacción se encuentra en la superficie de un sólido [34].

En este trabajo se propone el uso de los SBO como auxiliares en la degradación por vía Fenton a pH neutro del Flusilasol.

\subsubsection{Uso de los SBO y el extracto hidrosoluble de la Yerba Mate como plantilla en la síntesis de nanopartículas. \\ Dentro de los estudios desarrollados también se investiga el uso de los} SBO y del extracto hidrosoluble de la Yerba Mate como plantilla para la síntesis de diferentes nanopartículas. Se espera que su uso afecte las propiedades morfológicas y fisicoquímicas de los nanomateriales tendientes a mejorar el proceso de adsorción de diferentes contaminantes en solución acuosa.

\subsubsection{Remediación de cuerpos de agua mediante la adsorción - Uso de superficies para la depuración.}

Los procesos de remediación mediante degradación de los contaminantes son efectivos a altas concentraciones de estos, pero cuando se encuentran a concentraciones bajas, es recomendable utilizar otras tecnologías como la adsorción, que es la acumulación de moléculas de una sustancia disuelta (adsorbato) en un solvente sobre la superficie de un material (adsorbente)[18]. Las moléculas del adsorbato quedan retenidas debido a la interacción física o química con las moléculas del adsorbente. Debido a que la adsorción es un fenómeno netamente superficial, los adsorbentes deberían tener una gran cantidad de área superficial efectiva disponible para la adsorción.

Las características ideales de un adsorbente son un área superficial elevada efectiva para la adsorción, selectividad sobre el contaminante deseado y facilidad de separación de la fase acuosa. En este trabajo se utilizaron 
nanopartículas de Hidroxiapatita dopadas con óxidos de hierro modificadas con SBO y nanopartículas de magnetita tratadas con extracto de Yerba Mate (YM) para la adsorción de diferentes contaminantes, entre otras cosas debido al comportamiento magnético que estas presentan que facilitan su separación. 


\subsection{Objetivos.}

Basado en todo lo expuesto anteriormente, se plantea como objetivo principal de este trabajo de tesis:

- "Evaluar la posibilidad del uso de los residuos SBO, Yerba Mate y Cascara de Naranja para la obtención de materiales de interés ambiental y nanotecnológico".

Los objetivos secundarios considerados en el marco de este trabajo son:

- Estudiar la capacidad de los SBO de actuar como agentes fotosensibilizadores. Se emplearán al Azul de Metileno y el Pireno en solución acuosa como compuestos prueba.

- Investigar el efecto de la presencia de los SBO en el rendimiento de la degradación por vía tipo Fenton. Se estudiará la degradación del Flusilasol a pH 5.0 como caso prueba. Postular el mecanismo de degradación inicial del Flusilasol.

- Utilizar los SBO como plantillas en la síntesis de nanomateriales. Caso de la síntesis de nanocompositos de Hidroxiapatita/Óxido de hierro que presenten propiedades magnéticas. Aplicación de los nanomateriales obtenidos en la adsorción de metales, $\mathrm{Cu}^{+2}$ y $\mathrm{Pb}^{+2}$.

- Sintetizar y caracterizar diferentes nanopartículas utilizando la Yerba Mate como materia prima. Obtención y evaluación de propiedades de nanopartículas de carbono. Uso de la cáscara de naranja en la obtención de Nanopartículas de Cy en la variación de sus propiedades.

- Elucidar el efecto del uso del extracto hidrosoluble de la Yerba Mate como estabilizante superficial en la síntesis de nanopartículas de magnetita y sobre sus propiedades y en la eficiencia de adsorción. Aplicaciones de estas partículas en la degradación catalizada mediante el anión radical $\mathrm{SO}_{4}^{-}$de azul de metileno. 


\subsection{Referencias bibliográficas.}

[1] T. J. Collins, "Review of the twenty-three year evolution of the first university course in green chemistry: Teaching future leaders how to create sustainable societies," J. Clean. Prod., pp. 1-18, 2014.

[2] J.-C. Charpentier, "What Kind of Modern 'Green' Chemical Engineering is Required for the Design of the 'Factory of Future'?," Procedia Eng., vol. 138, no. 10, pp. 445-458, 2016.

[3] N. Georgescu-Roegen, "The Entropy Law and the Economic Process inRretrospect," East. Econ. J., vol. XII, no. 1, 1986.

[4] F. A. Klink and V. Alcántara, De la economía ambiental a la economía ecológica, 1st ed. Barcelona: FUHEM, 1994.

[5] A. B. Prevot, P. Avetta, S. Berto, P. G. Daniele, S. Tabasso, D. Mainero, and E. Montoneri, "Soluble Bio-based Substances Isolated From Urban Wastes," 2015.

[6] E. Montoneri, V. Boffa, P. Savarino, D. Perrone, M. Ghezzo, C. Montoneri, and R. Mendichi, "Acid soluble bio-organic substances isolated from urban bio-waste. Chemical composition and properties of products," Waste Manag., vol. 31, no. 1, pp. 10-17, 2011.

[7] P. Avetta, "Sensitizing effect of soluble bio-organic substances isolated from urban biomases on the photodegradation of organic pollutants," Università degli studi di torino, 2012.

[8] G. Vittone, "Degradazione foto indotta del 4-clorofenolo in resenza di sostanze Bio-Organiche isolate da biomasse vegetali.," Università degli studi di torino, 2011.

[9] P. Aiken, G. R.;McKnight, D. M.;Wershaw, R. L.;MacCarthy, Ed., Humic substances in soil, sediment, and water: geochemistry, isolation and characterization. 1989.

[10] F. Cherubini, "The biorefinery concept: Using biomass instead of oil for producing energy and chemicals," Energy Convers. Manag., vol. 51, no. 7, pp. 1412-1421, 2010.

[11] INYM, "¿Qué es la Yerba Mate?," 2015. [Online]. Available: http://yerbamateargentina.org.ar/.

[12] M. E. Ramallo, L.A.; Smorczewski, M.; Valdez, E.; Paredes, A. M. y Schmalko, "Composición Química del Extracto Acuoso de la Yerba Mate," in I Congresso SulAmericano da Erva -Mate, 2011.

[13] M. C. Alexandre Marcelo, C. A. Martins, D. Pozebon, and M. F. Ferrão, "Methods of multivariate analysis of NIR reflectance spectra for classification of yerba mate," Anal. Methods, vol. 6, no. 19, pp. 7621-7627, 2014.

[14] I. Cerón-Salazar and C. Cardona-Alzate, "Evaluación del proceso integral para la obtención de aceite esencial y pectina a partir de la cáscara de naranja," Ing. y Cienc. - ing.cienc., vol. 7, no. 13, pp. 65-86, 2011.

[15] J. Trujillo-Reyes, J. R. Peralta-Videa, and J. L. Gardea-Torresdey, "Supported and unsupported nanomaterials for water and soil remediation: Are they a useful solution for worldwide pollution?," J. Hazard. Mater., vol. 280, pp. 487-503, 2014.

[16] E. Lipczynska-Kochany and J. Kochany, "Effect of humic substances on the Fenton treatment of wastewater at acidic and neutral pH.," Chemosphere, vol. 73, no. 5, pp. 745-750, 2008.

[17] Y. Yamauchi, S. Noda, and H. Komiyama, "Chemical Engineering for Technology Innovation.," Chem. Eng. Commun., vol. 196, no. 1/2, pp. 267-276, 2009.

[18] T. H. Y. Tebbutt, Principles of water Quality Control, 4th ed. New York: Pergamon Press, 1992.

[19] R. Mailler, J. Gasperi, Y. Coquet, A. Bulet??, E. Vulliet, S. Deshayes, S. Zedek, C. Mirande-Bret, V. Eudes, A. Bressy, E. Caupos, R. Moilleron, G. Chebbo, and V. Rocher, "Removal of a wide range of emerging pollutants from wastewater treatment plant discharges by micro-grain activated carbon in fluidized bed as tertiary treatment at large pilot scale," Sci. Total Environ., vol. 542, pp. 983-996, 2016. 
[20] B. Akadar, B. Mohamed, M. Nabil, and B. Alaoui-sossé, "Wastewater use in agriculture in Djibouti: Effectiveness of sand filtration treatments and impact of wastewater irrigation on growth and yield of Panicum maximum," Ecol. Eng., vol. 84, pp. 607-614, 2015.

[21] M. Varol, "Assessment of heavy metal contamination in sediments of the Tigris River (Turkey) using pollution indices and multivariate statistical techniques," $\mathrm{J}$. Hazard. Mater., vol. 195, pp. 355-364, 2011.

[22] A. Corami, S. Mignardi, and V. Ferrini, "Cadmium removal from single- and multimetal $(\mathrm{Cd}+\mathrm{Pb}+\mathrm{Zn}+\mathrm{Cu})$ solutions by sorption on hydroxyapatite," J. Colloid Interface Sci., vol. 317, no. 2, pp. 402-408, 2008.

[23] M. Šljivić, I. Smičiklas, I. Plećaš, and M. Mitrić, "The influence of equilibration conditions and hydroxyapatite physico-chemical properties onto retention of $\mathrm{Cu} 2+$ ions," Chem. Eng. J., vol. 148, no. 1, pp. 80-88, 2009.

[24] E. Mavropoulos, A. M. Rossi, A. M. Costa, C. A. C. Perez, J. C. Moreira, and M. Saldanha, "Studies on the mechanisms of lead immobilization by hydroxyapatite," Environ. Sci. Technol., vol. 36, no. 7, pp. 1625-1629, 2002.

[25] C. Radio, "\$120 millones de multa a Fabricato por contaminación del río Medellín," Medellín, 11-Dec-2013.

[26] P. R. Gogate and A. B. Pandit, "A review of imperative technologies for wastewater treatment II: Hybrid methods," Adv. Environ. Res., vol. 8, no. 3-4, pp. 553-597, 2004.

[27] H. Lippold, U. Gottschalch, and H. Kupsch, "Joint influence of surfactants and humic matter on PAH solubility. Are mixed micelles formed?," Chemosphere, vol. 70, no. 11, pp. 1979-1986, 2008.

[28] G. Basu Ray, I. Chakraborty, and S. P. Moulik, "Pyrene absorption can be a convenient method for probing critical micellar concentration $(\mathrm{cmc})$ and indexing micellar polarity," J. Colloid Interface Sci., vol. 294, no. 1, pp. 248-254, 2006.

[29] N. J. Turro, Modern Molecular Photochemistry. Mill Valley, USA: University Science Books, 1991.

[30] C. J. M. Wolff, M. T. H. Halmans, and H. B. van der Heijde, "The formation of singlet oxygen in surface waters," Chemosphere, vol. 10, no. 1, pp. 59-62, 1981.

[31] T. Mill, D. G. Hendry, and H. Richardson, "Free-radical oxidants in natural waters," Science (80-. )., vol. 207, no. 4433, pp. 886-887, 1980.

[32] W. J. Cooper and R. G. Zika, "Photochemical formation of hydrogen peroxide in surface and ground waters exposed to sunlight.," Science, vol. 220, no. 4598, pp. 711-712, 1983.

[33] E. Neyens and J. Baeyens, "A review of classic Fenton's peroxidation as an advanced oxidation technique," J. Hazard. Mater., vol. 98, no. 1-3, pp. 33-50, 2003.

[34] C. L. Yap, S. Gan, and H. K. Ng, "Fenton based remediation of polycyclic aromatic hydrocarbons-contaminated soils," Chemosphere, vol. 83, no. 11, pp. 1414-1430, 2011.

[35] V. Kavitha and K. Palanivelu, "The role of ferrous ion in Fenton and photo-Fenton processes for the degradation of phenol," Chemosphere, vol. 55, no. 9, pp. 12351243, 2004. 


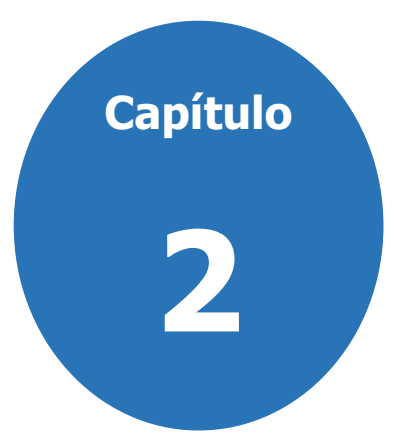

\section{Materiales y métodos Una aproximación teórico-experimental.}

En este capítulo se describen los materiales y métodos utilizados para la realización de la parte experimental y analítica de este trabajo de tesis. Además, se hace una introducción del fundamento y funcionamiento de los métodos más relevantes para tratar de explicar por qué se realizaron estos ensayos y que información de utilidad nos podrían brindar.

\subsection{Métodos.}

\subsubsection{Métodos de fotolisis.}

\subsubsection{Fotolisis Continua.}

Se utilizaron dos equipos diferentes para los ensayos de irradiación estudiados en este trabajo debido a las diferentes condiciones requeridas. El primero de ellos es el mostrado en la figura 2.1 desde diferentes perspectivas.

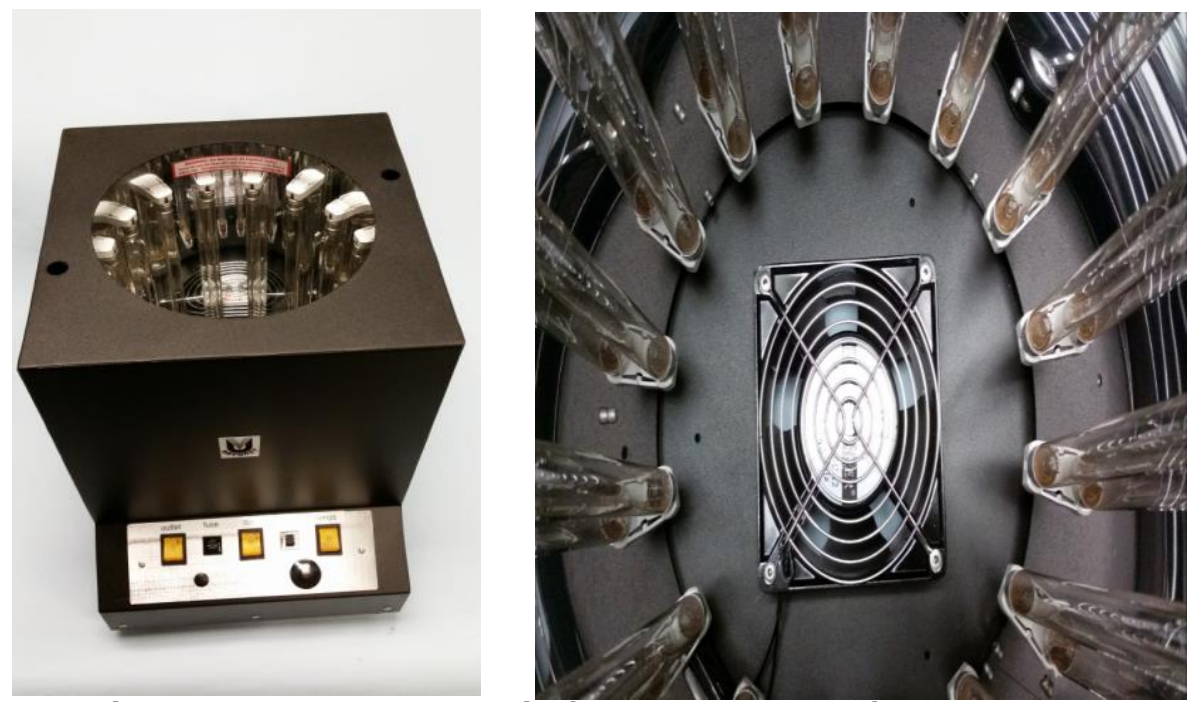

Fig. 2.1- Rayonet $(R P R$-100Izquierda: Vista externa. Derecha: Vista interna. 
Los ensayos de irradiación con luz monocromática se llevaron a cabo en un reactor cilíndrico fotoquímico Rayonet $\AA$ RPR-100, mostrado en la página anterior, dentro del cual se ubica la solución a irradiar en el centro del mismo. Este equipo permite irradiar con un máximo de 16 lámparas de $8 \mathrm{~W}$ cada una. Posee un sistema de ventilación para evitar un aumento excesivo de la temperatura, el cual funciona también como medio de agitación para garantizar el mezclado dentro del reactor y evitar zonas muertas o de estratificación dentro del mismo. Puntualmente en los ensayos en los que se empleó este equipo, se utilizaron 8 lámparas distribuidas simétricamente que poseen una distribución normal de máximos de emisión centradas en $(254.7 \pm 20.0)$ y $(350 \pm 20) \mathrm{nm}$, de acuerdo al caso de interés. En estos ensayos, se trabajó con un volumen máximo de $50 \mathrm{~mL}$ para garantizar que no existiera estratificación en el volumen de reacción.

También se realizaron ensayos de irradiación continúa utilizando luz policromática, para lo cual se utilizó un simulador solar ORIEL Instrument 81160 equipado con una lámpara de Xe de $300 \mathrm{~W}$, la cual posee un espectro de emisión que similar al que llega a la superficie de la tierra y posee una irradiancia de 67 $\mathrm{W} / \mathrm{m}^{2}$ en la zona de 320 a $400 \mathrm{~nm}$. Para evitar la irradiación por debajo de 350 nm se utilizó un filtro óptico Los experimentos se realizaron en un vaso cilíndrico abierto $(7,5 \mathrm{~cm}$ de diámetro y $8 \mathrm{~cm}$ alto) conteniendo $250 \mathrm{ml}$ de la solución de estudio.

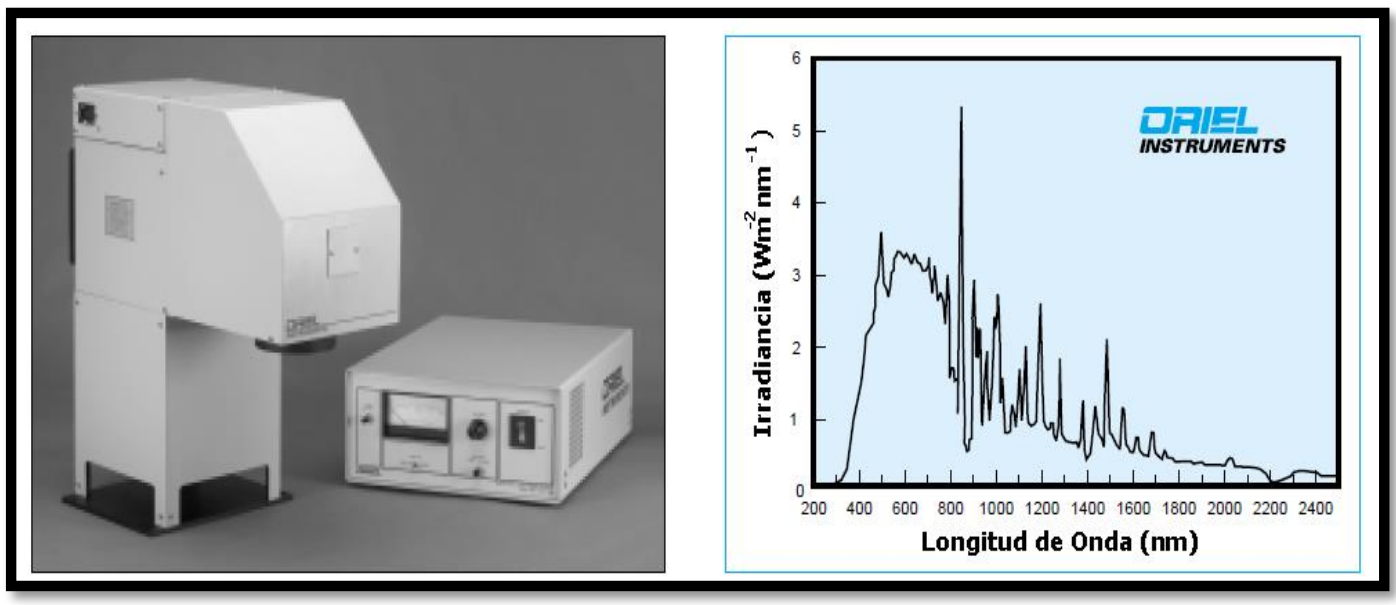

Fig. 2.2-Derecha: Simulador solar ORIEL Instrument 81160.Izquierda: Espectro de Irradiancia de la lámpara utilizada.

\subsubsection{Fotólisis resuelta en el tiempo.}

\section{$>$ Laser Flash Fotólisis.}

La técnica de flash fotólisis es una herramienta ampliamente utilizada para el análisis cualitativo y cuantitativo de estados excitados e intermediarios que participan en procesos fotoquímicos con vida media corta (hasta $10^{-12} \mathrm{~s}$ ) [1]. Para ello el sistema de estudio es irradiado con un pulso de luz con menor duración que el de los procesos de estudio y de alta intensidad, generando así grandes concentraciones de intermediarios en un tiempo muy corto. La 
concentración de intermediarios se monitorea en función del tiempo por diferentes métodos de acuerdo a la naturaleza intrínseca del sistema de estudio, el más comúnmente utilizado es la espectrofotometría [2]. Pero independientemente del método de detección seleccionado el tiempo de resolución del método está limitado por la duración del pulso de excitación[3]. Debido a esto en la actualidad se usan comúnmente láseres con tiempos característicos del pulso de excitación menores a $10^{-9} \mathrm{~s}$, con alta intensidad y frecuencia de repetición y con un rango angosto y preciso de longitudes de onda[4].Específicamente hablando para este caso de estudio, la espectroscopia Uv/Vis fue el método de detección utilizado, debido a que los intermediarios de interés presentaban altos coeficientes de extinción molar y espectros de absorción conocidos.
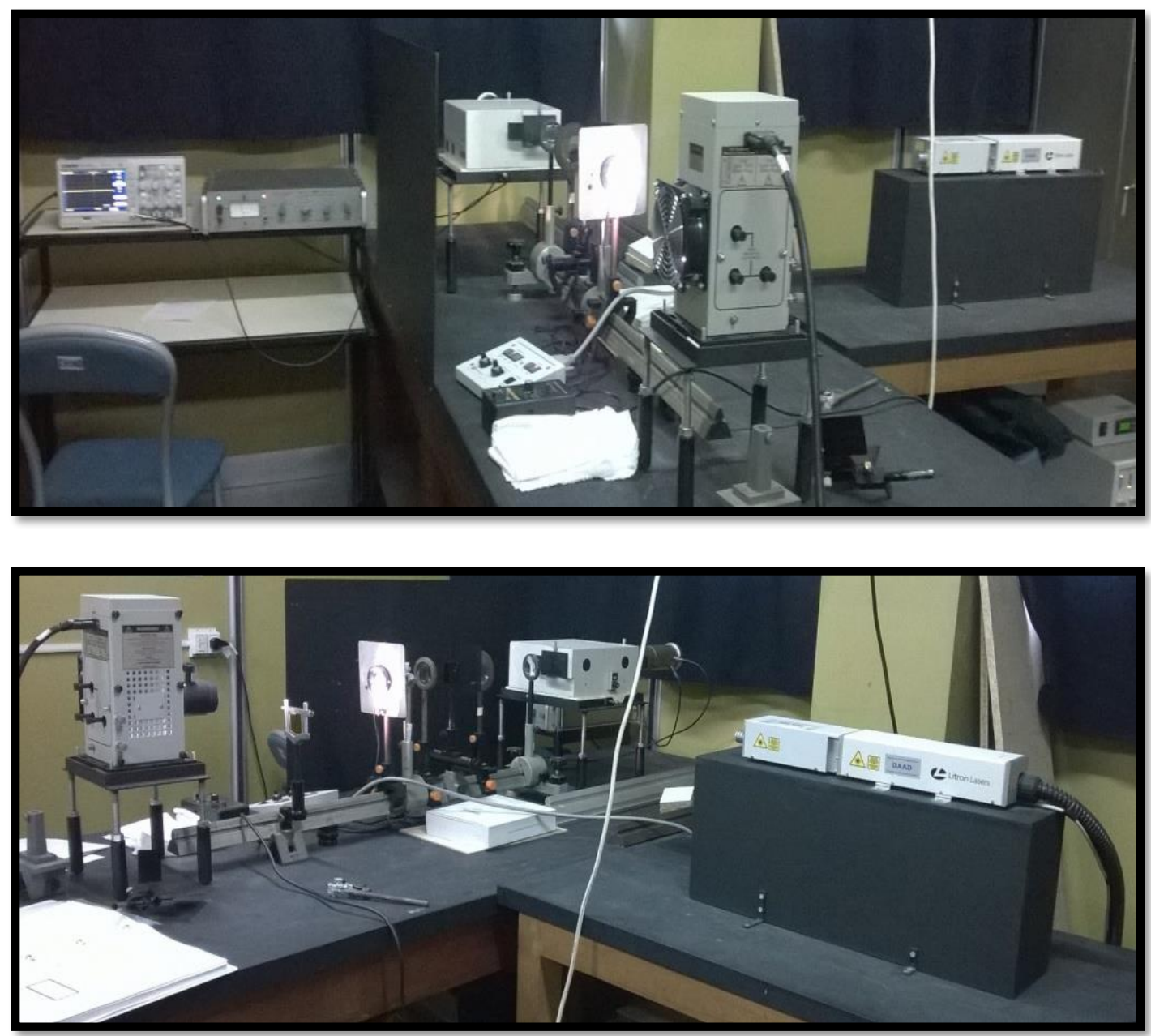

Fig. 2.3-Diferentes vistas del equipo de Laser Flash Fotolisis utilizados.

El arreglo experimental consta de una lámpara de análisis que se encuentra a $90^{\circ}$ respecto al haz del láser. La radiación laser es absorbida por el sistema en estudio para producir especies reactivas, en general estados excitados o radicales libres, cuya absorción característica es detectada por el sistema de análisis consistente en un monocromador y un fotomultiplicador de respuesta rápida capaz de convertir la señal lumínica en una señal eléctrica. Esta última es recibida por un osciloscopio conectado a una computadora para finalmente convertir la señal eléctrica en absorbancia. La absorbancia de estos 
intermediarios reactivos disminuye en el tiempo de acuerdo a los procesos por los cuales el intermediario reacciona con otras moléculas [2]. La figura 2.4 muestra un decaimiento típico obtenido en estos experimentos.

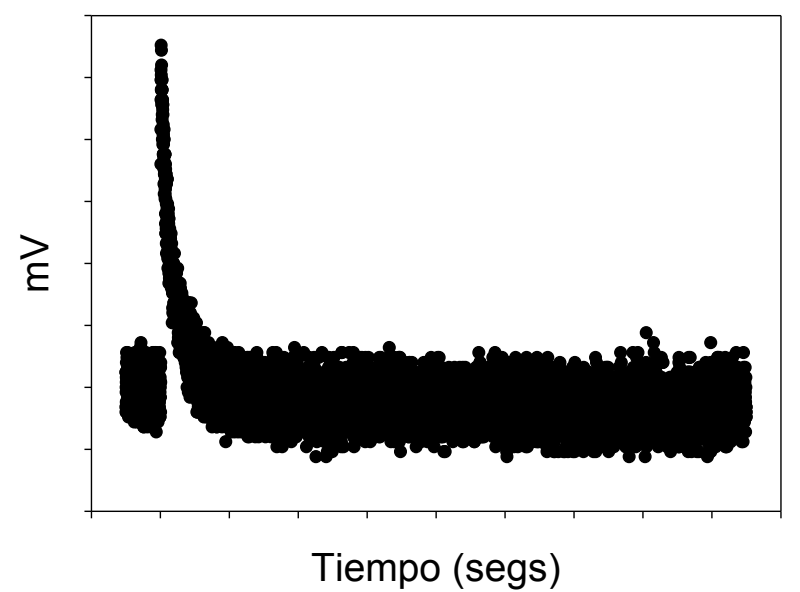

Fig. 2.4-Decaimiento típico de señal obtenido en estos experimentos.

Cambiando la longitud de onda de análisis por medio del monocromador ubicado delante del detector, permite obtener el espectro de absorción de los intermediarios reactivos y la evolución temporal de su concentración.

\section{> Análisis de los decaimientos de Laser Flash Fotolisis.}

Antes de realizar cualquier análisis matemático, se requiere convertir la señal de Voltajes en función del tiempo a absorbancia en función del tiempo. Para ello, en cada corrida experimental se realizan mediciones antes del pulso del láser. A este valor se asigna el $100 \%$ de transmitancia y se le asocia un mismo valor de voltaje para todas las longitudes de onda utilizando un comparador diferencial conectado al osciloscopio. La respuesta detectada por el osciloscopio $\mathrm{x}$ es proporcional a la luz transmitida $\mathrm{I}=\mathrm{kx}$, donde la constante $\mathrm{k}$ depende de la sensibilidad del detector y $\mathrm{x}$ es la señal en $\mathrm{mV}$. Combinando esta relación con la ley de Lambert-Beer es posible la conversión de estos datos a absorción:

$$
A(t)=-\log \left(\frac{I(t)}{I_{0}}\right)=-\log \left(\frac{x}{x_{0}}\right)=\varepsilon_{\lambda} \cdot l \cdot c(t)
$$

Donde $A(t)$ es la absorbancia al tiempo t producido por el pulso de luz, $\varepsilon(\lambda)$ es el coeficiente de extinción molar de la especie transiente a la longitud de onda seleccionada, $\mathrm{c}(\mathrm{t})$ es la concentración molar al tiempo t y $l$ el camino óptico en centímetros. Para ajustar el valor de $x_{0}$ se toma el promedio de los valores medidos antes del disparo del flash.

Una vez obtenidos los perfiles de absorbancia de los transientes observados en la parte experimental, estos se ajustaron por cinéticas de primer orden, segundo orden, o mixto a cada longitud de onda dada.

Para la cinética de primer orden $A=A_{0} e^{-a t}$

Para la cinética de segundo orden: $A=\frac{1}{\left(\frac{1}{A_{0}}\right)+C(\lambda) t}$ 
Para cinética de orden mixto: $A=\frac{a}{b(\lambda) e^{a t}-C(\lambda)}$

Para todos los casos $A_{0}$ es la absorbancia a tiempo cero, $a$ es la constante cinética de primer orden, $b(\lambda)=\left(a / A_{0}\right)+c(\lambda)$, a partir de $c(\lambda)=2 k / \varepsilon$ l puede calcularse la componente de segundo orden $(2 \mathrm{k} / \varepsilon) \mathrm{d}(\lambda)$ corresponde a la absorción de especies de vida larga que se forman después de la desaparición del transiente. Los análisis para la comprobación del menor número de especies presentes se realizaron mediante un análisis bilineal que se discutirá posteriormente.

El láser utilizado en este trabajo fue un Laser Litron Nd:YAG (2 ns de disparo y $6 \mathrm{~mJ}$ por pulso a $266 \mathrm{~nm}$ ), la lámpara de análisis utilizada es de Xe a presión de 1 a 3 atmosferas con una potencia de $350 \mathrm{~W}$, el haz de luz es enfocado mediante un sistema de lentes sobre un monocromador PTI 1695 y amplificado en un fotomultiplicador 1P28 PTM. La salida se conecta a un osciloscopio Tektronix 520A, 500MHz. Se recolectaron un promedio de 64 señales individuales. Las soluciones preparadas presentaban una absorbancia de 0.5 a $266 \mathrm{~nm}$ y $\left[\mathrm{Na}_{2} \mathrm{~S}_{2} \mathrm{O}_{8}\right]=(1.0-2.5) \times 10^{-2} \mathrm{M}$ y la concentración de los reactivos de estudio será mencionada en el respectivo capítulo.

\subsubsection{Métodos de Fluorescencia.}

\subsubsection{Fluorescencia en estado estacionario.}

Los espectros de excitación y emisión a temperatura ambiente se

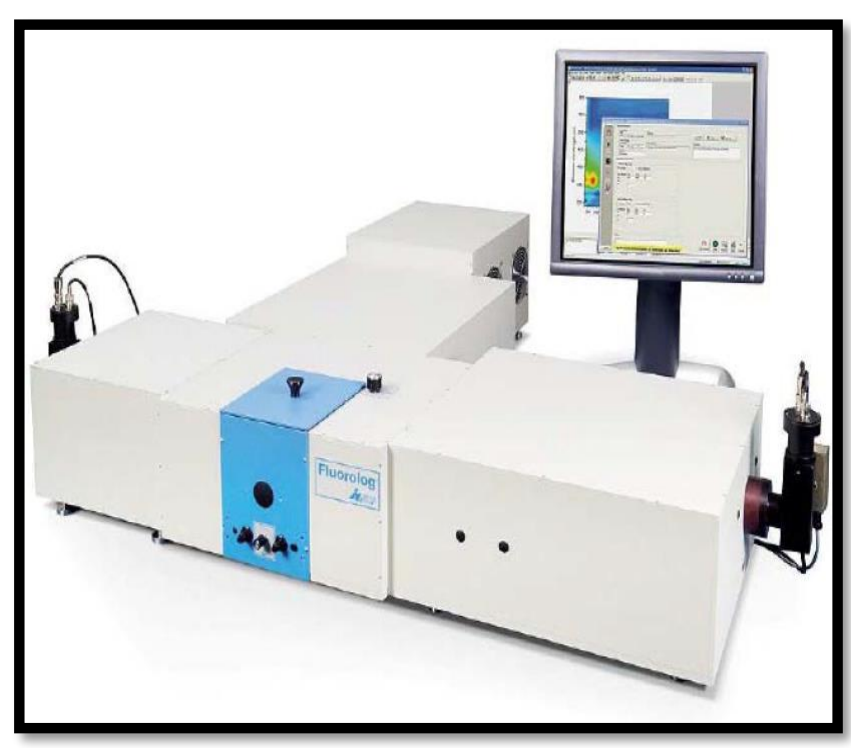
obtuvieron mediante un equipo JOBIN-YVON SPEX FLUOROLOG FL3-11 usando la metodología Time Correlated Single Photon Counting (TCSPC). El equipo se muestra en la figura 2.5 y su disposición óptica en la Figura 2.6. Siempre se emplearon celdas de cuarzo con camino óptico de $10 \mathrm{~mm}$. Se utilizó un paso de longitud de onda de barrido $1 \mathrm{~nm}$ y un tiempo de integración en

Fig. 2.5- Fluorometro SpexFluorolog FL3-11 Horriba - JovinYvon. cada paso de 0,3 seg.

Para la excitación se usó una lámpara de Xe de presión media acoplada a un monocromador con $1 \mathrm{~nm}$ de paso de banda. Luego de la excitación de la muestra, la emisión se detecta a 90 grados y se dirige a un monocromador de doble red con paso de banda $1 \mathrm{~nm}$. La detección se realizó mediante un detector R928 PM (Hamamatsu). La señal adquirida fue corregida por la distribución 
espectral de la lámpara y el detector. A su vez, los espectros fueron corregidos considerando las señales adquiridas para el solvente puro utilizado en cada caso.

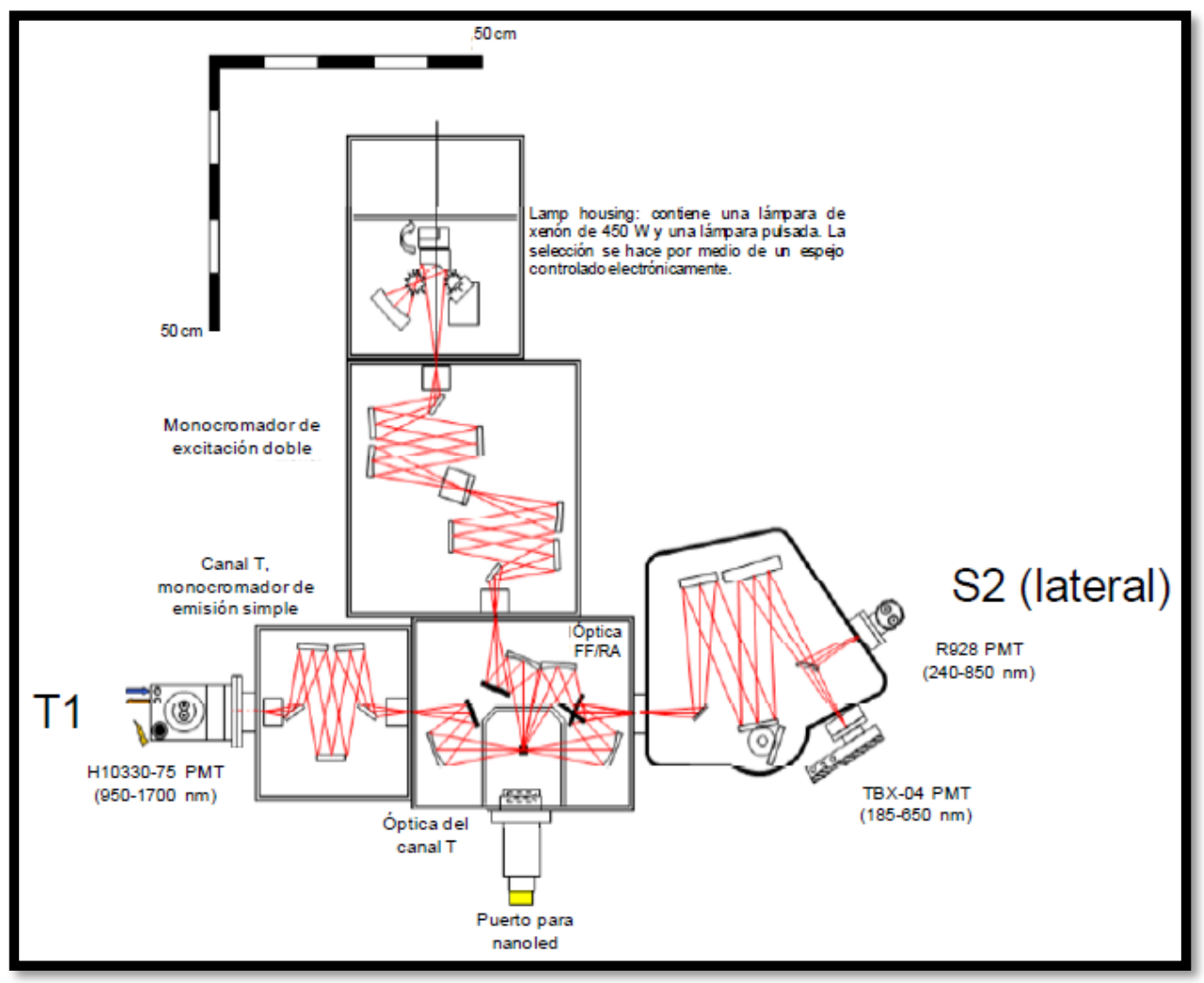

Fig. 2.6-Sistema óptico del espectrofluorómetro SpexFluorolog FL3-11 utilizado para los ensayos de fluorescencia en estado estacionario.

Para la estimación de los rendimientos cuánticos de emisión, las muestras y la referencia se midieron bajo las mismas condiciones (pasos ópticos, energía del haz de excitación, paso de banda). Se empleó como referencia una solución acuosa de sulfato de quinina en ácido sulfúrico $0.5 \mathrm{M}(\varnothing=0.546 \pm 0.02)$ [5], [6].Para ello se utilizó la siguiente relación:

$$
\emptyset_{e m i}=\left(\frac{A_{r}}{A_{m}}\right)\left(\frac{I_{m}}{I_{r}}\right) \emptyset_{e m i, r}\left(\frac{n_{m}}{n_{r}}\right)^{2} ;
$$

Donde los subíndices $r$ y $\mathrm{m}$ corresponden a la referencia y muestra respectivamente. A es la absorbancia a la longitud de onda de excitación, I es la intensidad de fluorescencia a la longitud de onda de emisión, $Q$ es el rendimiento cuántico de emisión bajo las condiciones estudiadas y $\mathrm{n}$ es el índice de refracción del solvente puro. Además de lo anteriormente mencionado, se requiere que las soluciones o suspensiones de estudios sean ópticamente diluidas $(A<0.1)$.

\subsubsection{Fluorescencia resuelta en el tiempo.}

Para las determinaciones de emisión y anisotropía resuelta en el tiempo se utilizó la técnica de fluorometría en el dominio del tiempo con el mismo equipo que se empleó para las medidas en estado estacionario, pero con diferente modo 
de operación, fuente de excitación y sistema óptico de recolección de señales. Como fuente de excitación se usó un LED pulsado de 341 nm (FWHM 400 ps), y se detectó en el máximo de emisión de cada muestra empleando un fotodiodo de avalancha TBX-100, (Horiba) bajo la técnica de TCSPC.

El espectro resuelto en el tiempo del LED, necesario para la posterior deconvolución de las señales obtenidas por excitación de la muestra, se determinó siguiendo las recomendaciones del fabricante usando una suspensión de sílice coloidal Ludox (SM-30, $30 \% \mathrm{SiO}_{2}$ en agua a pH 10,2 con un diámetro de partícula medio de $7 \mathrm{~nm}$ y un área superficial de $345 \mathrm{~m}^{2} / \mathrm{g}$, Sigma-Aldrich). El ajuste de los decaimientos de luminiscencia resueltos en el tiempo fue realizado optimizando los valores de $\chi^{2}$ para obtener los parámetros.

\subsubsection{Análisis Computacional (Billineal).}

Durante el desarrollo de los ensayos resueltos en el tiempo se obtuvieron varios perfiles de absorbancia (o emisión) en el rango de longitudes de onda de interés. De esta forma los datos obtenidos constituyen una matriz de absorbancia (o emisión) función de la longitud de onda y del tiempo.

Para los cálculos que involucra el método, la matriz de absorbancia se escribe de la forma $[a]=[\varepsilon][c]$, donde $[a],[\varepsilon]$ y $[c]$ representan las matrices de la absorbancia o emisión, coeficiente de absorción y concentración, respectivamente. A partir de los valores de [a] y de una primera apuesta de los valores de $[\varepsilon]$ o de $[c]$ se obtienen los espectros individuales y concentraciones de las especies involucradas. Estos valores se combinan linealmente de forma de simular los valores experimentales obtenidos para [a]. El método converge hasta que se cumple la condición de tolerancia y minimizando los elementos de la matriz error. De esta última matriz se obtiene la matriz de absorbancia o de emisión corregida $\left[\mathrm{a}^{\mathrm{c}}\right]$, permitiendo calcular así el número de especies involucradas ya que se selecciona el mínimo valor que permite una aproximación razonable entre las matrices $\left[\mathrm{a}^{\mathrm{c}}\right]$ y $[\mathrm{a}]$.

\subsubsection{Identificación y cuantificación de moléculas en solución.}

\subsubsection{Espectrometría de Masas.}

La espectrometría de masas es una técnica ampliamente utilizada para la identificación de la estructura molecular de compuestos desconocidos, por lo que es un arma de suma importancia en la detección productos de reacción. Para ello se excita a la molécula a estudiar y se detectan los iones resultantes y el patrón de fragmentación. En este proceso se produce un electrón libre y un ión cargado positivamente, este último puede poseer energía excesiva que puede ser disipada a través de la fragmentación de ciertos enlaces químicos. Este rompimiento lleva a la producción de fragmentos de ión cuya masa es igual a la suma de las masas de los iones producidos por su ruptura.

Para este trabajo, se utilizó un equipo de cromatografía gaseosa acoplada a espectrometría de masa (GC-MS). Se utilizó la técnica para el estudio de los 
subproductos de la degradación del Flusilasol, por lo cual se preconcentraron 250 $\mathrm{mL}$ de la solución de Flusilasol saturada a $25^{\circ} \mathrm{C}$ mediante extracción en fase sólida (SPE). Con este fin, mas muestras se hicieron pasar a través de un cartucho LiChrolut EN $200 \mathrm{mg}$ (Merck), los extractos metanólicos fueron inyectados en un GCMS-QP2010S (Shimadzu) equipado con una fuente de ionización de impacto de electrones y un analizador cuadrupolar. Las muestras se inyectaron en modo split con una temperatura de inyector de $200^{\circ} \mathrm{C}$. La temperatura se incrementó de $60^{\circ} \mathrm{C}$ a $250^{\circ} \mathrm{C}$ con una velocidad de $5^{\circ} \mathrm{C} / \mathrm{min}$. Se utilizó helio (Praxair) como gas portador. La columna utilizada fue Meta X5 Teknokroma de $30 \mathrm{~m}$ de longitud, 0,25 mm de diámetro y recubrimiento interno (fase estacionaria) de 0,25 $\mu \mathrm{m}$.

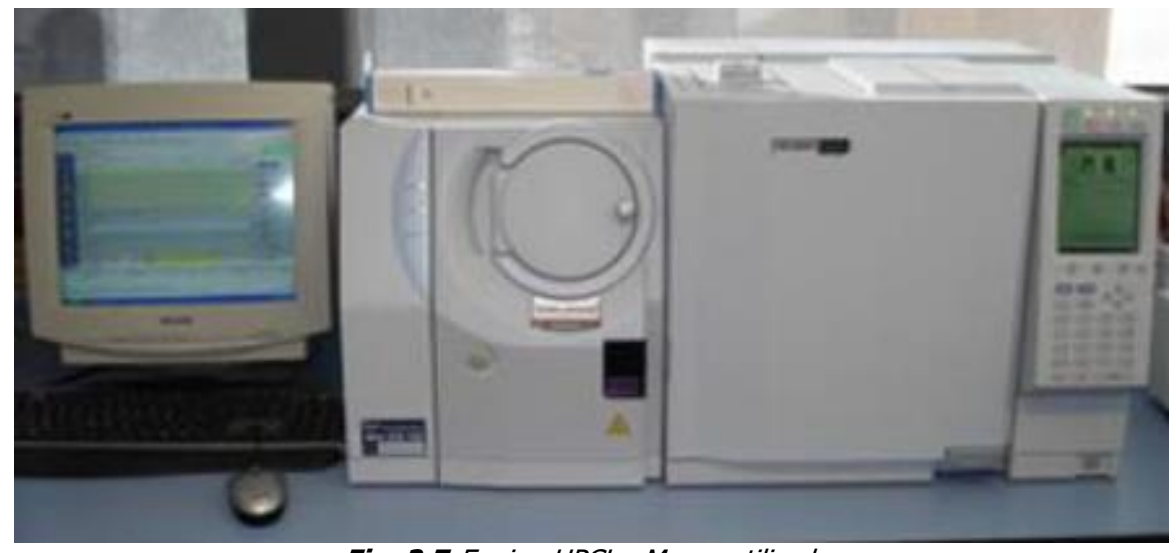

Fig. 2.7-Equipo HPCL - Masas utilizado.

\subsubsection{Espectroscopia UV-VIS.}

Esta técnica debe su nombre a la fracción del espectro electromagnético correspondido entre 100 y $800 \mathrm{~nm}$, aprovechando que la materia es capaz de absorber fotones entre estas longitudes de onda.

La Ley de Lambert - Beer establece que la absorbancia depende logarítmicamente con la transmisión ( $T$ ) de la luz a través de una sustancia. A su vez, también se define como el producto del coeficiente de absorción de la sustancia $(\varepsilon)$ por su concentración (c) y el camino óptico de la luz $(L)$ a través del material [5], [6].Las siguientes ecuaciones muestran las relaciones entre los parámetros considerados:

$$
\begin{aligned}
& A(\lambda)=-\ln T(\lambda) \\
& A(\lambda)=\varepsilon(\lambda) \cdot L \cdot c \\
& 1-T(\lambda)=1-P(\lambda) / P_{0} \\
& P(\lambda) / P_{0}=1-10^{-A(\lambda)}
\end{aligned}
$$

Donde $P(\lambda)$ es el poder radiante luego de pasar por el camino óptico $L$ y $\mathrm{P}_{0}$ es el poder radiante incidente. Debido a ello, es posible conocer la concentración de una especie conociendo la absorbancia de esta en cierta 
longitud de onda y el coeficiente de absorción del mismo. Esta ley se cumple solo cuando $\mathrm{P}_{0}$ es pequeño y los procesos multifotonicos y las reacciones fotoquímicas son también despreciables [7].

Para los ensayos de UV/Vis se utilizó un equipo espectrofotómetro Shimadzu UV-1800 de doble haz con celdas de cuarzo de un paso óptico de 1 $\mathrm{cm}$.

\section{$>$ Cromatografía HPLC}

Para los ensayos de degradación de Flusilasol también se utilizó un cromatógrafo Merk Hitachi XL Autosystem D-7000, equipado con un detector de arreglo de diodos. La columna empleada es una LiChroCART $\circledR 125-4$ con fase reversa LiChrospher ${ }^{\circledR} 100 \mathrm{RP}-18(5 \mu \mathrm{m})$ de la marca Merck. Muestras de $0.5 \mathrm{~mL}$ de la solución del contaminante se diluyeron con $0.5 \mathrm{~mL}$ de metanol. El volumen de inyección fue de $80 \mu \mathrm{L}$. Como fase móvil se utilizó una mezcla agua: metanol (20:80) y un flujo de $0.8 \mathrm{~mL} \mathrm{~min}^{-1}$. La longitud de onda de detección fue $230 \mathrm{~nm}$ y el tiempo de retención del compuesto de interés fue de $5.1 \min [8]-[11]$.

\subsubsection{Determinación indirecta de Producción de Oxígeno Molecular Singulete $\mathrm{O}_{2}\left({ }^{1} \Delta_{g}\right)$ - Consumo de Oxigeno Molecular Disuelto $\mathrm{O}_{2}\left({ }^{3} \Sigma_{g}\right)$.}

La formación de $\mathrm{O}_{2}\left({ }^{1} \Delta_{g}\right)$ por parte de algunos de los materiales y compuestos de estudio en este trabajo, fue detectada de forma indirecta mediante el monitoreo de consumo de oxígeno molecular en un reactor cerrado. Para ello se utilizó un montaje como el mostrado en la figura 2.8 que consta de una lámpara Rayonet $\circledast$ con emisión en $(350 \pm 20)$ nm, un reactor cerrado donde se sitúa el fotosensibilizador (materiales de estudio) en una atmosfera saturada de oxígeno lo que se logra burbujeando la solución durante 30 minutos con un flujo de $\mathrm{O}_{2}$. Para el monitoreo se utilizó un electrodo sensible de oxígeno molecular (Orion 97-0899).

Para evidenciar que la formación $\mathrm{O}_{2}\left({ }^{1} \Delta_{\mathrm{g}}\right)$ es necesario realizar tres ensayos. En el primero se irradia la solución de estudio y se mide el consumo de oxígeno. Si se registra consumo de oxígeno podría ser debido a que se genera oxígeno singulete y este reaccione con algún componente del sistema en estudio, o bien que por irradiación de la solución se forme superóxido o radicales que consumen oxígeno. Para evidenciar si se trata de oxígeno singulete, se realiza un segundo ensayo bajo las mismas condiciones experimentales, pero se añade alcohol furfurílico (FA). El FA reacciona selectivamente con el oxígeno singulete. Como consecuencia de esta reacción se elimina $\mathrm{O}_{2}\left({ }^{3} \Sigma_{g}\right)$ del medio, siendo detectado este consumo por el electrodo. En el tercer ensayo se agrega azida sódica $\mathrm{NaN}_{3}$ a la anterior solución en una concentración un orden de magnitud mayor que la de FA. El oxígeno singulete interacciona con la azida sódica desactivándose al estado basal del oxígeno por lo que este no se consume. Al existir una competencia por el $\mathrm{O}_{2}\left({ }^{1} \Delta \mathrm{g}\right)$ entre el alcohol furfurílico y la azida sódica, donde esta última se encuentra en mucha mayor proporción, se inhibe el 
consumo de $\mathrm{O}_{2}\left({ }^{1} \Delta \mathrm{g}\right)$. [12] Las reacciones siguientes muestran las reacciones que compiten por el oxígeno singulete en el ensayo, de no mediar otro compuesto (por ejemplo la superficie de las partículas) que también consuman $\mathrm{O}_{2}\left({ }^{1} \Delta \mathrm{g}\right.$ ).

$$
\begin{array}{ll}
\mathrm{O}_{2}\left({ }^{1} \Delta_{\mathrm{G}}\right) \rightarrow \mathrm{O}_{2}\left({ }^{1} \Sigma_{\mathrm{G}}\right) & k=2.9 \times 10^{5} \mathrm{~s}^{-1} \\
\mathrm{O}_{2}\left({ }^{1} \Delta_{\mathrm{G}}\right)+\mathrm{AF} \rightarrow \mathrm{AF}_{\mathrm{OXD}} & k=1.8 \times 10^{8} \mathrm{~s}^{-1} \mathrm{M}^{-1} \\
\mathrm{O}_{2}\left({ }^{1} \Delta_{\mathrm{G}}\right)+\mathrm{N}_{3}^{-} \rightarrow \mathrm{O}_{2}\left({ }^{1} \Sigma_{\mathrm{G}}\right)+\mathrm{N}_{3}^{-} & k=4.5 \times 10^{8} \mathrm{~s}^{-1} \mathrm{M}^{-1}
\end{array}
$$

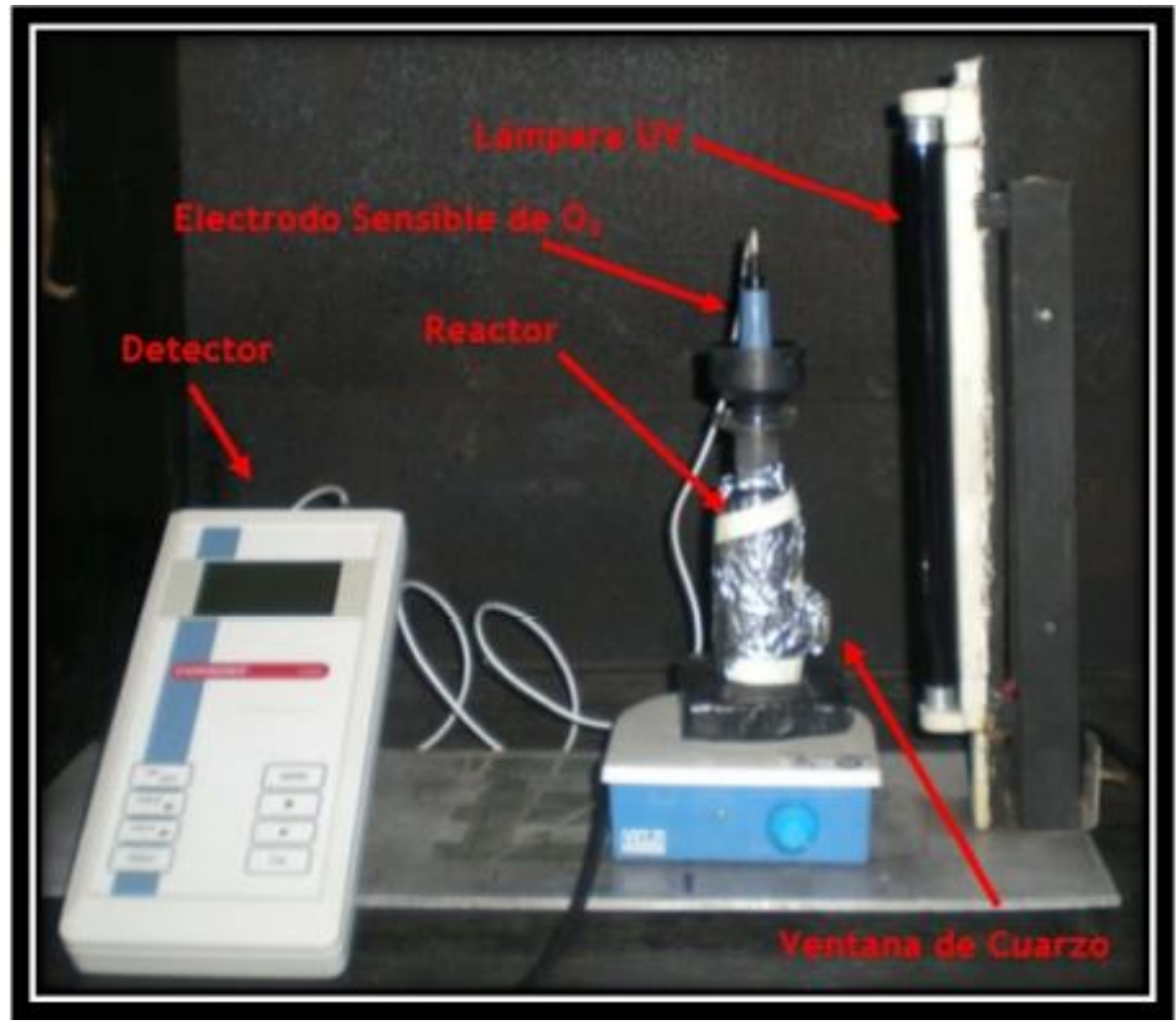

Fig. 2.8-Esquema ilustrativo del sistema utilizado para el consumo de oxígeno molecular.

\subsubsection{Determinación indirecta de Producción Anión Radical Superóxido $\mathbf{O}_{2}{ }^{-"}$}

La generación de este radical se determinó de forma indirecta detectando $\mathrm{H}_{2} \mathrm{O}_{2}$ producida por la siguiente reacción:

$$
\mathrm{HO}_{2} \cdot+\mathrm{HO}_{2} \cdot / \mathrm{O}_{2} \cdot-\rightarrow \mathrm{O}_{2}+\mathrm{H}_{2} \mathrm{O}_{2}
$$

Por su parte, la concentración de $\mathrm{H}_{2} \mathrm{O}_{2}$ en las muestras se midió utilizando un metodo enzimático colorimétrico usando un kit comercial Wiener para la determinación de colesterol. El kit comercial provee los siguientes reactivos: una solución de 4- aminofenazona (4-AF), una solución de fenol y una mezcla de enzimas (peroxidasa (POD), lipasa funcal y colesterol oxidasa (CHOD)). El método se basa en la reacción del $\mathrm{H}_{2} \mathrm{O}_{2}$ con una mezcla de 4-AF y fenol para dar como producto la quinonaimina (4-( $p$-benzoquinona monoimino)-fenazona) que presenta un máximo de absorbancia a $505 \mathrm{~nm}\left(\varepsilon(505 \mathrm{~nm})=5035 \mathrm{M}^{-1} \mathrm{~cm}^{-1}\right)$. La reacción catalizada por la POD se muestra a continuación: 


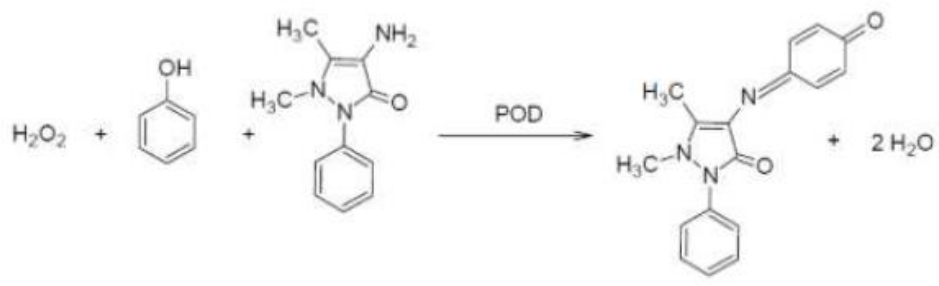

\subsubsection{Determinación de Carbono Orgánico Total (TOC).}

Para este fin se utilizó un equipo Shimadzu TOC-5000A que utiliza un método experimental para la determinación del Carbono Orgánico Total que se basa en una determinación indirecta, midiendo inicialmente el Carbono Total (TC) y el Carbono Inorgánico Total (TIC) y posteriormente por un balance másico de la masa Total de Carbono es posible calcular el TOC así:

TOC $=$ TC - TIC.

Para ello, este equipo posee dos canales de análisis, uno para el TC y otro para el TIC que son medidos directamente. Para la determinación del TC se requiere que todo el Carbono de la muestra sea oxidado a $\mathrm{CO}_{2}$ mediante una conversión catalítica en un horno a $680^{\circ} \mathrm{C}$, para su posterior transporte hacia la cámara de detección. En el segundo canal para la determinación del TIC se realiza una conversión selectiva a baja temperatura de los carbonatos y bicarbonatos a $\mathrm{CO}_{2}$, mediante la acidificación de la muestra con ácido fosfórico. Posterior a ello el $\mathrm{CO}_{2}$ es transportado a un deshumificador para la remoción del agua remanente y se lleva a la cámara de análisis.

En ambos casos la cámara de detección es la misma, basada en una fuente de irradiación infrarroja que se divide en dos haces, uno se hace pasar por la muestra y el segundo por la referencia. La celda de muestra recibe el flujo del canal seleccionado que consiste en gas portador que lleva consigo los productos de reacción de la muestra inyectada. La referencia es una celda que contiene $\mathrm{N}_{2}$, el que no absorbe en el IR. La radiación infrarroja es absorbida por el $\mathrm{CO}_{2}$ en la celda de la muestra, y el porcentaje de la radiación absorbida es proporcional al valor de la concentración de $\mathrm{CO}_{2}$. Para la calibración del equipo se utilizaron soluciones patrones de biftalato de potasio de concentración conocida.

\subsubsection{Espectroscopiaóptica de emisión (ICP-AES).}

La determinación de elementos en solución acuosa se realizó mediante la técnica de Espectroscopia óptica de Emisión (ICP - AES) utilizando un equipo Perkin Elmer Optima Modelo 7000DV. Para el sistema de detección de utilizó una precámara de spray ciclónica, un nebulizador PTFE Mira Mist y un monocromador Echelle. Las condiciones experimentales en las que se realizaron todos los test relacionados son: Potencia de plasma $1.3 \mathrm{~kW}$, velocidad de aspiración de muestra $1.2 \mathrm{~mL} / \mathrm{min}$, flujo de enfriamiento de argón $1.5 \mathrm{~L} / \mathrm{min}$, flujo de argón para muestreo $0.6 \mathrm{~L} / \mathrm{min}$. La relación P:Ca:Fe de las partículas de Hidroxiapatita sintetizadas se obtuvo mediante esta técnica por disolución previa por digestión ácida del material seguida de la cuantificación de los elementos en solución. 


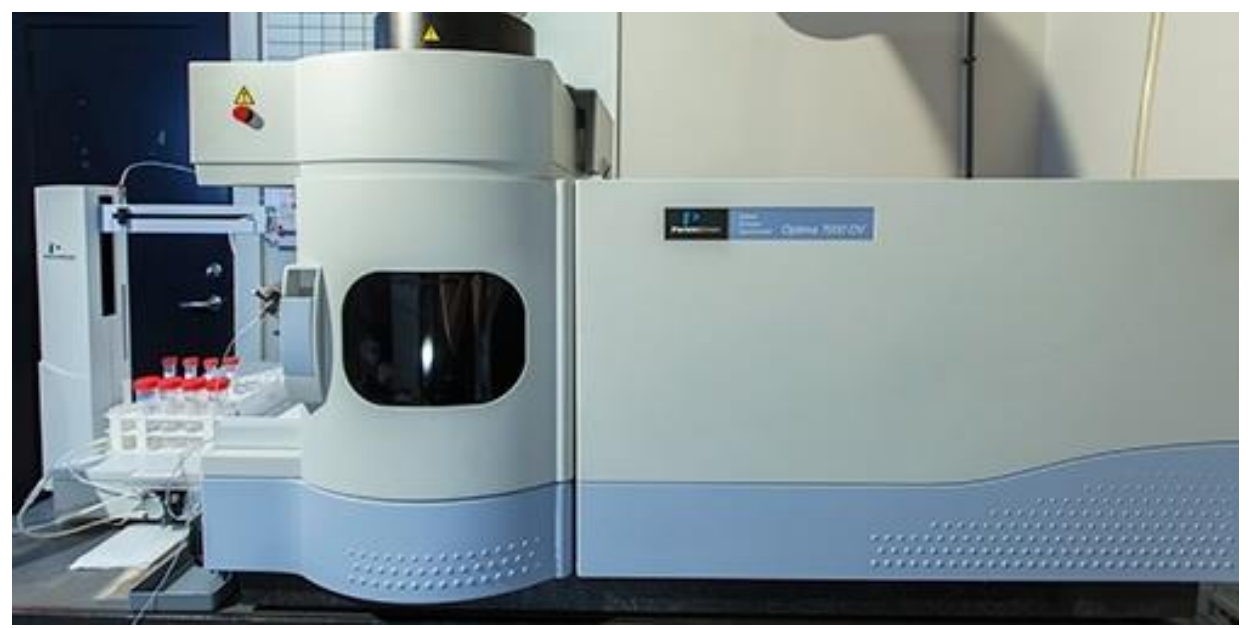

Fig. 2.9- Equipo Perkin Elmer Optima Modelo 7000DV.

\subsubsection{Síntesis y Caracterización de Nanomateriales.}

Se utilizó una Mufla FAC equipada con un controlador MTA ALRE bajo un sistema de control PDI para la obtención de nanopartículas de carbono y sílice. De igual forma se utilizó un Microondas modelo ML-2077A operando a $220 \mathrm{~V}$ y a $600 \mathrm{~W}$ de potencia.

\subsubsection{Determinación de distribución de Tamaños de partículas - Microscopio Electrónico de Transmisión (TEM)}

Se utilizaron dos microscopios electrónicos de transmisión en el desarrollo experimental de este trabajo. Primero se utilizó un Microscopio electrónico de transmisión de alta resolución (HRTEM) referencia a JEOL JEM 3010UHR (300 $\mathrm{kV}$ ) con un filamento de $\mathrm{LaB}_{6}$. $\mathrm{Y}$ el segundo equipo utilizado fue un microscopio JEOL 100 CX II. Las nanopartículas se suspendieron en agua, posteriormente se sembró la muestra de a gotas sobre soportes de Cu permitiendo la evaporación del solvente.

Las distribuciones de tamaño de partícula fueron obtenidas utilizando el programa ImageJ y el universo del sondeo estuvo alrededor de 400 nanopartículas para todos los casos.

\subsubsection{Espectroscopia Infrarroja (IR)}

Esta técnica debe su nombre a que utiliza la fracción media del espectro infrarrojo correspondido entre $(4000-400) \mathrm{cm}^{-1}$ y aprovecha el hecho que las moléculas o grupos funcionales dentro de ellas poseen frecuencias donde tienen vibraciones fundamentales. Las moléculas alcanzan estas frecuencias vibracionales al absorber energía de esta región del espectro electromagnético. Este método es típicamente utilizado para la identificación de grupos funcionales presentes en una muestra. 
El método básico de funcionamiento de la técnica utiliza un haz de luz infrarroja dividido en dos fracciones, una utilizada como referencia y otra que atraviesa la muestra. Ambos haces son reflejados hacia un detector y a continuación se comparan los haces y se registran los cambios en la intensidad para cada longitud de onda $(\widetilde{\nu}=1 / \lambda)$.

\section{> Espectroscopia IR por Transformada de Fourier (FTIR).}

Es una modificación en cuanto a la forma de detección en la técnica de Espectroscopia IR básica. El FTIR en lugar de registrar los datos modificando la frecuencia de luz infrarroja monocromática, se utiliza un haz de Luz IR que pasa a través de un interferómetro. Una vez el haz pasa a través de la muestra se obtiene un interferograma a partir del cual mediante una transformada de Fourier se obtiene un espectro idéntico al que se obtendría por la vía convencional.

Debido a la forma en la que funciona la adquisición de datos en el FTIR, todas las frecuencias son detectadas al mismo tiempo, lo que permite realizar múltiples lecturas de una sola muestra aumentando así la sensibilidad de la medida. Comúnmente, para la toma del espectro de muestras en estado sólido, estás son diluidas en una solución sólida con alguna sal transparente al IR, comúnmente $\mathrm{KBr}$, para ajustar la transmitancia de la muestra dentro del rango de detección del equipo.

\section{Espectroscopia IR acoplada a Reflexión Total Atenuada (ATR-IR).}

Mientras que en el FTIR se analiza la transmitancia de la muestra haciendo que un haz de luz la atraviese, el ATR usa la reflectancia de la muestra. En una medida típica se monitorean los cambios que ocurren en el haz de luz IR reflectado totalmente cuando se encuentra en contacto con la muestra. Para ello se utiliza un cristal ópticamente denso con un índice de refracción alto y se irradia a un ángulo conocido. Este cristal crea una onda evanescente con una penetración de entre 0.5 y $5 \mu \mathrm{m}$, como se evidencia en la figura 2.10.

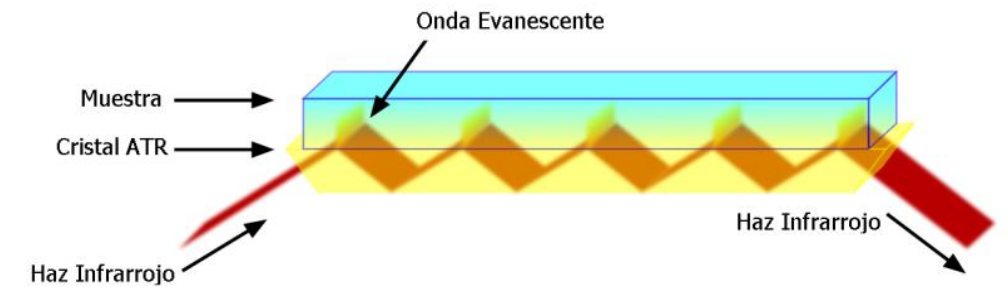

Fig. 2.10- Esquema de funcionamiento del sistema Cristal/Muestra/Haz en un equipo ATR-IR.

Debido a que en esta nueva modalidad de la técnica el haz incide sobre una pequeña fracción del material debido a la penetración de la onda evanescente, esta técnica se utiliza ampliamente para la caracterización de superficies. Además, tiene la ventaja de no requerir preparación de las muestras sólidas ya que se pueden medir directamente. 
Todas las mediciones FTIR consideradas durante este trabajo fueron realizadas con un espectrofotómetro Bruker IFS28 equipado con una fuente GLOBAR y un detector DTGS trabajando a 128 escaneos con una resolución de 4 $\mathrm{cm}^{-1}$ en todo el rango de $(4000-400) \mathrm{cm}^{-1}$. Todas las muestras fueron preparadas utilizando un $1 \%$ de sólido mezclado con $99 \%$ de $\mathrm{KBr}$ seco. Para la preparación de la pastilla se aplicó una fuerza de 5 toneladas mediante el uso de una prensa hidráulica. Por su parte, los ensayos ATR-IR fueron llevados a cabo en un equipo AgilentCary 630 FTIR dentro del rango $(4000-650) \mathrm{cm}^{-1}$ con una resolución de $4 \mathrm{~cm}^{-1}$, el método de recolección de datos tomó 8 veces el background, es decir el cristal sin la muestra y el mismo número de veces para el sólido de interés.

\subsubsection{Análisis Termogravimétrico (TGA)}

El análisis termogravimétrico (TGA) es una técnica que permite evidenciar la variación de la masa de la muestra de interés, cuando es calentada o enfriada a una velocidad constante bajo una atmosfera controlada (comúnmente $\mathrm{N}_{2} \mathrm{O}$ Aire). Se registra la variación de la masa en función del tiempo y de la temperatura mediante una termobalanza que registra continuamente la masa de la muestra.

Durante la rampa de calentamiento en el rango de temperaturas y atmosfera de trabajo, la muestra puede reaccionar modificando su masa, por ello es una técnica muy útil para la determinación de pérdida de materia de sólidos por calentamiento como pueden ser; desorción de gases, eliminación de materia orgánica, descomposición química, entre otros.

En este trabajo de investigación se utilizó esta técnica para cuantificar la cantidad de materia orgánica presente en los materiales sintetizados bajo atmosfera de aire o $\mathrm{N}_{2}$. Para ello se utilizó un equipo Q600 TA Instruments. El calentamiento se inicia a $50^{\circ} \mathrm{C}$ con dos minutos de precalentamiento seguido por una rampa de $10^{\circ} \mathrm{C} / \mathrm{min}$ hasta un máximo de $1100^{\circ} \mathrm{C}$ (dependiendo de la experiencia) y mantenido en esta temperatura por 10 minutos.

\subsubsection{Dynamic Light Scattering (DLS).}

La Dispersión Dinámica de Luz es una técnica que permite la determinación del radio hidrodinámico de partículas hasta la región del nanómetro $\left(1 \times 10^{-9} \mathrm{~m}\right)$. Para ello se utiliza un láser de luz monocromática y coherente y haciéndolo incidir sobre la muestra de estudio suspendida en un solvente adecuado, se observa así una fluctuación en la intensidad de luz dispersada dependiente del tiempo debido a los movimientos de tipo Brownianos de las partículas en la suspensión.

La velocidad del movimiento Browniano depende del coeficiente de difusión traslacional (D). El tamaño de las partículas se calcula a partir de la ecuación de Stokes-Einstein: 


$$
\mathrm{d}(\mathrm{H})=\frac{\mathrm{kT}}{6 \pi \mu \mathrm{D}} ; \text { Donde } \mathrm{d}(\mathrm{H}) \text { es el diámetro hidrodinámico; } k \text { la constante }
$$

de Boltzman; $\mathrm{T}$ la temperatura absoluta a la cual se realizó el experimento; D el coeficiente de difusión. El diámetro obtenido aplicando la técnica de DLS corresponde al diámetro de una esfera que posee el mismo coeficiente de difusión que las partículas.

Los ensayos de DLS fueron realizados a $(25 \pm 0.1)^{\circ} \mathrm{C}$, a pH 7.0 controlado por un Buffer de HEPES-Na y una fuerza iónica de 0.01 M. Se utilizó un equipo90 Plus Particle Size Analyzer de Brookhaven Instrument Corporation. Las medidas de dispersión se realizaron monitoreando la intensidad de luz dispersada en un ángulo fijo de $90^{\circ}$ y se hicieron mediciones por triplicado.

\subsubsection{Movilidad Electroforéticay Potencial de Carga Cero.}

La movilidad electroforética fue medida en algunos casos utilizando un equipo Laser Doppler Velocimetry-Photon Correlation Spectroscopy que empleaba un espectrofotómetro DELSA 440(Beckman Coulter Electronics, Hialeah, FL) y equipado con un láser de $5 \mathrm{~mW}$ HeNe $(632.8 \mathrm{~nm})$. Otros ensayos fueron realizados con un equipo Plus Particle Size Analyzer de Brook haven Instrument Corporation mencionado en la sección 2.1.5.4.

Por otro lado, la determinación del Potencial de Carga Cero $\left(\mathrm{pH}_{\mathrm{PZC}}\right)$ de partículas se realizó siguiendo un método publicado en el cual se prepara una serie de suspensiones de los materiales a estudiar[13]. En esta serie, se modifica el $\mathrm{pH}$ de cada solución usando $\mathrm{NaOH}$ o $\mathrm{HCl}$ de forma de abarcar un rango amplio entre $(4-11)$ y estas se dejan bajo agitación y temperatura controlada por más de 48 horas. Posteriormente se cuantifica el pH final de las suspensiones. Se grafica el cambio $\Delta \mathrm{pH}$ sufrido por cada suspensión en función del $\mathrm{pH}$ inicial. Los valores de $\Delta \mathrm{pH}$ (diferencia entre los estados iníciales y finales) fueron graficados contra el $\mathrm{pH}$ inicial. El pH inicial al cual el $\Delta \mathrm{pH}$ es cero es tomado como el pH pzc. En la figura 2.11 se muestra una curva típica experimental obtenida con en esta serie de experimentos en los cuales las partículas tienen un $\mathrm{pH}_{\mathrm{PZC}}$ alrededor de 8.5 .

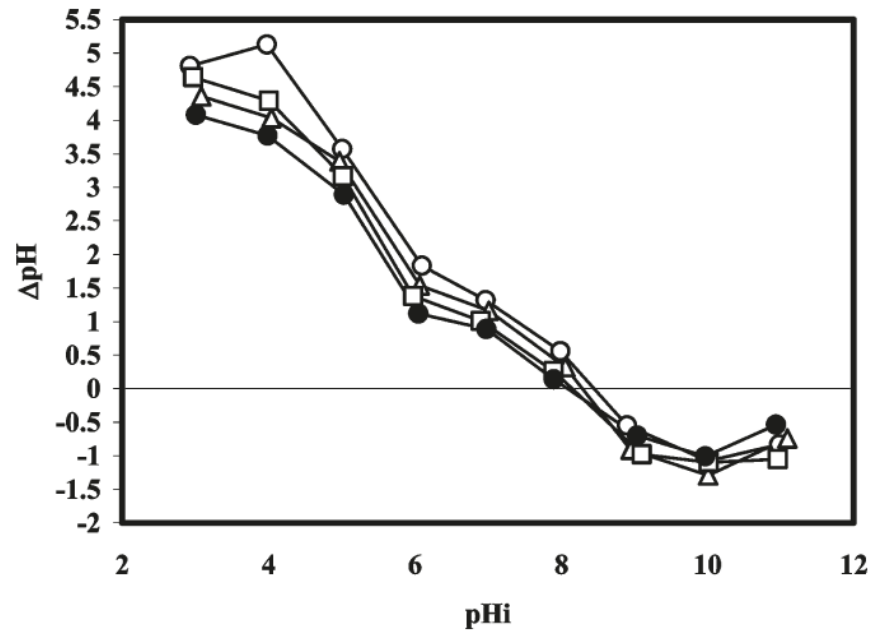

Fig. 2.11 - Curvas de resultado típico de los ensayos de la determinación del pH pzc de partículas. Fuente [13]

\subsubsection{6. Área Superficial Específica.}

El cálculo del área superficial especifica de las muestras en estado sólido se realizaron usando el modelo de adsorción de Brunauer-Emmett-Teller (BET) [14]bajo el supuesto que el área superficial ocupada por una molécula de $\mathrm{N}_{2}$ es 
de $0.1620 \mathrm{~nm}^{2}$. Para este fin se utilizó un equipo ASAP2020, las medidas se realizaron a $77 \mathrm{~K}$. Previo a dicho análisis las muestras se desgasaron mediante calentamiento a $80^{\circ} \mathrm{C}$ y realizando vacío hasta una presión residual de $10^{-2} \mathrm{mbar}$ para garantizar la eliminación de moléculas fisisorbidas sobre la superficie.

\subsubsection{Difracción de Rayos X (XRD).}

Los rayos $X$ son una forma de radiación electromagnética con longitud de onda entre los 10 y $0.01 \mathrm{~nm}$; apareciendo en el espectro electromagnético entre los rayos $\mathrm{y}$ y el ultravioleta. Los rayos $X$ utilizados en esta técnica son coherentes y monocromáticos producidos a través de la excitación de un elemento (comúnmente $\mathrm{Cu}$ ), al cual se le lleva a un

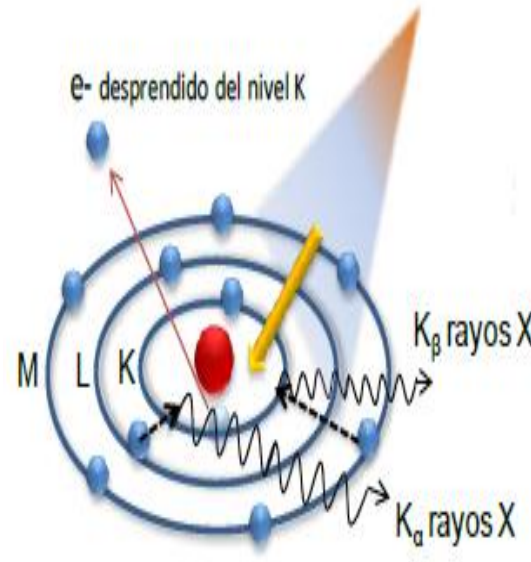
estado excitado mediante irradiación de rayos $\mathrm{X}$ policromáticos. Así se desprende un electrón de la capa más interna del material y como consecuencia para disminuir la energía de la especie excitada formada, los electrones de energía más alta rellenan la vacancia emitiendo rayos $X$ al bajar de nivel. En la figura 2.12 se esquematiza este proceso, donde un electrón de un orbital más externo ( $2 p$ o $3 p$ ) pasa a ocupar la vacancia del nivel 1s, y la energía liberada en este proceso aparece como radiación $\mathrm{X}$.

Fig. 2.12 - Esquema básico de la generación de un haz de rayos $X$ monocromático. Fuente [15].

Específicamente hablando del $\mathrm{Cu}$, la transición entre los orbitales $2 \mathrm{p} \rightarrow 1 \mathrm{~s}$ es conocido como $\mathrm{K}_{\alpha}$ y tiene una longitud de onda de $1.5418 \AA$; entre los orbitales $3 p \rightarrow 1$ s es llamado $K_{\beta}$ y tiene un valor de $1.3922 \AA[16]$. La difracción de rayos $X$ es un fenómeno físico que se produce al interaccionar un haz de rayos $X$ coherente y monocromático con una longitud de onda similar al de la distancia interplanar de los átomos de un material cristalino, produciéndose una interferencia o dispersión coherente del haz producto de la interacción con los átomos del material cristalino. Cuando en una determinada dirección se observa la dispersión cooperativa procedente de varios átomos es porque entre las ondas que se emiten en esa dirección existe concordancia de fases [16], [17].

Siendo así, en un material cristalino la difracción solo se da en determinados ángulos de acuerdo la ley de Bragg:

$$
n \lambda=2 d_{h k l} \cdot \operatorname{Sen} \boldsymbol{\theta}
$$

Donde $\lambda$ es la longitud de onda de la fuente de rayos $X, \theta$ es el ángulo que forman el haz incidente y los planos cristalinos, $n$ es un número entero y $d_{\mathrm{hkl}}$ es la distancia entre planos cristalinos, la figura 2.13esquematiza lo anterior. 
Del difractograma obtenido es posible calcular el tamaño cristalino de partícula siguiendo el modelo de Scherrer:

$$
D_{D R X}=\frac{k \lambda}{B_{c} \operatorname{Cos} \theta} ; \text { siendo } \mathrm{B}_{\mathrm{C}} \text { la }
$$
anchura del pico de mayor intensidad, $\lambda$ es la longitud de onda de la fuente de rayos $X, \theta$ es el ángulo donde tiene lugar la difracción y k es una constante que depende de la estructura cristalina del material analizado.

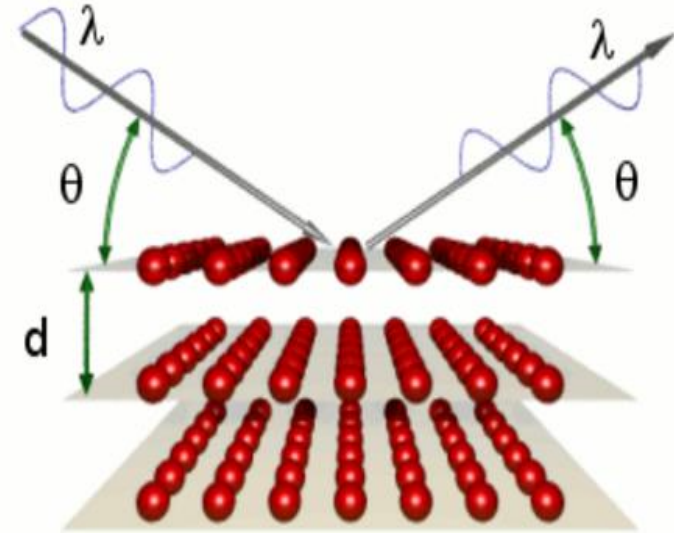

Fig. 2.13 - Esquema de difracción de rayos $X$ por los planos cristalinos de un material.

El equipo utilizado en este trabajo fue un difractometro de rayos $X$ PW3040/60 X'Pert PRO MPD de PANalytical utilizado en geometría tipo BraggBrentano, equipado con un tubo cerámico PW3373/10 LFF que utiliza como fuente un cátodo de $\mathrm{Cu}$. El análisis cualitativo de las fases presentes en los materiales se realizó utilizando el software EVA con la base de datos analítica ICDD-PDF-2. Se empleó la radiación $\mathrm{K}_{\alpha}$ del $\mathrm{Cu}$.

\subsubsection{Dispersión de Rayos X a bajo ángulo - SAXS}

Este método analítico permite determinar la estructura de las partículas en término promedio de su forma o tamaño. Es un método no destructivo para investigar nanoestructuras con un tamaño entre $1 \mathrm{~nm}$ hasta los $200 \mathrm{~nm}$. El requisito fundamental para la generación de dispersión a bajo ángulo es la presencia en la muestra de heterogeneidades en la densidad electrónica del material.

El sistema de SAXS utilizado es un equipo XEYSS $1.0 \mathrm{HR}$ (XENOCS, Grenoble) enmarcado en el proyecto "Nanopymes" EuropeAid/132184/D/SUP/ARContract 331-896. Este equipo cuenta con una fuente de irradiación a $1.5419 \AA$ y una fuente de detección Pilatus $100 \mathrm{~K}$ (Dectris, Sw). La intensidad dispersada (en unidades arbitrarias) fue medida como una función del vector q de dispersión con $q=(4 \Pi / \lambda) *(\sin \theta)$ donde $\lambda$ es la longitud de irradiación y $2 \theta$ el ángulo de dispersión. Las curvas fueron ajustadas utilizando el software SASfit.

El análisis de las curvas obtenidas fue realizado siguiendo el modelo unificado de Beaucage[18], [19] en el que se relaciona la intensidad dispersada con el radio de giro $\left(r_{g}\right)$ de la partícula. Es preciso aclarar que este radio de giro corresponde al volumen de partícula más el volumen de solvente que se mueve solidariamente con esta. Es posible calcular el tamaño de partícula conociendo el radio de giro bajo el supuesto que son partículas esféricas, para ello se utiliza la relación: $r=\sqrt{5 / 3} r_{g}$ 


\subsubsection{Espectroscopia de fotoelectrones emitidos por Rayos X(XPS),}

La espectroscopia de fotoelectrones emitidos por Rayos $X$ es una técnica de análisis superficial (hasta $5 \mathrm{~nm}$ de profundidad, dependiendo del elemento) cuantitativa, de alta sensibilidad y baja resolución espacial. Esta provee información sobre la estequiometria, estructura electrónica y estado químico de todos los elementos presentes en la superficie de un material.

En una experiencia típica de XPS, se somete el material a analizar a un ambiente de ultra alto vacío $\left(<10^{-9}\right.$ torr) para la eliminación de moléculas fisisorbidas que afecten el análisis de la superficie de interés. Posterior a ello, se irradia la superficie con un haz de Rayos X para generar la fotoemisión de electrones que se cuantifican en función de la energía incidente sobre la superficie, proporcionando información sobre la energía de enlace de cada nivel y, por tanto, sobre la naturaleza de cada átomo emisor y su entorno químico. La figura 2.14 esquematiza el modo básico de operación de la técnica.

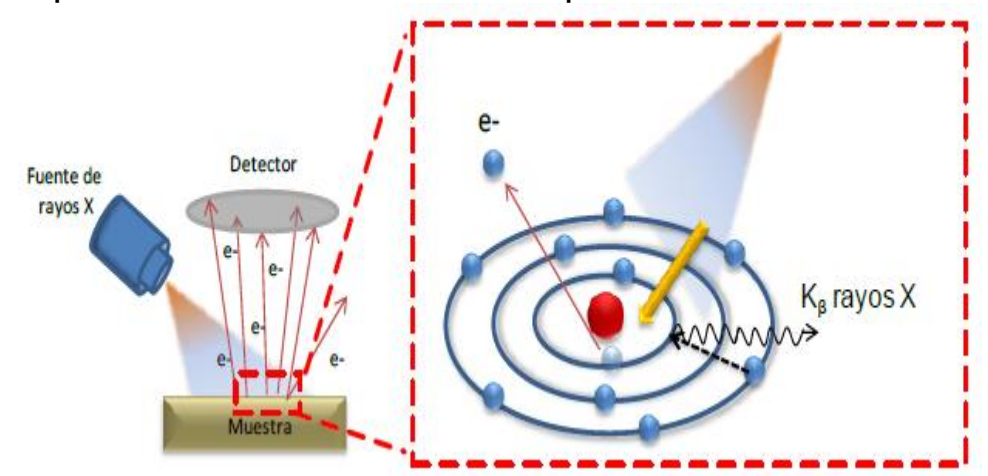

Fig. 2.14 - Ilustración del funcionamiento básico de la técnica XPS. Fuente [15]

Asumiendo que la energía del haz de electrones se describe adecuadamente en forma de cuantos de energía $E=h v$, que la totalidad de la energía de un cuanto es aceptada por un único electrón, y que el fotoelectrón desprendido egresa con una energía cinética $E_{K}$, realizando un balance de energía es posible calcular la energía del enlace $\left(E_{E}\right)$ del que proviene dicho electrón.

$$
E_{E}=h v-E_{K}
$$

Durante el desarrollo de la parte experimental de este trabajo de tesis, los ensayos de caracterización mediante XPS se llevaron a cabo en un Espectrofotómetro Specs $\mathrm{GmbH}$ XR50 usando $\mathrm{Mg} \mathrm{K}(\alpha)$ como fuente de excitación y como analizador una media esfera analizadora de energía de electrones PHOIBOS 100. Para todos los ensayos realizados durante este trabajo se tomó una calibración para la escala de energía de enlace utilizando Oro puro (Au 4f7/2 - $84.00 \mathrm{eV}$ ) y Cobre (Cu 2p3/2 - $932.67 \mathrm{eV}$ ). Para la corrección de la posibilidad de carga superficial de la muestra debido al bombardeo con Rayos $X$ se utilizó el pico de Carbono Espurio ( $\mathrm{C} 1 \mathrm{~s}$ - $284.6 \mathrm{eV}$ ) como referencia interna. Las líneas bases utilizadas o background fueron tipo Shirley. Para los análisis individuales de cada elemento se tomaron espectros XPS de alta resolución y las curvas de cada una de las especies involucradas se simularon con una combinación lineal de curvas Gaussianna-Lorentziana manteniendo valores mínimos de $\chi^{2}$. 
Para los análisis cuantitativos obtenidos durante los ensayos y para obtener alguna relación de abundancia atómica $\mathrm{n}_{1} / \mathrm{n}_{2}$ se utilizó la ecuación:

$$
\frac{n_{1}}{n_{2}}=\frac{I_{1} / S_{1}}{I_{2} / S_{2}} ; \text { siendo } n_{i} \text { el átomo de interés, } I_{i} \text { y } S_{i} \text { la intensidad de la }
$$

señal y el factor de sensibilidad atómico respectivo. La tabla 1.1 muestra los valores utilizados del factor de sensibilidad atómica para los elementos considerados durante el desarrollo de la parte experimental de esta tesis y la señal correspondiente:

\begin{tabular}{|c|c|c|}
\hline Elemento & Línea & $\begin{array}{c}\text { Factor de Sensibilidad Atómico } \\
\text { (S) }\end{array}$ \\
\hline $\mathbf{C}$ & $1 \mathrm{~s}$ & 0.25 \\
\hline $\mathbf{N}$ & $1 \mathrm{~s}$ & 0.38 \\
\hline $\mathbf{0}$ & $1 \mathrm{~s}$ & 0.63 \\
\hline $\mathbf{C l}$ & $2 \mathrm{p}$ & 0.48 \\
\hline $\mathbf{S i}$ & $2 \mathrm{p}$ & 0.17 \\
\hline $\mathbf{C a}$ & $2 \mathrm{p}^{3 / 2}$ & 0.71 \\
\hline $\mathbf{F e}$ & $2 \mathrm{p}$ & 3.8 \\
\hline $\mathbf{A g}$ & $3 \mathrm{~d}^{5 / 2}$ & 2.25 \\
\hline $\mathbf{P b}$ & $4 \mathrm{f}^{7 / 2}$ & 2.55 \\
\hline
\end{tabular}

Tabla 2.1 - Factores de Sensibilidad atómica de los elementos de interés para este trabajo experimental y las señales en las que son adecuado su uso.

\subsubsection{Caracterización de propiedades magnéticas.}

Cuando un material es sometido a la acción de un campo magnético, sus electrones generan dipolos magnéticos que se ordenan con el campo dando lugar a un momento magnético dentro de este. Los sólidos pueden clasificarse en función de su respuesta al aplicar un campo magnético. La figura 2.15 representa este comportamiento. Si el sólido solo posee átomos con electrones apareados es diamagnético, como es el caso del agua. Caso contrario, es el de los átomos con electrones desapareados y que las interacciones entre estos sean débiles, entonces el sólido es paramagnético. Al aplicar un campo magnético a un material paramagnético los dipolos magnéticos producidos a escalas atómicas tienden a alinearse con la dirección del campo global al que es sometido, sin embargo, al eliminar el efecto del campo externo, las fluctuaciones térmicas hacen que los momentos magnéticos se muevan al azar obteniéndose un momento magnético nulo. La ley de Curie representa el comportamiento antes mencionado: 


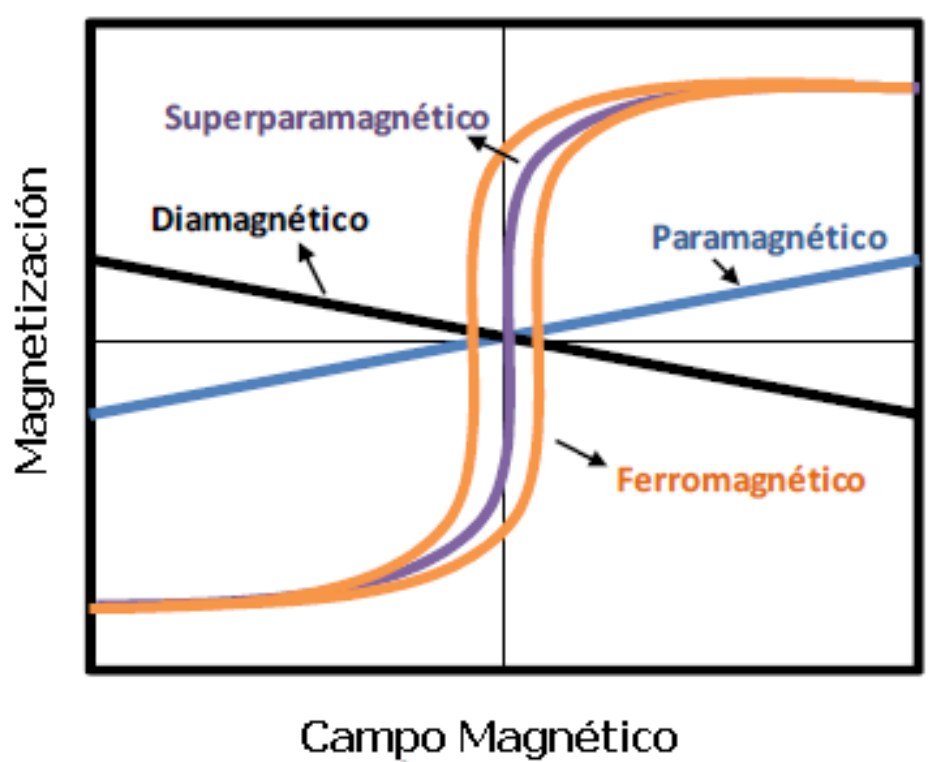

Fig. 2.15-Curvas típicas Magnetización vs. Campo Magnético de diferentes tipos de materiales. Fuente: [15]

$$
M=C \frac{H}{T}
$$

Donde $\mathrm{M}$ es la magnetización, $\mathrm{H}$ es el campo externo aplicado, $\mathrm{T}$ es la temperatura absoluta a la que está sometida el sistema y $\mathrm{C}$ es la constante de Curie, típica de cada material. Un ejemplo de un material paramagnético es el Titanio.

Cuando existen interacciones no despreciables entre los electrones desapareados de átomos vecinos, el sólido posee comportamiento ferromagnético. En este caso, todos los momentos magnéticos están orientados de forma paralela o antiparalela respecto a la dirección del campo externo aplicado. Incluso en ausencia de un campo magnético externo aplicado, la relación en las orientaciones sigue siendo la misma entre los momentos internos del sólido. El Hierro es un ejemplo por excelencia de un material ferromagnético. La relación Magnetización vs. campo aplicado en estos materiales no es tan sencilla como en los casos anteriores, ya que esta relación no es lineal, sino que tiene lugar una histéresis. Estos materiales llegan a un estado de saturación magnético, en el que por más que se aumente el campo aplicado la magnetización de la muestra no aumenta, a este valor se le conoce como Magnetización de saturación y esta es función de la temperatura. Además, por la presencia de la histéresis, una vez se retira el campo, la magnetización no se pierde totalmente, sino que es "guardada", lo que se le conoce como magnetización remanente.

Ahora bien, en los materiales macroscópicos las propiedades magnéticas dependen principalmente de su composición, estructura cristalina, energía de anisotropía magnética, vacantes y defectos [20]. Sin embargo, cuando el tamaño disminuye a escala nanométrica, la relación superficie/volumen y la composición química superficial controlan las propiedades magnéticas de dicho material [20].

En los experimentos considerados en este trabajo, los momentos magnéticos de la nanopartículas fueron medidos en función de un campo magnético aplicado utilizando un magnetómetro de muestra vibrante (VSM) 
LakeShore 7304 en el rango de campo de $\left[-1.5 \times 10^{5}, 1.5 \times 10^{5}\right] \mathrm{A} / \mathrm{m}$. La ventana de tiempo experimental para estas medidas es $\tau_{\mathrm{VSM}} \approx 30 \mathrm{~s}$.

La susceptibilidad ac de cada muestra fue determinada midiendo el momento magnético de esta en función de la temperatura $(30 \mathrm{~K}<\mathrm{T}<325 \mathrm{~K}$ ) bajo la aplicación de un campo aplicado de una amplitud de $80 \mathrm{~A} / \mathrm{m}$ y frecuencia $f=825 \mathrm{~Hz}$. En este caso la ventana de tiempo experimental será $\boldsymbol{\tau}_{\mathrm{AC}}=1 / \omega$, con $\omega=2 \pi f$.

Para las medidas magnéticas, se utilizaron las nanopartículas en polvo y en suspensión (ferrofluido o coloide). Con los polvos, se encapsularon $60 \mathrm{mg}$ de cada muestra en un cilindro delgado de PCV sellado al calor para evitar la pérdida de la muestra. Mientras que los ferrofluidos fueron preparados utilizando agua grado MilliQ en la cual fueron suspendidos $10 \mathrm{~g} / \mathrm{L}$ de la muestra en consideración. Se colocaron $50 \mu \mathrm{L}$ de esta suspensión en un tubo de material contraíble de $4 \mathrm{~mm}$ de ancho y 5 de ancho sellando al calor en las puntas. Los tubos se mantuvieron a $277 \mathrm{~K}$ durante algunos minutos antes del inicio de las mediciones para evitar la precipitación de las partículas. Las capsulas fueron introducidas dentro de un contenedor cilíndrico de plástico fijado en el final del VSM o del susceptometro dependiendo del caso. En el caso del VSM, la muestra está sometida a una frecuencia de oscilación de $82 \mathrm{~Hz}$ durante 30 minutos antes del inicio de las medidas para promover la distribución uniforme de las nanopartículas en el interior del volumen. Por el mismo motivo, en las medidas ac las muestras fueron sometidas a 10 minutos de vibración ultrasonido y enfriadas hasta $50 \mathrm{~K}$ inmediatamente después.

\subsubsection{Tratamiento matemático de las isotermas de adsorción.}

Al poner en contacto el adsorbente y el adsorbato la cantidad de adsorbato sobre la superficie del primero aumenta hasta alcanzar el equilibrio. La naturaleza del fenómeno en el que ocurre la adsorción puede estudiarse relacionando la capacidad de adsorción en el equilibrio con la concentración de adsorbato remanente en la solución manteniendo la temperatura constante.

En la actualidad hay muchos modelos matemáticos utilizados para tratar de explicar el comportamiento de este fenómeno. A continuación, planteamos 2 de ellos.

El primero de ellos es la isoterma de Langmuir. Este modelo describe de forma cuantitativa la formación de una monocapa de adsorbato sobre la superficie del adsorbente. Comúnmente esta isoterma representa satisfactoriamente la adsorción de iones metálicos sobre adsorbentes con heteroátomos con pares de electrones libres [21]. Cabe señalar que, si bien los puntos experimentales pueden ajustarse a una función equivalente a la isoterma de adsorción obtenida para el modelo de Langmuir, el sistema en estudio no necesariamente cumple con las condiciones del modelo.

Este modelo asume que la barrera energética para la adsorción sobre la superficie es uniforme a lo largo de la misma suponiendo que posee un número finito de sitios idénticos disponibles para la adsorción. El modelo también plantea 
que no existen interacciones entre las moléculas de adsorbato, por lo que la barrera energética no se ve modificada por el grado de recubrimiento de los sitios de adsorción. Además, no se considera la migración de moléculas de adsorbente a lo largo de la superficie. La relación matemática de este modelo se muestra a continuación.

$$
x / m=\frac{K_{l} \times b \times C_{e}}{1+K_{L} C_{e}}
$$

Donde $\mathrm{x}=$ masa del soluto adsorbido,

$\mathrm{m}=$ masa del adsorbente,

$\mathrm{b}$ = número de sitios disponibles para la adsorción del adsorbato

$(\mathrm{mg} / \mathrm{g})$ que posee un gramo de adsorbente.

$\mathrm{K}_{\mathrm{L}}=$ Constante de binding, es relativa a la fuerza entre el adsorbente y el adsorbato

$\mathrm{C}_{\mathrm{e}}=$ Concentración remanente del adsorbato en solución una vez alcanzado el equilibrio.

El segundo modelo considerado es el de Freundlich. Este es un modelo semi-empírico que considera dos modificaciones importantes respecto al modelo de Langmuir. Por un lado considera la interacción lateral entre moléculas de adsorbato y también la heterogeneidad de la barrera energética de adsorción asumiendo que no todos los sitios son idénticos. La forma empírica de esta isoterma es aplicable a la adsorción en monocapas (Quimisorción). La relación matemática de este modelo es la siguiente:

$$
x / m=K_{f} \times C_{e}^{1 / n}
$$

Donde $x=$ masa del soluto adsorbido,

$\mathrm{m}=$ masa del adsorbente,

$\mathrm{C}_{\mathrm{e}}=$ Concentración remanente del adsorbato en solución una vez alcanzado el equilibrio.

adsorbente.

$\mathrm{K}_{\mathrm{f}}$ y $\mathrm{n}$ son parámetros dependientes de la interacción adsorbato -

Los dos últimos parámetros, $\mathrm{K}_{\mathrm{f}}$ y $\mathrm{n}$ son constantes que son función de las propiedades microscópicas de las moléculas de adsorbato y del sustrato, así como de la temperatura. Es decir que son propiedades características del sistema[22].

\subsection{Materiales.}

\subsubsection{Equipo de Agua MilliQ.}

Toda el agua utilizada para síntesis y los diferentes ensayos utilizada durante este trabajo fue obtenida mediante un sistema Millipore con 
conductividad menor a $18 \mathrm{M} \Omega \mathrm{cm}^{-1}$ y con Carbono Orgánico total disuelto menor a 4 ppb de carbono orgánico.

\subsubsection{Balanza.}

Para la cuantificación de la masa de los reactivos utilizados se utilizó una microbalanza electrónica Denver modelo TP-214 con una incertidumbre de medida de $\pm 0.1 \mathrm{mg}$.

\subsubsection{Medición de pH.}

La determinación potenciométrica de $\mathrm{pH}$ y de iones disueltos se llevó a cabo utilizando electrodos selectivos y un analizador multicanal C832.

\subsubsection{Reactivos.}

Los reactivos $\mathrm{FeCl}_{2} \cdot 4 \mathrm{H}_{2} \mathrm{O}, \mathrm{FeCl}_{3} \cdot 6 \mathrm{H}_{2} \mathrm{O}, \mathrm{NaOH}, \mathrm{HCl}, \mathrm{H}_{2} \mathrm{SO}_{4}$, Biftalato de potasio, $\mathrm{NaBH}_{4}, \mathrm{HEPES}-\mathrm{Na}$, Azul de metileno, Pireno y Flusilasol fueron comprados a Sigma-Aldrich y fueron utilizados sin ningún paso de purificación. Las soluciones patrones de metales fueron preparados por el grupo de investigación de la Universidad de Torino bajo la dirección de la Dra. Mery Malandrino.

Las muestras de SBO fueron entregadas por el grupo de investigación a cargo de la Dra. Alessandra Bianco-Prevot de la Universidad de Torino. Todos los ensayos realizados con estos compuestos utilizaron el mismo batch de producción.

La Yerba Mate utilizada es de carácter comercial marca "Playadito" Lote de producción 45-03. Por su lado la cascara de naranja utilizada fue obtenida del producto fresco. 


\subsection{Referencias bibliográficas.}

[1] J. A. Barltrop and J. D. Coyle, Principles of photochemistry, 1st ed. Great Britain: Wiley Inc., 1978.

[2] G. A. Porte and M. A. West, Investigation of rates and mechanism of reactions, Parte 2, 3rd ed. New York: Wiley Inc., 1974.

[3] M. A. West, Creation and detection of excited states, 4th ed. New York: Ware, W. R., 1976.

[4] M. J. Pilling, Seakins, Reaction kinetics. New York: Oxford University Press Inc., 1995.

[5] J. R. Lakowicz, Principles of Fluorescence Spectroscopy, 3rd ed. Baltimore: Plenum Press, 1999.

[6] B. Valeur, Molecular Fluorescence. Principles and Applications. New York: Wiley $\mathrm{VCH}, 2002$.

[7] J. L. Bourdelande, S. Nonell, and J. W. Verhoeven, Glosario de terminos usados en fotoquimica. 1999.

[8] C. Blasco, G. Font, and Y. Picó, "Comparison of microextraction procedures to determine pesticides in oranges by liquid chromatography-mass spectrometry," $\mathrm{J}$. Chromatogr. A, vol. 970, no. 1-2, pp. 201-212, 2002.

[9] M. J. Nozal, J. L. Bernal, J. J. Jiménez, M. T. Martín, and J. Bernal, "Determination of azolic fungicides in wine by solid-phase extraction and high-performance liquid chromatography-atmospheric pressure chemical ionization-mass spectrometry, ${ }^{\prime} \mathrm{J}$. Chromatogr. A, vol. 1076, no. 1-2, pp. 90-96, 2005.

[10] A. Sannino, L. Bolzoni, and M. Bandini, "Application of liquid chromatography with electrospray tandem mass spectrometry to the determination of a new generation of pesticides in processed fruits and vegetables," J. Chromatogr. A, vol. 1036, no. 2, pp. 161-169, 2004.

[11] A. D. Bokare and W. Choi, Review of iron-free Fenton-like systems for activating H2O2 in advanced oxidation processes, vol. 275. Elsevier B.V., 2014.

[12] C. R. Lillo, J. J. Romero, M. L. Portolés, R. P. Diez, P. Caregnato, and M. C. Gonzalez, "Organic coating of 1-2-nm-size silicon nanoparticles: Effect on particle properties," Nano Res., vol. 8, no. 6, pp. 2047-2062, 2015.

[13] T. Mahmood, M. T. Saddique, A. Naeem, P. Westerhoff, S. Mustafa, and A. Alum, "Comparison of different methods for the point of zero charge determination of NiO," Ind. Eng. Chem. Res., vol. 50, no. 17, pp. 10017-10023, 2011.

[14] D. Dutta, S. Chatterjee, K. T. Pillai, P. K. Pujari, and B. N. Ganguly, "Pore structure of silica gel: A comparative study through BET and PALS," Chem. Phys., vol. 312, no. 1-3, pp. 319-324, 2005.

[15] M. Castrillón García, "Síntesis de nanopartículas magnéticas y su aplicación en nanocompuestos de matriz polimérica con propiedades magnéticas," Universidad de Zaragoza, 2012.

[16] C. Suryanarayana and M. G. Norton, "X-ray Diffraction: A Practical Approach.," Microsc. Microanal., vol. 4, no. 5, pp. 513-515, 1998.

[17] S. Zhang, L. L., and A. Kumar, Materials characterization techniques. New York: CRC press, 2008.

[18] G. Beaucage, "Small-Angle Scattering from Polymeric Mass Fractals of Arbitrary Mass-Fractal Dimension," J. Appl. Crystallogr., vol. 29, no. 2, pp. 134-146, 1996.

[19] G. Beaucage, "Approximations Leading to a Unified Exponential/Power-Law Approach to Small-Angle Scattering," J. Appl. Crystallogr., vol. 28, no. 6, pp. 717$728,1995$.

[20] X. Batlle and A. A. Labarta, "Finite-size effects in fine particles:magnetic and transport properties," J. Phys. D Appl. Phys., vol. 35, p. R15, 2002.

[21] A. Dada, A. Olalekan, A. Olatunya, and O. Dada, "Langmuir, Freundlich , Temkin and Dubinin - Radushkevich Isotherms Studies of Equilibrium Sorption of Zn $2+$ Unto Phosphoric Acid Modified Rice Husk," IOSR J. Appl. Chem., vol. 3, no. 1, pp. 
D. Fabio Mercado

38-45, 2012.

[22] C. Yang, "Statistical Mechanical Study on the Freundlich Isotherm Equation.," J. Colloid Interface Sci., vol. 208, no. 2, pp. 379-387, 1998. 


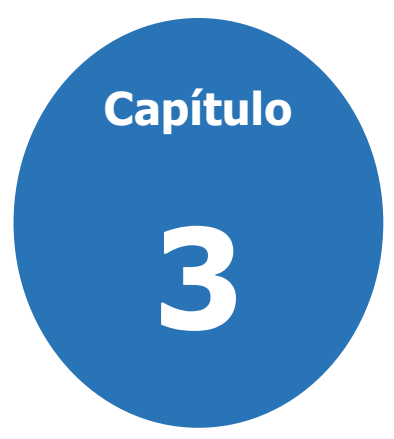

\section{Estudio de diferentes aplicaciones ambientales de los SBO en la remediación de cuerpos de aguas contaminados.}

Los procesos fotoquímicos actualmente han adquirido gran interés debido a su capacidad de remediación de cuerpos de aguas contaminados que presentan resistencia a procesos químicos y/o biológicos convencionales.

La materia orgánica presente en los cuerpos de agua naturales juega un rol importante en el proceso de degradación de contaminantes por vías fotoquímicas. Estas son capaces de aumentar o disminuir el rendimiento del proceso general ya que pueden modificar los mecanismos de reacción dando lugar a productos diferentes. En este caso sería necesario una evaluación de los productos formados y del estudio de la toxicidad de los mismos. También es posible su uso como agentes complejantes de hierro en solución acuosa en pH superior a 3.0 para su uso en procesos fotofenton para la degradación de contaminantes.

En este capítulo se muestra los resultados sobre la caracterización básica de una sustancia tipo húmica obtenida de residuos verdes en la región Piamonte, Italia, y se describen los estudios desarrollados para evaluar su fotoestabilidad. Posteriormente se describen las investigaciones desarrolladas para determinar la efectividad de los SBO como fotocatalizadores de la degradación de moléculas orgánicas modelo, tales como el pireno (Pyr) y el azul de metileno (AM) moléculas presentes en las aguas residuales de la industria de hidrocarburos y textil, respectivamente. Finalmente se evalúa la capacidad de los SBO como agente quelante de hierro en solución para su uso en el proceso fotofenton de la degradación del funguicida Flusilasol.

\subsection{Materiales y métodos.}

Las condiciones experimentales específicas para cada ensayo se muestran en su respectiva discusión, sin embargo, a continuación se explicará la 
preparación y cuantificación de los reactivos contaminantes modelos considerados en este estudio.

\subsubsection{Preparación de las soluciones y cuantificación de Pireno, AM y Flusilasol.}

Debido a la diversidad de bibliografía en cuanto a la solubilidad, preparación de muestras y detección de los hidrocarburos poliaromáticos (PAH's); se utilizó una combinación de los métodos publicados[1]-[6]. Se preparó una solución saturada de Pyr en etanol con concentración 53,7 mM de la cual se tomó una alícuota garantizando una relación $0,5 \% \mathrm{v} / \mathrm{v}$ en agua, obteniendo concentraciones de hasta un máximo de $2,5 \mu \mathrm{M}$. Previo a la cuantificación de la concentración de Pyr en fase acuosa, este se extrajo con ciclohexano cuando los SBO estuvieran presentes en el sistema. En ensayos exploratorios se observó que, dentro del margen de error experimental, es posible separar el $100 \%$ del Pyr de la fase acuosa cuando se lo extrae con ciclohexano. El Pyr se cuantificó a partir de su intensidad de emisión de fluorescencia bajo condiciones controladas.

Las soluciones de AM se prepararon por pesada directa del sólido y posterior disolución en agua. Para la cuantificación del AM en soluciones conteniendo SBO, se separó el AM del SBO acidificando la solución para hacer precipitar la fracción húmica de estos compuestos. La cuantificación se realizó por espectroscopia UV/Vis usando el coeficiente de absorción molar $79092 \mathrm{M}^{-1} \mathrm{~cm}^{-1}$ a $664 \mathrm{~nm}$ calculado a partir de ensayos blanco y en concordancia con el valor publicado en literatura [7].

Las soluciones de Flusilasol se prepararon adicionando una cantidad en exceso de este sólido a un matraz con $250 \mathrm{~mL}$ de Agua MilliQ. Se mantuvo la mezcla con agitación constante a $25{ }^{\circ} \mathrm{C}$ durante 24 horas hasta lograr una solución saturada. La concentración de este se cuantificó mediante medidas de TOC y GC.

\subsection{Resultados y análisis.}

\subsubsection{Propiedades de los SBO.}

El espectro de absorción de una solución acuosa de CVT230 se muestra en la figura 3.1. A partir de este espectro fue posible calcular el parámetro $Q_{4} / 6^{\prime}$ que relaciona la absorbancia a $465 \mathrm{~nm}\left(\mathrm{E}_{4}\right)$ y $665 \mathrm{~nm}\left(\mathrm{E}_{6}\right) Q_{4} / 6=E_{4} / E_{6}$. Esta relación es un parámetro sumamente utilizado para la caracterización de las sustancias tipo húmicas, ya que permite relacionar cualitativamente el grado de humificación del material, la madurez y el grado de condensación de las cadenas carbonadas [8], [9].

Se ha demostrado que en la zona del espectro a $465 \mathrm{~nm}$ absorben los componentes asociados con las primeras fases del proceso de humificación, mientras que a $665 \mathrm{~nm}$ lo hacen los componentes de alto grado de humificación. 
Para el rango de $10-1000$ ppm de CVT230 se calculó un valor $Q_{4 / 6}=4.1 \pm 0.2$. Valores bajos de este parámetro $(<4)$ indican una alto grado de humificación, un alto grado de condensación de las cadenas carbonadas del sistema y de alta calidad para su uso en suelos [8]-[10].

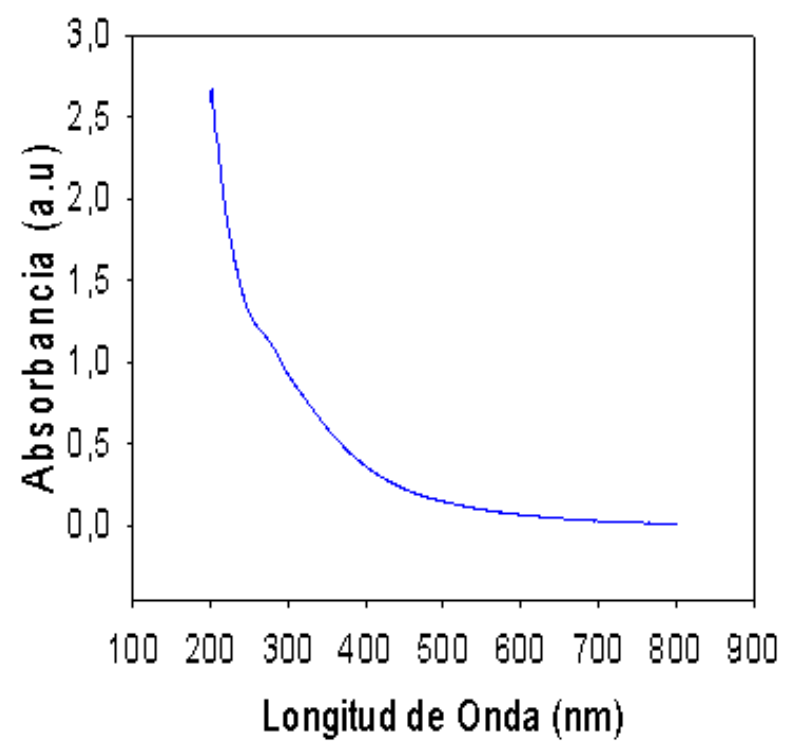

Fig. 3.1 - Espectro de Absorción Uv/Vis de una solución de SBO CVT 230 de 50 ppm.

Paralelamente se hicieron ensayos de consumo de oxígeno molecular para verificar si una solución de estos compuestos al ser irradiada por luz $(\lambda=350$ $\mathrm{nm})$, reacciona con Oxígeno o si es capaz de producir especies reactivas de Oxígeno. El consumo de oxígeno en función del tiempo de irradiación se muestra en la figura 3.2.

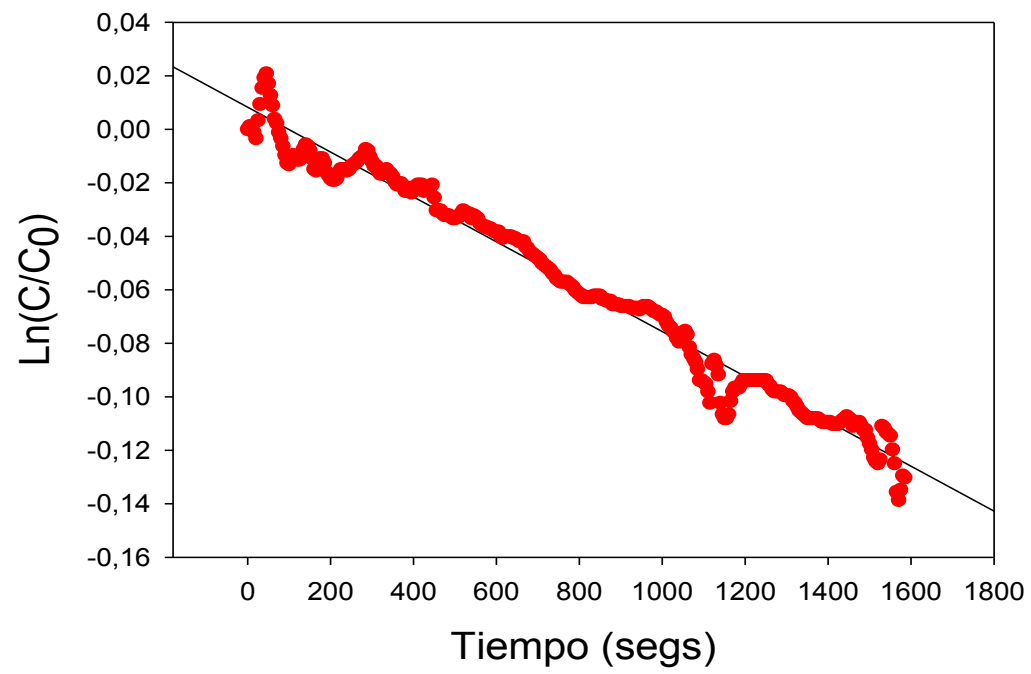

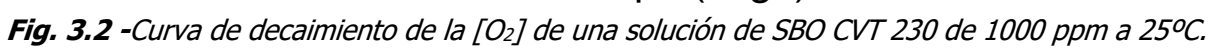

La relación de consumo de oxígeno molecular obtenida es $\mathrm{d}\left[\mathrm{O}_{2}\right] / \mathrm{t}=-0.0013[\mathrm{ppm} \mathrm{O} / \mathrm{s}]$ para una solución de 1500ppm de SBO. Se utilizó esta elevada concentración ya que para concentraciones menores no se evidencia disminución de la concentración de $\mathrm{O}_{2}$, incluso en presencia de scavengers de especies reactivas, como oxígeno singulete y anión radical superóxido, que inician el consumo de oxígeno. Estos resultados indican que los SBO no se fotooxidan fácilmente por irradiación a $350 \mathrm{~nm}$.

Paralelamente se calculó la relación de la DQO de una solución de SBO CVT230 en función de la concentración del mismo, arrojando como resultado una 
relación $0.96 \mathrm{mgO}_{2} / \mathrm{mg}$ CVT230. Estos valores indican que casi toda la materia orgánica presente en la muestra es susceptible a la oxidación. Dicho valor indica que los SBO actuarán como atrapadores eficientes de especies reactivas del oxígeno capaces de iniciar su oxidación.

\subsubsection{Fotoestabilidad de los SBO.}

Para comprobar la fotoestabilidad en solución acuosa de los CVT230, se hicieron varios ensayos en estado estacionario. Para ello se utilizó un reactor cilíndrico Rayonet ${ }^{\circledR}$ con 8 lámparas monocromáticas de 254 y $350 \mathrm{~nm}$ y un reactor con camisa de cuarzo con una lámpara de $\mathrm{Hg}$ de media presión (125 W), en esta última experiencia se monitoreó el espectro de absorción, DQO y TOC en el tiempo.

A continuación, se muestran los resultados obtenidos después de las experiencias con las lámparas monocromáticas. Empezando con 8 lámparas de $254 \mathrm{~nm}$, en donde se irradiaron $500 \mathrm{~mL}$ de una solución de CVT230 de 100ppm y se apreciaron cambios espectrales durante 140 minutos. La Figura 3.3 muestra dicha evolución:

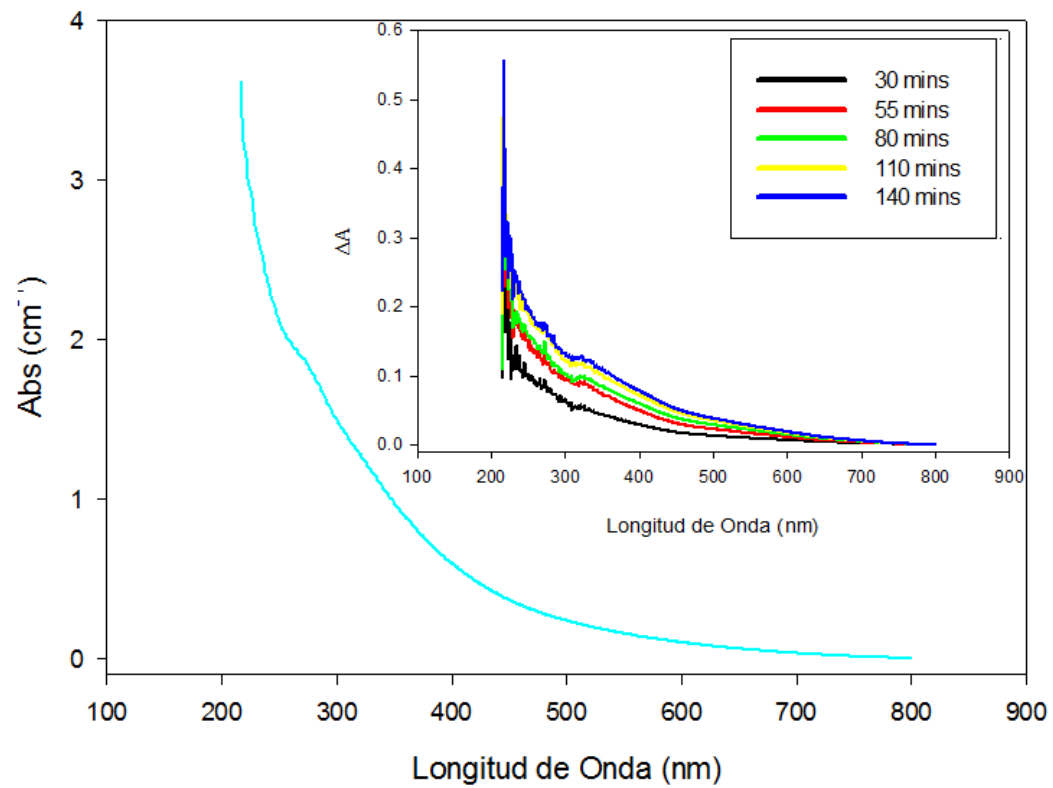

Fig. 3.3. - Espectro de absorción de una solución 100 ppm de CVT230 sin irradiar. Recuadro: Cambios espectrales calculados como $\Delta A=A b s\left(t_{0}\right)-A b s\left(t_{x}\right)$ siendo $t_{x}$ el tiempo de irradiación en consideración.

La experiencia anterior se repitió bajo las mismas condiciones solo que esta vez se utilizaron lámparas monocromáticas de 350nm. En este experimento no se evidencian cambios en el espectro de absorción aún por más de 6 horas de irradiación.

Cabe resaltar entonces que estos compuestos poseen una gran fotoestabilidad ya que incluso al ser irradiados con fotones de la región UVC(64 Watts) no hay cambios significativos en la absorbancia de la solución después de 2 horas continuas de irradiación. Además, se evidenció que el cambio en los espectros de absorción se debe a cambios estructurales donde el grado de condensación de las cadenas carbonadas parece aumentar. 
Para la irradiación con lámpara de $\mathrm{Hg}$ de media presión se utilizó una solución de CVT230 de 1600 ppm, se introdujo en el reactor dotado con camisa de refrigerante que mantuvo la temperatura en $(27 \pm 3){ }^{\circ} \mathrm{C}$ y se encendió la lámpara. Posterior a los 5 minutos de estabilización de la misma se inició el monitoreo de los diferentes parámetros. En la figura 3.4 se muestra un resumen de la variación de las absorbancias a diferentes longitudes de onda con respecto al tiempo de irradiación, al igual que la DQO y el TOC de la solución. Se evidencia así que hay una variación de las absorbancias en las diferentes longitudes de onda a lo largo del tiempo de irradiación. Se monitorearon longitudes de onda atribuidas a grupos de compuestos de diferente comportamiento químico presentes en sustancias tipo húmicas[10]. La fracción aromática que absorbe a longitudes de onda $250 \mathrm{~nm}$, no muestra cambios apreciables después de 150 minutos de irradiación. Todas las absorbancias disminuyen en el tiempo, a excepción de la de $665 \mathrm{~nm}$, que no sigue el mismo comportamiento. Esto es evidencia de la formación de productos de reacción con mayor condensación aromática y dobles enlaces acoplados[10].

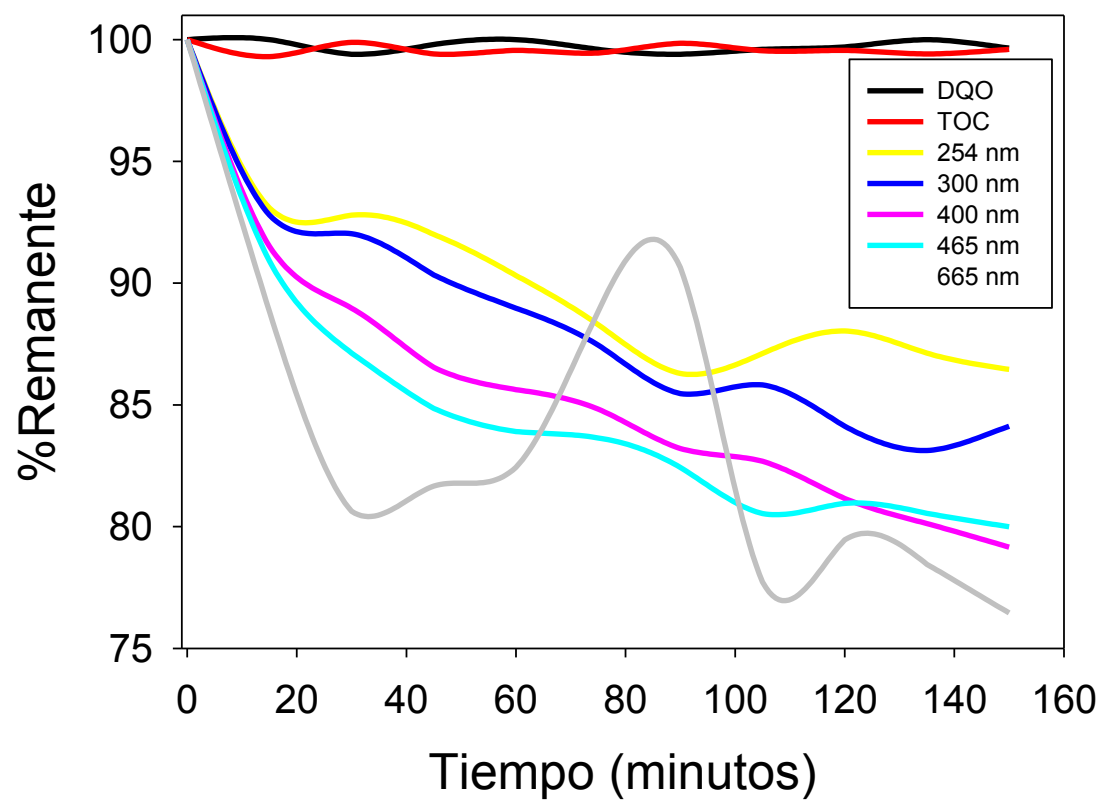

Fig. 3.4 - Seguimiento de la absorbancia, DQO y TOC de la solución de CVT230 en función del tiempo de irradiación con lámpara de $\mathrm{Hg}$ en estado estacionario.

De manera paralela, ensayos realizados por otros investigadores pertenecientes al grupo de trabajo del proyecto EnvinBOS concluyeron en un estudio más detallado, que los ensayos de irradiación modifican en pequeña proporción las propiedades fisicoquímicas de estos compuestos luego de ser irradiados por la misma fuente de luz por más de 12 horas. Además, no hay cambios dentro del margen de error de los valores de TOC de la solución, lo que si hay es una disminución en la fracción húmica de los CVT230 que se convierten en parte de la fracción fúlvica [12]. Lo anterior es posible explicar bajo la hipótesis de la formación fotoinducida de especies más hidrofílicas que conllevan al aumento de la solubilidad de la fracción considerada en agua. De manera general de nuestros ensayos y los presentados en la literatura, se puede concluir que los CVT 230 presentan una alta fotoestabilidad bajo las condiciones testeadas. Además, las transformaciones químicas durante las 12 horas de 
irradiación máximas consideradas conllevan a la conversión de la fracción tipo húmica a la tipo fúlvica [12]-[14].

\subsubsection{Interacción del Pyr y del AM con los SBO.}

Previo a estudiar la capacidad de esta clase de SBO para promover la fotodegradación de contaminantes orgánicos en fase acuosa, se hizo un estudio preliminar para evidenciar si existe algún tipo de interacción importante entre los sustratos de estudio con los SBO. Las moléculas utilizadas en esta sección experimental se muestran en la figura 3.5.<smiles>c1cc2ccc3cccc4ccc(c1)c2c34</smiles><smiles>CN(C)c1ccc2c(c1)SC1C=C([N+](C)C)C=CC1=N2</smiles>

Fig. 3.5 - Formulas moleculares del Izquierda: Pireno Derecha: Azul de metileno.

El pireno presenta una fluorescencia fuertemente dependiente de la polaridad del medio y de su concentración [3]. En las condiciones consideradas a $25{ }^{\circ} \mathrm{C}$ se obtuvieron los espectros de absorción y emisión del pireno que se muestran en la figura 3.6. Los picos del espectro de absorción del pireno coinciden con los reportados: $232^{\mathrm{D}}, 242^{\mathrm{F}}, 252^{\mathrm{D}}, 260^{\mathrm{D}}, 272^{\mathrm{F}}, 308^{\mathrm{D}}, 320^{\mathrm{F}}$ y $334^{\mathrm{F}}$ $\mathrm{nm}$, indicativo del alto grado de pureza del reactivo[3]. Los superíndices $D$ y $F$ indican si la señal es débil o fuerte. Por su lado, el espectro de emisión $\left(\lambda_{\mathrm{Exc}}=334\right.$ nm) presentó los 5 picos típicos a 373, 379, 383, 389 y 393 nm. Considerando que no se evidencia ningún pico a longitudes de ondas mayores, puede descartarse la formación de dímeros. La solubilidad máxima reportada del Pyr en agua es de $2 \mu \mathrm{M}$ mientras que los dímeros se forman a partir de $(3-4) \mu \mathrm{M}$ en otros solventes orgánicos [3]. La fig. 3.7muestra los espectros del pireno en presencia y ausencia de SBO.

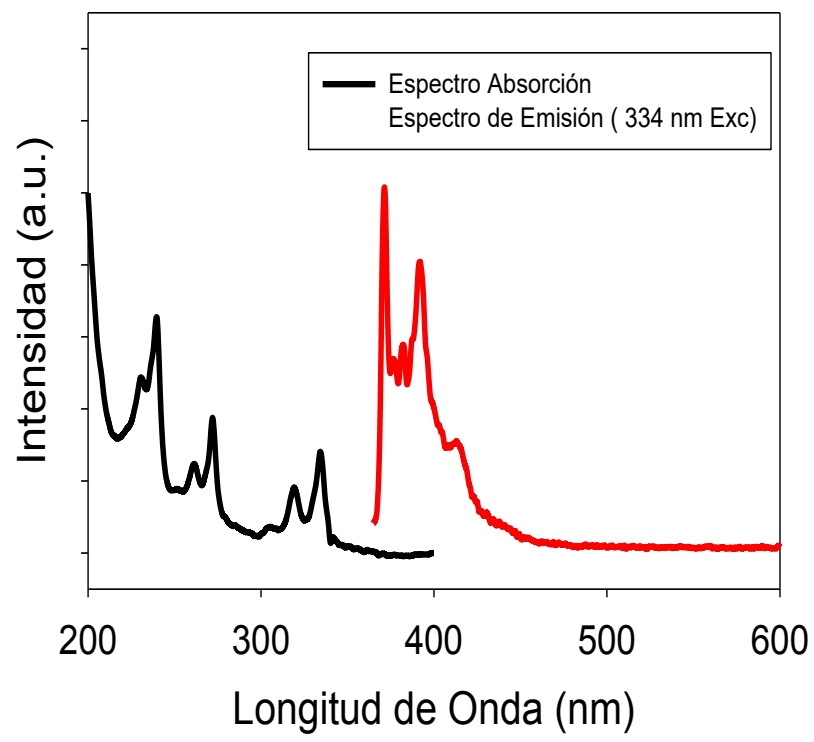

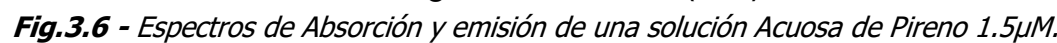


La relación $\mathrm{I}_{\mathrm{I}} / \mathrm{I}_{\text {III }}$ se utiliza para la determinación cualitativa de la polaridad de los alrededores inmediatos a la molécula del pireno en solución, siendo $\mathrm{I}_{\mathrm{I}}$ e $\mathrm{I}_{\mathrm{III}}$ las intensidades de emisión del pireno a $(371 \pm 2) \mathrm{nm}$ y $(381 \pm 2) \mathrm{nm}$ respectivamente, cuando se irradia con una longitud de onda de excitación de $(334 \pm 2) \mathrm{nm}$. Estos valores son dependientes de factores experimentales como la concentración, la temperatura, el grado de pureza, el solvente, entre otros [3], [15]. En este estudio se comparó la relación $\mathrm{I}_{\mathrm{I}} / \mathrm{I}_{\mathrm{III}}$ para soluciones de Pyr $1.5 \mu \mathrm{M}$ en agua en presencia y ausencia de SBO. La figura 3.7 muestra el espectro de fluorescencia normalizado $\left(\lambda_{\mathrm{EXC}}=334 \mathrm{~nm}\right)$ respecto a $\mathrm{I}_{\mathrm{III}}=381 \mathrm{~nm}$ de una solución en agua y otra con $150 \mathrm{mg} / \mathrm{L}$ de SBO.

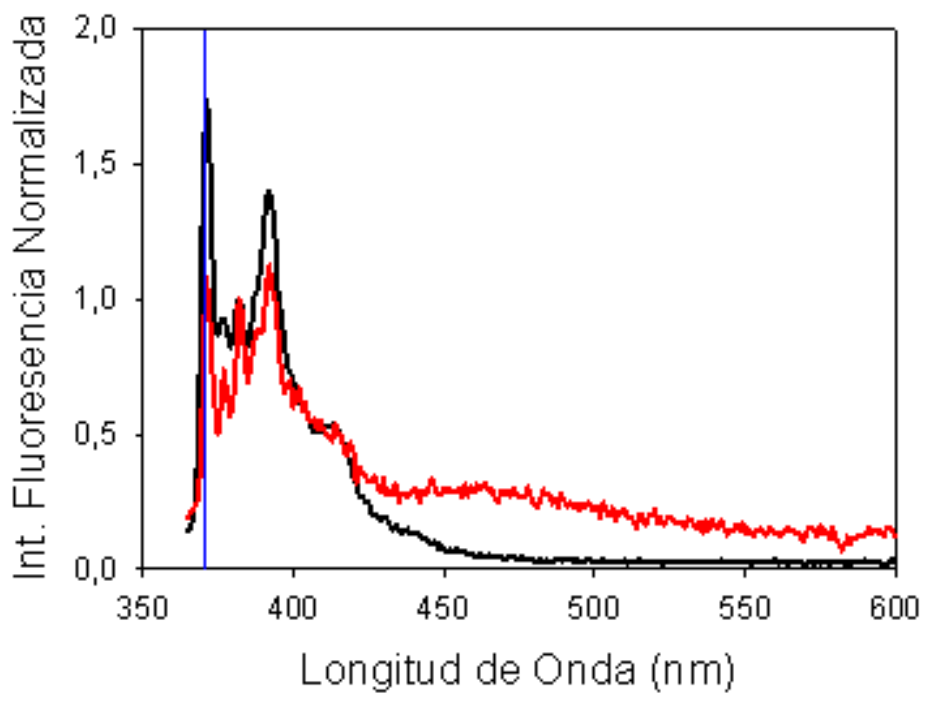

Fig. 3.7 - Espectros de emisión normalizados de soluciones $1.5 \mu \mathrm{M}$ de Pyr en agua (curva negra) y agua $+150 \mathrm{mg} / \mathrm{L} \mathrm{SBO}$ (curva roja).

En esta figura se puede apreciar que el valor $\mathrm{I}_{\mathrm{I}} / \mathrm{I}_{\text {III }}$ (marcado con la línea azul) para el agua está alrededor de 1.75, mientras que para la solución de 150 ppm de SBO en agua es de 1.08. La disminución de este parámetro es indicativo de una disminución en la polaridad en el microambiente circundante a las moléculas del pireno, en este caso debido al efecto de los SBO [3].La figura 3.8 muestra la evolución del parámetro $\mathrm{I}_{\mathrm{I}} / \mathrm{I}_{\text {III }}$ a medida que se aumenta la concentración de SBO.

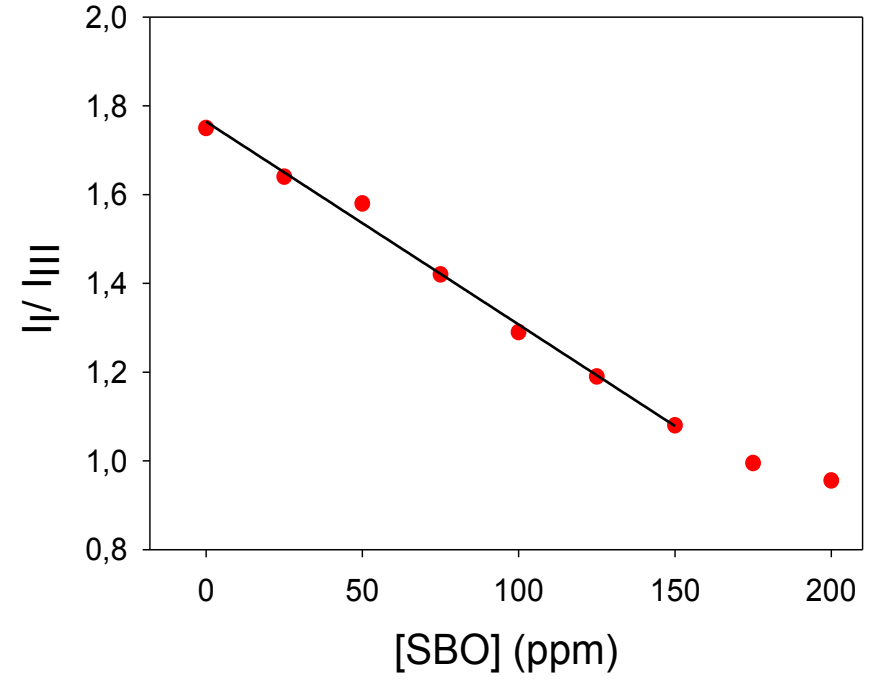

Fig. 3.8 - Variación del parámetro $I_{I} / I_{I I I}$ con el aumento de la concentración de SBO en solución acuosa. 
Como se puede apreciar, la disminución del parámetro $\mathrm{I}_{\mathrm{I}} / \mathrm{I}_{\mathrm{III}}$ va de la mano con el aumento de la introducción del SBO en el sistema. Las señales por encima a 150 ppm no se ajustan adecuadamente debido a que como se puede apreciar en la figura 3.7, en el espectro de emisión del Pyr en presencia de SBO alrededor de $475 \mathrm{~nm}$ aparece un pico que en presencia de agua no está. Este pico puede ser atribuido a la formación de dímeros, que son interferentes para el método considerado [3], [15].

Por otro lado, se evaluó la posibilidad de interacción entre el AM y los SBO. En este caso los ensayos se siguieron por Espectroscopía UV/Vis. La Figura 3.9 muestra los espectros de absorción de la mezcla de Azul de Metileno (60 ppm) y SBO (50ppm).

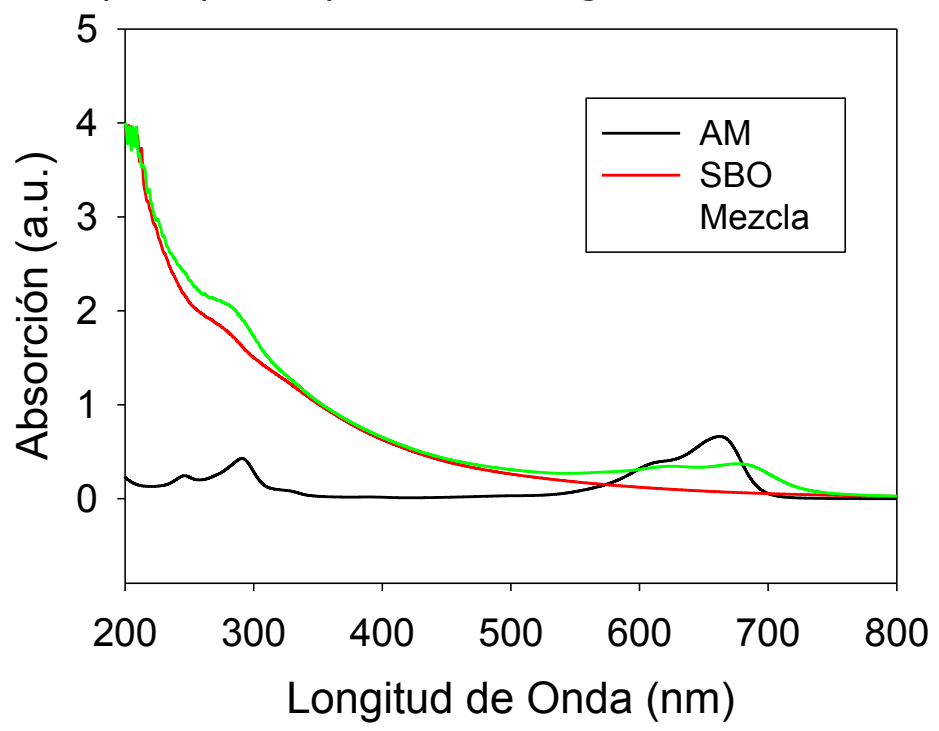

Fig. 3.9 -Espectros de absorción UV/Vis del AM (60 ppm), SBO (100 ppm) y de la mezcla de las mismas concentraciones.

La figura 3.10 muestra el espectro del AM en solución acuosa (curva negra) y del mismo colorante luego de sustraer la contribución del SBO (curva verde) de los espectros de la figura 3.9. En esta figura se evidencia un cambio importante en el espectro de absorción del AM luego de la introducción del SBO al sistema. Se observa un corrimiento a mayores longitudes de onda del máximo a $663 \mathrm{~nm}$ que aparece a $674 \mathrm{~nm}$ en presencia de SBO. Es oportuno mencionar que debido a la naturaleza anionica de los SBO y el carácter cationico del AM existe una interacción electrostática entre estos compuestos [12], [16][18]. De hecho hay estudios donde se muestra que este comportamiento se observa para sistemas en los que este colorante interactúa con ácidos nucleícos debido a una interacción electrostática[19].

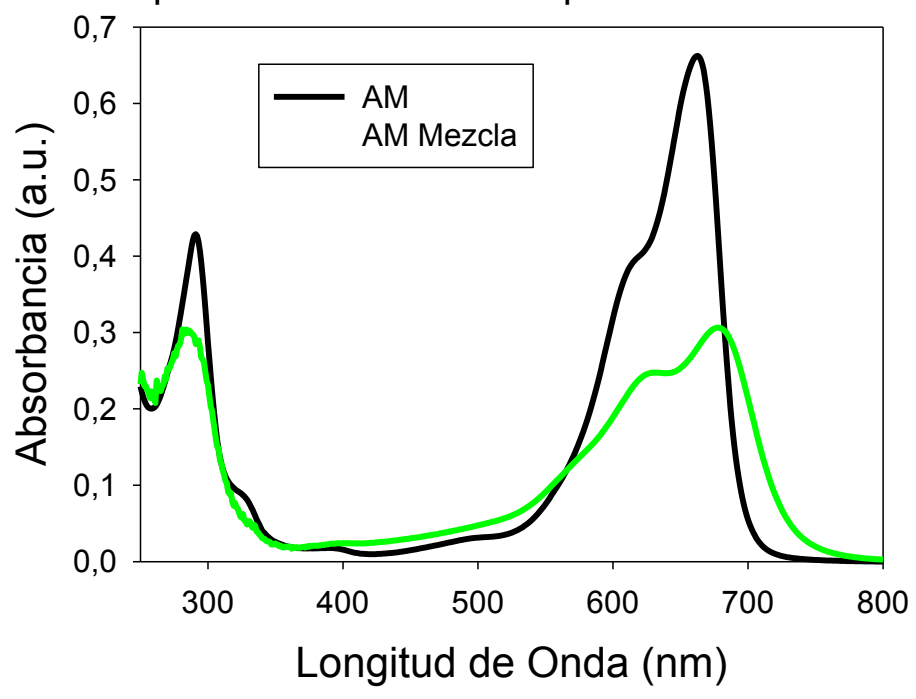

Fig. 3.10 -Espectros de absorción UV/Vis del AM en presencia y ausencia de SBO luego de sustraer la contribución de la absorbancia del SBO. 


\subsubsection{Degradación fotoasistida de Pireno y Azul de Metileno.}

Se realizaron ensayos sobre la degradación de pireno en presencia y ausencia de SBO a distintas longitudes de onda. La figura 3.11 muestra los cambios espectrales debido a la irradiación con luz policromática durante más de 7 horas de una solución acuosa de $1 \mu \mathrm{M}$ de pireno y $25 \mathrm{ppm}$ de SBO. De la figura se observa la disminución de la absorbancia de los SBO con el tiempo de irradiación.

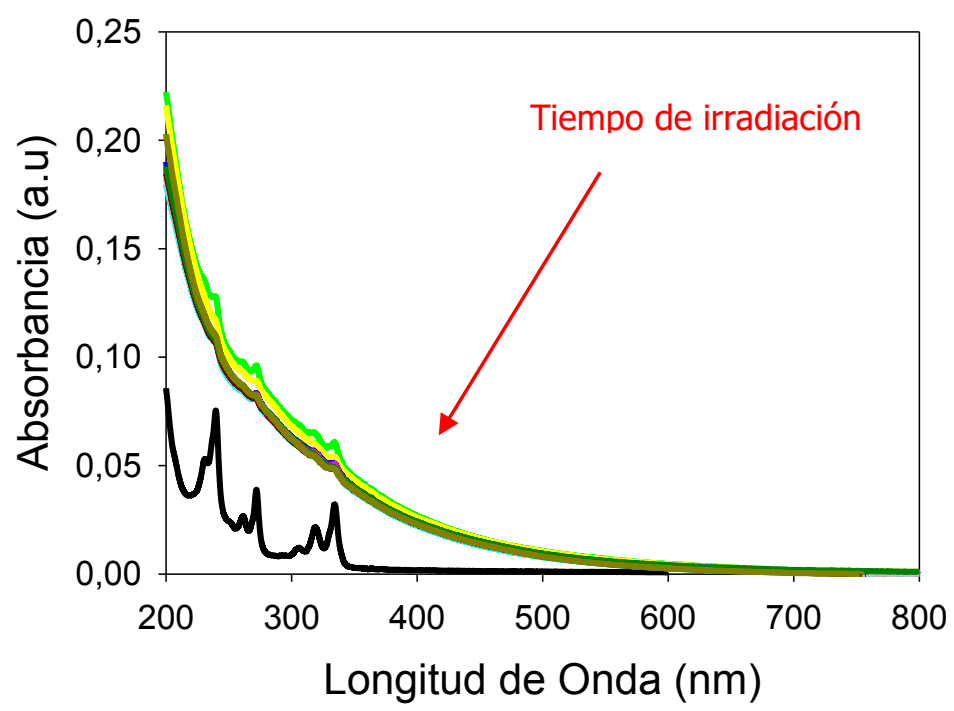

Fig. 3.11 -Cambios espectrales debido a la irradiación con Lámpara de Hg en presencia de SBO.

La figura 3.12 muestra un resumen de los ensayos a 2 longitudes de onda de irradiación, 254 y $456 \mathrm{~nm}$, respectivamente. De estos ensayos se puede concluir que la luz visible $(456 \mathrm{~nm})$ no resulta efectiva para la degradación del

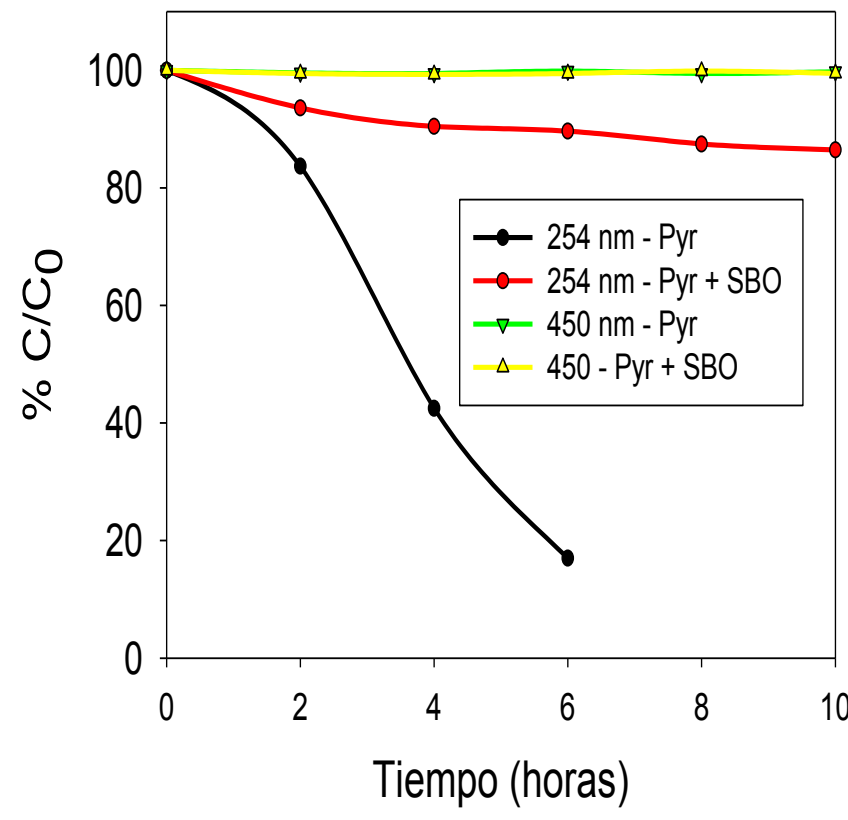
pireno. Por otro lado, si se compara con la irradiación UV $(254 \mathrm{~nm})$ del pireno solo con la misma lámpara e intensidad de emisión, ver figura 3.12, el agregado de SBO no mejora, sino que disminuye la degradación de pireno. Debido a la fuerte absorción del SBO en el UV/Vis, este estaría actuando como filtro interno disminuyendo la velocidad de la fotolisis directa del contaminante a $254 \mathrm{~nm}$. En efecto, tal como se mencionó anteriormente (ver Figura 3.3), se observa el consumo de SBO.

Fig. 3.12 - Curvas de desaparición del Pireno por irradiación con luz de 254 y $450 \mathrm{~nm}$, en presencia y ausencia de SBO. 
Por otro lado, para la evaluación de la concentración de AM remanente en solución, se procedió a la eliminación de la fracción soluble de los SBO mediante la disminución del pH por debajo de 2.0 y posterior cuantificación por Uv/Vis. Los resultados de los ensayos de degradación de AM en estos experimentos se muestran en la figura 3.13.

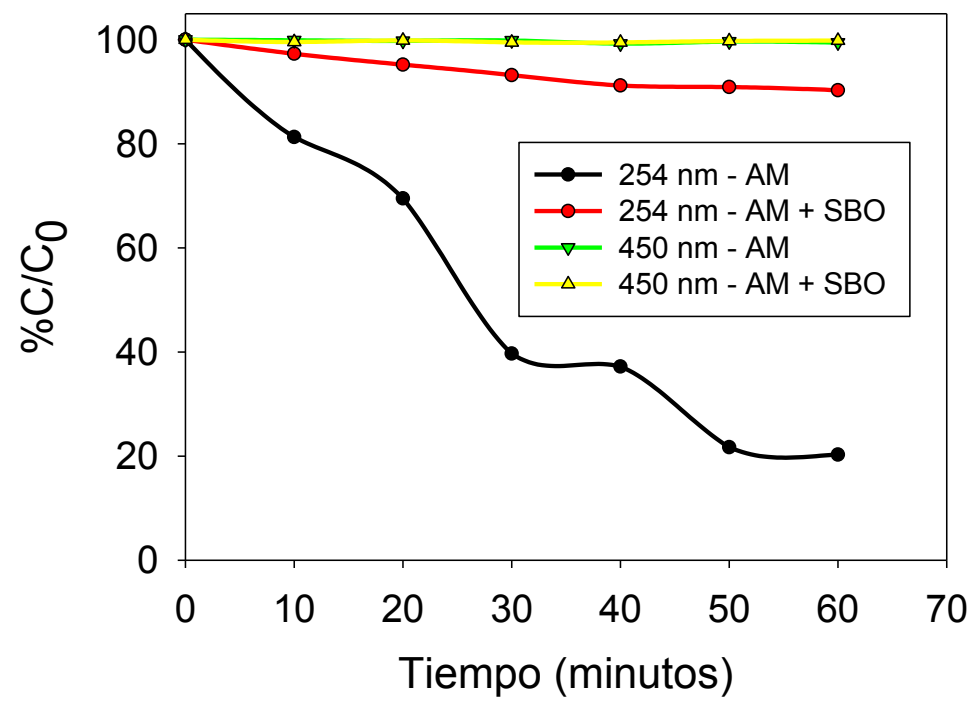

Fig. 3.13 - Curvas de desaparición del AMpor irradiación con luz de 254 y 450 nm, en presencia y ausencia de $B O S$.

Al igual que lo observado para el pireno, de los ensayos en la figura 3.13se puede concluir que la luz $(456 \mathrm{~nm})$ visible no resulta efectiva para la degradación del AM ni para la fotosensibilización por el SBO.Por otro lado, si se compara con la irradiación UV (254 nm) del AM solo con la misma lámpara e intensidad de emisión, el agregado de SBO no mejora, sino que disminuye considerablemente la degradación del AM. Todos los resultados obtenidos indican que los SBO no son fotosensibilizadores adecuados para la degradación del AM y del pireno.

\subsubsection{Degradación del Flusilasol mediante procesos del tipo} fenton tipo fenton usando a los SBO como agentes complejantes de Fe.

Se procedió a la evaluación de las propiedades de los SBO como complejantes de los iones $\mathrm{Fe}^{+2} / \mathrm{Fe}^{+3}$ para promover la degradación por vías tipo fenton en soluciones de $\mathrm{pH}>3$. Existe en la literatura una discusión sobre la identidad de los radicales involucrados en sistemas de estas características, ya que la materia orgánica capaz de complejar los iones metálicos permitiría formaciones de radicales orgánicos y peróxidos que pueden iniciar la oxidación[13], [14], [20].

Las condiciones experimentales de estos ensayos se encuentran en el cap. 2 de materiales y métodos. Resumiendo, para todos los ensayos se utilizaron las siguientes condiciones: $\left[\mathrm{Fe}^{+2}\right]$ : 5 ppm, pH 3.0 o 5.0 según corresponda ajustado con $\mathrm{HCl}, 50 \mu \mathrm{L}$ de $\mathrm{H}_{2} \mathrm{O}_{2} 30 \%$ en $250 \mathrm{~mL}$ con una 
concentración de Flusilasol de $1.2 \times 10^{-3} \mathrm{M}$ y 0 o $25 \mathrm{ppm}$ de SBO de acuerdo al caso. La figura 3.14 muestra el espectro de absorción UV/Vis del insecticida.

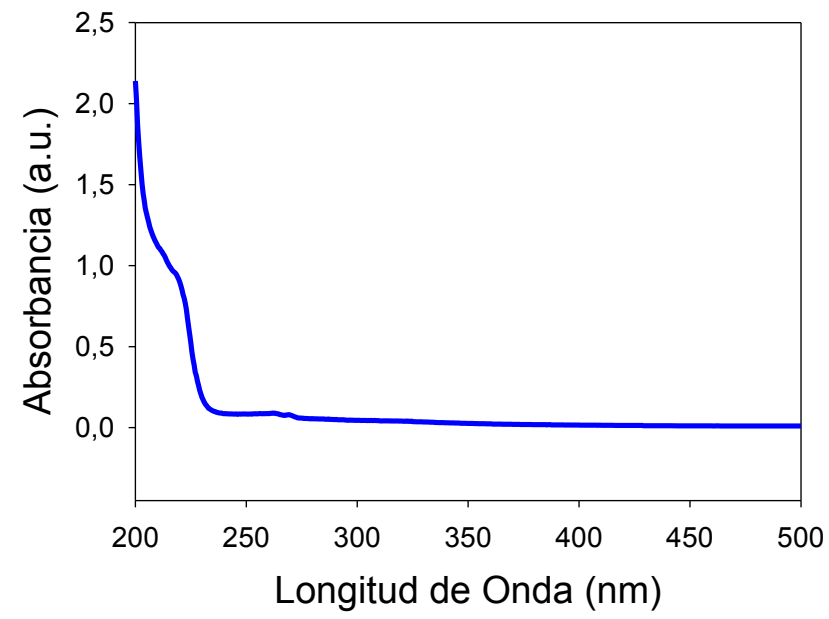

Fig. 3.14- Espectro de absorción UV/Vis del Flusilasol.

La figura 3.15 muestra las curvas experimentales de degradación del Flusilasol. Primeramente, cabe resaltar que como en el caso del Pireno y del AM se evidencia que los SBO no poseen capacidad fotosensibilizadora para promover la degradación del Flusilasol (curva azul de la misma figura) para ambos pH considerados. La degradación más eficiente, en la cual se alcanza la degradación total del Flusilasol en aproximadamente 15 minutos, es a pH 3.0 sin presencia de SBO, ya que está es la condición óptima de la reacción fenton típica [21].

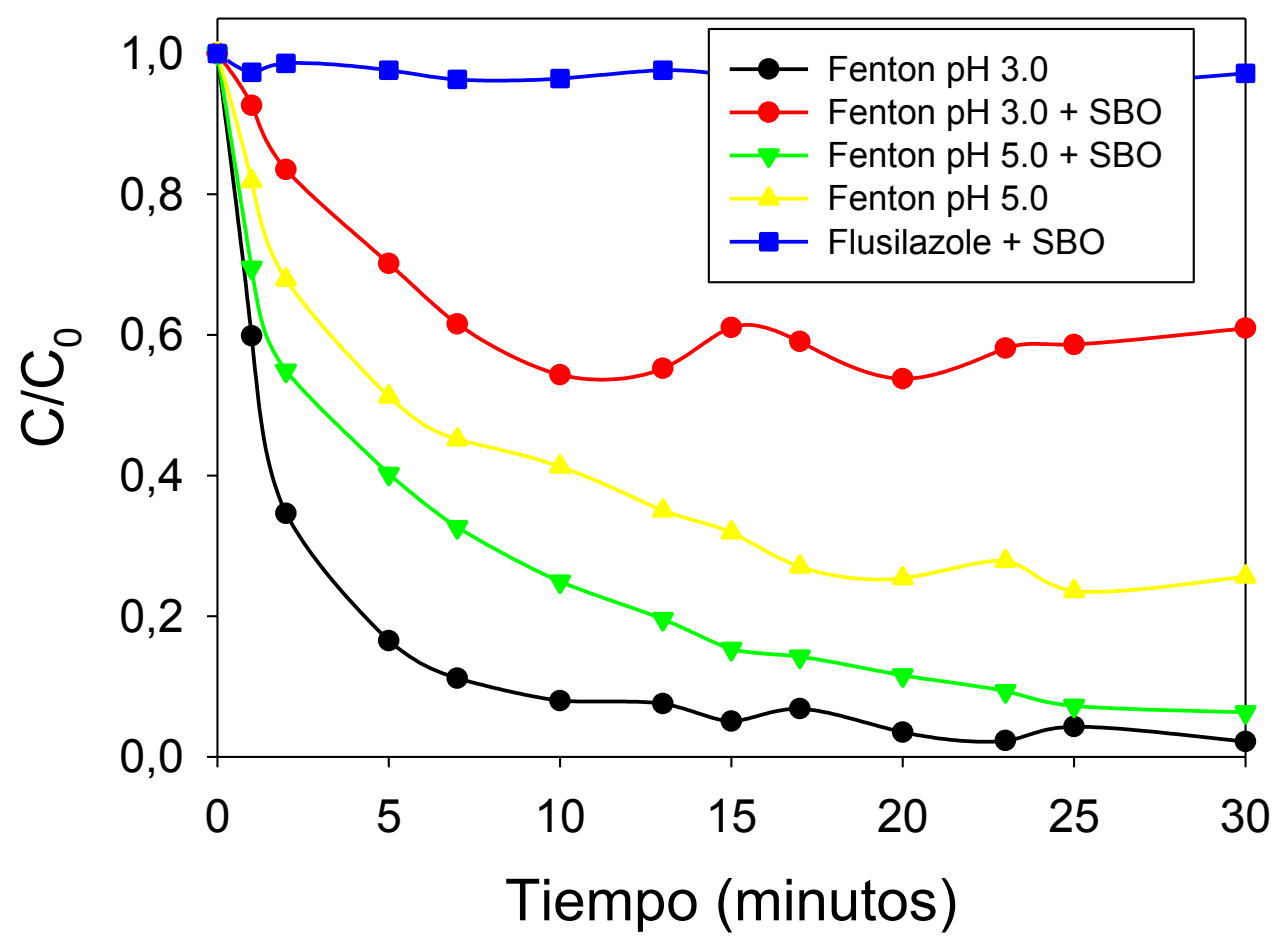

Fig. 3.15 - Curvas de degradación del Flusilasol por vía tipo fotofenton bajo las diferentes condiciones testeadas.

Como es sabido[21] el $\mathrm{pH}$ es un factor importante para la eficiencia de los procesos tipo fenton, ya que la solubilidad del $\mathrm{Fe}^{+3}$ por encima de $\mathrm{pH} 2.8$ 
disminuye significativamente. La disminución en la solubilidad del Fe explicaría el comportamiento de la degradación de Flusilasol a pH 5.0, donde en la ventana experimental se alcanza una degradación de casi el $70 \%$ en 30 minutos de reacción. Sin embargo a este mismo $\mathrm{pH}$, la adición de SBOfavorece la cinética de degradación del Flusilasol. Estudios similares con materia orgánica menos compleja han arrojado resultados similares en procesos de degradación tipo Fenton [14]. Por ello, los resultados obtenidos a pH 5 serían consecuentes con la capacidad de los SBO de actuar como agentes complejantes del $\mathrm{Fe}^{3+}$ en solución. En soluciones de pH 5.0 la solubilidad del $\mathrm{Fe}^{+3}$ es muy baja pero a este $\mathrm{pH}$ una gran fracción de los grupos - $\mathrm{COOH}$ de los $\mathrm{SBO}$ se encontrarían desprotonados, lo que permitiría la complejación del hierro[22],[23], [24].En soluciones de pH 3.0 los grupos - $\mathrm{COOH}$ de los SBO se encontrarían protonados por lo que estarían impedidos de complejar al hierro que se encuentra soluble en solución. En estas condiciones, los SBO solo actuarían como scavengers de especies reactivas. La fotólisis de los complejos del Fe con SBO conllevaría a la posibilidad de formación de radicales orgánicos con menor poder oxidativo que el $\mathrm{HO}$, lo que explicaría una diferencia en cuanto a la velocidad de degradación del Flusilasol a pH 3.0 por el proceso fenton convencional y a pH 5.0 con la introducción de los SBO.

\subsubsection{Elucidación del mecanismo inicial de degradación del} Flusilasol mediado por los radicales oxidantes.

En el estudio de los procesos de degradación de contaminantes, es importante conocer los subproductos e intermediarios de reacción generados antes de que se alcance la mineralización total a $\mathrm{CO}_{2}, \mathrm{H}_{2} \mathrm{O}$ y ácidos inorgánicos, ya que estos mismos pueden tener mayor toxicidad que los reactivos. En estos estudios se investigó sobre la degradación del Flusilasol en presencia de radicales oxidantes para determinar cuál sería el centro reactivo más reactivo de la molécula del fungicida ante estas condiciones de degradación.

Hasta el momento no se ha encontrado en la bibliografía estudios de mecanismos de degradación del Flusilasol, por lo que se investigó la reactividad del Flusilasol con radicales libres oxidantes como el anión radical Sulfato y aquellos producidos durante los procesos fenton.

La tabla 3.1 muestra los picos más importantes observados mediante el análisis por GC-Masas y los fragmentos detectados para la degradación del Flusilasol en los ensayos de degradación a pH 3.0 con 10 y 20 minutos de reacción en ausencia y presencia de los SBO. Cabe mencionar que todos estos productos se encontraban en todos los espectros de masas.

\begin{tabular}{|c|c|c|c|}
\hline $\begin{array}{c}\mathbf{R}_{\mathbf{t}} \\
(\mathbf{m i n})\end{array}$ & $\begin{array}{c}\mathbf{M W} \\
\mathbf{( m / z )}\end{array}$ & $\begin{array}{c}\text { Productos } \\
\text { Asignados }\end{array}$ \\
\hline 19.6 & $250(236$, & \\
$235,155,96)$ & & \\
\hline
\end{tabular}




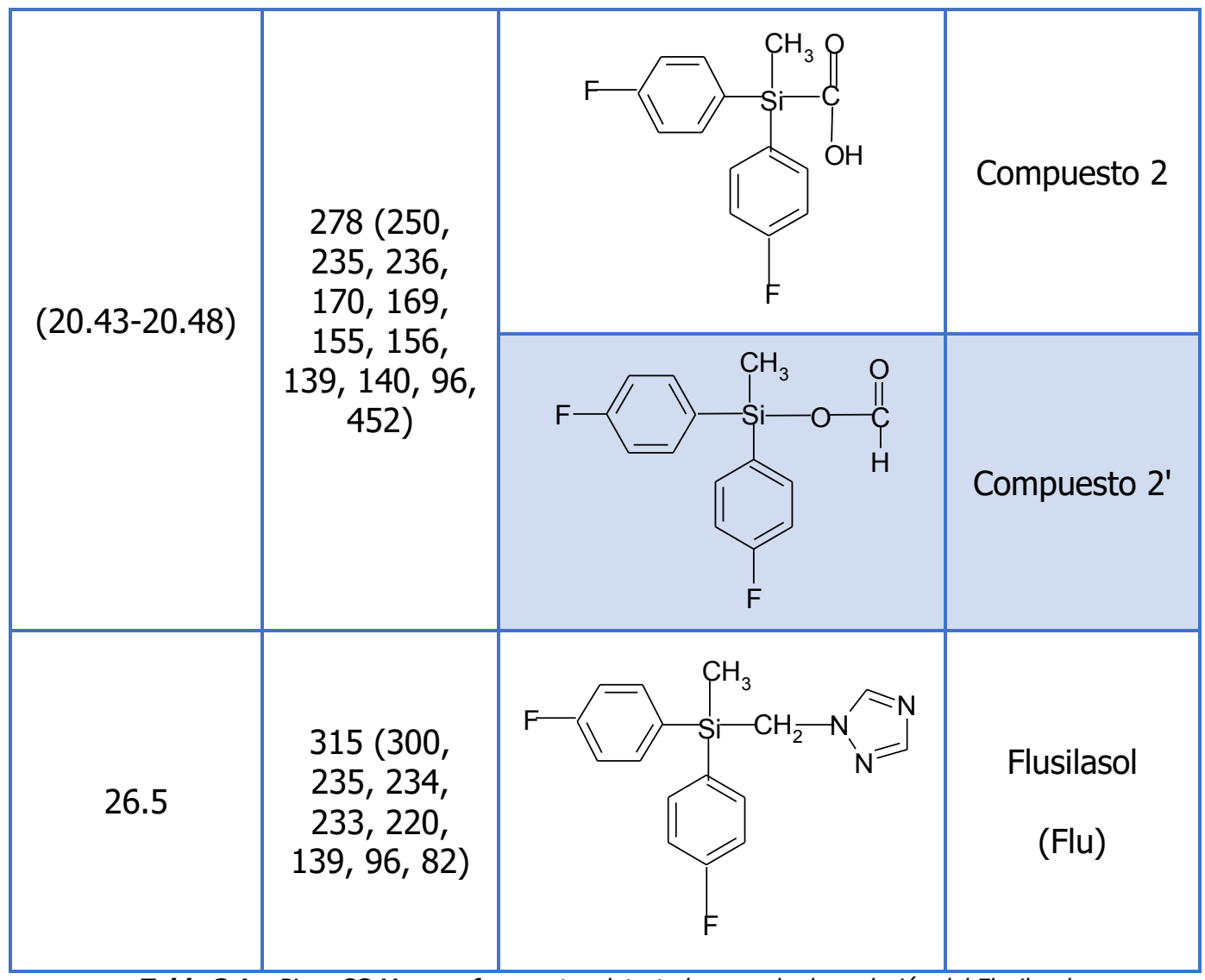

Tabla 3.1 - Picos CG-Masas y fragmentos detectados para la degradación del Flusilasol.

También se realizaron ensayos de laser flash fotolisis de soluciones de peroxodisulfato de sodio en un rango de concentraciones $(1.0-2.5) \times 10^{-2} \mathrm{M}$. En estos experimentos se observa la formación del radical sulfato que presenta un espectro en la zona de 330 - $550 \mathrm{~nm}$ con $\lambda_{\max }$ en $450 \mathrm{~nm}$. Estas señales presentan un decaimiento que se ajusta con una ecuación de orden mixto con constantes $\mathrm{k}=(3.2 \pm 0.1) \times 10^{3} \mathrm{~s}^{-1} \mathrm{y} \mathrm{k}=9.8 \times 10^{6} \mathrm{~s}^{-1} \mathrm{M}^{-1}$ correspondientes al primer y segundo orden respectivamente. Estos fueron calculados para soluciones de $1.0 \times 10^{-2} \mathrm{M}$ de $\mathrm{Na}_{2} \mathrm{~S}_{2} \mathrm{O}_{8}$ [25], [26],[27]. Las siguientes reacciones explican la ocurrencia de un orden mixto en estos experimentos:

$\mathrm{SO}_{4} \cdot{ }^{-}+\mathrm{S}_{2} \mathrm{O}_{8}^{-2} \longrightarrow \mathrm{S}_{2} \mathrm{O}_{8}^{-\cdot}+\mathrm{SO}_{4}^{-2}$

$2 \mathrm{SO}_{4} \cdot-\mathrm{S}_{2} \mathrm{O}_{8}{ }^{-2}$

\section{Reacción 1}

Reacción 2

De igual forma se realizaron experimentos en presencia de Flusilasol en concentraciones entre $4.25 \times 10^{-5} \mathrm{M}>[\mathrm{F}]>1.12 \times 10^{-4} \mathrm{M}$ y concentración de $\mathrm{Na}_{2} \mathrm{~S}_{2} \mathrm{O}_{8}$ de $2.5 \times 10^{-2} \mathrm{M}$. En ellos se evidenció un decaimiento de la señal a 450 nm mucho más rápida que cuando no se encuentra el Flusilasol en solución. La Fig. 3.16 muestra los resultados de ensayos de laser flash fotolisis para sistemas con el anión radical $\mathrm{SO}_{4}^{--}$en ausencia y presencia de Flusilasol $4.25 \times 10^{-5} \mathrm{M}$. 


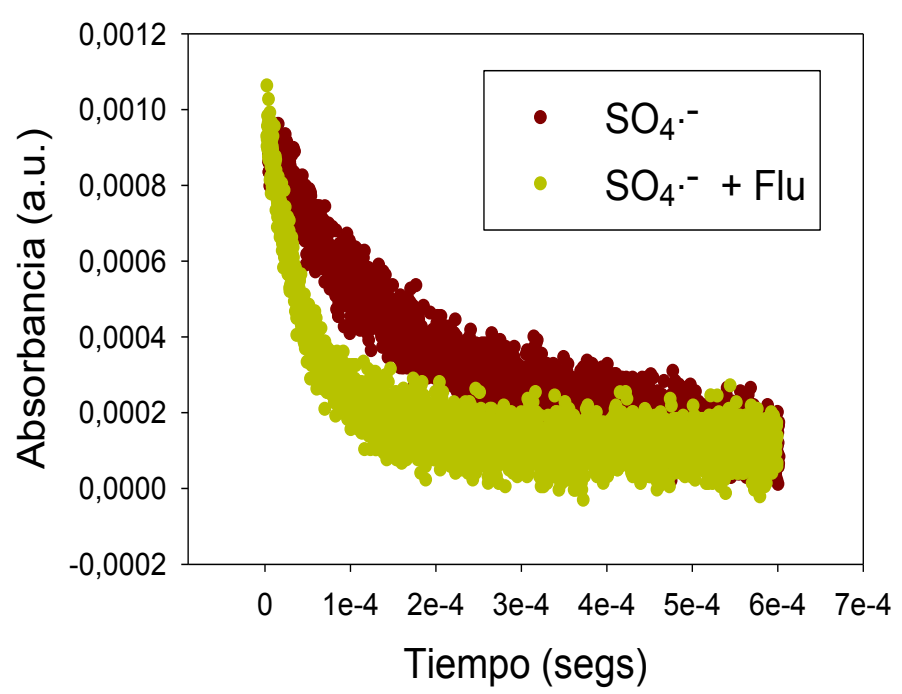

Fig. 3.16 - Curvas de decaimiento de Abs a $450 \mathrm{~nm}$ para los dos sistemas estudiados.

En estos experimentos se observó la formación de transientes en la zona del espectro entre 300 - $400 \mathrm{~nm}$. La cinética de decaimiento de las trazas observadas depende fuertemente de la longitud de onda, por lo cual se realizó un análisis bilinear a los decaimientos y a los espectros obtenidos para determinar el mínimo número de especies involucradas en la mezcla de reacción. Este análisis permitió concluir que una de las especies presentes era el radical $\mathrm{SO}_{4}{ }^{-}$ya que tanto el espectro de absorción como la cinética de decaimiento en todas las longitudes de onda corresponden a los reportados para esta especie [25], [26]. El perfil de absorbancia de esta especie se ajusta con una ecuación de orden mixto, donde la constante de primer orden aumenta a medida que se aumenta la concentración de Flusilasol en la solución. Lo anterior evidencia la contribución de una reacción entre estas especies.

$$
\begin{aligned}
& \mathrm{S}_{2} \mathrm{O}_{8}^{-2} \stackrel{h v}{\longrightarrow} 2 \mathrm{SO}_{4}^{-\cdot} \\
& \mathrm{SO}_{4}^{--}+\mathrm{Flu} \longrightarrow \text { Productos }
\end{aligned}
$$

Reacción 3

Reacción 4

La figura 3.17 muestra la relación entre la constante de pseudo-primer orden de reacción del $\mathrm{SO}_{4} \cdot$ a medida que se aumenta la concentración de Flusilasol en el medio. De la pendiente de esta línea recta es posible cuantificar la constante de reacción entre estas dos especies, que para este caso resultó ser de $(4.6 \pm 0.4) \times 10^{8} \mathrm{M}^{-1} \mathrm{~s}^{-1}$.

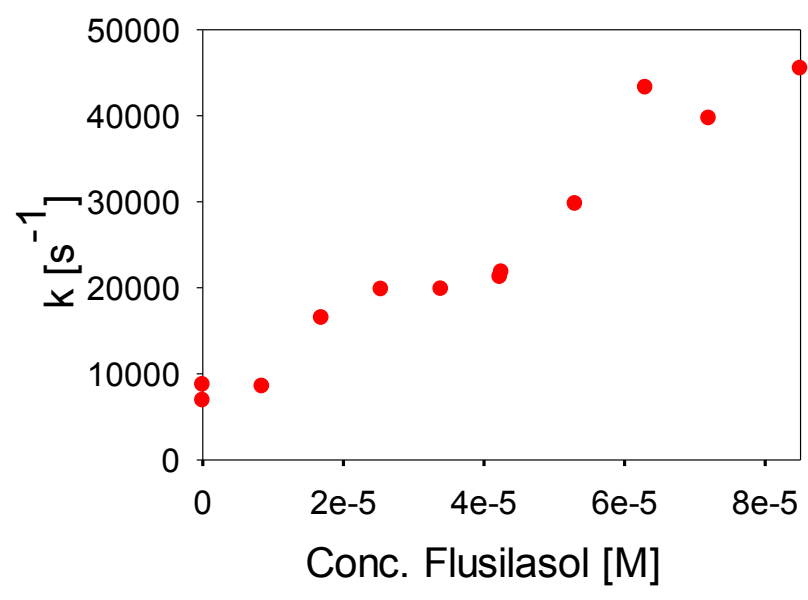

Fig. 3.17 -Relación experimental entre la constante de reactividad del $\mathrm{SO}_{4}^{-}$con la concentración de Flusilasol. 
El segundo transiente presente según el análisis bilineal, presenta un espectro de absorción en el rango de 300 - $400 \mathrm{~nm}$. La señal cinética de esta especie crece rápidamente después del disparo del láser alcanzando su máximo a $30 \mu \mathrm{s}$ y decae entre los siguientes $100 \mu$ s. Debido a lo anterior, esta especie es atribuida a radicales formados a partir de la reacción entre el radical $\mathrm{SO}_{4}{ }^{-}$y el fungicida. La figura 3.18 muestra el espectro de absorción de este radical

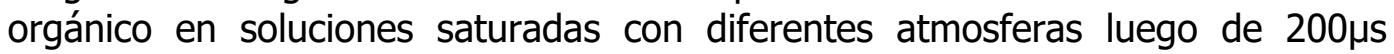
después del disparo del láser.

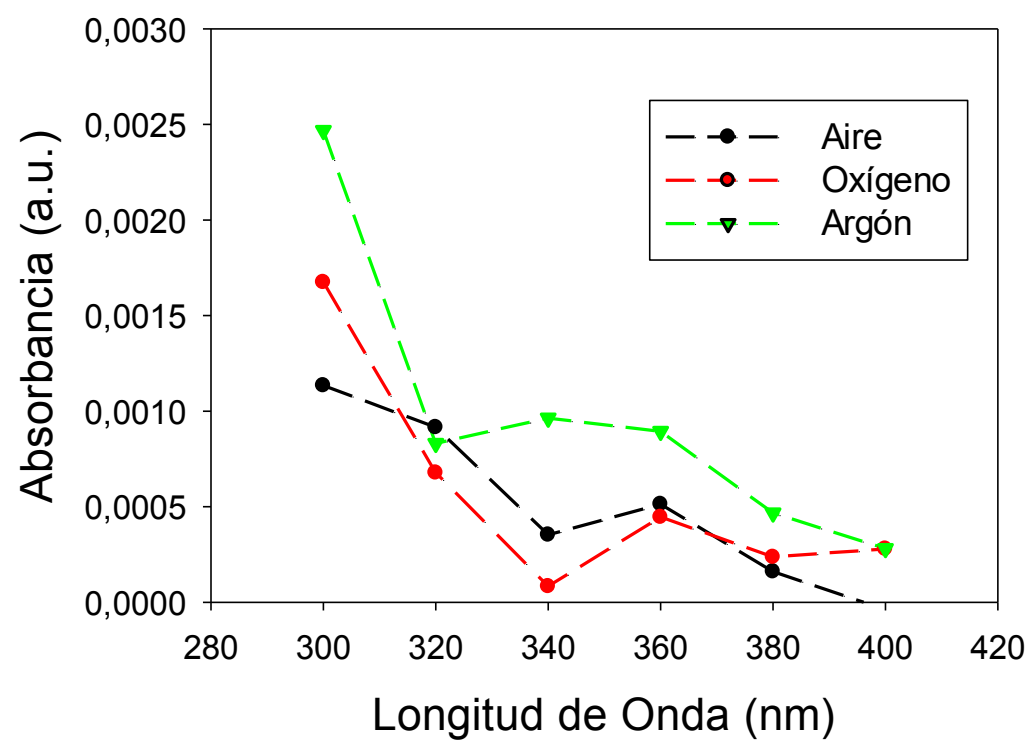

Fig. 3.18 - Espectros de absorción del transciente orgánico detectado en la región.

Analizando los decaimientos para las distintas condiciones mencionadas a $320 \mathrm{~nm}$, se concluyó que los mismos dependen de la concentración de oxígeno molecular presente en la solución. El ajuste mixto simula adecuadamente el decaimiento en atmosfera de Argón y de Aire (con constante de segundo orden $2 \mathrm{k} / \varepsilon(\mathrm{l})=1 \times 10^{6} \mathrm{~s}^{-1} \mathrm{M}^{-1}$ ) mientras que para la atmosfera saturada en Oxígeno se requirió el uso de una cinética de decaimiento de primer orden. Estos valores se muestran en la tabla 3.2 y con ellos se evidencia que esta especie reacciona con el Oxígeno molecular disuelto en solución.

\begin{tabular}{|c|c|}
\hline Atmosfera & $\mathbf{k}_{\mathbf{1}}\left[\mathbf{s}^{\mathbf{- 1}}\right]$ \\
\hline Argón & $(8.5 \pm 0.4) \times 10^{3}$ \\
\hline Aire & $(1.0 \pm 0.3) \times 10^{4}$ \\
\hline Oxígeno & $(1.1 \pm 0.3) \times 10^{4}$ \\
\hline
\end{tabular}

Tabla 3.2- Constantes de primer orden calculada para el decaimiento del transiente orgánico en diferentes atmosferas

Todos los ensayos anteriores y una búsqueda bibliográfica permiten plantear un mecanismo de degradación del Flusilasol con radicales oxidantes, el cual se muestra en la Figura 3.19. La reacción de transferencia de un electrón desde el Nitrógeno del grupo aminado hacia el radical $\mathrm{SO}_{4}^{--}$en este sistema es 
factible, dando lugar a la formación de un catión radical centrado en el $\mathrm{N}$ cabeza del anillo triazol. Además, se encuentra reportado que estos cationes radicales son capaces de eliminar átomos de $\mathrm{H}$ de la posición $\alpha$ del radical aminoalquil ya que son altamente estabilizados por los pares de electrones libres presentes en los nitrógenos vecinos. Esto lleva a la formación del $\alpha$-aminoalcaliradical $\left(-\mathrm{HC}{ }^{\bullet}-\right.$ $\mathrm{N}<$ ). Estos mismos radicales presentan un máximo de absorción entre (360 - 380) $\mathrm{nm}$ y reaccionan efectivamente con el Oxígeno molecular[28]-[31] tal cual se comprobó en este estudio. Además, son conocidos por sus propiedades reductoras [32] y son capaces de reducir el oxígeno molecular a radical superóxido $\mathrm{O}_{2} \cdot$ [33] formando así el radical resaltado con verde en la figura 3.19. A partir de ese último radical hay dos posibilidades de reacción:

1. El primer mecanismo propuesto involucra intermediarios de silicio pentacoordinados. Hay reportes de la obtención de estos debido a la adición de un anión a un silano-orgánico para producir un complejo aniónico de silicio pentacoordinado. Además, ha sido reportado que la hidrolisis de silicatos tetracoordinados mediante un ataque nucleofilico es a través de un intermadiario pentacoordinado siguiendo un mecanismo de reacción $\mathrm{SN}_{2}$ [34], [35]. A partir de este mecanismo se puede explicar la formación de los compuestos 1 y $2^{\prime}$ de la tabla 3.1 y enmarcados en cuadros azules y rojos en la parte inferior izquierda de la figura 3.19.

2. El segundo mecanismo considerado involucra una reacción entre dos de estos radicales dando formación a la cetona y al alcohol respectivo, los cuales a su vez pueden reaccionar con el radical $\mathrm{SO}_{4}-$ mediante transferencia de carga por el $\mathrm{N}$, dando lugar a la formación del ácido carboxílico llamado compuesto 2 en la tabla 3.1 o del aldehído previo a la oxidación del mismo ácido.

Inicialmente se descarta el ataque al anillo 4-FluoroBenceno debido a que ni los espectros de absorción ni los decaimientos se ajustan a los reportados para este tipo de reacciones[36]. El ataque del $\mathrm{SO}_{4}{ }^{-}$al Flusilasol no es mediante la extracción del $\mathrm{H}$ del grupo metilo. Lo anterior es posible concluirlo dado que la constante de reactividad media para este tipo de reacciones $\left(10^{5}-10^{7} \mathrm{M}^{-1} \mathrm{~s}^{-1}\right)$ que son menores que la constante de reactividad entre el Flusilasol y este el radical $\mathrm{SO}_{4}-[37]$.

Por último, los análisis de los CG-Masas para 20 minutos de reacción por vía fenton del Flusilasol conllevan a la formación de productos de mayor peso molecular al del fungicida evidenciado $a t_{R}>28$ minutos que pueden ser asignados a compuestos con grupos $\mathrm{Si}-\mathrm{O}-\mathrm{C}$ y $\mathrm{Si}-\mathrm{O}-\mathrm{Si}$. Por su parte los grupos $\mathrm{Si}-$ $\mathrm{O}-\mathrm{C}$ se pudieron explicar mediante el mecanismo que involucra la formación del compuesto de silicio pentacoordinado.

De estos estudios puede concluirse que los radicales oxidantes atacarán preferentemente el $\mathrm{N}$ cabeza del anillo triazol por transferencia de carga o bien abstraerán un $\mathrm{H}$ del $\mathrm{C} \alpha$ a este nitrógeno que resulta ser la parte más vulnerable de la molécula. A partir de este ataque pueden explicarse todos los productos de reacción detectados, aún para las reacciones implicadas en el proceso de tipo Fenton, tal como se plasmó en la Figura 3.19. 


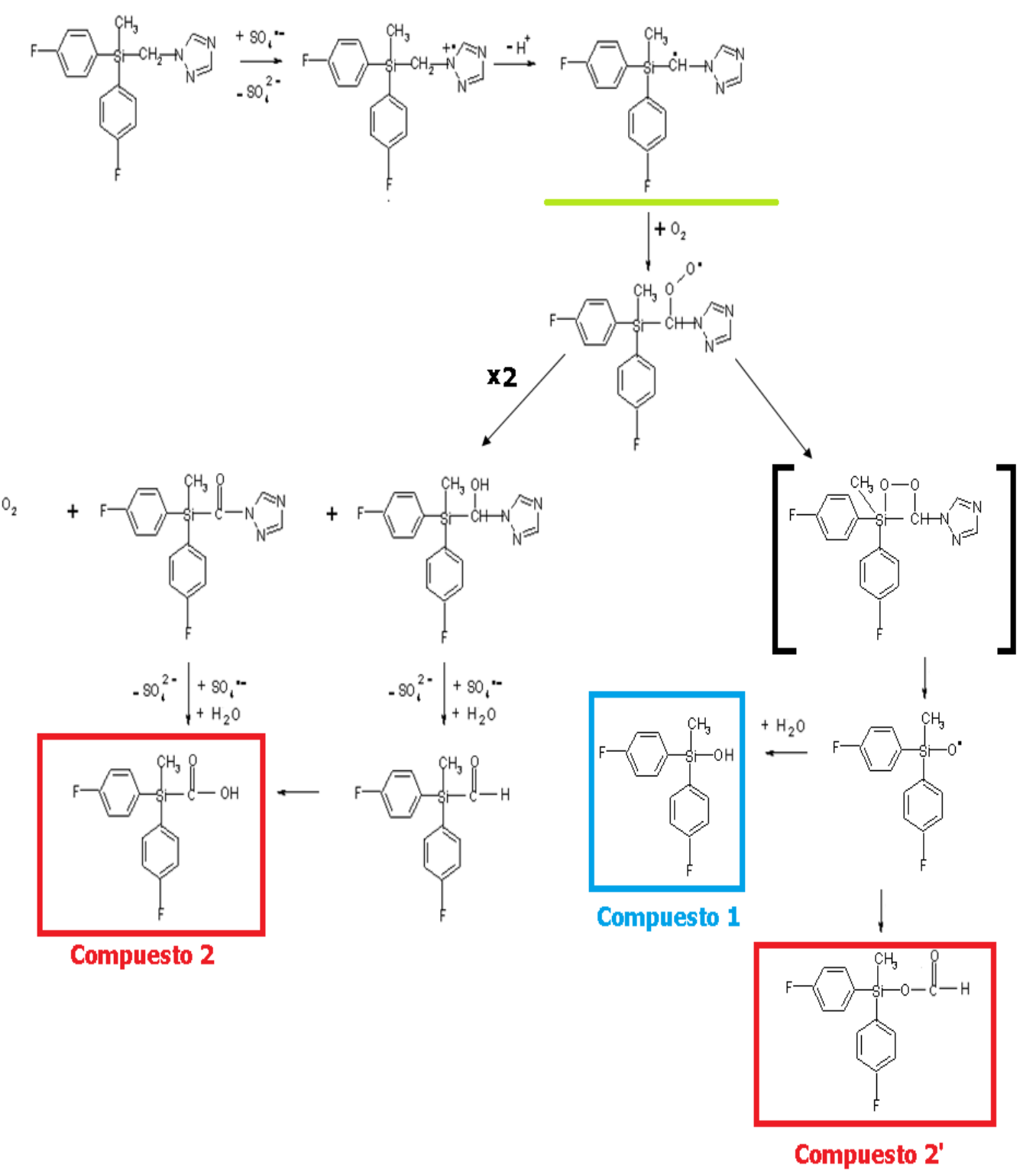

Fig. 3.19 - Mecanismo inicial de degradación del Flusilasol iniciado por especies reactivas Oxidantes. 


\subsection{Conclusiones.}

Se evidenció la gran fotoestabilidad de los SBO CVT 230 dado que en los ensayos realizados no hubo cambios significativos en el espectro de absorción UV/Vis y según estudios de otros grupos de investigación no hay cambios significativos en propiedades fisicoquímicas. De igual forma se apreció que estas sustancias tipo húmicas presentan un grado de humificación medio, son una mezcla 80:20 de un componente húmico y fúlvico.

El uso de los mismos como fotosensibilizadores en la degradación asistida de Pireno, Azul de Metileno y Flusilasol no arrojó resultados prometedores, pero sin embargo se pudo apreciar que estos interaccionan de forma débil con moléculas apolares tipo el pireno y de forma fuerte con compuestos cationicos como el azul de metileno.

Los SBO funcionan efectivamente como agentes favorecedores de la degradación por vía tipo Fenton a pH más neutro (5.0) del Flusilasol, sin embargo, su uso en las condiciones óptimas de $\mathrm{pH}$ típicas para estos procesos, (3.0) tiene un efecto adverso sobre la eficiencia de la degradación.

Los estudios del mecanismo de degradación de Flusilasol mediante su reacción con $\mathrm{SO}_{4}$-permitieron calcular la constante de reactividad entre el fungicida y esta especie reactiva $(4.6 \pm 0.4) \times 10^{8} \mathrm{M}^{-1} \mathrm{~S}^{-1}$. En estos mismos experimentos también fue posible diferenciar las vías iníciales de degradación, siguiendo una transferencia de carga desde el fungicida hacia el radical sulfato característica de las aminas terciarias, que mediante la eliminación de un $\mathrm{H}$ del $\mathrm{C}$ vecino al $\mathrm{N}$ de cabeza del grupo triazol lleva a la formación de un radical $\alpha-$ aminoalquilo. 


\subsection{Referencias bibliográficas.}

[1] W. E. Acree and M. H. Abraham, "Solubility predictions for crystalline polycyclic aromatic hydrocarbons (PAHs) dissolved in organic solvents based upon the Abraham general solvation model," Fluid Phase Equilib., vol. 201, no. 2, pp. 245258, 2002.

[2] J. S. Miller, "Determination of polycyclic aromatic hydrocarbons by spectrofluorimetry," Anal. Chim. Acta, vol. 388, no. 1-2, pp. 27-34, 1999.

[3] G. Basu Ray, I. Chakraborty, and S. P. Moulik, "Pyrene absorption can be a convenient method for probing critical micellar concentration $(\mathrm{cmc})$ and indexing micellar polarity," J. Colloid Interface Sci., vol. 294, no. 1, pp. 248-254, 2006.

[4] T. Tsukamoto and T. Hikida, "Absorption spectra of pyrene in bovine serum albumin and caffeine aqueous solutions," J. Photochem. Photobiol. A Chem., vol. 95, no. 3, pp. 271-273, 1996.

[5] M. Yan, B. Li, and X. Zhao, "Determination of critical aggregation concentration and aggregation number of acid-soluble collagen from walleye pollock (Theragra chalcogramma) skin using the fluorescence probe pyrene," Food Chem., vol. 122, no. 4, pp. 1333-1337, 2010.

[6] S. Pandey, R. A. Redden, A. E. Hendricks, K. A. Fletcher, and C. P. Palmer, "Characterization of the solvation environment provided by dilute aqueous solutions of novel siloxane polysoaps using the fluorescence probe pyrene," $J$. Colloid Interface Sci., vol. 262, no. 2, pp. 579-587, 2003.

[7] X. Yan, T. Ohno, K. Nishijima, R. Abe, and B. Ohtani, "Is methylene blue an appropriate substrate for a photocatalytic activity test? A study with visible-light responsive titania," Chem. Phys. Lett., vol. 429, no. 4-6, pp. 606-610, 2006.

[8] M. Antilén, K. Silva, S. Acevedo, F. Amiama, M. Faúndez, H. Knicker, and C. Pizarro, "Characterization of humic acids extracted from biosolid amended soils," J. Soil Sci. Plant Nutr., vol. 14, no. 4, pp. 1005-1020, 2014.

[9] N. FASUROVÁ and L. POSPÍŚILOVÁ, "Characterization of soil humic substances by ultraviolet-visible and synchronous fluorescence spectroscopy," J. Cent. Eur. Agric., vol. 11, no. 3, pp. 351-357, 2010.

[10] P. Aiken, G. R.;McKnight, D. M.;Wershaw, R. L.;MacCarthy, Ed., Humic substances in soil, sediment, and water: geochemistry, isolation and characterization. 1989.

[11] E. Tipping, S. Lofts, H. Hooper, B. Frey, D. Spurgeon, and C. Svendsen, "Critical Limits for $\mathrm{Hg}$ (II) in soils, derived from chronic toxicity data," Environ. Pollut., vol. 158, no. 7, pp. 2465-2471, 2010.

[12] P. Avetta, S. Berto, A. Bianco Prevot, M. Minella, E. Montoneri, D. Persico, D. Vione, M. C. Gonzalez, D. O. Mártire, L. Carlos, and A. Arques, "Photoinduced transformation of waste-derived soluble bio-based substances," Chem. Eng. J., vol. 274, pp. 247-255, 2015.

[13] J. Gomis, R. F. Vercher, A. M. Amat, D. O. Mártire, M. C. González, A. Bianco Prevot, E. Montoneri, A. Arques, and L. Carlos, "Application of soluble bio-organic substances (SBO) as photocatalysts for wastewater treatment: Sensitizing effect and photo-Fenton-like process," Catal. Today, vol. 209, pp. 176-180, 2013.

[14] J. Gomis, A. Bianco Prevot, E. Montoneri, M. C. González, A. M. Amat, D. O. Mártire, A. Arques, and L. Carlos, "Waste sourced bio-based substances for solardriven wastewater remediation: Photodegradation of emerging pollutants," Chem. Eng. J., vol. 235, pp. 236-243, 2014.

[15] K. W. Street and W. E. Acree, "Experimental Artifacts and Determination of Accurate Py Values," Analyst, vol. 111, no. October, pp. 1197-1201, 1986.

[16] G. Magnacca, A. Allera, E. Montoneri, L. Celi, D. E. Benito, L. G. Gagliardi, and L. Carlos, "Novel magnetite nanoparticles coated with waste sourced bio- based substances as sustainable and renewable adsorbing materials," ACS Sustain. Chem. Eng., vol. in press, 2014.

[17] F. Deganello, M. L. Tummino, C. Calabrese, M. L. Testa, P. Avetta, D. Fabbri, A. B. Prevot, E. Montoneri, and G. Magnacca, "A new, sustainable LaFeO 3 material 
prepared from biowaste-sourced soluble substances," New J. Chem., vol. 39, no. 2, pp. 877-885, 2015.

[18] P. Avetta, "Sensitizing effect of soluble bio-organic substances isolated from urban biomases on the photodegradation of organic pollutants," Università degli studi di torino, 2012.

[19] K. Bergmann and C. T. O'Konski, "a Spectroscopic Study of Methylene Blue Monomer, Dimer, and Complexes With Montmorillonite," J. Phys. Chem., vol. 67, no. 10, pp. 2169-2177, 1963.

[20] J. Gomis, L. Carlos, A. Bianco Prevot, A. C. S. C. Teixeira, M. Mora, A. M. Amat, R. Vicente, and A. Arques, "Bio-based substances from urban waste as auxiliaries for solar photo-Fenton treatment under mild conditions: Optimization of operational variables," Catal. Today, vol. 240, no. PA, pp. 39-45, 2015.

[21] Y. W. Kang and K. Y. Hwang, "Effects of reaction conditions on the oxidation efficiency in the Fenton process," Water Res., vol. 34, no. 10, pp. 2786-2790, 2000.

[22] E. Montoneri, V. Boffa, P. Savarino, D. Perrone, M. Ghezzo, C. Montoneri, and R. Mendichi, "Acid soluble bio-organic substances isolated from urban bio-waste. Chemical composition and properties of products," Waste Manag., vol. 31, no. 1, pp. 10-17, 2011.

[23] A. Machulek, J. E. F. Moraes, C. Vautier-Giongo, C. A. Silverio, L. C. Friedrich, C. A. O. Nascimento, M. C. Gonzalez, and F. H. Quina, "Abatement of the inhibitory effect of chloride anions on the photo-fenton process," Environ. Sci. Technol., vol. 41, no. 24, pp. 8459-8463, 2007.

[24] V. Nadtochenko and J. Kiwi, "Photoinduced mineralization of xylidine by the fenton reagent. 2. Implications of the precursors formed in the dark," Environ. Sci. Technol., vol. 32, no. 21, pp. 3282-3285, 1998.

[25] W. J. Mcelroy and S. J. Waygood, "Kinetics of the Reactions of the Radical SO4.with SO4-, S2O8-, H2O and Fe2+," vol. 86, no. 14, pp. 2557-2564, 1990.

[26] D. O. Mártire and M. C. Gonzalez, "Aqueous phase kinetic studies involving intermediates of environmental interest: Phosphate radicals and their reactions with substituted benzenes," Prog. React. Kinet. Mech., vol. 26, no. 2-3, pp. 201218, 2001.

[27] M. C. GONZALEZ, D. O. MARTIRE, and A. M. BRAUN, "Aqueous phase kinetic studies involving highly reactive species of environmental interest," Recent Res. Dev. Photochem. Photobiol., pp. 25-45.

[28] M. L. Dell 'Arciprete, L. Santos-Juanes, A. A. Sanz, R. Vicente, A. M. Amat, J. P. Furlong, D. O. Mártire, and M. C. Gonzalez, "Reactivity of hydroxyl radicals with neonicotinoid insecticides: mechanism and changes in toxicity," Photochem. Photobiol. Sci., vol. 8, no. 7, pp. 1016-1023, 2009.

[29] K. O. Hiller and K. D. Asmus, "Formation and reduction reactions of .alpha.-amino radicals derived from methionine and its derivatives in aqueous solutions," $\mathrm{J}$. Phys. Chem., vol. 87, no. 19, pp. 3682-3688, Sep. 1983.

[30] J. Lalevée, B. Graff, X. Allonas, and J. P. Fouassier, "Aminoalkyl radicals: direct observation and reactivity toward oxygen, 2,2,6,6-tetramethylpiperidine-N-oxyl, and methyl acrylate.," J. Phys. Chem. A, vol. 111, no. 30, pp. 6991-8, Aug. 2007.

[31] E. Baciocchi, T. Del Giacco, and A. Lapi, "Oxygenation of benzyldimethylamine by singlet oxygen. Products and mechanism.," Org. Lett., vol. 6, no. 25, pp. 4791-4, Dec. 2004.

[32] M. Gobl, B. Masloch, H. E. Edwards, B. J. Parsons, B. Masloch, M. Gobl, R. Braams, M. Bonifaeie, H. Mockel, and D. Bahnemann, "Formation and Reduction Reactions of a-Amino Radicals Derived from Methionine and Its Derivatives in Aqueous Solutions," vol. 201, no. 7, pp. 3682-3688, 1983.

[33] M. G. Gonzalez, E. Oliveros, M. Wörner, and A. M. Braun, "Vacuum-ultraviolet photolysis of aqueous reaction systems," J. Photochem. Photobiol. C Photochem. Rev., vol. 5, no. 3, pp. 225-246, 2004. 
[34] and Q. W. R. J. P. Corriu, C. Guerin, G. J. L. Henner and S. M. Available, "Pentacoordinate Intermediates in the Hydrolysis Reaction of Organic Silicates," no. 4, pp. 3200-3205, 1991.

[35] Q. Kong, X. Zhang, Y. Quan, and Q. Chen, "Synthesis of 4-vinyl benzyl tetracoordinate silicate monomer," Polym. Bull., vol. 59, no. 2, pp. 235-242, 2007.

[36] J. A. Rosso, P. Caregnato, V. C. Mora, M. C. Gonzalez, and D. O. Mártire, "Reactions of phosphate radicals with monosubstituted benzenes. A mechanistic investigation," Helv. Chim. Acta, vol. 86, no. 7, pp. 2509-2524, 2003.

[37] P. Neta, J. Grodkowski, and A. B. Ross, "Rate Constants for Reactions of Aliphatic Carbon-Centered Radicals in Aqueous Solution," J. Phys. Chem. Ref. Data, vol. 25, no. 3, p. 709, 1996. 


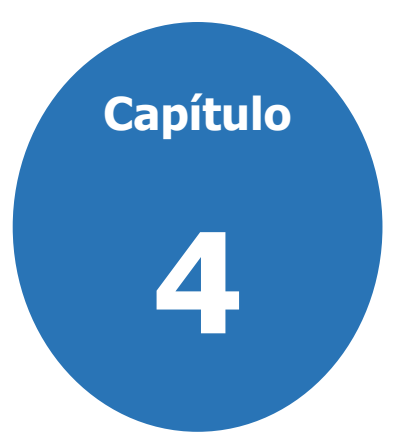

\section{Uso de los SBO como plantilla de síntesis de nanocompositos de Hidroxiapatita/Óxidos de Hierro - Estudio de las propiedades mejoradas de estos nanomateriales para la adsorción de $\mathrm{Cu}^{+2}$ y $\mathrm{Pb}^{+2}$ en sistemas \\ acuosos.}

La remediación ambiental de cuerpos de agua contaminados con metales pesados ha sido ampliamente estudiada debido, entre otros aspectos, a la toxicidad y bioacumulación de los mismos. La obtención de nuevos materiales capaces de adsorber metales es de gran importancia tecnológica, así como también la comprensión del comportamiento del sistema adsorbente - metal que permita establecer las condiciones necesarias en el diseño de absorbentes optimizados para aplicaciones ambientales. El principal componente del tejido óseo de los vertebrados, la hidroxiapatita, $\mathrm{Ca}_{10}\left(\mathrm{PO}_{4}\right)_{6}(\mathrm{OH})_{2}$, es uno de los materiales adsorbentes de metales más prometedores debido a su alta biocompatibilidad, estabilidad y su capacidad de adsorción en el rango de pH 6 7. Apatitas (Ap) de diferente naturaleza y origen observan variaciones en la capacidad de adsorción, lo que denota la posibilidad de optimizar este material.

Los humatos, sales análogas de las sustancias húmicas, son utilizados ampliamente en la remediación de suelos y aguas contaminadas con metales pesados. Su formación está basada en la habilidad de enlazar cationes a los grupos carboxílicos e hidróxidos de ácidos húmicos y/o fúlvicos. En ese sentido el $\mathrm{Ca}^{2+}$ es especialmente efectivo en la precipitación de humatos y provee una ruta para la transferencia de los metales contaminantes desde solución a fase sólida.

Por su lado, los nanomateriales han adquirido gran interés en las últimas décadas debido a su gran relación área superficial/volumen que podría aumentar las capacidades adsorbentes referentes a sus análogos macroscópicos. En particular, destacan los nanomateriales magnéticos por ser fáciles de remover de suspensiones acuosas mediante la aplicación de un campo magnético.

Por lo antes dicho, resulta de interés el desarrollo de nanocompositos magnéticos basados en la hidroxiapatita/óxidos de hierro como sustratos para la adsorción de metales. En el presente trabajo se desarrollarán estos nanomateriales y se evaluará el efecto del uso de los SBO como plantillas en los 
procesos de síntesis, sobre sus propiedades morfológicas y capacidad adsorbente de metales.

Además, se plantea estudiar la eficiencia del proceso de adsorción de $\mathrm{Cu}^{+2}$ y $\mathrm{Pb}^{+2}$ en sistemas mono y bi-componentes, para elucidar el mecanismo de adsorción de estos sobre las diferentes partículas y tratar de evidenciar en que afectan las diferentes condiciones de síntesis.

\subsection{Materiales y métodos.}

\subsubsection{Síntesis de las nanopartículas.}

Para la obtención de las nanopartículas de hidroxiapatita (n-HAp) dopadas con óxidos de Hierro con recubrimiento orgánico provisto por los SBO, se hizo una adaptación de varios métodos publicados [1]-[5]para la síntesis de hidroxiapatita con el objetivo de obtener un único sólido híbrido estable y con propiedades magnéticas. Para la obtención de las $n-H A p$ se empleó el método de coprecipitación en el cual se prepara una suspensión de $5,5 \mathrm{~g} \mathrm{Ca}(\mathrm{OH})_{2}$ en $40 \mathrm{~mL}$ de $\mathrm{H}_{2} \mathrm{O}$ sometida a agitación magnética de $400 \mathrm{rpm}$ y a una temperatura de $80^{\circ} \mathrm{C}$. La solución de $\mathrm{H}_{3} \mathrm{PO}_{4}\left(4,44 \mathrm{~g}\right.$ en $60 \mathrm{~mL}$ de $\left.\mathrm{H}_{2} \mathrm{O}\right)$ se agrega por goteo con una velocidad aproximada de $0,5 \mathrm{~mL} / \mathrm{min}$ a la suspensión de $\mathrm{Ca}(\mathrm{OH})_{2}$. Una vez finalizado el mezclado, la suspensión resultante se mantiene bajo calentamiento y agitación durante un periodo de 2 horas. Posterior a ello, la suspensión se centrifuga y se filtra $(Q=0,22 \mu \mathrm{m})$. El sólido blanco obtenido se lava varias veces con Agua Milli-Q y se seca a $80^{\circ} \mathrm{C}$ durante un periodo de 12 horas.

Para la síntesis de las Nanopartículas de Hidroxiapatita magnética dopadas con óxidos de Hierro $(F e-n A p)$ se modificó brevemente el método anterior.Sedisuelven $1,27 \mathrm{~g} \mathrm{FeCl}_{2} \cdot 3 \mathrm{H}_{2} \mathrm{O}$ y $1,79 \mathrm{~g} \mathrm{FeCl}_{3} \cdot 6 \mathrm{H}_{2} \mathrm{O}$ en la solución ácida previo al mezclado. El procedimiento siguiente es exactamente el mismo. Se utilizó la relación molar $\mathrm{Fe}_{\text {total }} / \mathrm{Ca} \approx 0,2$ ya que se observó que para esta relación se maximiza el comportamiento magnético del material[6]. Además la relación molar Fe(II):Fe(III) fue 1:1 debido a que esta es la relación optima, bajo las condiciones de síntesis, para la obtención de magnetita $\mathrm{Fe}_{3} \mathrm{O}_{4}$ que es el óxido de Hierro con mayor respuesta magnética. El sólido Fe-nAp obtenido es de color marrón y presenta respuesta magnética.

Para la obtención de las Nanopartículas de Hidroxiapatita dopada con óxidos de Hierro y recubierta con SBO, se modificó el método de síntesis de FenAp solubilizando diferentes cantidades de SBO en la suspensión de $\mathrm{Ca}(\mathrm{OH})_{2}(20$, 100 o $1000 \mathrm{mg}$ ) y manteniendo constante los demás parámetros de síntesis. El sólido resultanteselava con Agua Milli-Q hasta que no se evidenció presencia de SBO restante en el agua lavado mediante espectroscopia Uv/Vis y TOC. Los sólidos obtenidos fueron nombrados como 0,05SBO-Fe-nAp, 0,5SBO-Fe-nAp y $2,5 S B O-F e-n A p$ de acuerdo con la relación $\mathrm{SBO} / \mathrm{Ca}$ utilizado en la síntesis. Para elucidar el efecto de la capa orgánica que proveen los SBO en la adsorción de $\mathrm{Cu}^{+2}$ y $\mathrm{Pb}^{+2}$ se calcinó a $600^{\circ} \mathrm{C}$ una fracción del sólido 2,5SBO-Fe- $n A p$ denominada 2,5SBO-Fe-nAp-Calc. Todos los sólidos obtenidos excepto el2,5SBO$F e-n A p-C a l c$ son de color marrón más intenso que el referente a la Fe-nAp. 


\subsubsection{Ensayos de adsorción de $\mathrm{Cu}^{+2}$ y $\mathbf{P b}^{+2}$ sobre las nanopartículas en solución acuosa.}

Ensayos de adsorción de un solo metal: Todos los experimentos de adsorción fueron llevados a cabo en sistemas Batch a $(25 \pm 2){ }^{\circ} \mathrm{C}, \mathrm{pH} 7,0 \mathrm{con}$ buffer de HEPES-Na y una fuerza iónica de 0,01M. Alícuotas de diferentes volúmenes de soluciones patrón de $1000,0 \mathrm{mg} \mathrm{L}^{-1}$ de $\mathrm{Cu}\left(\mathrm{NO}_{3}\right)_{2} \circ \mathrm{Pb}\left(\mathrm{NO}_{3}\right)_{2}$ fueron mezclados con $5 \mathrm{~mL}$ de suspensiones de $100 \mathrm{mg} \mathrm{L}^{-1}$ de alguna de las partículas: $n A p$, Fe-nAp, 0.05SBO-Fe-nAp, 0.5SBO-Fe-nAp, 2.5SBO-Fe-nAp o 2.5SBO-Fe$n A p$-calc. Las suspensiones resultantes fueron diluidas hasta un volumen final de $25 \mathrm{~mL}$ con una solución de HEPES-Na con las características antes mencionadas. Las concentraciones más altas de $\mathrm{Cu}^{+2}$ y $\mathrm{Pb}^{+2}$ utilizadas fueron delimitadas por la solubilidad de estos iones en las condiciones de trabajo [7]-[9]. Las suspensiones se mezclaron usando un agitador de placas paralela giratorias. Luego de dos horas, en que se alcanza el equilibrio, la suspensión se centrifuga a $4000 \mathrm{rpm}$ durante 10 minutos y se separa el sobrenadante del precipitado. Se ajustó el pH del sobrenadante hasta aproximadamente 1,0 con la adición de $\mathrm{HNO}_{3}$ concentrado para evitar la dilución de la solución. La concentración de $\mathrm{Cu}^{+2}$ $0 \mathrm{~Pb}^{+2}$ remanente en el sobrenadante se mide mediante ICP-AES.

Ensayos de adsorción simultánea de $\mathbf{C u}^{+2}$ y $\mathbf{P b}^{+2}$ : Los ensayos de adsorción bi-metálica corresponden a la determinación de la isoterma de $\mathrm{Pb}^{+2}$ en presencia de una concentración inicial de 6,4 ppm de $\mathrm{Cu}^{+2}[7]-[9]$. Los métodos de preparación y métodos de cálculo de la cantidad de metal adsorbido son exactamente los mismos que los mencionados para ensayos de un solo metal.

Caracterización de nanopartículas con $\mathbf{P b}^{+2}$ adsorbido: Con el objetivo de elucidar el mecanismo de adsorción de este metal sobre las partículas se buscó aislar el sólido luego del proceso de adsorción. Para ello y debido a limitaciones intrínsecas del sistema de estudio se hizo un escalado (hasta $4 \mathrm{~L}$ ) del proceso con el fin de obtener mayor cantidad de sólido para su posterior estudio.

Ensayos de desorción de $\mathbf{P b}^{\mathbf{+ 2}}$ : Las condiciones experimentales para los ensayos de desorción fueron exactamente las mismas del proceso de adsorción, es decir en sistemas Batch a $(25 \pm 2){ }^{\circ} \mathrm{C}, \mathrm{pH} 7,0$ con buffer de HEPES-Na y una fuerza iónica de 0,01M. Para llevar a cabo estos experimentos se filtró una suspensión de nanopartículas luego de haber alcanzado el equilibrio del proceso de adsorción.El papel de filtro con las partículas fue sumergido en 25 $\mathrm{mL}$ de agua y sometido a sonicación durante 30 minutos. La suspensión resultante se sometió por más de 12 horas a agitación bajo las mismas condiciones que el proceso de adsorción.

Determinación de concentración de metales en solución: Se utilizó un Espectrofotómetro (ICP-AES) de emisión atómica con plasma inductivamente acoplado Perkin Elmer Optima Modelo 7000 D acoplado a un monocromador con una cámara de inyección ciclónica de espray y un nebulizador PTFE Mira Mist. Las condiciones experimentales son las siguientes: Potencia del plasma de $1,3 \mathrm{~kW}$; con una velocidad de aspiración de la muestra de $1,2 \mathrm{~mL} / \mathrm{min}$. El equipo fue refrigerado con un flujo de Ar de $1,5 \mathrm{~L} / \mathrm{min}$ y un flujo de inyección de argón de $0,6 \mathrm{~L} / \mathrm{min}$. 


\subsection{Resultados y análisis.}

\subsubsection{Caracterización de las nanopartículas.}

Todas las nanopartículas sintetizadas fueron caracterizadas con el fin de elucidar el efecto de la introducción del Fe y de los SBO sobre la matriz de hidroxiapatita. Los espectros IR de los sólidos obtenidos y de los SBO se muestran en la figura 4.1. Además, los picos característicos y los grupos funcionales identificados se muestran en la tabla 4.1.

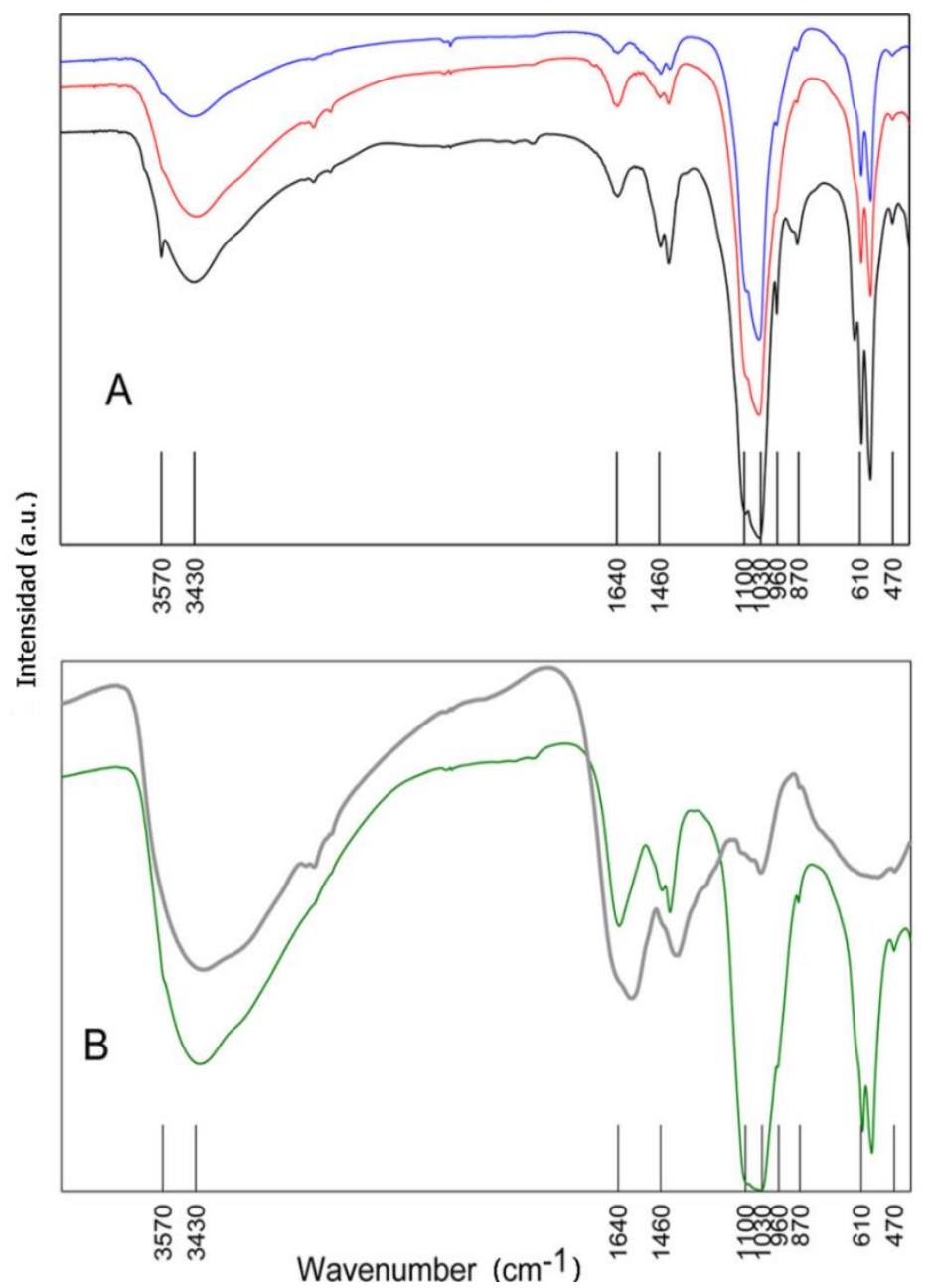

Fig. 4.1 - Espectros FTIR de las muestras (de abajo hacia arriba): (A) nAp, Fe-nAp y 2,5SBO-Fe-nAp-calc. (B) $S B O$ y 2,5SBO-Fe-nAp.

El espectro obtenido para la n-HAp muestra los modos vibracionales fundamentales para los grupos $\mathrm{PO}_{4}$ de estructuras de apatita alrededor de 470, $560,610,960$, y $1030-1100 \mathrm{~cm}^{-1}[10]$, [11]. Por otro lado, las bandas ubicadas a 870 y $1460 \mathrm{~cm}^{-1}$ evidencian la formación de carbonato residual atrapado en la red cristalina de la apatita, esto puede ser debido a que el pH inicial de la suspensión de $\mathrm{Ca}(\mathrm{OH})_{2}$ era aproximadamente 13 y bajo estas condiciones el $\mathrm{CO}_{2}$ atmosférico puede disolverse en el agua dando formación de carbonatos[12]. 


\begin{tabular}{|c|c|}
\hline $\begin{array}{c}\text { Grupo } \\
\text { Funcional }\end{array}$ & $\begin{array}{c}\text { Wave } \\
\text { Number } \\
\left(\mathbf{c m}^{-1}\right)\end{array}$ \\
\hline & 470 \\
& 560 \\
$\mathbf{P O}_{\mathbf{4}}$ & 610 \\
& 960 \\
& $1030-1100$ \\
\hline $\mathbf{C O}_{\mathbf{3}}$ & 870 \\
& 1460 \\
\hline & 632 \\
\hline $\mathbf{O H}$ & 1640 \\
& 3430 \\
& 3572 \\
\hline $\mathbf{F e O}$ & 400 \\
\hline $\mathbf{C - O H}$ & 600 \\
\hline $\mathbf{C =}$ & 16430 \\
\hline
\end{tabular}

Las bandas en la región 1640 y 3430 $\mathrm{cm}^{-1}$ corresponden a las bandas $\delta \mathrm{HOH}$ y $\mathrm{OH}$ debido a moléculas de agua en la red cristalina fisisorbidas sobre la superficie, mientras que las bandas a 632 y $3572 \mathrm{~cm}^{-1}$ corresponden a grupos $\mathrm{OH}$ pertenecientes a una apatita con alto grado de cristalinidad.

La Fe-nAp presenta los mismos picos de la nHAp salvo los picos a 632 y $3572 \mathrm{~cm}^{-1}$ indicando una disminución en la cristalinidad de la fase de hidroxiapatita debida a la introducción del Hierro en el sistema. Este método no es concluyente respecto a la fase óxidos de Hierro debido a que las señales de estos en la región de $600-400 \mathrm{~cm}^{-1}$ [13] pueden estar ocluidos por los de la n-HAp debido a la baja relación $\mathrm{Fe} / \mathrm{Ca}$ utilizado en la síntesis.

Tabla 4.1 - Bandas vibracionales de los grupos Funcionales para estructuras de apatita y de fracciones residuales típicas.

En el espectro de la muestra 2.5SBO-Fen-Ap se pueden apreciar las señales de los grupos funcionales de la nAp sobrepuestos con aquellos pertenecientes a los SBO. Las bandas ubicadas a 3430 y $1649 \mathrm{~cm}^{-1}$ indican la presencia de grupos $\mathrm{OH}$ de grupos fenoles, alcoholes y carboxílicos y de grupos $\mathrm{C}=\mathrm{O}$ para fracciones carboxílicas y carbonílicas, respectivamente. El espectro correspondiente a la 2.5SBO-FenAp-cal no presenta las señales asignadas a los grupos funcionales aportados por el SBO y las señales que se observan corresponden totalmente a aquellos de la Fe-nAp, indicando que la calcinación elimina completamente el SBO.

Los patrones de difracción de los materiales se muestran en la figura 4.2. En la misma se puede apreciar que todas las muestras poseen los picos característicos de la fase de apatita [5], [6], [14] denotados como líneas negras continuas. El pico $2 \theta=31.8$ es el pico más intenso de la hidroxiapatita y se mantiene así para todos los demás materiales. Luego de la introducción de $\mathrm{Fe}^{+2} / \mathrm{Fe}^{+3}$ hay un aumento en la señal del pico $2 \theta=35.5$ correspondiente a las fases de magnetita/maghemita (denotado con líneas celeste y rosada en la figura), sin embargo, no hay desaparición de ningún pico importante de la fase de hidroxiapatita. Lo anterior permite concluir que la fase de hidroxiapatita está presente en todos los sólidos obtenidos y que la introducción de $\mathrm{Fe}^{+2} / \mathrm{Fe}^{+3}$ no modificó la celda básica cristalina de la misma, pero si agrega una fase de magnetita/maghemita al sistema. 


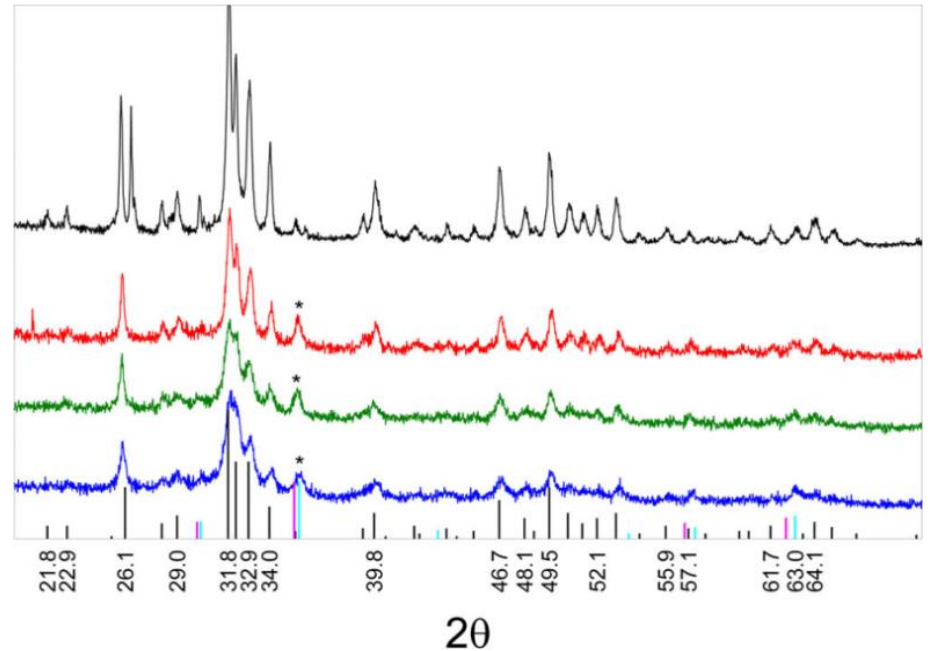

Figura 4.2 - Difractogramas de Rayos X de cada muestra (de arriba hacia abajo): nAp, Fe-nAp,2.5SBO-Fe-nAp, and 2.5SBO-Fe-nAp-cal. Picos típicos de patrones de Hydroxiapatita (negro) y magnetita/hematita (azul/rosa). $E I *$ indica el pico $2 \theta=35.5^{\circ}$.

De igual forma, debido a la reducción de la definición de la estructura de los picos respecto a la nAp con un máximo en $2 \theta=31,8^{\circ}$, se evidencia que las demás muestras presentan una reducción de la cristalinidad importante tanto por la introducción de la fase de Hierro y como por la presencia de los SBO, resultado que concuerda con la desaparición de los picos de 632 y $3572 \mathrm{~cm}^{-1}$ en el IR de la nAp en las demás muestras. Es posible también que las muestras con hierro presentan un pico más intenso en $2 \theta=35,5^{\circ}$ como otros picos de menor intensidad en $2 \theta=30,2^{\circ}$ y $62,5^{\circ}$ que son característicos de estructuras de magnetita y hematita. Sin embargo esta técnica no permite distinguir entre estas dos fases[5], [6], [14].

Los resultados de los TGA se muestran en la figura 4.3. La muestra nAp presenta una pérdida de peso de aproximadamente $5,9 \%$ atribuido a la desorción de moléculas de agua $\left(T \leq 100^{\circ} \mathrm{C}\right)$, deshidratación de hidróxidos $(380-500)^{\circ} \mathrm{C}$ y eliminación de grupos carbonatos superficiales (500 $800)^{\circ} \mathrm{C}[15]$.

La curva de TGA correspondiente a la muestra Fe-nAp presenta una pérdida de peso de aproximadamente $8 \%$ atribuidos a moléculas de aguas adsorbidas, deshidratación de hidróxidos de hierro $(380-500)^{\circ} \mathrm{C}$ y eliminación de grupos carbonatos. Por su lado la muestra 2,5SBO-Fe-nAp presenta una pérdida de masa total de $14 \%$ indicando la presencia de una cantidad apreciable de SBO remanente mientras que la muestra 2,5SBO-Fe-nAp-calc solo presenta una pérdida de $4 \%$. Estos últimos resultados están en total concordancia con los obtenidos mediante IR, puesto que para la 2,5 SBO-Fe-nAp se evidencia la presencia de grupos orgánicos en la partícula mientras que para 2,5 SBO-Fe-nApcalc se aprecia la ausencia total de los mismos. Una primera aproximación de la cantidad de materia orgánica presente en las muestras se puede obtener considerando la perdida de materia en el rango de $(200-380)^{\circ} \mathrm{C}$ bajo atmosfera de $\mathrm{O}_{2}$. Aproximadamente $5 \%$ del peso de la muestra 2,5SBO-Fe-nAp es referido a los SBO. 


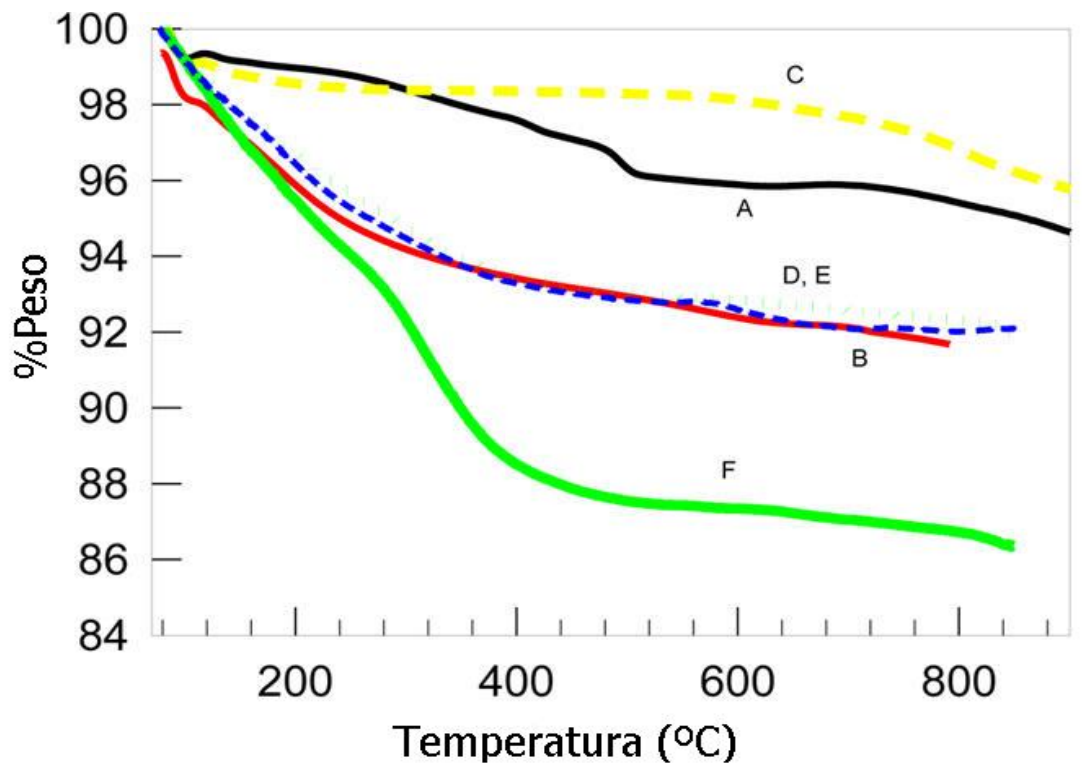

Fig. 4.3 -TGA en atmosfera de $N_{2}$, Curvas (A) nAp, (B) Fe-nApy (C) 2.5SBO-Fe-nAp-cal. TGA en atmosfera de $\mathrm{O}_{2}$, curvas (D) 0.05SBO-Fe-nAp, (E) 0.5SBO-Fe-nAp y (F) 2.5SBO-Fe-nAp.

La figura 4.4 muestra las imágenes TEM comparativas de las muestras más representativas. Se observa la formación de sólidos en la escala nanométrica con una aglomeración importante por lo que no fue posible un estudio de distribución de tamaño. La imagen correspondiente a la nAp presenta forma cilíndrica de aproximadamente (100-150) nm. La imagen HRTEM correspondiente en la figura 4.5 muestra una alta cristalinidad, ya que es posible la apreciación de los patrones de interferencia de los planos cristalinos referentes al plano ubicado a $2 \theta=31,8^{\circ}[4]$.

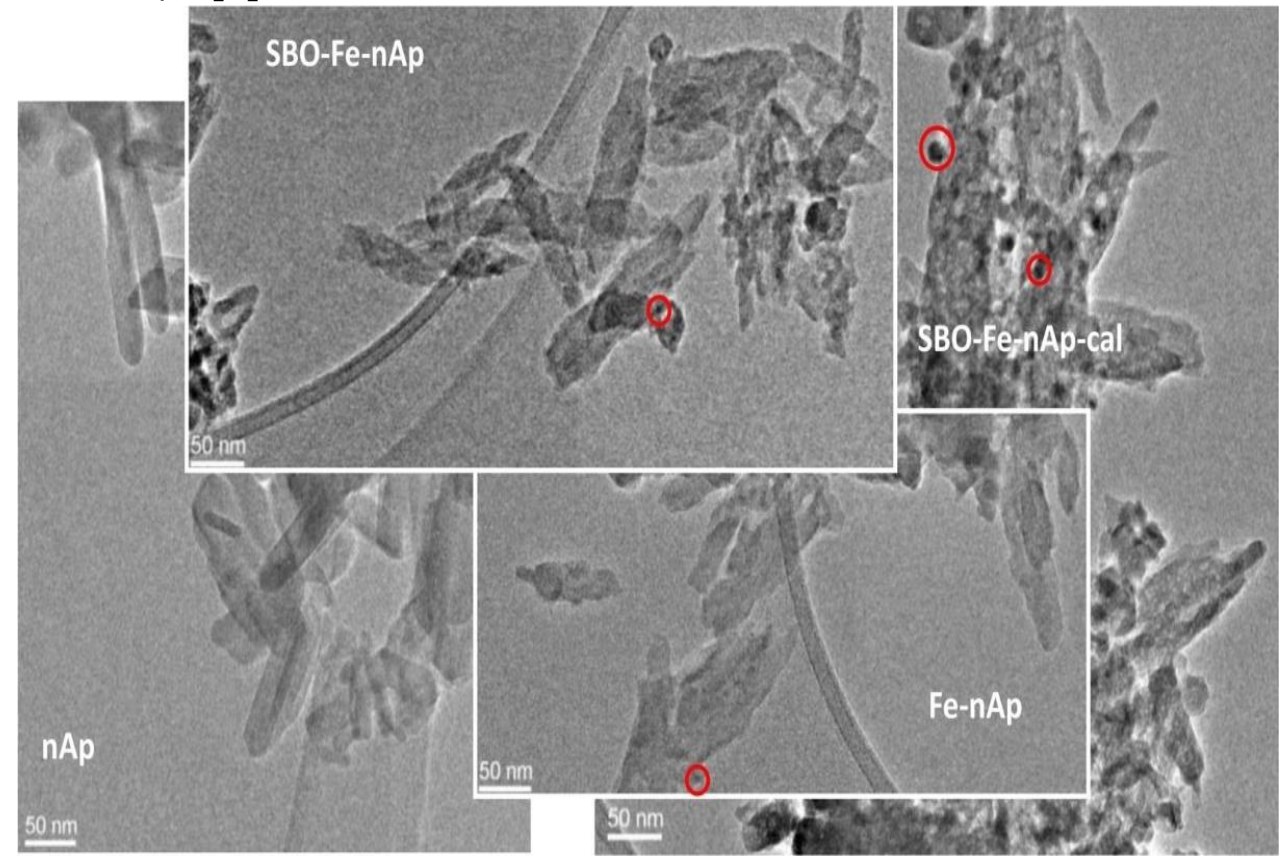

Fig. 4.4 - Imágenes HRTEM. Los círculos rojos muestran dominios de Fe. 


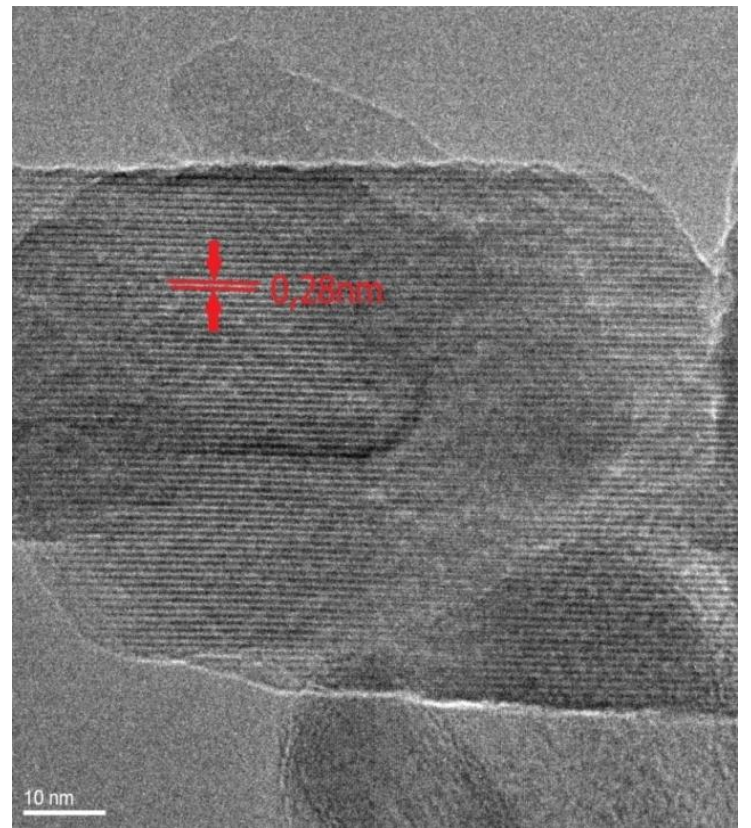

Fig. 4.5 - Imagen HRTEM de la muestra nAp.

De lo que se observa en la imagen TEM correspondiente, las partículas de Fe-nAp presentan una forma más irregular con menor tamaño $(50$ - 100) nm, en concordancia con reportes en la literatura donde se concluye que la morfología de hidroxiapatita nanocristalina se ve elongada y la cristalinidad disminuida por la introducción de iones de $\mathrm{Fe}^{+3}[16]$, [17].

La introducción de 2,5SBO/Ca w/w como plantilla de síntesis en las partículas conlleva a la obtención de partículas de morfología aún más irregular que las anteriores, mientras que el proceso de calcinación a $600^{\circ} \mathrm{C}$ genera un aumento de la heterogeneidad de los tamaños de partícula. Para todas las muestras con $\mathrm{Fe}$, se puede observar la presencia de pequeños depósitos con mayor densidad óptica, que pueden ser atribuidos a dominios nanométricos con tamaño menor a 10nmconteniendo Hierro [16]. Estas pequeñas fracciones podrían ser asignadas a depósitos de óxidos de Hierro que se encuentran distribuidas homogéneamente en el volumen de todas las partículas.

Las medidas de DLS permitieron analizar el tamaño de los aglomerados de las partículas que se forman cuando están suspendidas en agua. Para poder comparar estos resultados con los adquiridos en la adsorción de metales, los ensayos se realizaron en las mismas condiciones (concentración de partículas 20ppm, 0,01M concentración salina con HEPES-Na y pH 7,0). Se evidenció entonces que el diámetro hidrodinámico de las partículas es mucho mayor que el tamaño observado por HRTEM, indicando así una importante aglomeración de las mismas bajo estas condiciones experimentales. Estos resultados se muestran en la figura 4.6.

Se aprecia en esta figura que tanto la introducción del Fe como de SBO modifica el tamaño de los aglomerados que forman estas partículas en suspensión acuosa. La introducción del Fe disminuye el tamaño de los aglomerados respecto al de la Hidroxiapatita pura. Luego de ello la introducción de los SBO sobre la matriz Fe-nAp disminuye aún más este mismo parámetro. 


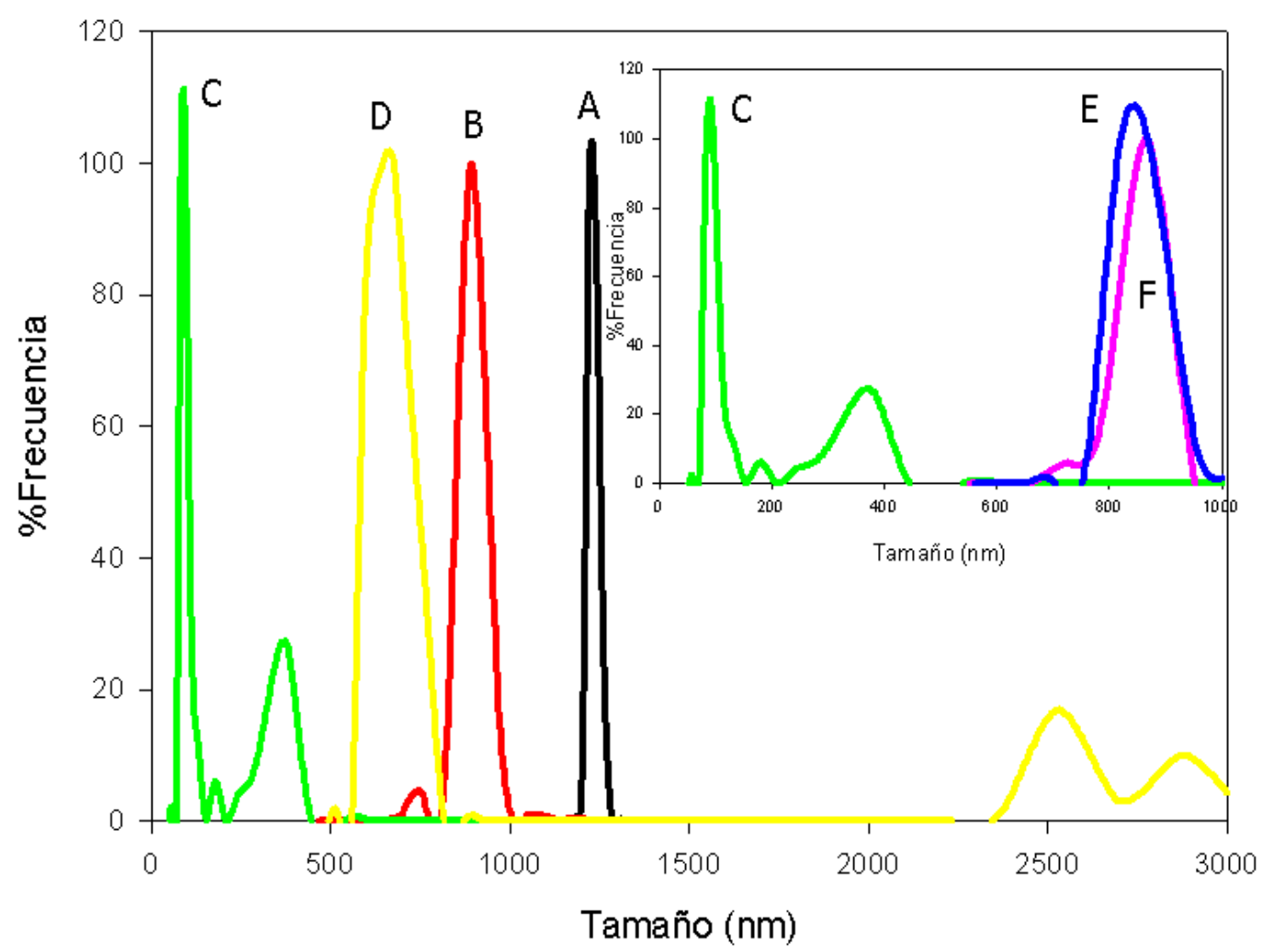

Fig. 4.6 - Distribución del tamaño hidrodinámico de partícula obtenido mediante DLS. (A)nAp,

(B) Fe-nAp, (C) 2,5SBO-Fe-nAp, (D) 2,5SBO-Fe-nAp-calc, (inset, E) 0.5SBO-Fe-nAp, y (inset, F) 0.05SBOFe-nAp.

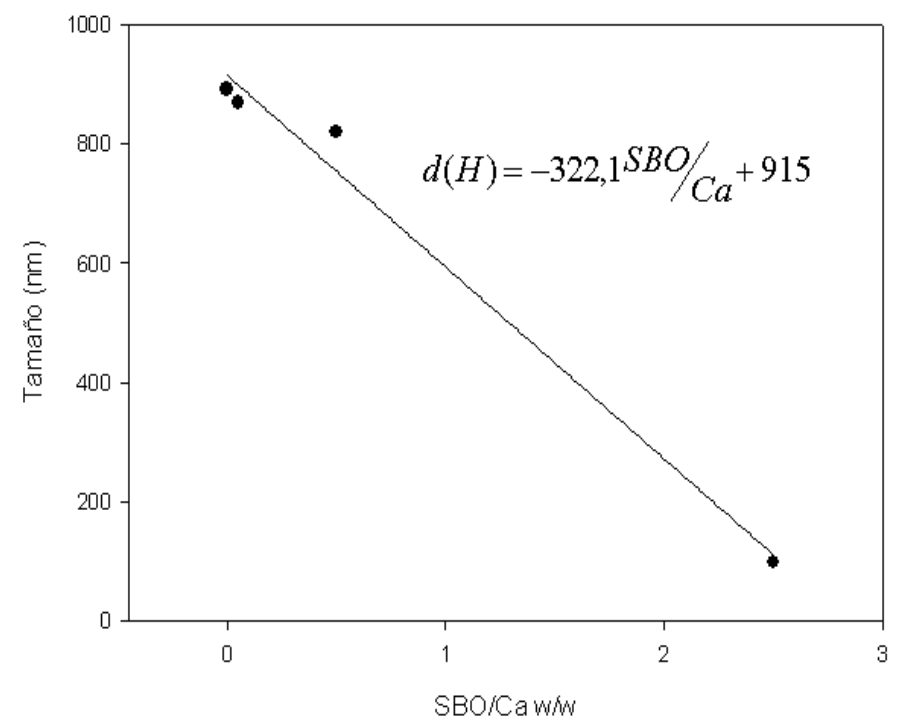

También es posible evidenciar que la cantidad de SBO usado durante la síntesis de las partículas influencia fuertemente en el tamaño delaglomerado que forman las partículas (curvas C, E y F). Sorprende la relación lineal observada entre la relación $\quad \mathrm{SBO} / \mathrm{Ca}$ utilizado en la síntesis y el diámetro hidrodinámico medido por DLS (fig 4.6).

Fig. 4.7 - Correlación experimental entre el Diámetro Hidrodinámico de los agregados de partículas y la relación $S B O / C a$ utilizado en la síntesis.

Sin embargo, luego de la calcinación de los SBO, las nanopartículas 2,5SBO-Fe-nAp-calc muestran un aumento significativo del tamaño de los aglomerados que forman. Estos resultados se discutirán en conjunto con los obtenidos por ensayos de XPS y movilidad electroforética más adelante. 
Los espectros XPS de las partículas más significativas se muestran en la figura 4.8. Se pueden apreciar las señales características para los átomos de $\mathrm{Ca}$, $\mathrm{O}$, P y Fe (excepto para la nAp). El pico de "carbono espurio" C(1s) fue utilizado como calibración interna para corregir los efectos de carga ubicándolo en $284,6 \mathrm{eV}$. Aun así, para las muestras con SBO se evidenció la presencia de carbonos tipo Carbonatos. Todas las muestras presentan las señales para Ca2p1/2 (350,8eV), Ca2p3/2 (347,4eV) y P2s (191eV) debido a los fosfatos de calcio en la estructura de la apatita.

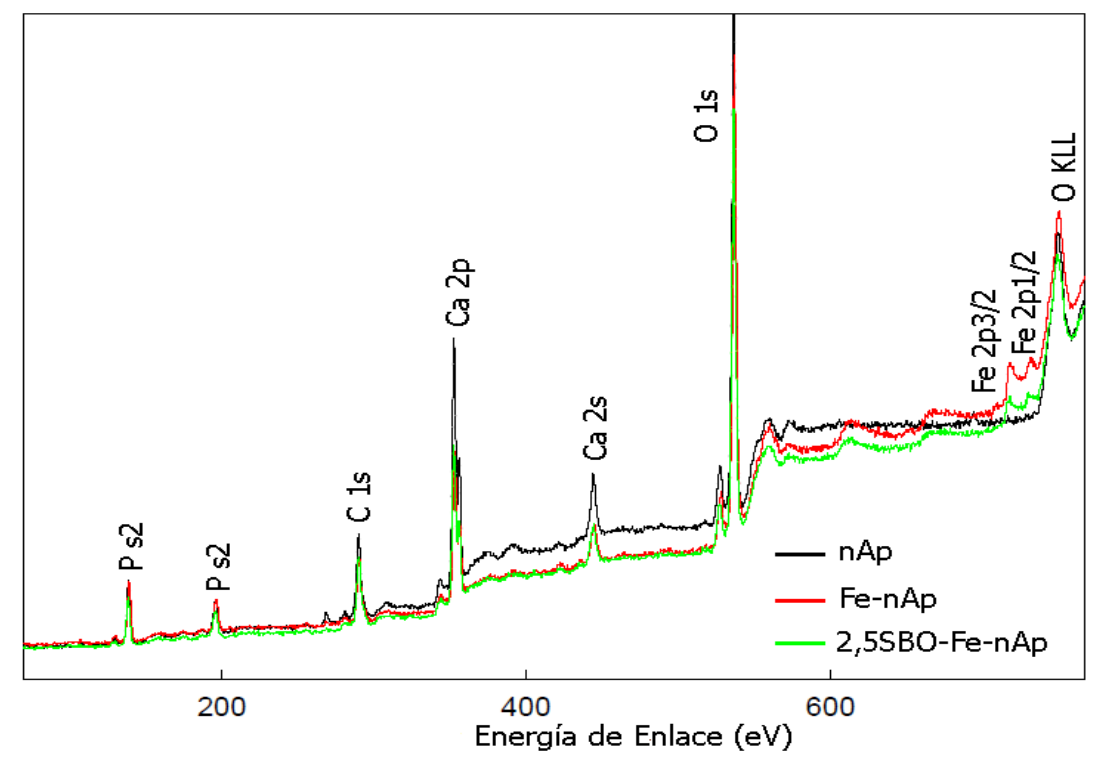

Fig. 4.8 - Espectro XPS para las muestras representativas.

La señal Fe2p3/2 (fig. 4.9) fue simulada usando una combinación de un patrón de multipletes de $\mathrm{Fe}^{+2}$ y $\mathrm{Fe}^{+3}$ para ambas porciones del espectro[18], [19]. La señal fue ajustada asumiendo una línea de base tipo Shirley y usando el menor número de picos permitidos con ancho máximo a mitad de altura de pico de $1,7 e V$, excepto para las señales atribuidas a los satélites de $\mathrm{Fe}^{+2}$ que fueron calculados sin ninguna restricción.

Todas las muestras presentan contribuciones de picos en 709,5 - 710,9712,2 - 713,4 y 714,9eV y una señal satélite de $\mathrm{Fe}^{+2}$ corrida 4,8 - $5 \mathrm{eV}$ en concordancia para fosfatos de $\mathrm{Fe}^{+2}$ y $\mathrm{Fe}^{+3}-\mathrm{OH}$ [18], [20].Además, no se evidenció ningún otro elemento descartando así la presencia de impurezas.

La señal satélite observada a $719 \mathrm{eV}$ aproximadamente puede ser asignada a la contribución de óxidos de Hierro. El $\Delta E(E 2 p 3 / 2-E$ 2p1/2) del orden de 13,0 - 13,3 eV concuerda con el valor reportado para sales y óxidos de hierro [19].Por todo lo expuesto se propone que las muestras obtenidas poseen una mezcla compleja de fosfatos y óxidos de $\mathrm{Fe}^{+2}$ y $\mathrm{Fe}^{+3}$ superficiales. 


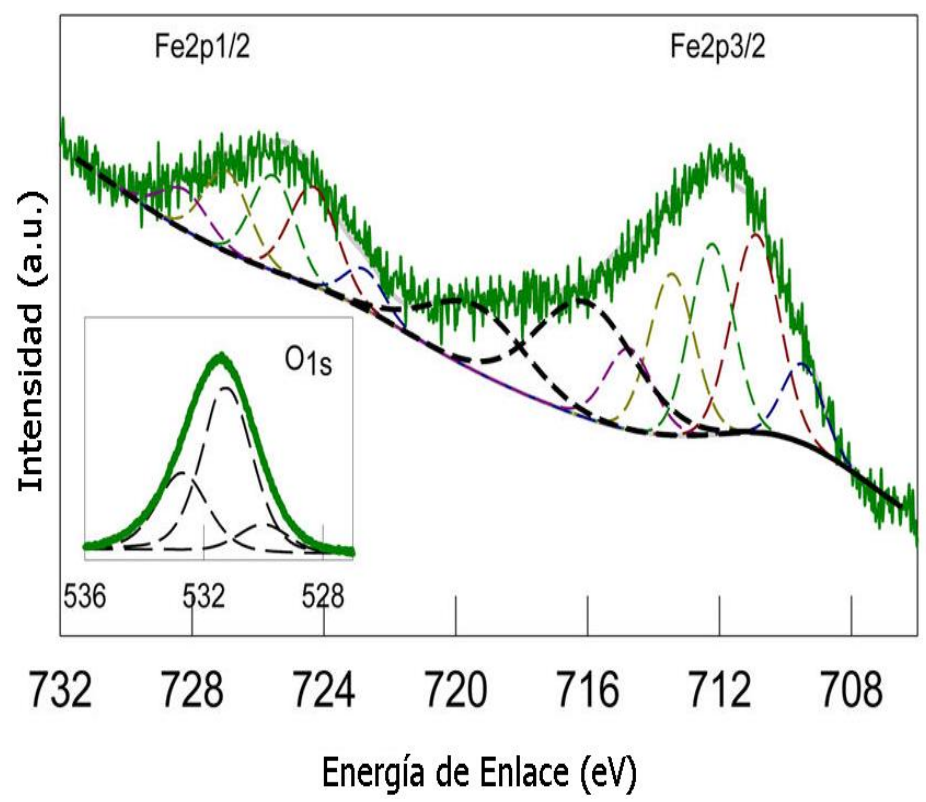

Fig. 4.9 - Señales de XPS de Fe2p3/2 y Fe2p1/2 (Línea continua) para 2,5SBO-FenAp y picos simulados (Líneas discontinuas). Inset: Señal O1s(Línea continua) y especies contribuyentes (líneas discontinuas).

Todas las señales de O1s se simularon con tres fases exceptuando la nAp, como se puede apreciar en la figura 4.10. La primera señal alrededor de 531,8 eV, luego una segunda a 532,8 eV y por ultimo una a 530,1 eV. De acuerdo con la literatura, estos picos pueden ser atribuidos respectivamente a átomos de Oxígeno en grupos fosfatos, hidroxilos y de agua adsorbida, en concordancia con reportes sobre hidroxiapatita. Mientras que para las muestras con fases de Hierro, aparece una tercera contribución en 530,1 eV característica de átomos de oxígeno en óxidos de hierro[18], [21]. La contribución de este pico para las muestras de Fe-nAp y 2,5SBO-Fe-nAp-calc fue de $22 \%$ y $13 \%$ respectivamente mientras que para las muestras 0,5SBO-Fe-nAp y 2,5SBOFe-nAp fue de $5 \%$. Estos resultados coinciden con la mayor área observada para el pico de los multipletes de Fe2p3/2 de energía de enlace mayor a 711 eV observados para la Fe-nAp y 2,5SBO-Fe-nApCal.

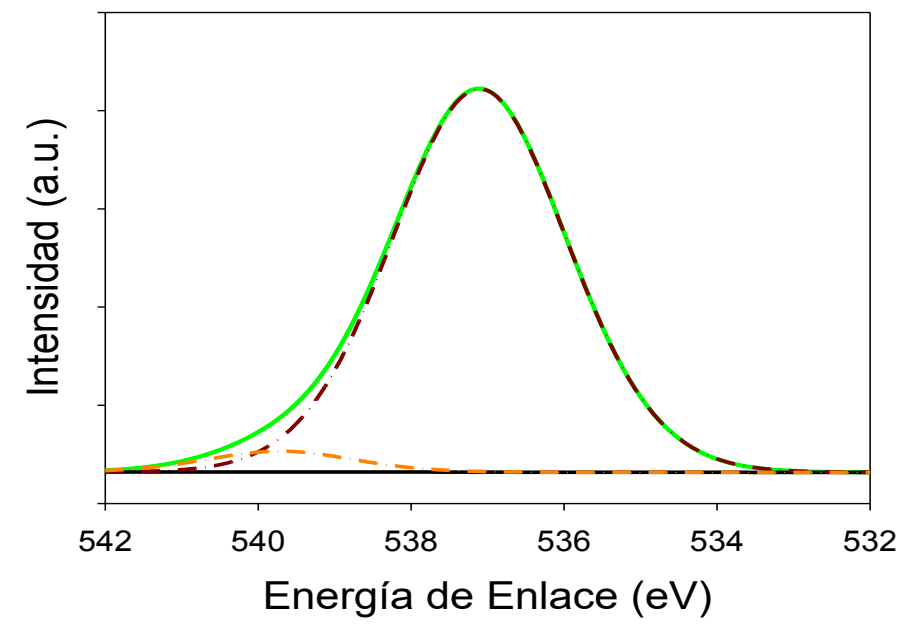

Fig. 4.10- Señales de XPS de O1s de la nAp

Teniendo en cuenta los factores de sensibilidad relativa en el XPS para los diferentes átomos, se cuantificó la relación $\mathrm{Ca}: \mathrm{P}: \mathrm{O}$. La relación $\mathrm{P} / \mathrm{Ca}$ para la $\mathrm{nAp}$ es mayor a la esperada teóricamente $\mathrm{Ca}\left(\mathrm{PO}_{4}\right)_{0,6} \mathrm{O}_{0,2}$ pero comparable con varias hidroxiapatitas reportadas en la literatura. Esta diferencia podría atribuirse a la presencia de grupos fosfatos ácidos superficiales[22]. Por otro lado, la relación $\mathrm{O} / \mathrm{P}$ para la nAp está en concordancia, dentro del error experimental, con la teórica, mientras que la Fe-nAp presenta relaciones $\mathrm{P} / \mathrm{Ca}$ y O/Ca mayores que la 
nAp. Todo lo anterior parece indicar que la presencia de los átomos de hierro aumenta el contenido de grupos fosfatos debido a la formación de Fosfatos de $\mathrm{Fe}^{+2} / \mathrm{Fe}^{+3}$ y se favorece la formación de óxido de hierro. Estas observaciones están en concordancia con la composición superficial publicada para la Hidroxiapatita sustituida con $\mathrm{Fe}^{+2}$ donde se observó un aumento en la hidrofilicidad superficial debido a la formación de grupos superficiales $\mathrm{Fe}-\mathrm{OH}$ [16]. Por otro lado, la introducción de los SBO en la síntesis conlleva a una disminución de la relación $\mathrm{Fe} / \mathrm{Ca}$, mientras que la relación $\mathrm{P} / \mathrm{Ca}$ no se vio afectada y $\mathrm{O} / \mathrm{Ca}$ aumentó significativamente, indicando la participación de grupos orgánicos superficiales conteniendo oxígeno. Mientras que la muestra 2,5SBO-FenAp-calc presenta una menor proporción de O/Ca atribuible a la perdida de materia orgánica.

\begin{tabular}{|c|c|c|c|c|c|c|}
\hline Partícula & $\begin{array}{c}\text { Área } \\
\text { superficial } \\
\text { especifica } \\
\left(\mathbf{m}^{\mathbf{2}} \mathbf{g}^{-\mathbf{1}}\right)\end{array}$ & $\begin{array}{c}\text { Tamaño del } \\
\text { dominio } \\
\text { cristalino } \\
\text { (nm) }\end{array}$ & $\begin{array}{l}\text { Composición } \\
\text { superficial }\end{array}$ & $\begin{array}{c}\% \\
w / w \\
\text { SBO }\end{array}$ & $\begin{array}{c}\underset{\mathrm{cm}}{\mu} \\
(\mathbf{m S} /\end{array}$ & $\begin{array}{c}\mathrm{Fe} / \mathrm{Ca} \\
\text { del } \\
\text { Bulk } \\
(\% \mathrm{Fe} \\
\mathrm{w} / \mathrm{w})\end{array}$ \\
\hline nAp. & 34 & $30-50$ & $\mathrm{Ca}_{1} \mathrm{P}_{0.7} \mathrm{O}_{3.1} \mathrm{Fe}_{0}$ & 0 & $+0,95$ & 0 \\
\hline Fe-nAp. & 64 & $20-40$ & $\mathrm{Ca}_{1} \mathrm{P}_{0.9} \mathrm{O}_{4.6} \mathrm{Fe}_{0.14}$ & 0 & $-1,8$ & 0.2 \\
\hline 0,05SBO-Fe-nAp. & 68 & --- & --- & $<1$ & $-1,5$ & 0,17 \\
\hline 0,5SBO-Fe-nAp. & 70 & --- & $\mathrm{Ca}_{1} \mathrm{P}_{0.7} \mathrm{O}_{3.7} \mathrm{Fe}_{0.09}$ & $<1$ & $-1,6$ & 0,17 \\
\hline 2,5SBO-Fe-nAp. & 71 & $10-30$ & $\mathrm{Ca}_{1} \mathrm{P}_{0.75} \mathrm{O}_{3.7} \mathrm{Fe}_{0.09}$ & $\sim 5$ & $-1,8$ & 0,17 \\
\hline $\begin{array}{c}\text { 2,5SBO-Fe-nAp- } \\
\text { Cal }\end{array}$ & 64 & $20-60$ & $\mathrm{Ca}_{1} \mathrm{P}_{0.8} \mathrm{O}_{3.3} \mathrm{Fe}_{0.06}$ & 0 & --- & 0,17 \\
\hline
\end{tabular}

Tabla 4.2 - Resumen de la caracterización de las partículas (en orden de columnas de izq. a der.) 1: Partícula 2: Área superficial especifica obtenida por el ajuste de la Isoterma BET en la adsorción de $N_{2}$ a 77k, 3: Mínimo tamaño de dominio cristalino estimado por la ecuación de Scherrer, 4:Estequiometría superficial obtenida por análisis XPS, 5: \%C presente en las muestras obtenido por TGA, 6:Movilidad electroforética y 7: Relación Fe/Ca del bulk de la partícula.

La movilidad electroforética de las partículas se obtuvo en el rango de $\mathrm{pH}$ de 6,5 a 7,0 y se muestra en la tabla 4.2. Los valores para nAp y Fe-nAp son $+0,95$ y $-1,8 \mathrm{mS} / \mathrm{cm}$ respectivamente, indicando que la incorporación de Fe en la hidroxiapatita conlleva a la inversión y al aumento de la carga superficial. Sin embargo, la introducción de los SBO a la síntesis parece no afectar la movilidad de las mismas, ya que dentro del error experimental el valor de movilidad para las partículas obtenidas con SBO es igual a la de la Fe-nAp. Este resultado sumado a lo observado por DLS sugiere que los SBO aumentan la hidrofilicidad de la superficie de la partícula estabilizando así las suspensiones acuosas de las partículas.

El comportamiento magnético de las partículas Fe-nAp y 2,5SBO-Fe-nAp se estudió midiendo el comportamiento de histéresis de las curvas Campo magnético vs magnetización mostrado en la figura 4.11. Estas muestras presentan una magnetización de saturación $\left(M_{s}\right)$ de aproximadamente 4 emu/g en concordancia con los valores reportados para Fe-nAp obtenidos por otras rutas sintéticas [6], [14]. Cabe resaltar que este valor es menor al esperado, 57 emu/g Fe [23] considerando que las muestras en promedio tienen un $7 \% \mathrm{w} / \mathrm{w}$ de hierro. Sin embargo, el XPS permitió concluir que no todo el hierro en la partícula contribuye a la formación de óxidos de hierro con comportamiento magnético, lo que disminuye la magnetización de las muestras. 
Analizando el comportamiento a campos bajos se evidencia la formación de un ciclo de histéresis correspondiente al comportamiento ferromagnético de las partículas de magnetita/maghemita. Sin embargo, realizando la comparación entre las dos muestras se evidencia una disminución en el área del ciclo de histéresis denotando la tendencia de las muestras a un comportamiento superparamagnético, debido posiblemente a la disminución del dominio magnético de las partículas causado por la introducción de los SBO en el sistema.
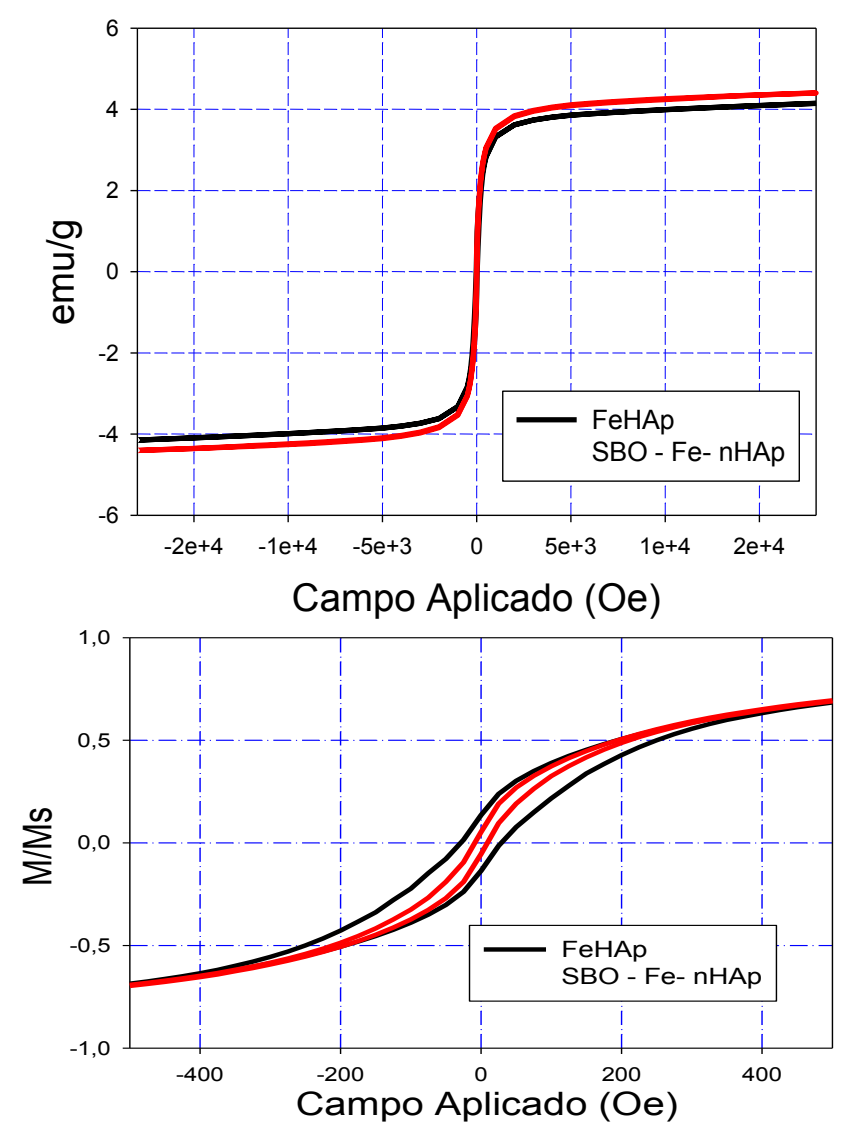

Fig. 4.11 - Arriba: Curvas de histéresis magnético para Fe-nAp (Negro) y 2,5SBO-Fe-nAp (rojo); Abajo: Curvas de histéresis magnética normalizada respecto a la $M_{s}$ a campos bajos.

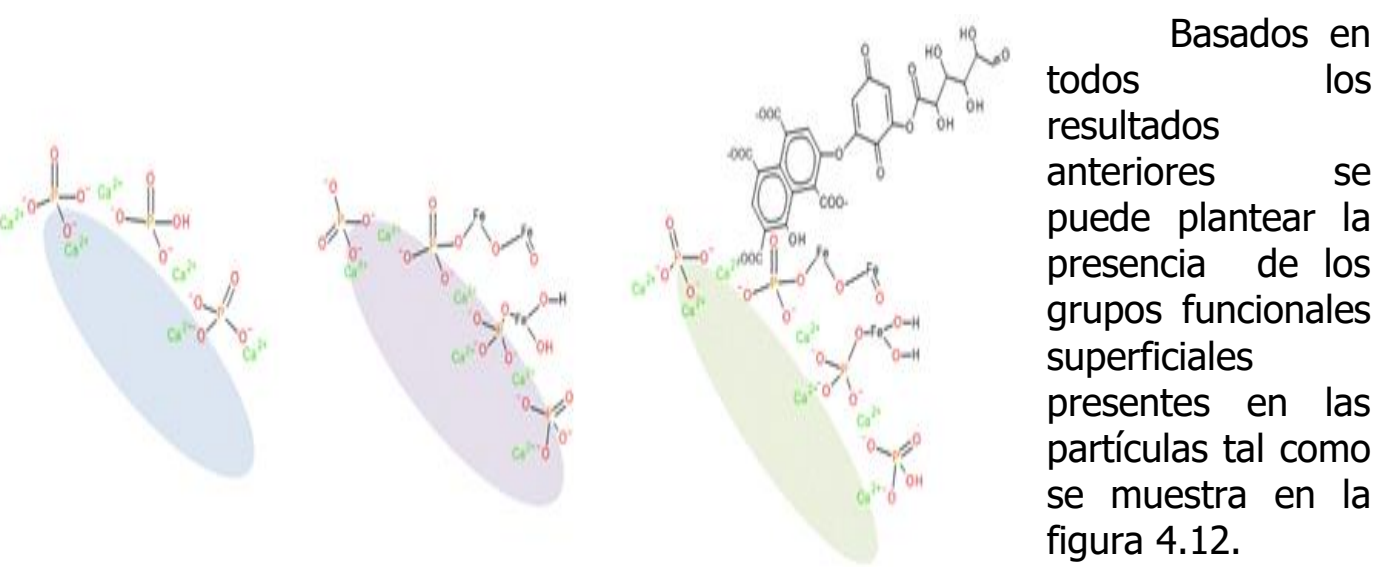

Fig. 4.12 - Representación de los grupos superficiales para las 3 partículas más representativas, de izquierda a derecha $n A p$, y Fe-nAp y 2,5SBO-Fe-nAp. 


\subsubsection{Ensayos de adsorción}

\subsubsection{Adsorción de $\mathrm{Cu}^{+2}$}

La figura 4.13 muestra las isotermas de adsorción obtenidas para todas las partículas. El modelo de Langmuir con un único sitio de adsorción (Ecuación 1) fue adecuado para ajustar las isotermas experimentales para nAp, Fe-nAp, 0,05SBO-Fe-nAp y 0,5SBO-Fe-nAp. Mientras que el modelo de Freundlich (Ecuación 2) fue utilizado para ajustar las isotermas de 2,5SBO-Fe-nAp y 2,5SBOFe-nAp-Calc.

$$
x / m=\frac{K_{l} \times b \times C_{e}}{1+K_{L} C_{e}} ; \quad \text { Ecuación } 1
$$

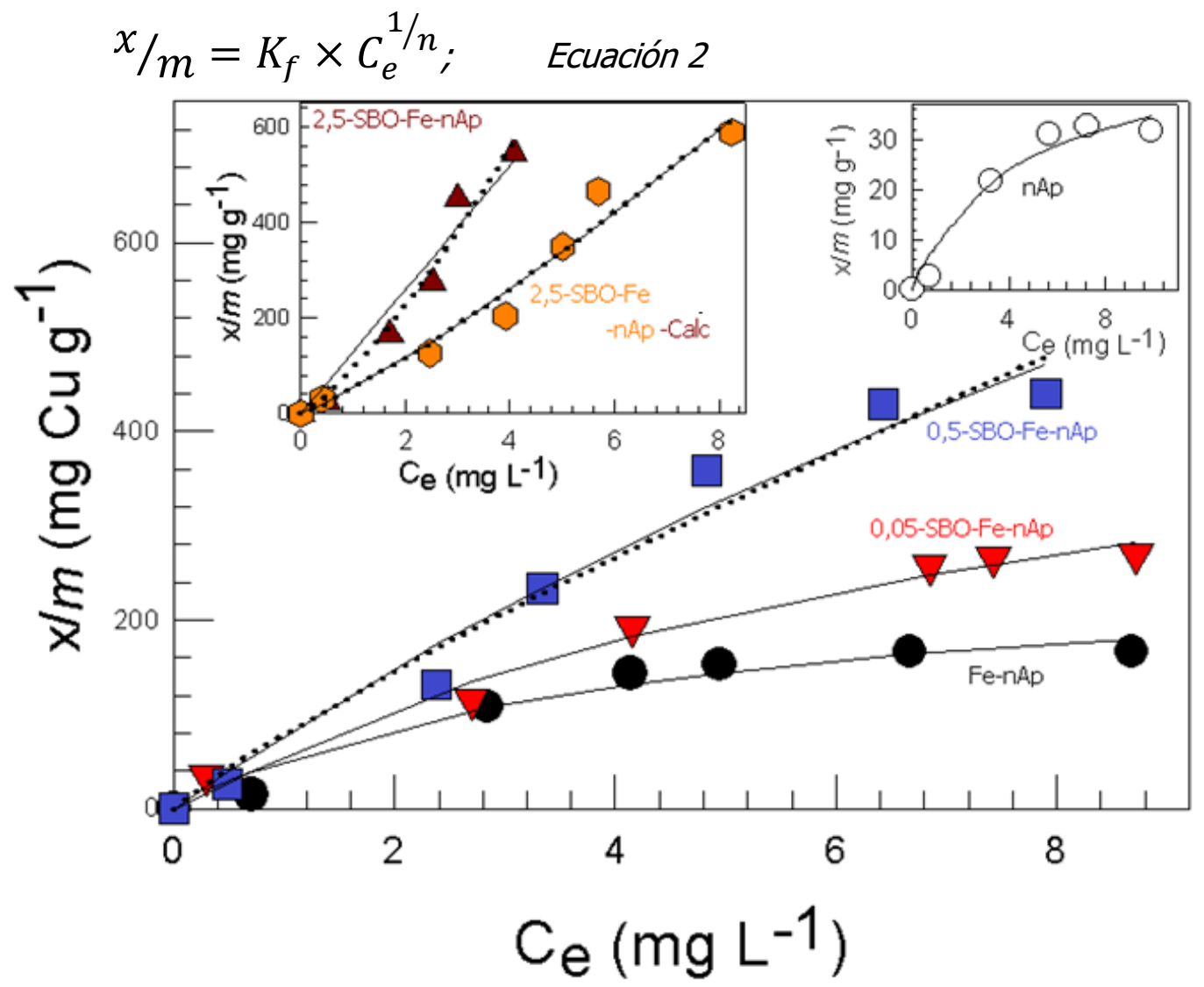

Fig. 4.13- Isotermas de adsorción de $\mathrm{Cu}^{+2}$ a $(25 \pm 2)^{\circ} \mathrm{C}, \mathrm{pH} 7,0$ y concentración salina 0,01M. Las líneas sólida corresponden al ajuste hecho por el modelo de Langmuir mientas que las líneas discontinuas por el modelo de Freundlich.

La tabla 4.3 muestra los parámetros de ajuste de los dos modelos utilizados para representar las isotermas de adsorción experimentales. Los coeficientes de afinidad adsorbente-adsorbato $\mathrm{K}_{\mathrm{L}}$ muestran la siguiente tendencia: $\mathrm{nAp} \approx \mathrm{Fe}-\mathrm{nAp}>0.05 \mathrm{SBO}-\mathrm{Fe}-\mathrm{nAp} \approx 0.5 \mathrm{SBO}-\mathrm{Fe}-\mathrm{nAp}$ mientras que el máximo número de sitios disponibles para adsorción b se incrementa en el orden nAp $<$ Fe-nAp < 0,05SBO-Fe-nAp < 0,5SBO-Fe-nAp. Por otro lado, la adsorción sobre 2,5SBO-FenAp y 2.5SBO-Fe-nAp-cal no se pudo simular mediante este modelo posiblemente debido a que no se alcanzó el máximo de adsorción por la limitación impuesta por la solubilidad del $\mathrm{Cu}^{+2}$ en solución. 


\begin{tabular}{|c|c|c|c|c|c|}
\hline Partícula & $\begin{array}{c}\mathbf{b} \\
{\left[\mathbf{m g ~ g}^{-\mathbf{1}}\right]}\end{array}$ & $\mathbf{K}_{\mathbf{L}}$ & $\mathbf{1 / n}$ & $\begin{array}{c}\mathbf{K}_{\mathbf{F}} \\
{\left[\mathbf{m g ~ g}^{-\mathbf{1}}\right]}\end{array}$ & $\mathbf{r}^{\mathbf{2}}$ \\
\hline nAp. & $50 \pm 25$ & $0,22 \pm 0,10$ & & & 0,967 \\
\hline Fe-nAp. & $265 \pm 60$ & $0,24 \pm 0,02$ & & & 0,969 \\
\hline 0,05SBO-Fe-nAp. & $550 \pm 200$ & $0,12 \pm 0,04$ & & & 0,978 \\
\hline 0,5SBO-Fe-nAp. & $850 \pm 400$ & $0,10 \pm 0,07$ & & & 0.953 \\
\hline 2,5SBO-Fe-nAp. & & & $1,3 \pm 0,2$ & $90 \pm 22$ & 0.974 \\
\hline 2,5SBO-Fe-nAp-Cal. & & & $1,2 \pm 0,2$ & $50 \pm 15$ & 0.970 \\
\hline
\end{tabular}

El valor obtenido para el máximo número de sitios b para la adsorción de $\mathrm{Cu}^{2+}$ sobre nAp calculado está en el orden para la adsorción de este mismo metal sobre hidroxiapatita comercial a pH 7,2 (b $\left.=64,8 \mathrm{mg} \mathrm{g}^{-1}\right)$ mientras que la constante de afinidad $K_{\mathrm{L}}$ es 4 veces mayor al calculado en este trabajo.

La HAp presenta en su superficie iones $\mathrm{Ca}^{+2}$ cargados positivamente y grupos funcionales que poseen Oxígenos cargados negativamente. Por ello se propone que el mecanismo para la adsorción de $\mathrm{Cu}^{+2}$ sobre partículas basados en materiales de apatita se debe al intercambio iónico de iones $\mathrm{Ca}^{+2}$ por iones $\mathrm{Cu}^{+2}$ y a la coordinación de iones $\mathrm{Cu}^{+2}$ con grupos $\mathrm{PO}_{4} \mathrm{u} \mathrm{OH}[24]$. Sin embargo, en

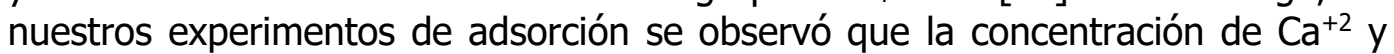
$\mathrm{Fe}^{+2} / \mathrm{Fe}^{+3}$ en solución permanecen invariables descartando el mecanismo de intercambio iónico. También se descarta que el aumento del área superficial especifica de las partículas (obtenida por el modelo BET aplicado a la isoterma de adsorción de $\mathrm{N}_{2}$ a $77 \mathrm{~K}$ ) sea una razón de la adsorción mejorada de las partículas, ya que, las isotermas normalizadas con el área respectiva de cada partícula siguen mostrando la misma tendencia.

En la literatura es posible encontrar materiales basados en magnetita con diferentes capacidades de adsorción de $\mathrm{Cu}^{+2}$ en el orden de los $150 \mathrm{mg} \mathrm{g}^{-1} 0$ menor [25]. Sin embargo, los nanocompositos sintetizados en este trabajo presentan una mayor capacidad de adsorción.

Por otro lado, se ha demostrado que los iones de $\mathrm{Cu}^{+2}$ forman complejos estables con ácidos fúlvicos y materia orgánica disuelta [26]; como grupos amino, fenoles, hidroxilos y grupos aromáticos. El número de estos sitios de interacción varía desde 1 a $100 \mu \mathrm{M} / \mathrm{mg} \mathrm{C}$ dependiendo del $\mathrm{pH}$, de la fuerza iónica, del origen de la materia orgánica y de su concentración. Una primera estimación de los sitios disponibles para la interacción de los SBO con $\mathrm{Cu}^{+2}$ puede ser calculada considerando el $5 \%$ de materia orgánica que posee la 2,5-SBO-Fe-nAp, de la cual un $38,5 \%$ es debido a átomos de C [27]. Tomando la máxima cantidad de sitios reportado $100 \mu \mathrm{M} / \mathrm{mg} \mathrm{C}$ se obtiene un valor de aproximadamente $121 \mathrm{mg}$ $\mathrm{Cu}^{+2} / \mathrm{mg} \mathrm{Np}$. El valor estimado es menor al número de sitios calculado a partir de las isotermas de los nanomateriales con SBO (ver Tabla 4.3). Por ello, no se puede atribuir la mejor adsorción de los materiales obtenidos solo a la presencia de los SBO en la superficie. En efecto, la muestra 2,5-SBO-Fe-nAp-Calc presenta una gran capacidad de adsorción a pesar de no poseer SBO remanente.

Como se discutió anteriormente, entre las principales diferencias entre las partículas de nAp y las sintetizadas con Fe pueden citarse: la reducción de los

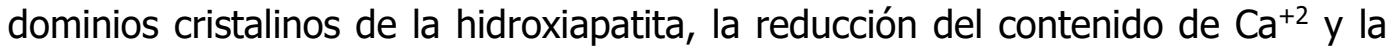


formación tanto de fases de magnetita/maghemita y de fosfatos de hierro superficiales. Todas estas modificaciones superficiales y morfológicas son las responsables del aumento de la capacidad de adsorción de $\mathrm{Cu}^{+2}$ de todos los materiales conteniendo hierro ya que aumentan la capacidad de formación de complejos de $\mathrm{Cu}^{+2}$ con los grupos $\mathrm{PO}_{4}$ y $\mathrm{OH}$ superficiales.

Dado que las partículas se aglomeran cuando se encuentran dispersas en agua, la aglomeración podría ser un factor que reduce la disponibilidad de área superficial para la adsorción de $\mathrm{Cu}^{+2}$. Es decir, las medidas de área superficial de material seco no necesariamente representan el área efectiva para la adsorción de $\mathrm{Cu}^{+2}$ en suspensiones acuosas debido a la aglomeración de las partículas [28], [29].

Una estimación del área superficial efectiva de las partículas en solución se podría obtener considerado que el $\mathrm{Cu}^{+2}$ se adsorbe sobre el área del aglomerado. Tomando los diámetros hidrodinámicos calculados por DLS y considerando el valor de la densidad de hidroxiapatita $\left(3,156 \mathrm{~g} / \mathrm{cm}^{3}\right)[30]$ invariable para todas las partículas, es posible calcular el área superficial especifica de los aglomerados en suspensión acuosa (tabla 4.4.)

\begin{tabular}{|c|c|}
\hline Partícula & $\begin{array}{c}\text { Área del aglomerado de partículas en } \\
\text { suspensión acuosa }\left[\mathbf{m}^{\mathbf{2}} \mathbf{g}^{-\mathbf{1}}\right]\end{array}$ \\
\hline nAp & 1,55 \\
\hline Fe-nAp & 2,10 \\
\hline 0,05-SBOFe-nAp & 2,22 \\
\hline , 5-SBOFe-nAp & 2,32 \\
\hline 2,5-SBOFe-nAp & 6,51 \\
\hline 2,5-SBO-Fe-nAp-Calc & 2,81 \\
\hline
\end{tabular}

Tabla 4.4 - Área superficial efectiva del aglomerado de partículas en suspensión acuosa en las condiciones de los ensayos de adsorción.

Las isotermas de adsorción de $\mathrm{Cu}^{+2}$ sobre las nanopartículas se normalizaron usando el área superficial específica calculada para el aglomerado de las mismas y el resultado se muestra en la figura 4.14. En esta figura se pueden clasificar las isotermas en dos grupos generales: nAp (puntos blancos) y otra para las partículas con Fe en su estructura. Estas últimas poseen $\mathrm{K}_{\mathrm{L}}$ similares y mayor capacidad de adsorción respecto a la nAp pura, en concordancia con las características superficiales descritas (vide supra). Para altas concentraciones de $\mathrm{Cu}^{+2}$ adsorbidas las isotermas presentan comportamiento diferente, debido tal vez a la introducción del metal al interior del aglomerado adsorbiéndose en las superficies internas del mismo, opción que no está considerada en el modelo propuesto. 


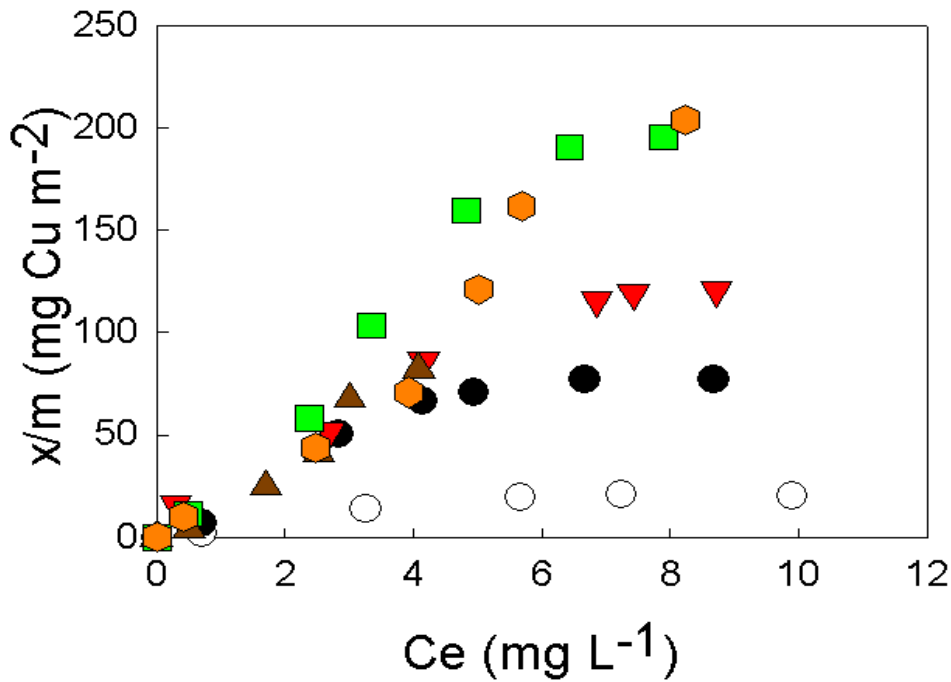

Fig. 4.14- Isotermas de adsorción de $\mathrm{Cu}^{2+}$ normalizadas respectoal área de los aglomerados de las partículas en suspensión acuosa. La nAp corresponde a los círculos blancos.

\subsubsection{Ensayos de adsorción de $\mathrm{Pb}^{+2}$}

Para el estudio de la adsorción de $\mathrm{Pb}^{+2}$ solo se utilizaron las partículas más representativas del sistema de estudio: nAp, Fe-nAp, 2,5SBO-Fe-nAp y 2,5SBO-Fe-nAp-Calc. La figura 4.15 muestra las isotermas de adsorción de $\mathrm{Pb}^{+2}$ obtenidas a 0,01M de concentración de HEPES-Na, concentración de partículas de 20 ppm y pH 7,0. El modelo de Langmuir con un único sitio de adsorción fue suficiente para describir la curva experimental con $r^{2}>0,95$ para todos los casos.

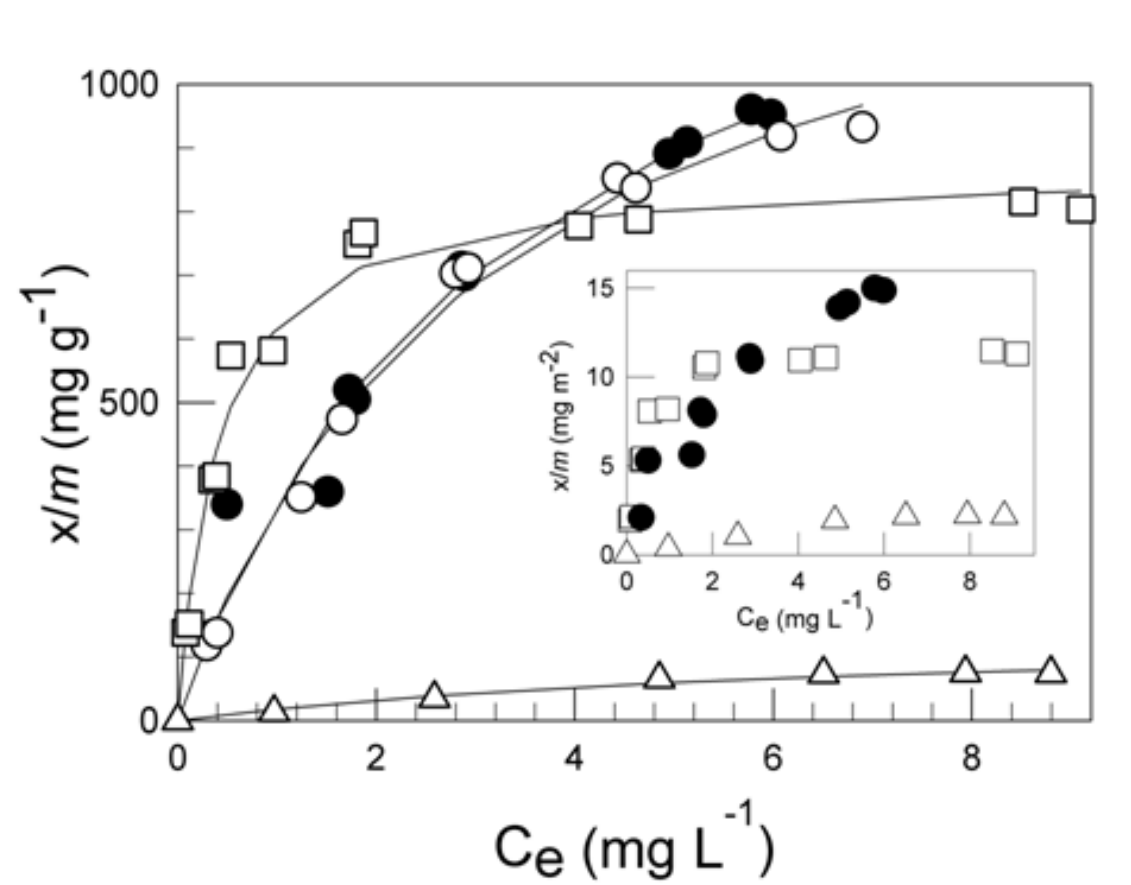

Fig. 4.15 - Isotermas de adsorción de $\mathrm{Cu}^{+2}$ a $(25 \pm 2)^{\circ} \mathrm{C}, \mathrm{pH} 7,0$ y concentración salina 0,01M. nAp (4), Fe-nAp (0),2,5-SBO-Fe-nAp (a) y 2,5-SBO-Fe-nAp-Calc(O)- Las líneas sólida corresponden al ajuste hecho por el modelo de Langmuir. Inset: Isotermas normalizadas respecto al área superficial específica de las partículas

El número máximo de sitios de adsorción b aumenta en el orden 
nAp $<2,5 S B O-F e-n A p<2,5 S B O-F e-n A p-C a l \approx F e-n A p$ mientras que la constante de afinidad para la adosorción de $\mathrm{Pb}^{+2}, \mathrm{~K}_{\mathrm{L}}$, sigue la tendencia $\mathrm{nAp}<\mathrm{Fe}-\mathrm{nAp} \approx 2,5-$ SBOFe-nAp-Cal<2,5SBO-Fe-nAp.

\begin{tabular}{|c|c|c|c|c|}
\hline Partícula & $\begin{array}{c}\mathbf{b} \\
{\left[\mathbf{m g ~ g}^{-\mathbf{1}}\right]}\end{array}$ & $\mathbf{K}_{\mathbf{L}}$ & $\mathbf{r}^{\mathbf{2}}$ & $\begin{array}{c}\Gamma \\
{\left[\mu \mathbf{m o l ~ m}^{-\mathbf{2}}\right]}\end{array}$ \\
\hline nAp. & $140 \pm 30$ & $0,15 \pm 0,07$ & 0,978 & 20 \\
\hline Fe-nAp. & $1500 \pm 150$ & $0,30 \pm 0,07$ & 0984 & 113 \\
\hline 2,5SBO-Fe-nAp. & $870 \pm 25$ & $2,40 \pm 0,30$ & 0,994 & 59 \\
\hline 2,5SBO-Fe-nAp-Calc. & $1400 \pm 70$ & $0,32 \pm 0,07$ & 0,994 & 106 \\
\hline
\end{tabular}

Tabla 4.5 - Parámetros de ajuste del modelo de Langmuir y $\Gamma$ la capacidad de adsorción máxima de $P b^{2+}$ expresada en moles de moléculas por unidad de área superficial.

El valor de b observado para la nAp está en el orden de los reportados para nanohidroxiapatitas sinteticas[31], [32] en el rango de $\mathrm{pH} 6,25-7,0$ pero entre 4 y 10 veces mayor a los reportados para arcilla rica en grupos fosfatos[33] y de apatitas obtenidas a partir de tejido oseo de animales[34]. Por otro lado, los valores obtenidos para $\mathrm{K}_{\mathrm{L}}$ están en el orden de los reportados para apatitas de diferentes orígenes [33], [35]-[37].

El valor de $b$ obtenido para la Fe-nAp es 10 veces más grande que el obtenido para la nAp, a pesar que en la literatura se encuentra que el $\mathrm{Fe}^{2+}$ inhibe la inmobilización de $\mathrm{Pb}^{+2}$ sobra la hidroxiapatita debido a la formación de fosfatos de hierro amorfos, disminuyendo así el número de $\mathrm{PO}_{4}^{-3}$ disponibles para precipitar el $\mathrm{Pb}^{+2}[38]$, [39]. Mientras que la adsorción máxima de $\mathrm{Pb}^{+2}$ sobre materiales basados en la magnetita están en el orden de (20-90) mg/g[40], [41], la capacidad de adsorción de compositos de Hidroxiapatita/ $\mathrm{Fe}_{3} \mathrm{O}_{4}$ obtenidos por

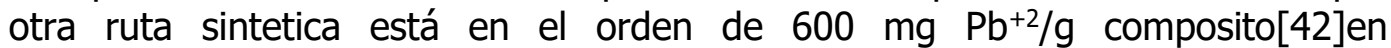
concordancia con los valores obtenidos en esta serie de experimentos. Por su lado, la 2,5SBO-Fe-nAp presenta una disminución en el número de sitios máximos disponibles para la adsorción respecto a la Fe-nAp. Dado que la isoterma de adsorción de 2,5-SBOFe-nAp-Calc se sobrepone con la de Fe-nAp, esto indicaría que los SBO inhiben la adsorción del metal al modificar la superficie de los materiales.

Para investigar el efecto del area superficial efectiva en estado sólido las isotermas fueron normalizadas respecto a este area (ver Inset de la Figura 4.16). Analizando esto, es posible apreciar que a concentraciones bajas de $\mathrm{Pb}^{+2}$ las partículas Fe-nAp y 2,5-SBOFe-nAp muestran capacidad de adsorción similar, mientras que a concentraciones altas de $\mathrm{Pb}^{+2}$, Fe-nAp muestra mayor capacidad de acomodación de iones $\mathrm{Pb}^{+2}$. El párametro $\Gamma$ está relacionado con la capacidad máxima de adsorción expresado en moles de iones por area superficial especifica de la nanopartícula. Para este sistema el valor de $\Gamma$ observado para nAp comparado para las demás no está relacionado con la relación superficie/volumen debido a que es menor para esta partícula que para todas las demas.

Para los ensayos de desorción se tomaron muestras de las partículas en equilibrio termodinamico ubicada en el plató de la isoterma. Estas partículas serán denotadas PbnAp, PbFe-nAp y Pb2,5-SBOFe-nAp. Los experimentos fueron llevados a cabo en función del pH manteniendo las demás condiciones experimentales invariables. Los resultados muestran que la concentración de 
iones $\mathrm{Pb}^{+2}$ está en el orden del límite de detección del equipo alrededor de la décima de ppm y es por lo tanto, tres ordenes de magnitud menor que la cantidad de $\mathrm{Pb}^{+2}$ adsorbida. Debido a esta diferencia se propone la adsorción irreversible del $\mathrm{Pb}^{+2}$ para todas las particulas.

\subsubsection{Caracterización de partículas con $\mathrm{Pb}^{2+}$ adsorbido.}

Se puede obtener información acerca del proceso de adsorción a través de la caracterización de las partículas con $\mathrm{Pb}^{+2}$, esto es de PbnAp - PbFe-nAp y $\mathrm{Pb}$ 2,5-SBOFenAp. Es importante resaltar que para los ensayos de caracterización utilizados en este estudio (vide infra), se requieren cantidades apreciables de material seco. Para ello se hizo un escalado considerando la relación Volumen de suspensión/Concentración de nanopartículas pero sin variar la concentración de $\mathrm{Pb}^{+2}$ debido a limitaciones de solubilidad del mismo[7], [9]. Además, por cuestiones prácticas el sistema de mezclado es diferente. Estas partículas serán denominadas $\mathrm{Pb}^{\prime} / / \mathrm{nAp}$ - $\mathrm{Pb}^{\prime} / /$ Fe-nAp y $\mathrm{Pb}^{\prime} / / 2,5$-SBOFenAp debido a que es probable que la cantidad de $\mathrm{Pb}^{+2}$ por gramo de partícula sea diferente.

La figura 4.16 muestra una imagen TEM comparativa entre $\mathrm{Pb} / / \mathrm{nAp}$ $\mathrm{Pb}^{\prime} / /$ Fe-nAp. Debido al alto grado de aglomeración de las partículas fue imposible un estudio estadistico de la distribución del tamaño medio de las mismas. Comparando estas partículas con las obtenidas antes del proceso de adsorción ( vide supra) se puede concluir que la nAp de (70 - 150) nm de longitud mantiene su morfología.

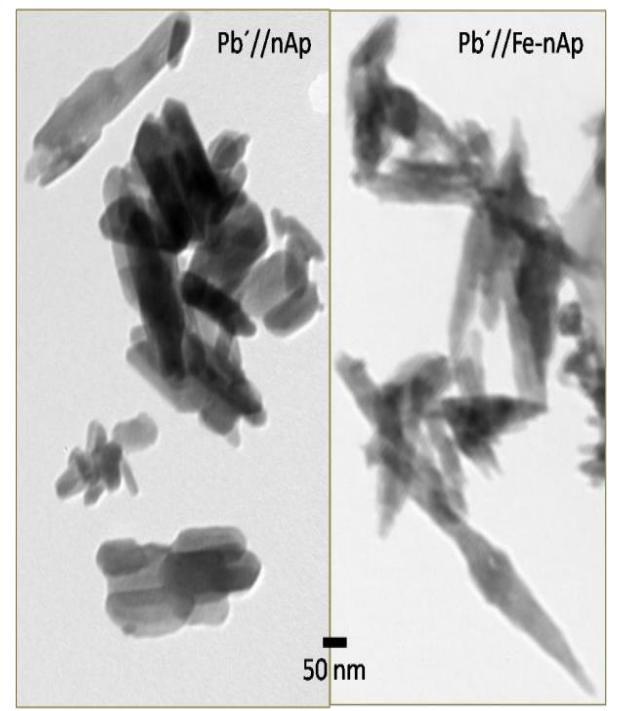

Fig. 4.16 - Imagen TEM de las partículas $P b^{\prime} / / n A p-P b^{\prime} / / F e-n A p$.

De igual forma, $\mathrm{Pb}^{\prime} / / \mathrm{Fe}-\mathrm{nAp}$ y $\mathrm{Pb} / / 2,5-\mathrm{SBOFenAp}$ no muestran diferencias visibles con los polvos respectivos antes de la adsorción. De estos resultados, podríamos concluir que la adsorción de $\mathrm{Pb}^{+2}$ sobre las partículas no afecta significativamente la morfología. El analisis de XRD de las partículas con $\mathrm{Pb}^{+2}$ adsorbido muestran los patrones y definición de picos de sus analogas sin metal adsorbido, como se evidencia en la figura 4.17. Debido a la similitud en la altura y definición de los picos antes y despues del proceso de adsorción, se estima que se conserva el tamaño mínimo del dominio cristalino. De allí se puede concluir que el dominio cristalino de la fase HAp no se modifica significativamente por la 
adsorción de $\mathrm{Pb}^{+2}$, en concordancia con resultados de la literatura[44].

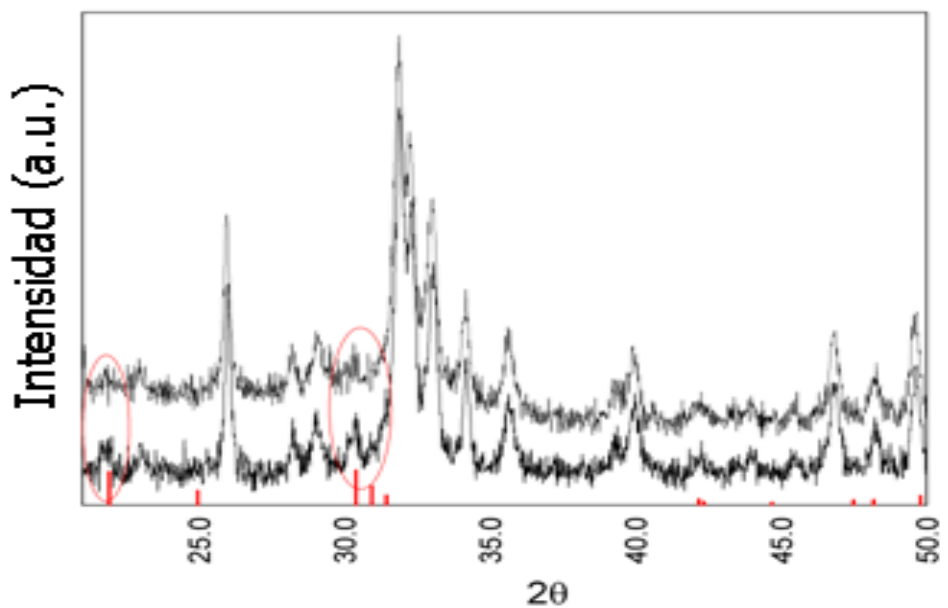

Fig. 4.17 - Patron de XRD para Fe-nAp y Pb'//Fe-nAp (de arriba a abajo). Barras: Principales picos de la formación de $\left(\mathrm{Ca}_{2} \mathrm{~Pb}_{3}\left(\mathrm{PO}_{4}\right)_{3} \mathrm{Cl}\right)$.

De todas las muestras estudiadas solo se evidenció en el difractogramra de $\mathrm{Pb} / / / \mathrm{Fe}-\mathrm{nAp}$ la aparición de dos picos pequeños señalados en rojo en la figura. Estos picos pueden ser atribuidos a la formación de $\left(\mathrm{Ca}_{2} \mathrm{~Pb}_{3}\left(\mathrm{PO}_{4}\right)_{3} \mathrm{Cl}\right)$ con $\mathrm{Ca}$ y $\mathrm{Pb}$ ordenados en dos sitios no equivalentes para la apatita [45].

El espectro FTIR de la muestra $\mathrm{Pb} / / 2,5 \mathrm{SBO}-\mathrm{Fe}-\mathrm{nAp}$ se muestra en la figura conjuta y se compara con el espectro de la nanopartícula $\sin \mathrm{Pb}$ adsorbido. En ambos espectros se aprecian los modos de vibración fundamentales de los grupos $\mathrm{PO}_{4}$ de la estructura de la apatita (vide supra)[12]. Por otro lado, el espectro de la $\mathrm{Pb}^{\prime} / / 2,5-\mathrm{SBO}$ Fe-nAp (vide supra) muestra mayor intensidad en las bandas de absorción a 1600 y $1410 \mathrm{~cm}^{-1}$ repecto de la partícula $\sin \mathrm{Pb}$. Este aumento puede deberse a la formación de complejos Carboxilatos- $\mathrm{Pb}^{+2}$

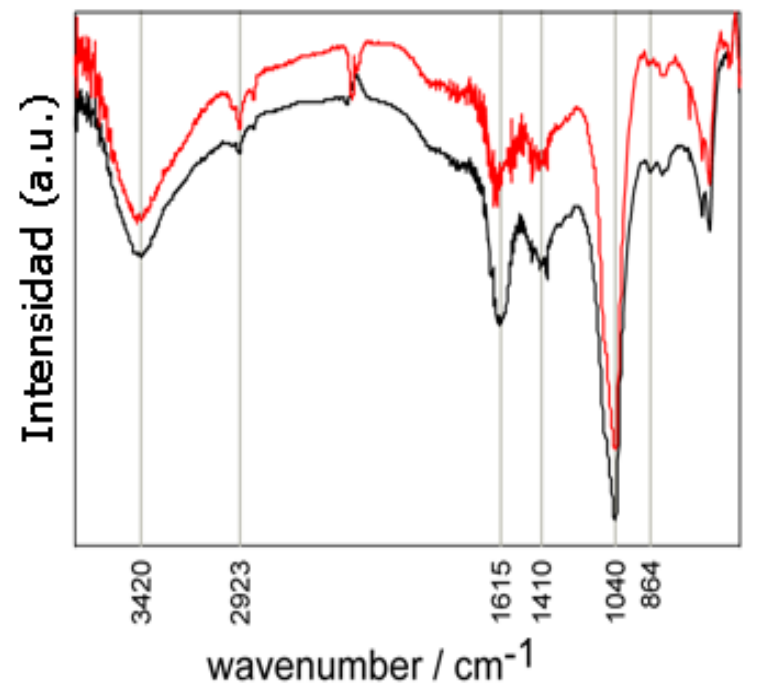

Fig. 4.18 - Espectro FTIR (De arriba - abajo): 2,5SBO-FenAp y $P b^{\prime} / / 2,5 S B O-F e-n A p$, respectivamente.

En efecto, los complejos carboxilato-metal muestran bandas de absorción fuertes en la región (1550-1620) $\mathrm{cm}^{-1}$ y una de menor intensidad en la región de $(1550-1620) \mathrm{cm}^{-1}$ tipica de estiramientos simetricos y asimetricos de grupos COO[12]. El espaciado $\Delta v \sim 200 \mathrm{~cm}^{-1}$ entre estos modos vibracionales ha sido evidenciado para complejos bidentados metal-carboxilato. Tambien se conoce que los iones $\mathrm{Pb}^{+2}$ forman complejos estables con grupos carboxilicos y fenolicos de ácidos húmicos en el rango de $\mathrm{pH}$ 4-9. Estos resultados sugieren que la 2,5$\mathrm{SBO}-\mathrm{Fe}-\mathrm{nAp}$ permitiría la retención de $\mathrm{Pb}^{2+}$ mediante la complejación con esos 
grupos superficiales. No se evidenciaron cambios en las otras muestras luego del proceso de adsorción.

Los espectros XPS de todas las nanoparticulas se muestran en la figura 4.19-(1). Aparte de los elementos presentes en las partículas antes del proceso de adsorción, también se evidencia la presencia de $\mathrm{Pb}$ en el material.
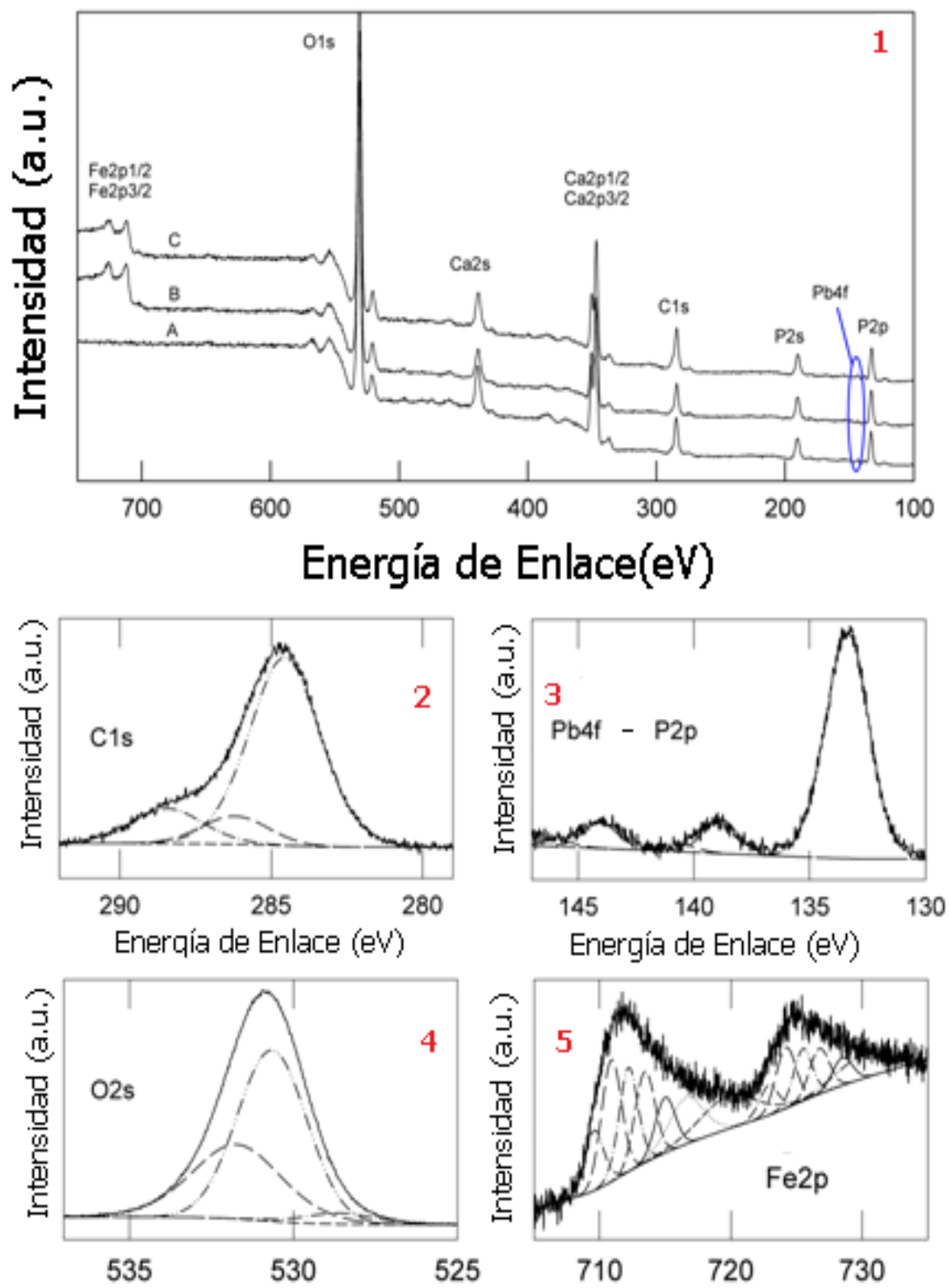

Enerqía de Enlace (ev)

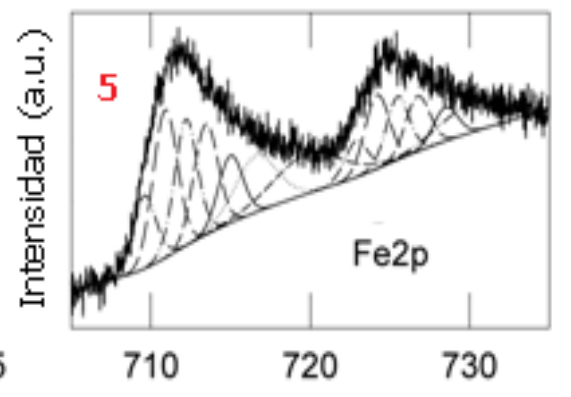

Enerqía de Enlace (eV)

Figura 4.19 - (1): Espectro XPS de las muestras $P b^{\prime} / / n A p(A), P b^{\prime} / / F e-n A p(B)$ y 2,5Pb' //SBO-Fe-nAp (C) y señales de la muestra 2,5-SBO-Fe-nAp (lineas continuas = (2): C2s, (3): P2p, Pb4f, (4): O2s y (5): Fe2py picos contribuyentes(linas discontinuas).

Todas las partículas presentan una contribución C1s a $288,5 \mathrm{eV}$ atribuido a ácidos carboxílicos, carbonatos metalicos y complejos carboxi- $\mathrm{Pb}[46]$, la contribución delúltimo pico es de especial importancia para la Pb'2,5-SBO-Fe- 
nAp, pero debido a la gran cantidad de "Carbono Espurio" es imposible diferenciar este del proveniente de los SBO.

Basandose en la caracterización por XPS de las partículas antes del proceso de adsorción (vide supra) y considerando que las especies contribuyentes a la banda delFe2p3/2 antes de la adsorción se mantienen luego de la adsorción de $\mathrm{Pb}^{+2}$, se concluye que la adsorción de plomo no tiene un efecto significativo en los grupos fosfato u óxidos de $\mathrm{Fe}^{+2} \circ \mathrm{Fe}^{+3}$, en coincidencia con datos publicadospara la adsorción de este mismo metal sobre Geothite [47].

Los picos $\mathrm{Pb} 4 \mathrm{f5} / 2$ y $\mathrm{Pb} 4 \mathrm{f} 5 / 2$ con una diferencia de energía de enlace de $4,87 \mathrm{eV}$ muestran una contribución a $138,9 \mathrm{eV}$ caracteristica de sales inorganicas y carboxilatos de $\mathrm{Pb}^{+2}$ [46], [47]. No se evidencia una contribución alrededor de $137 \mathrm{eV}$ correspondiente a óxidos de plomo. La tabla 4.6 muestra la composición química superficial de los materiales antes y despues del proceso de adsorción, de donde se puede concluir que la inclusión de $\mathrm{Pb}^{+2}$ no modifica sustancialmente la composición de las partículas.

\begin{tabular}{|c|c|c|c|c|}
\hline Partícula & $\begin{array}{c}\mu \\
(\mathrm{ms} / \mathrm{cm})\end{array}$ & Composición Superficial & Partícula & $\begin{array}{c}\mu \\
(\mathrm{mS} / \mathrm{cm})\end{array}$ \\
\hline nAp & $+1,0 \pm 0,2$ & $\mathrm{Ca}_{1} \mathrm{P}_{0.7} \mathrm{O}_{3.1} \mathrm{Fe}_{0}$ & $\mathrm{~Pb} / / / \mathrm{nAp}$ & $+1,3 \pm 0,2$ \\
\hline Fe-nAp & $-1,7 \pm 0,1$ & $\mathrm{Ca}_{1} \mathrm{P}_{0.9} \mathrm{O}_{4.6} \mathrm{Fe}_{0.14}$ & $\mathrm{~Pb} / / / \mathrm{Fe}-\mathrm{nAp}$ & $-0,8 \pm 0,2$ \\
\hline 2,5SBO-Fe-nAp & $-1,8 \pm 0,1$ & $\mathrm{Ca}_{1} \mathrm{P}_{0.75} \mathrm{O}_{3.7} \mathrm{Fe}_{0.09}$ & $\mathrm{~Pb}^{\prime} / / 2,5 \mathrm{SBO}-\mathrm{Fe}-\mathrm{nAp}$ & $-0,2 \pm 0,2$ \\
\hline
\end{tabular}

En la tabla 4.6 se muestra la comparación entre la movilidad electroforetica de las partículas antes y despues de la adsorción de $\mathrm{Pb}^{+2}$.Los resultados indican que la introducción del metal en el sistema genera una ganancia neta de carga positiva para todas, salvo la nAp, que dentro del error experimental, no ve modificada su movilidad electroforetica. Considerando que el tamaño y la forma de las partículas no se ven significativamente alterados durante el proceso y dado que todos los ensayos de movilidad electroforetica fueron llevados a cabo bajos las mismas condiciones, la diferencia se debe originalmente al cambio de carga superficial de las partículas.

La figura 4.20 muestra el radio hidródinámico de las partículas antes y después de la adsorción de iones $\mathrm{Pb}^{+2}$, todos determinados en suspensión acuosa a $\mathrm{pH} 7,0$ y fuera ionica $0,01 \mathrm{M}$ de HEPES-Na. Todas las partículas presentan un incremento importante en la dispersión de tamaños del radio hydrodinámico en suspensión acuosa luego de la adsorción. En particular, la $\mathrm{Pb}$ 2,5-SBOFenAp observa un especial aumento del radio hidrodinámico indicando un aumento en la aglomeración de estas partículas luego de la absorción. 


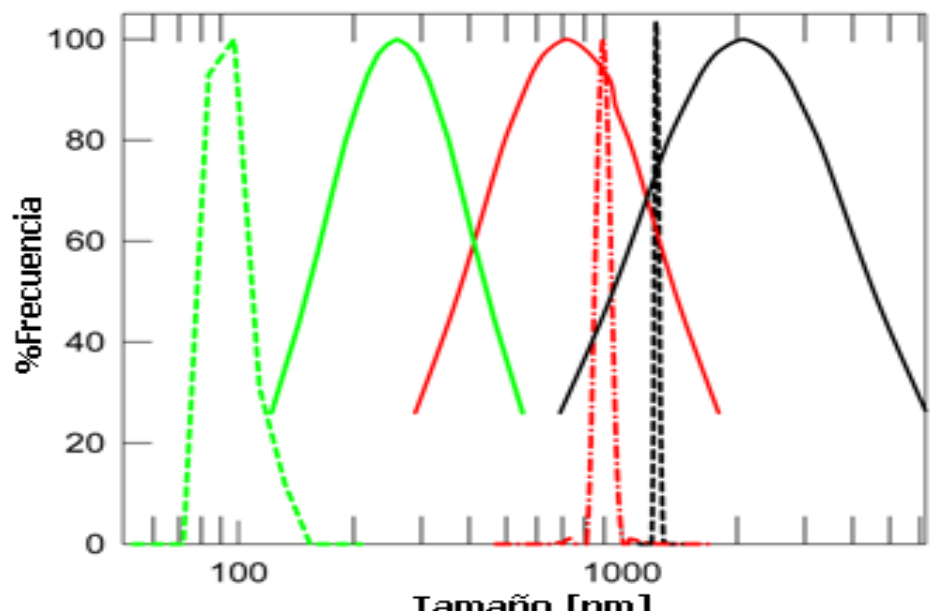

Fig. 4.20 - Distribución de diámetro hidrodinámico obtenido por $D L S$ en suspensiones a pH 7,0 y 0,01M de fuerza iónica de las partículas nAp (---), Pb//nAp (-), Fe-nAp (---), Pb//Fe-nAp (-), 2,5SBO-Fe-nAp (---) y $\mathrm{Pb} / / 2,5 \mathrm{SBO}-\mathrm{Fe}-n A p(-)$.

De acuerdo a investigaciones reportadas[33], [35]-[37], [44] la adsorción de $\mathrm{Pb}^{+2}$ sobre hidroxiapatita involucra la disolución de la apatita seguida de la formación de estructuras inestables de hidropiromorfita $\mathrm{Pb}_{(10-\mathrm{x})} \mathrm{Ca}_{\times}\left(\mathrm{PO}_{4}\right)_{6}(\mathrm{OH})_{2}$, a partir de la cual se forman estructuras mas estables de $\mathrm{Pb}$. En la investigación llevada a cabo en este trabajo no se pudo identificar la formación de piromorfita mediante XRD, pero debido a que la movilidad electroforetica permaneció invariable dentro del error experimental para nAp esto puede ser debido al intercambio cationico de iones $\mathrm{Ca}^{+2}$ y $\mathrm{Pb}^{+2}$. Además, la gran polidispersión en la distribución de tamaño hidrodinamico que sufre esta partícula sugiere una modificación en la superficie de la partícula a pesar de no haber diferencias en la movilidad electroforetica.

La Fe-nAp al presentar baja cristalinidad, dominios superficiales con grupos fosfatos y óxidos de hierro y fases de magnetita/maghemita, muestra multiples opciones capaces de aumetar la adsorción de $\mathrm{Pb}^{+2}$ respecto a la nAp. Se encuentra repotado que los óxidos e hidroxidos de $\mathrm{Fe}$ son agentes reguladores de $\mathrm{Pb}^{+2}$ en aguas naturales debido a sus grupos $-\mathrm{OH}$ y/o $-\mathrm{OH}_{2}$ superficiales[48], [49]. Recientemente, la adsorción de $\mathrm{Pb}^{+2}$ sobre materiales basados en magnetita fue atribuida a interacciones electrostaticas inespecificas y complejación superficial[40], [41]. De hecho, la disminución en la carga negativa superficial despues de la adsorción de $\mathrm{Pb}^{+2}$ puede atribuirse a la interacción electrostatica entre Fe-nAp y los iones $\mathrm{Pb}^{+2} / \mathrm{Pb}(\mathrm{OH})^{+}$presentes en solución, de tal manera que la formación de hidróxidos de $\mathrm{Pb}^{+2}$ es posible, en concordancia con los resultados reportados para la adsorción de este metal sobre geothita [47].

La 2,5SBO-Fe-nAp presenta isotermas con valores de $b$ menores y $K_{L}$ más altos que aquellos obtenidos para la Fe-nAp. Esta observación sugiere la disponibilidad de menor número de sitios y probablemente diferentes para la adsorción de $\mathrm{Pb}^{+2}$. Como ya se mencionó, vide supra, los resultados de los espectros FTIR permiten proponer que la complejación de $\mathrm{Pb}^{+2}$ con los grupos hidroxilos y carbonilos de los SBO, es posible. Considerando el número de sitios $\mathrm{OH}$ y $\mathrm{C}=\mathrm{O}$ de los $\mathrm{SBO}$ y que estos a su vez son el $5 \%$ de la masa de la particula se puede estimar un valor b de $46 \mu \mathrm{mol} \mathrm{m}^{-2}$ que se encuentra en concordancia 
con el valor de $59 \mu \mathrm{mol} \mathrm{m} \mathrm{m}^{-2}$ encontrado usando el ajuste del modelo de Langmuir en la isoterma experimental. Además, debido a que los SBO pueden ser tratados como estructura polimericas con alta concentracion de grupos carboxilatos[50], la formación de complejos entre $\mathrm{Pb}^{+2} / \mathrm{Pb}(\mathrm{OH})^{+}$con los grupos carboxilatos de los SBO remanentes en la superficie de la particula conllevaria a la formación de macroestructuras interparticulas, con carga baja 0 nula que favorecen considerablemente el estado de agregación de estas particulas posterior al proceso de adsorción.

\subsubsection{Adsorción simultanea de $\mathrm{Cu}^{+2}$ y $\mathrm{Pb}^{+2}$.}

Los ensayos de adsorción bi-metalicos se realizaron con una concentración inicial de 6,4 ppm de $\mathrm{Cu}^{+2}$ necesaria para alcanzar el plató de la isoterma de adsorción de este metal sobre las partículas nAp y Fe-nAp bajos las mismas condiciones experimentales. Las isotermas obtenidas se muestran en la Figura 4.21 donde el exceso superficial se expresa como iones por gramo de partículas para facilitar la comparación.
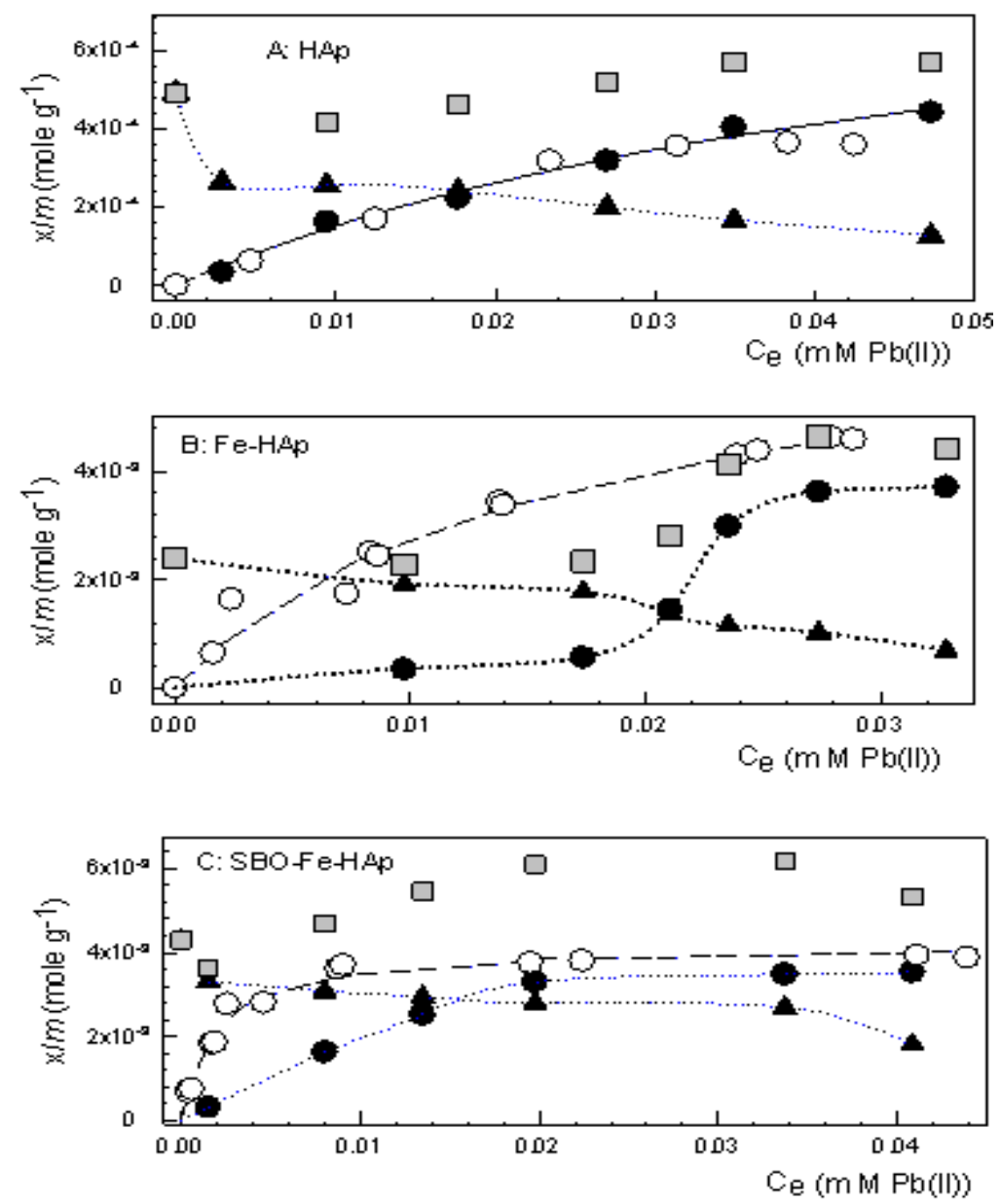

Fig.4.21 - Isotermas de Adsorción de $\mathrm{Pb}^{+2}$ (ט) y de $\mathrm{Cu}^{+2}$ ( $\left.\boldsymbol{\nabla}\right)$ a $25^{\circ} \mathrm{C}$ en experimentos de adsorción bimetálico. Para (de abajo hacia arriba) nAp, Fe-nAp y 2,5-SBO-Fe-nAp. El número total de iones adsorbidos $n_{T}(\square)$. Para efectos comparativos se muestra la isoterma de adsorción de $\mathrm{Pb}^{+2}$ en el sistema mono-metálico (O). 
Bajo estas condiciones, la isoterma de adsorción de $\mathrm{Pb}^{+2}$ sobre $\mathrm{nAp}$ concuerda con el comportamiento observado para el sistema monometalico. De esta forma la cantidad de $\mathrm{Cu}^{+2}$ adsorbida disminuye a medida que aumenta la adsorción de $\mathrm{Pb}^{+2}$ como se muestra en la figura 4.23. El número total de iones adsorbidos $\left(n_{T}\right)$ permanece constante dentro del error experimental en $\sim 0,6 \mathrm{mmol}$ ión $\mathrm{g}^{-1}$. Este último valor está en armonía con el valor calculado para el número máximo de capacidad de adsorción de iones $\mathrm{Pb}^{+2}$ calculado en el sistema unimetal $\left(b_{n}\right)=0,67 \mathrm{mmol} \mathrm{g}^{-1}$. Esto parece indicar que sobre la partículas $\mathrm{nAp}$ los iones $\mathrm{Cu}^{+2}$ y $\mathrm{Pb}^{+2}$ comparten el mismo sitio de adsorción y que la afinidad entre el $\mathrm{Pb}^{+2}$ y la partícula es mayor que para el $\mathrm{Cu}^{+2}$. Resultados similares han sido reportados para hidroxiapatitas sinteticas[24].

Sin embargo, el comportamiento de adsorción sobre Fe-nAp de los dos metales parece ser competitiva dependiendo de la $\left[\mathrm{Pb}^{+2}\right]$. Los mayores valores de $\mathrm{n}_{T}$ para altas concentraciones de $\mathrm{Pb}^{+2}$ parece indicar que los metales comparten el mismo sitio de adsorción, aunque se evidencia mayor capacidad de adsorción de moles de $\mathrm{Pb}^{+2}$ por area superficial y que la afinidad de la superficie por este metal es mayor que la que muestra por el $\mathrm{Cu}^{+2}$. Un comportamiento similar fue reportado para suelos y se explicó mediante la diferencia de los tamaños de los radios iónicos. El $\mathrm{Pb}^{+2}(4.01 \AA)$ presenta un radio iónico menor comparado al del $\mathrm{Cu}^{+2}(4.19 \AA)$ favoreciando así la complejación del metal con grupos hidroxilos[51].

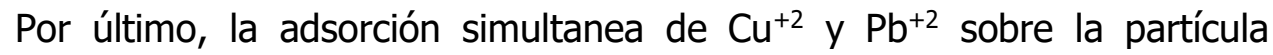
2,5SBO-Fe-nAp muestra una competencia no tan marcada. Ambos elementos son adsorbidos independiente de la concentración del otro. Lo anterior se podría explicar con la existencia de sitios de adsorción disponible para ambos iones y que no necesariamente son los mismos. 


\subsection{Conclusiones.}

Por un lado, los ensayos de caracterización de todas las nanopartículas sintetizadas en este capítulo indican que el uso de los SBO y la incorporación de iones de Fe en la síntesis de nAp modifican la morfología y la química superficial de las mismas. Entre los cambios observados se remarcan la reducción de la cristalinidad de la hidroxiapatita, disminución del tamaño de las partículas acompañado de una mayor área superficial específica, disminución del contenido superficial de $\mathrm{Ca}^{+2}$ y la introducción de fosfatos y óxidos de hierro, incrementando así el contenido de oxígeno y la carga negativa superficial de estos materiales. El comportamiento magnético de las partículas se debe a la formación de óxidos de hierro.

Todos los cambios morfológicos descriptos favorecen el proceso de adsorción de $\mathrm{Cu}^{+2}$ sobre la superficie de las partículas al introducir las fases de hierro y los SBO. Aun así, el tamaño de los aglomerados que forman estas partículas en suspensión acuosa parece afectar el área superficial específica disponible para la adsorción de $\mathrm{Cu}^{+2}$.

Los ensayos de adsorción de $\mathrm{Pb}^{+2}$ indican que el proceso de adsorción sobre las nanopartículas es un proceso irreversible. La introducción de Fe en las nanopartículas incrementa la eficiencia de este proceso al igual que el uso de los SBO en la síntesis.

Los ensayos de adsorción bi-metálico muestran resultados diferentes para todas las partículas. Por su parte la nAp muestra una adsorción selectiva de $\mathrm{Pb}^{+2}$ sobre $\mathrm{Cu}^{+2}$, para las partículas Fe-nAp esta selectividad depende fuertemente de la relación $[\mathrm{Pb}] /[\mathrm{Cu}]$ mientras que por su parte la 2,5-SBO-Fe-nAp muestra igual afinidad por ambos metales.

De todo lo expuesto se puede concluir que todos los materiales aquí estudiados poseen gran potencial para su uso en la remediación de cuerpos acuosos debido a la alta eficiencia que poseen para adsorber $\mathrm{Cu}$ y $\mathrm{Pb}$ y por ser ambientalmente amigables. 


\subsection{Referencias Bibliográficas.}

[1] M. N. Salimi, R. H. Bridson, L. M. Grover, and G. A. Leeke, "Effect of processing conditions on the formation of hydroxyapatite nanoparticles," Powder Technol., vol. 218, pp. 109-118, 2012.

[2] M. Aminzare, A. Eskandari, M. H. Baroonian, A. Berenov, Z. Razavi Hesabi, M. Taheri, and S. K. Sadrnezhaad, "Hydroxyapatite nanocomposites: Synthesis, sintering and mechanical properties," Ceram. Int., vol. 39, no. 3, pp. 2197-2206, 2013.

[3] J. Lemus and E. Bedolla, "3 er Foro de Ingeniería e Investigación en Materiales," vol. 3, pp. 49-54, 2006.

[4] M. Sadat-Shojai, M. T. Khorasani, E. Dinpanah-Khoshdargi, and A. Jamshidi, "Synthesis methods for nanosized hydroxyapatite with diverse structures," Acta Biomater., vol. 9, no. 8, pp. 7591-7621, 2013.

[5] Y. Li, C. T. Nam, and C. P. Ooi, "Iron(III) and manganese(II) substituted hydroxyapatite nanoparticles: Characterization and cytotoxicity analysis," J. Phys. Conf. Ser., vol. 187, p. 012024, 2009.

[6] A. Tampieri, T. D'Alessandro, M. Sandri, S. Sprio, E. Landi, L. Bertinetti, S. Panseri, G. Pepponi, J. Goettlicher, M. Ba??obre-L??pez, and J. Rivas, "Intrinsic magnetism and hyperthermia in bioactive Fe-doped hydroxyapatite," Acta Biomater., vol. 8, no. 2, pp. 843-851, 2012.

[7] J. R. B. Argar, G. E. B. J. R. Rown, and G. A. P. Arks, "Surface complexation of Pb ( II ) at oxide-water interfaces: III . XAFS determination of $\mathrm{Pb}$ ( II ) and $\mathrm{Pb}$ ( II ) -chloro adsorption complexes on goethite and alumina," vol. 62, no. 2, pp. 193207, 1998.

[8] L. Hidmi and M. Edwards, "Role of Temperature and pH in $\mathrm{Cu}(\mathrm{OH}) 2$ Solubility," Environ. Sci. Technol., vol. 33, no. 15, pp. 2607-2610, Aug. 1999.

[9] A. Corami, S. Mignardi, and V. Ferrini, "Cadmium removal from single- and multimetal $(\mathrm{Cd}+\mathrm{Pb}+\mathrm{Zn}+\mathrm{Cu})$ solutions by sorption on hydroxyapatite," J. Colloid Interface Sci., vol. 317, no. 2, pp. 402-408, 2008.

[10] V. Dhand, K. Y. Rhee, and S. J. Park, "The facile and low temperature synthesis of nanophase hydroxyapatite crystals using wet chemistry," Mater. Sci. Eng. C, vol. 36, no. 1, pp. 152-159, 2014.

[11] E. O. López, A. L. Rossi, B. S. Archanjo, R. O. Ospina, A. Mello, and A. M. Rossi, "Crystalline nano-coatings of fluorine-substituted hydroxyapatite produced by magnetron sputtering with high plasma confinement," Surf. Coatings Technol., vol. 264, pp. 163-174, 2015.

[12] I. Rehman and W. Bonfield, "Characterization of hydroxyapatite and carbonated apatite by photo acoustic FTIR spectroscopy," J. Mater. Sci. Mater. Med., vol. 8, no. 1, pp. 1-4, 1997.

[13] Y.-S. LI, J. S. CHURCH, and A. L. WOODHEAD, "Infrared and Raman spectroscopic studies on iron oxide magnetic nano-particles and their surface modifications," $\mathrm{J}$. Magn. Magn. Mater., vol. 324, no. 8, pp. 1543-1550.

[14] S. Panseri, C. Cunha, T. D'Alessandro, M. Sandri, G. Giavaresi, M. Marcacci, C. T. Hung, and A. Tampieri, "Intrinsically superparamagnetic Fe-hydroxyapatite nanoparticles positively influence osteoblast-like cell behaviour," $J$. Nanobiotechnology, vol. 10, no. 1, p. 32, 2012.

[15] A. Costescu, I. Pasuk, F. Ungureanu, A. Dinischiotu, F. Huneau, S. Galaup, P. L. E. Coustumer, D. Predoi, and C. Ftir, "Physico-Chemical Properties of Nano-Sized Hexagonal Hydroxyapatite Powder Synthesized By Sol-Gel," vol. 5, no. 4, pp. 989$1000,2010$.

[16] K. Kandori, S. Toshima, M. Wakamura, M. Fukusumi, and Y. Morisada, "Effects of modification of calcium hydroxyapatites by trivalent metal ions on the protein adsorption behavior," J. Phys. Chem. B, vol. 114, no. 7, pp. 2399-2404, 2010.

[17] R. Morrissey, L. M. Rodríguez-Lorenzo, and K. A. Gross, "Influence of ferrous iron incorporation on the structure of hydroxyapatite," J. Mater. Sci. Mater. Med., vol. 
16, no. 5, pp. 387-392, 2005.

[18] T. Yamashita and P. Hayes, "Analysis of XPS spectra of Fe2+ and Fe3+ ions in oxide materials," Appl. Surf. Sci., vol. 254, no. 8, pp. 2441-2449, 2008.

[19] M. C. Biesinger, B. P. Payne, A. P. Grosvenor, L. W. M. Lau, A. R. Gerson, and R. S. C. Smart, "Resolving surface chemical states in XPS analysis of first row transition metals, oxides and hydroxides: $\mathrm{Cr}, \mathrm{Mn}, \mathrm{Fe}$, $\mathrm{Co}$ and Ni," Appl. Surf. Sci., vol. 257, no. 7, pp. 2717-2730, 2011.

[20] J. L. Grosseau-Poussard, B. Panicaud, F. Pedraza, P. O. Renault, and J. F. Silvain, "Iron oxidation under the influence of phosphate thin films," J. Appl. Phys., vol. 94, no. 1, pp. 784-788, 2003.

[21] H. B. Lu, C. T. Campbell, D. J. Graham, and B. D. Ratner, "Surface Characterization of Hydroxyapatite and Related Calcium Phosphates by XPS and TOF-SIMS," Anal. Chem., vol. 72, no. 13, pp. 2886-2894, Jul. 2000.

[22] M. Khachani, M. Kacimi, A. Ensuque, J. Y. Piquemal, C. Connan, F. BozonVerduraz, and M. Ziyad, "Iron-calcium-hydroxyapatite catalysts: Iron speciation and comparative performances in butan-2-ol conversion and propane oxidative dehydrogenation," Appl. Catal. A Gen., vol. 388, no. 1-2, pp. 113-123, 2010.

[23] K. Nishio, M. Ikeda, N. Gokon, S. Tsubouchi, H. Narimatsu, Y. Mochizuki, S. Sakamoto, a. Sandhu, M. Abe, and H. Handa, "Preparation of size-controlled (30$100 \mathrm{~nm}$ ) magnetite nanoparticles for biomedical applications," J. Magn. Magn. Mater., vol. 310, no. 2 SUPPL. PART 3, pp. 2408-2410, 2007.

[24] S. B. Chen, Y. B. Ma, L. Chen, and K. Xian, "Adsorption of aqueous Cd 2+ , Pb 2+ , $\mathrm{Cu} 2+$ ions by nano-hydroxyapatite: Single- and multi-metal competitive adsorption study," Geochem. J., vol. 44, pp. 233-239, 2010.

[25] K. F. Sze, Y. J. Lu, and P. K. Wong, "Removal and recovery of copper ion (Cu2+) from electroplating effluent by a bioreactor containing magnetite-immobilized cells of Pseudomonas putida 5X*," Stud. Environ. Sci., vol. 66, no. C, pp. 131-149, 1997.

[26] Y. Yamashita and R. Jaffé, "Characterizing the Interactions between Trace Metals and Dissolved Organic Matter Using Excitation-Emission Matrix and Parallel Factor Analysis," Environ. Sci. Technol., vol. 42, no. 19, pp. 7374-7379, Oct. 2008.

[27] F. Deganello, M. L. Tummino, C. Calabrese, M. L. Testa, P. Avetta, D. Fabbri, A. B. Prevot, E. Montoneri, and G. Magnacca, "A new, sustainable LaFeO 3 material prepared from biowaste-sourced soluble substances," New J. Chem., vol. 39, no. 2, pp. 877-885, 2015.

[28] M. Senna, "Determination of Effective Surface Area for the Chemi Reaction of Fine Particulate Materials," vol. 6, pp. 163-167, 1989.

[29] A. R. Murray, E. R. Kisin, A. V Tkach, N. Yanamala, R. R. Mercer, S.-H. Young, B. Fadeel, V. E. Kagan, and A. a Shvedova, "Factoring-in agglomeration of carbon nanotubes and nanofibers for better prediction of their toxicity versus asbestos," Part. Fibre Toxicol., vol. 9, no. 1, p. 10, 2012.

[30] G. De With, H. J. A. Van Dijk, N. Hattu, and K. Prijs, "Preparation, microstructure and mechanical properties of dense polycrystalline hydroxy apatite," J. Mater. Sci., vol. 16 , no. 6, pp. 1592-1598, 1981.

[31] a Oasmaa, D. C. Elliott, and S. Mu, "Quality Control in Fast Pyrolysis Bio-Oil Production and Use," Environ. Prog., vol. 28, no. 3, pp. 404-409, 2009.

[32] S. T. Ramesh, N. Rameshbabu, R. Gandhimathi, M. Srikanth Kumar, and P. V. Nidheesh, "Adsorptive removal of $\mathrm{Pb}(\mathrm{II})$ from aqueous solution using nano-sized hydroxyapatite," Appl. Water Sci., vol. 3, pp. 105-113, 2012.

[33] S. P. Singh, L. Q. Ma, and M. J. Hendry, "Characterization of aqueous lead removal by phosphatic clay: Equilibrium and kinetic studies," J. Hazard. Mater., vol. 136, no. 3, pp. 654-662, 2006.

[34] J. Cha, M. Cui, M. Jang, S. H. Cho, D. H. Moon, and J. Khim, "Kinetic and mechanism studies of the adsorption of lead onto waste cow bone powder (WCBP) surfaces," Environ. Geochem. Health, vol. 33, no. SUPPL. 1, pp. 81-89, 
2011.

[35] V. Laperche, T. J. Logan, P. Gaddam, and S. J. Traina, "Effect of apatite amendments on plant uptake of lead from contaminated sail," Environ. Sci. Technol., vol. 31, no. 10, pp. 2745-2753, 1997.

[36] T. L. Dowd, J. F. Rosen, L. Mints, and C. M. Gundberg, "The effect of Pb2+ on the structure and hydroxyapatite binding properties of osteocalcin," Biochim. Biophys. Acta - Mol. Basis Dis., vol. 1535, no. 2, pp. 153-163, 2001.

[37] D. Liao Dexiang, W. Zheng, X. Li, Q. Yang, X. Yue, L. Guo, and G. Zeng, "Removal of lead(II) from aqueous solutions using carbonate hydroxyapatite extracted from eggshell waste," J. Hazard. Mater., vol. 177, no. 1-3, pp. 126-130, 2010.

[38] L. Li and R. Stanforth, "Distinguishing Adsorption and Surface Precipitation of Phosphate on Goethite (alpha-FeOOH).," J. Colloid Interface Sci., vol. 230, pp. 12-21, 2000.

[39] Q. Y. Ma, S. J. Traina, T. J. Logan, and J. A. Ryan, "Effects of Aqueous Al, Cd, Cu, $\mathrm{Fe}(\mathrm{Ii}), \mathrm{Ni}$, and $\mathrm{Zn}$ On $\mathrm{Pb}$ Immobilization By Hydroxyapatite," Environ. Sci. Technol., vol. 28, no. 7, pp. 1219-1228, 1994.

[40] Y. I. N. Wang, Y. Xie, W. Li, Z. Wang, and D. E. Giammar, "Formation of Lead ( IV ) Oxides from Lead ( II ) Compounds," vol. 44, no. 23, pp. 8950-8956, 2010.

[41] S. Nasrazadani, V. Paliwal, M. Du, R. F. Reidy, J. Stevens, and R. Theimer, "Lead adsorption on magnetite at 200??C," Corrosion, vol. 64, no. 6, pp. 509-516, 2008.

[42] L. Dong, Z. Zhu, Y. Qiu, and J. Zhao, "Removal of lead from aqueous solution by hydroxyapatite/magnetite composite adsorbent," Chem. Eng. J., vol. 165, no. 3, pp. 827-834, 2010.

[43] G. Pan and P. S. Liss, "Metastable-Equilibrium Adsorption Theory," J. Colloid Interface Sci., vol. 201, no. 1, pp. 77-85, 1998.

[44] E. Mavropoulos, A. M. Rossi, A. M. Costa, C. A. C. Perez, J. C. Moreira, and M. Saldanha, "Studies on the mechanisms of lead immobilization by hydroxyapatite," Environ. Sci. Technol., vol. 36, no. 7, pp. 1625-1629, 2002.

[45] A. R. Kampf, I. M. Steele, and R. A. Jenkins, "Phosphohedyphane, $\mathrm{Ca} 2 \mathrm{~Pb} 3(\mathrm{PO} 4) 3 \mathrm{Cl}$, the phosphate analog of hedyphane: Description and crystal structure," Am. Mineral., vol. 91, no. 11-12, pp. 1909-1917, 2006.

[46] NIST, "NIST X-ray Photoelectron Spectroscopy Database; Version 4.1," 2012. [Online]. Available: http://srdata.nist.gov/xps/.

[47] H. Abdel-Samad and P. R. Watson, "An XPS study of the adsorption of lead on goethite (alpha-FeOOH)," Appl. Surf. Sci, vol. 136, no. June, pp. 46-54, 1998.

[48] G. Morin, J. D. Ostergren, F. Juillot, P. Ildefonse, G. Calas, and G. E. J. Brown, "XAFS determination of the chemical form of lead in smelter-contamined soils and mine tailing: Importance of adsorption processes," Am. Mineral., vol. 84, pp. 420434, 1999.

[49] C. Liu and P. M. Huang, "Kinetics of lead adsorption by iron oxides formed under the influence of citrate," Geochim. Cosmochim. Acta, vol. 67, no. 5, pp. 1045$1054,2003$.

[50] E. Montoneri, V. Boffa, P. Savarino, D. Perrone, M. Ghezzo, C. Montoneri, and R. Mendichi, "Acid soluble bio-organic substances isolated from urban bio-waste. Chemical composition and properties of products," Waste Manag., vol. 31, no. 1, pp. 10-17, 2011.

[51] F. Zhang, X. Ou, S. Chen, C. Ran, and X. Quan, "Competitive adsorption and desorption of copper and lead in some soil of North China," Front. Environ. Sci. Eng., vol. 6, no. 4, pp. 484-492, 2012. 


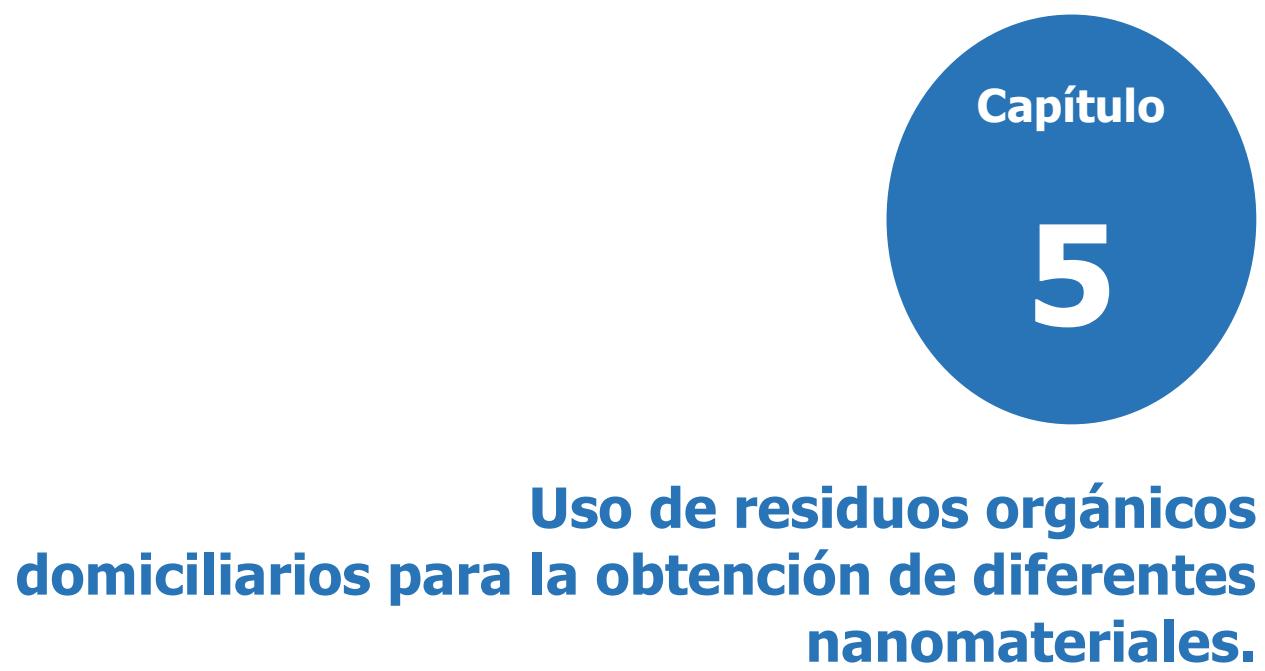

El desarrollo de nuevas técnicas de conversión de materias primas no convencionales para la obtención de materiales ha sido foco de estudio en las últimas décadas. Específicamente, es de mucho interés el aprovechamiento de la biomasa para la obtención de diversos nanomateriales, ya sea como precursor o como auxiliar de síntesis. Entre las técnicas no convencionales más utilizadas para la obtención de materiales a partir de residuos se encuentran la pirolisis por vía térmica o por irradiación microondas, entre otras.

La yerba mate (Ilexparaguariensis) es una planta argentina fuertemente comercializada ya que se utiliza para preparar infusiones de alto grado de aceptación en la región. La comercialización de la yerba mate es un mercado en expansión que involucra alrededor de 750.000 toneladas anuales de producto para consumo.

Existen en la literatura algunas publicaciones sobre la obtención de nanopartículas de $\mathrm{CuO}, \mathrm{ZnO}$ y Au que utilizan extractos solubles de la biomasa proveniente de residuos vegetales[1]-[3].

En el desarrollo de este trabajo se utilizó la Yerba Mate (YM) en la síntesis de diversas nanopartículas. El extracto hidrosoluble de la YM se utilizó como aditivo en la obtención de partículas de plata y magnetita, mientras que el residuo carbonoso de la pirolisis de la YM se utilizó en la síntesis de partículas de C y sílice. 


\subsection{Materiales y métodos.}

\subsubsection{Síntesis de las nanopartículas.}

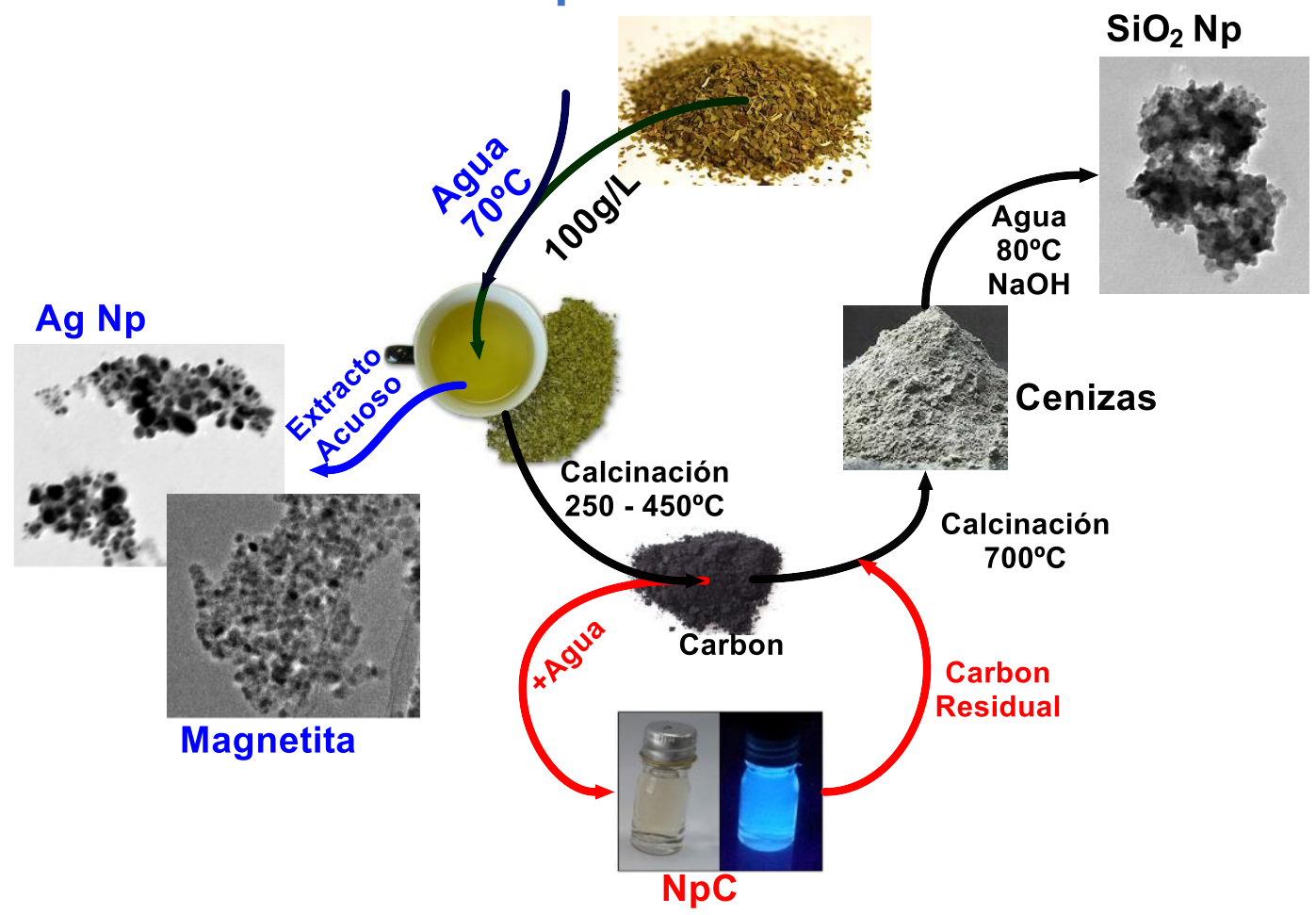

Fig.5.1- Esquema de síntesis de las Nanopartículas de interés a partir de la YM.

Se utilizó la yerba mate como materia prima en la obtención de diferentes nanopartículas. La Figura 5.1 resume el proceso de síntesis de las mismas y a continuación se explica el procedimiento para cada partícula. Los procesos empleados se diseñaron tomando como base las síntesis convencionales de las partículas a partir de diferentes materias primas[1], [4]-[17].

Nanopartículas de Ag: Se agregó agua a $70^{\circ} \mathrm{C}$ en $10 \mathrm{~g}$ de Yerba Mate (YM) hasta un volumen final de 1L. La temperatura se mantuvo constante durante una hora. El extracto acuoso obtenido se utilizó para la síntesis de las nanopartículas de Ag mientras que el sólido (YM) remanente se reservó para otras síntesis. Se disolvieron $0,05 \mathrm{~g}$ de $\mathrm{AgNO}_{3}$ en $50 \mathrm{~mL}$ del extracto de $\mathrm{YM}$ a temperatura ambiente y se sometió la solución a agitación durante 1 hora. El sólido formado se separó por filtración $(Q=0,22 \mu \mathrm{m})$ y se secó a $40^{\circ} \mathrm{C}$ en vacío durante 8 horas.

Nanopartículas de $\mathbf{F e}_{3} \mathrm{O}_{4}:$ El extracto de yerba mate se preparó de la misma forma que para la síntesis de las nanopartículas de Ag, vide supra. Para la síntesis de las nanopartículas de magnetita se mezclaron $6,1 \mathrm{~g} \mathrm{FeCl} 36 \mathrm{H}_{2} \mathrm{O}$ y $4,2 \mathrm{~g}$ $\mathrm{FeSO}_{4} .7 \mathrm{H}_{2} \mathrm{O}$ en $100 \mathrm{~mL}$ de $\mathrm{H}_{2} \mathrm{O}$ Milli-Q. La mezcla se somete a agitación hasta la disolución de los sólidos, momento en el que se empieza el calentamiento para llevar a $90^{\circ} \mathrm{C}$. Una vez alcanzada la temperatura se procede a agregar $10 \mathrm{~mL}$ de $\mathrm{NH}_{3}$ 25\% seguido de $50 \mathrm{~mL}$ del extracto de YM. Para evaluar el efecto del extracto de YM en las propiedades y morfología de las nanopartículas, se utilizaron diferentes volúmenes de extracto $(50,30,10$ y $0 \mathrm{~mL})$ completando con agua el volumen hasta completar los $50 \mathrm{~mL}$. Se mantuvo la agitación y el 
calentamiento de la solución durante los siguientes 30 minutos. Posteriormente, se procede a la separación del precipitado obtenido utilizando un magneto y lavando el sólido tres veces con agua Milli-Q para la eliminación productos secundarios no magnéticos. Los sólidos obtenidos se secaron a $70^{\circ} \mathrm{C}$ en un horno con vacío durante varias horas. Posterior a ello se almacenaron en frascos color ámbar y se protegieron de la luz. Los sólidos obtenidos se denominan YM0 YM10 - YM30 - YM50, de acuerdo a la cantidad de extracto usado en cada caso.

Nanopartículas de Carbono:El sólido (YM) remanente de la síntesis de las nanopartículas de $\mathrm{Ag} \mathrm{O} \mathrm{Fe}_{3} \mathrm{O}_{4}$ se calcinó a $400^{\circ} \mathrm{C}$. Para llegar a esa temperatura se utilizó inicialmente una rampa de calentamiento con pendiente de $10^{\circ} \mathrm{C} / \mathrm{min}$ y se mantuvo a la temperatura deseada durante 2 horas. Luego, cuando el carbón de yerba mate (CYM) obtenido se encontrara a temperatura ambiente, se suspendió en agua MilliQ en una relación 0,03g CYM/10mL de agua. Esta suspensión se sometió a agitación mediante ultrasonido durante 1 hora, posterior a ello el sólido fue separado por filtración $(\alpha=0.22 \mu \mathrm{M})$ y guardado mientras que el filtrado obtenido es una suspensión de nanopartículas de Carbono (NpC).

Además de la síntesis mencionada, se obtuvieron partículas de Carbono a partir de la Cascara de Naranja (CN), previamente lavada y secada a $80^{\circ} \mathrm{C}$ durante 4 horas. Las cáscaras se sometieron a pirolisis siguiendo el mismo protocolo mencionado anteriormente para la YM. De manera simultánea, se utilizó la pirolisis asistida por microondas utilizando la $\mathrm{CN}$ para la obtención de nanopartículas de carbono. En este caso $2 \mathrm{~g}$ de $\mathrm{CN}$ seca se suspendieron en 25 $\mathrm{mL}$ de agua y se sometieron a la irradiación de las microondas por 110 minutos. Luego de ello se procede a resuspender el sólido color ámbar formado con otros $25 \mathrm{~mL}$ de agua. Para la obtención de las nanopartículas se procedió a una extracción mediante ciclohexano de forma de remover los contaminantes orgánicos remanentes en la solución acuosa donde permanecen las partículas.

Las nanopartículas de carbono obtenidas por los tres métodos descritos se denominan: NpC YM 400, NpC CN 400 y NpC CN Mw, respectivamente.

Nanopartículas de $\mathbf{S i O}_{2}:$ El CYM residual de la síntesis de las NpC se calcinó a $700^{\circ} \mathrm{C}$. El calentamiento se inició con una rampa de $10^{\circ} \mathrm{C} / \mathrm{min}$, una vez alcanzado los $700^{\circ} \mathrm{C}$ se mantuvo la temperatura durante 12 horas. Se utilizaron $0,5 \mathrm{~g}$ de las cenizas para la obtención de las partículas.

\subsection{Resultados y análisis.}

\subsubsection{Nanopartículas de Ag.}

En las síntesis típicas de nanopartículas de $\mathrm{Ag}$ se parte de una solución acuosa de $\mathrm{Ag}^{+}$, comúnmente $\mathrm{AgCl}$ y $\mathrm{AgNO}_{3}$, a la cual se le agrega de forma controlada un agente reductor como el $\mathrm{NaBH}_{4}$ que promueve la reducción a $\mathrm{Ag}^{0}$ y a la vez la nucleación de los mismos. Posteriormente se agrega un agente orgánico que presenta una doble función: regular el tamaño de las partículas mediante la inclusión de las mismas en agregados, y como estabilizante superficial evitando la oxidación. La figura 5.2 resume un esquema típico de síntesis de estas nanopartículas. 


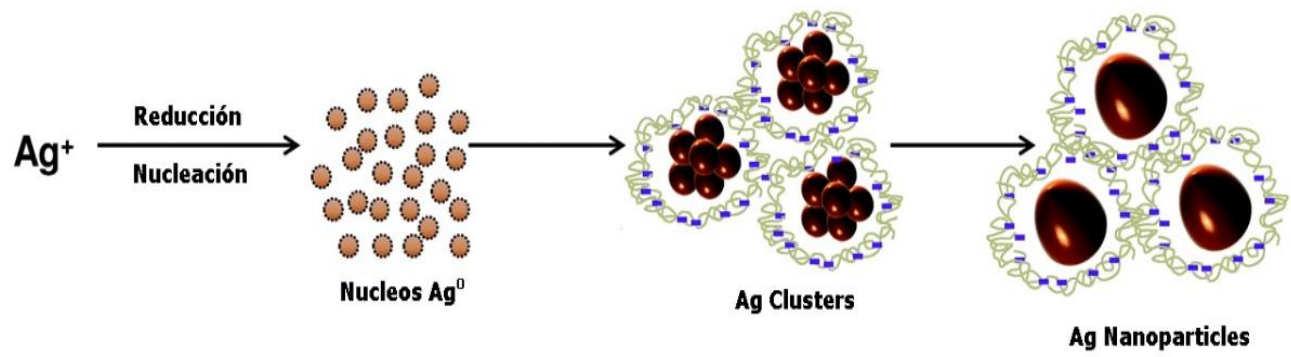

Fig. 5.2 - Mecanismo típico de la síntesis de Nanopartículas de Ag.

Las nanopartículas de $\mathrm{Ag}$ han sido ampliamente utilizadas, entre otros, en campos de la medicina para el tratamiento de diversas enfermedades debido a sus propiedades fisicoquímicas y optoelectrónicas inusuales. Por ello, es de suma importancia su obtención a través de procesos factibles económica y ambientalmente. En este contexto, el uso de la biomasa en los procesos de síntesis puede ser una buena alternativa, según los usos, debido a los bajos costos de las materias primas utilizadas y porque es amigable con el ambiente. Estos métodos de síntesis operan normalmente en condiciones ambientales, no son tóxicos y los materiales obtenidos son altamente biocompatibles[1], [2].

En este trabajo se utilizó el extracto hidrosoluble de YM para la obtención de nanopartículas de plata. Dicho extracto fue utilizado como agente reductor y estabilizante superficial de las nanopartículas. Por ello no fue requerido el uso de ningún otro agente químico. La figura 5.3 ejemplifica el proceso de síntesis.

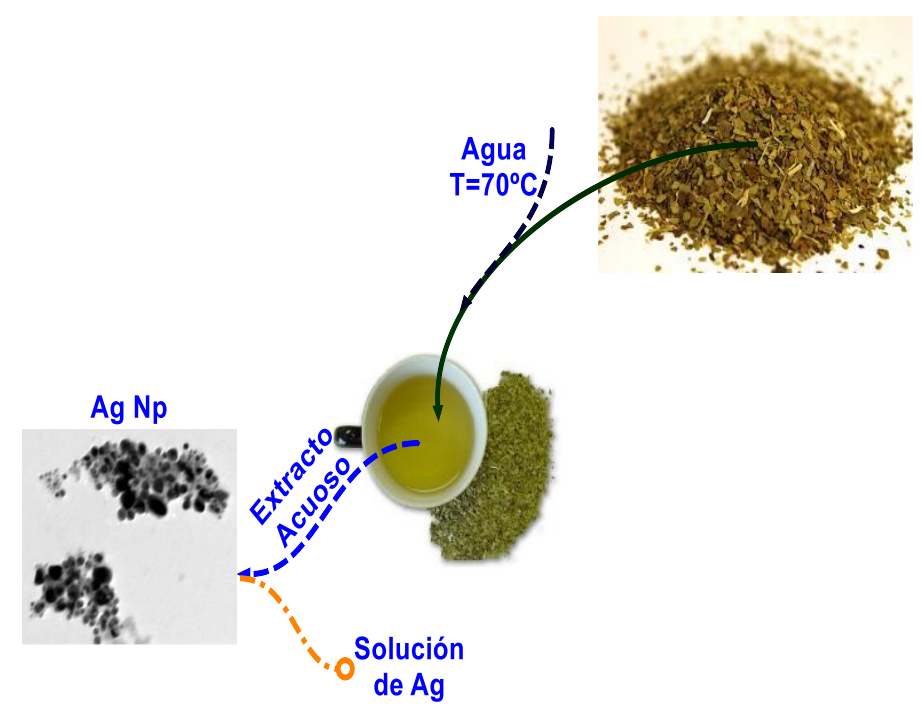

Fig. 5.3 - Síntesis de las Nanopartículas de Ag.

La figura 5.4 muestra una imagen TEM de las Nanopartículas de Ag. En ella se aprecia la formación de material nanoparticulado con una geometría aproximada esférica, típica de nanopartículas de $\mathrm{Ag}$ [1], [18]. Un análisis estadístico utilizando varias imágenes TEM (no mostradas) tomando como muestra más de 400 partículas permitió concluir que estas partículas siguen una

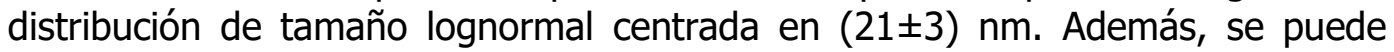
evidenciar que la muestra presenta alta dispersión en el tamaño. 

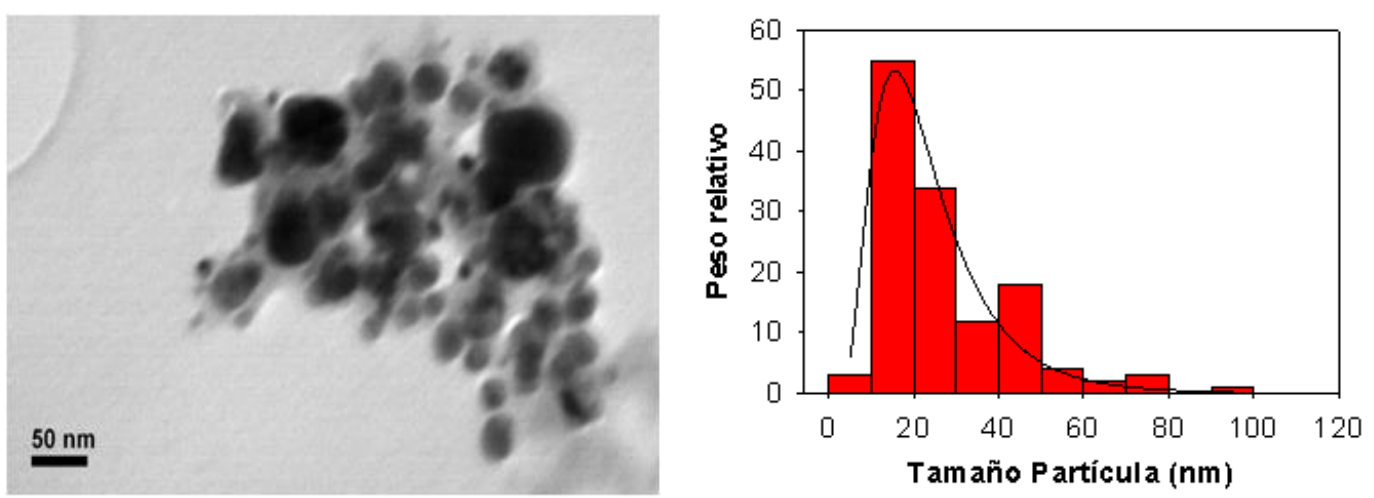

Fig. 5.4 -Izq: Imagen TEM de las Np Ag obtenidas. - Der: Distribución de tamaño de partícula de las Np Ag.

\begin{abstract}
El espectro FTIR de las nanopartículas confirma la presencia de material orgánico adsorbido sobre la superficie. La señal a $3389 \mathrm{~cm}^{-1}$ puede atribuirse al estiramiento del enlace $\mathrm{O}-\mathrm{H}$, la señal en 2735 $\mathrm{cm}^{-1}$ corresponde

estiramiento del enlace $\mathrm{C}-\mathrm{H}$ y en $1138 \mathrm{~cm}^{-1}$ se observa la señal respectiva al estiramiento del $\mathrm{C}=\mathrm{O}$. Todos estos grupos funcionales también se encuentran presentes en el extracto de YM utilizado para la síntesis de las $\mathrm{Np} \mathrm{Ag[5]} \mathrm{y} \mathrm{se}$ atribuyen a las moléculas orgánicas presentes.
\end{abstract}

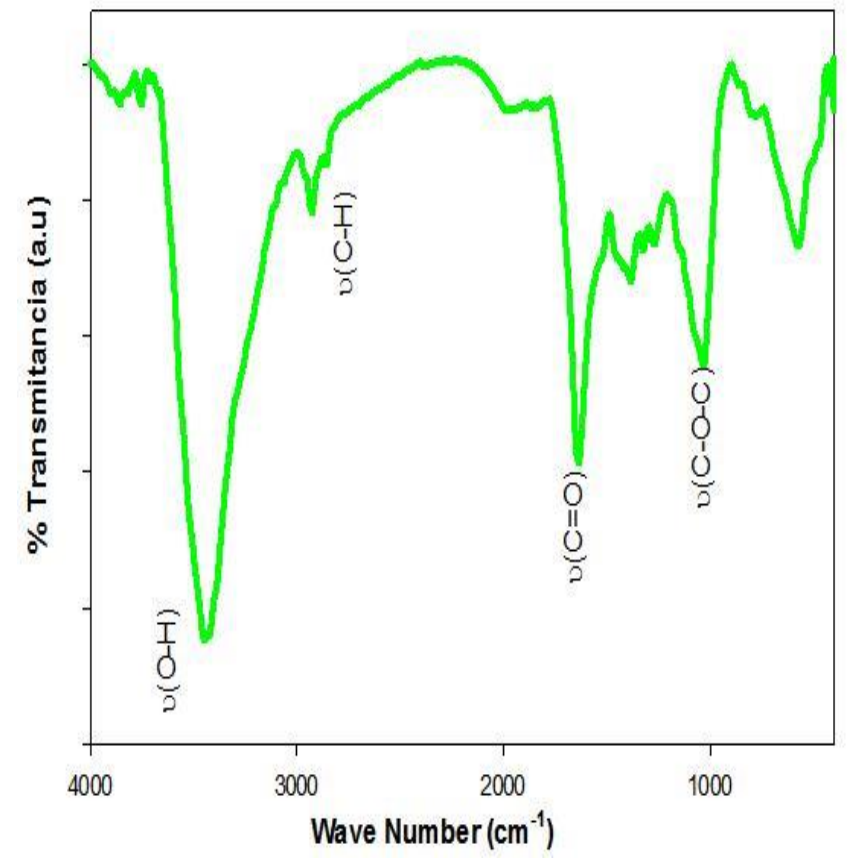

Fig. 5.5 - Espectro FTIR de las Np Ag.

El plasmón correspondiente a las nanopartículas de $\mathrm{Ag}$ [18] puede apreciarse en el espectro UV-visible de una suspensión acuosa de nanopartículas que se muestra en la figura 5.6. La banda de absorción con máximo en $489 \mathrm{~nm}$ es característico de nanopartículas de $\mathrm{Ag}$ de simetría esférica y de tamaños del orden de los $40 \mathrm{~nm}[18]$. La absorción en la región de los $200-300 \mathrm{~nm}$ puede deberse, en parte, a la materia orgánica adsorbida.

En la misma figura 5.6 se muestra el espectro de emisión $\left(\lambda_{\mathrm{EXC}}=350 \mathrm{~nm}\right)$ de las $\mathrm{Np} \mathrm{Ag}$, con el cual se evidenciaque las nanopartículas presentan propiedades fluorescentes que es atribuido a las presencia de grupos orgánicos remanentes en la superficie.La fluorescencia realzada por las nanopartículas de plata es una propiedad de actual interés científico y tecnológico. A pesar de ello, este campo de estudio no será abarcado en el contexto de esta tesis. 


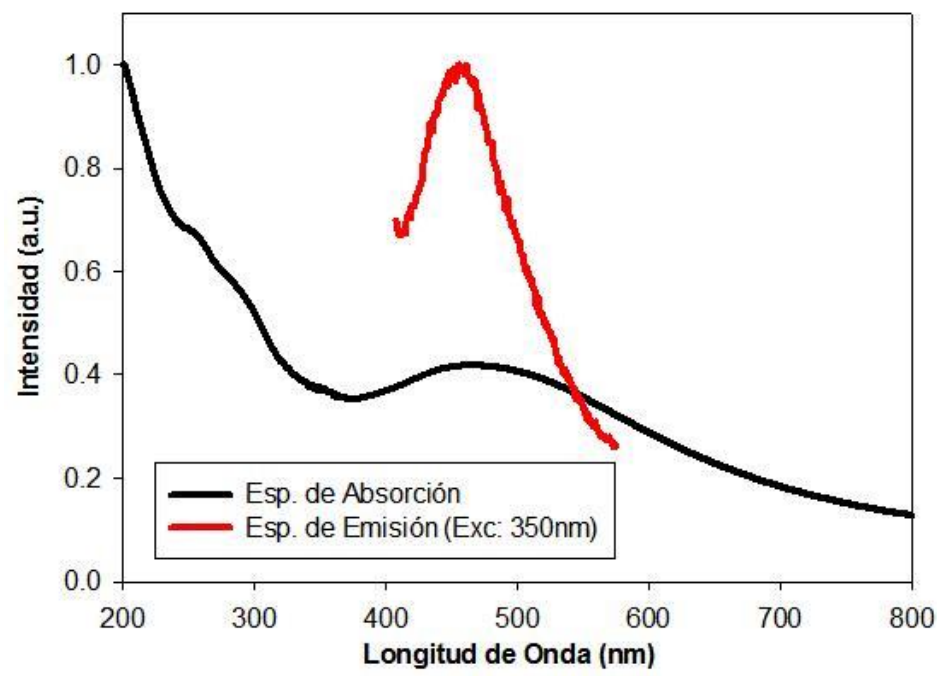

Fig. 5.6 - Espectro de Absorción UV/Vis y de Emisión de Fluorescencia $\left(\lambda_{E X C}=350 \mathrm{~nm}\right)$ de las Np Ag.

Como último ensayo de caracterización de las partículas de Ag se utilizó la técnica de XPS. Las señales correspondientes a Ag3d y C1s se muestran en la figura 5.7. Previo a cualquier análisis de los picos simulados resultantes de la deconvolución de la señal experimental, se corrigieron todas las señales debido a la carga que pueden haber adquirido las partículas durante el ensayo, ubicando la banda del C1s espurio a $384.6 \mathrm{eV}$. La señal Ag3d es un doblete correspondiente a las señales $3 \mathrm{~d} 3 / 2$ y $3 \mathrm{~d} 5 / 2$. La $\Delta \mathrm{E}$ obtenida durante las mediciones es de $6.2 \mathrm{eV}$ en concordancia con la reportada para sistemas similares de $6 \mathrm{eV}[19]$. Este doblete se deconvolucionó considerando dos picos. El primero ubicado en $367.8 \mathrm{eV}$ en concordancia para los valores reportados para la $\mathrm{Ag}^{0}$ a granel[19]. Es interesante notar que este pico tiene una Energía de enlace asociada reportada para la plata metálica en sistemas de tamaño masivo, y es bien sabido que esta puede variar dependiendo del tamaño de las nanopartículas de $\mathrm{Ag}^{0}$, sin embargo este desplazamiento a mayores energías de enlace solo ocurre para partículas de plata metálica de tamaño menor a $10 \mathrm{~nm}$, y de la distribución del tamaño de partícula si bien podemos apreciar que hay una fracción de este tamaño o menor, la fracción que supera este límite es más representativa[19], [20].
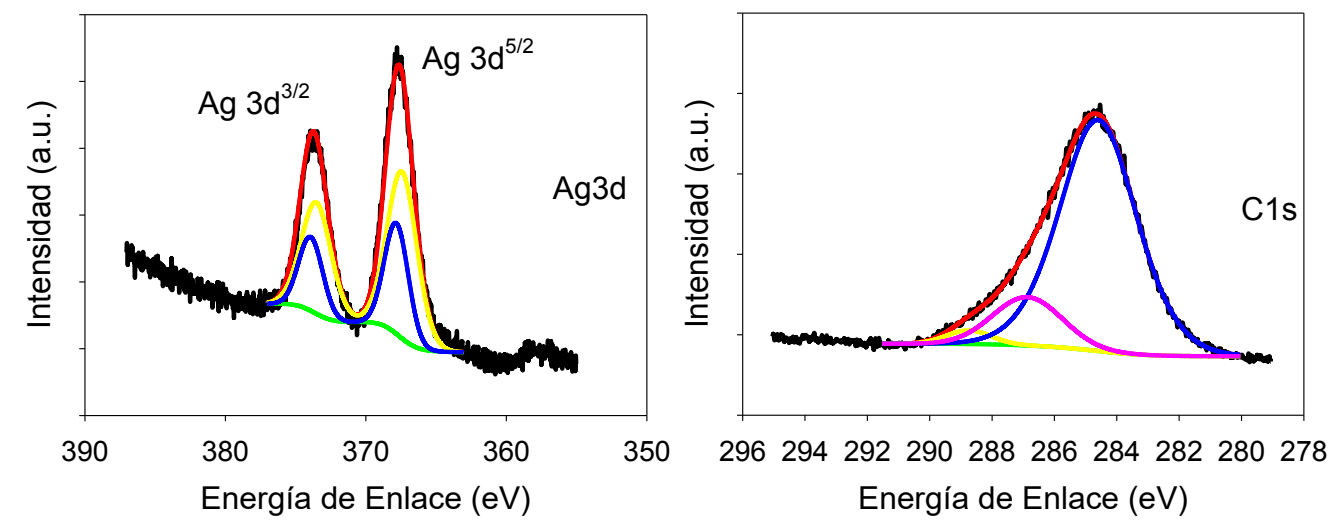

Fig. 5.7- Señales XPS de la muestra Ag en diferentes regiones. Izq: Ag3 $d^{5 / 2}$ y Ag3d/2 (Línea Negra) y picos simulados (Líneas de Colores) Der: C1s (Línea Negra) y picos simulados (Líneas de Colores). 
La otra señal de este doblete está ubicado en 367.4 eV correspondiente a la señal de $\mathrm{Ag}^{+}[19]$, esto último es indicativo de que la superficie de la nanopartículas están expuestas a la oxidación y que una fracción de la $\mathrm{Ag}^{0}$ superficial es oxidada a $\mathrm{Ag}^{+}$. Dado que la relación $\mathrm{Ag}^{+} / \mathrm{Ag}^{0}$ es de 0.53 resulta evidente que existe un grado de oxidación superficial de las nanopartículas, indicando que si bien el material orgánico actúa como antioxidante evitando la oxidación de la $\mathrm{Ag}^{0}$ superficial, la protección que esta provee no es suficiente para evitar una oxidación parcial. El $\Delta E V$ entre los máximos de los picos obtenidos para las dos especies de $\mathrm{Ag}$ es de $0.4 \mathrm{eV}$, en armonía con valores reportados para los mismos con valor de $0.3 \mathrm{eV}$ [19], [21].

Referente a la deconvolución de la señal de C1s y de los picos simulados, cabe mencionar que además del carbono espurio a $284.6 \mathrm{eV}$ (curva azul), se evidencian dos picos ubicados el primero ubicado en 286.9 eV (Curva fucsia)correspondiente a enlaces $\mathrm{C}-\mathrm{N}, \mathrm{C}-\mathrm{O} \mathrm{y} / \mathrm{o} \mathrm{C}=\mathrm{O}$ mientras que el segundo pico con máximo en $288.8 \mathrm{eV}$ es atribuido a enlaces $\mathrm{O}-\mathrm{C}=\mathrm{O}[22]$, que podrían deberse a la presencia de materia orgánica adsorbida.
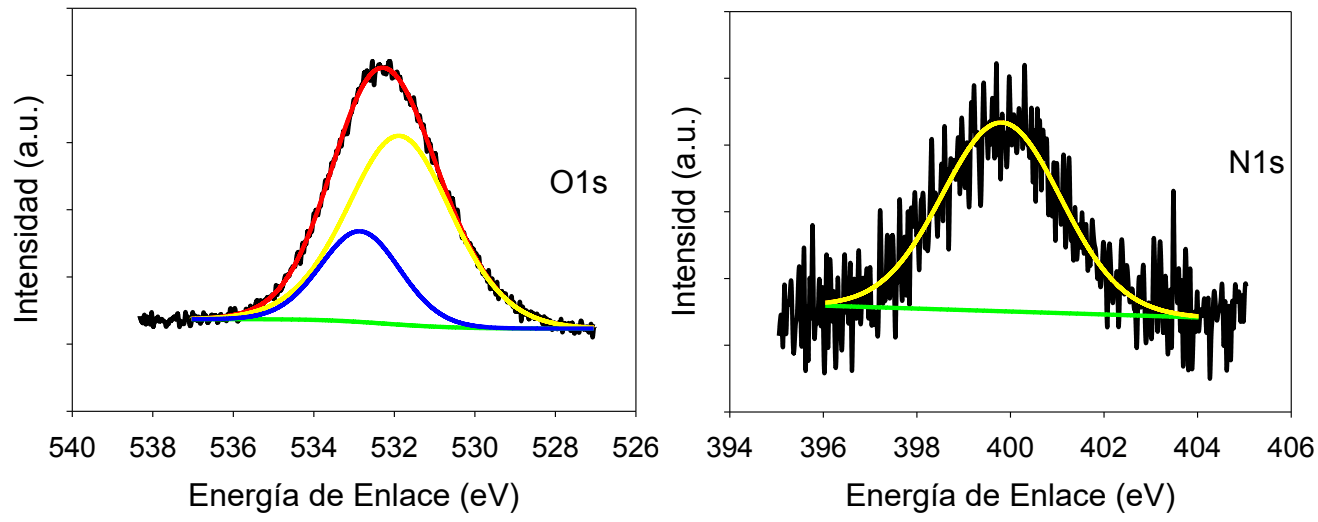

Fig. 5.8- Señales XPS de la muestra Ag en diferentes regiones. Izq: O1s (Línea Negra) y picos simulados (Líneas de Colores) Der: N1s (Línea Negra) y picos simulados (Líneas de Colores).

Las señales de O1s y N1s de la muestra se pueden apreciar en la Figura 5.8. Cabe resaltar que la región correspondiente al Oxígeno se ajusta utilizando dos curvas. La primera ubicada a 531,9 eV (curva amarilla) está en concordancia con los valores reportados para $\mathrm{Ag}-\mathrm{O}$, y que se corresponde con el pico atribuido a la $\mathrm{Ag}^{+}$con energía $367.7 \mathrm{eV}$. De igual forma se podría atribuir a enlaces metal-OH [19]. El segundo pico ubicado a $532.7 \mathrm{eV}$ (curva azul) es atribuido a los enlaces $\mathrm{O}-\mathrm{C}$ y $\mathrm{O}=\mathrm{C}$ relacionado con la señal de $\mathrm{C} 1$ ubicada a 286.9 eV[23]. Por su lado la señal de XPS de N1s se puede ajustar a una única curva con máximo en $399.8 \mathrm{eV}$ referente a enlaces C-N de diferentes naturalezas [22]. La tabla 5.1 resume el análisis realizado de las señales de XPS.

\begin{tabular}{|c|c|c|}
\hline Señal XPS & Posición (eV) & Especie Atribuida \\
\hline C1s & $\begin{array}{l}286.9 \\
288.8\end{array}$ & $\begin{array}{c}\mathrm{C}-\mathrm{N}, \mathrm{O}-\mathrm{C} \text { y } \mathrm{C}=\mathrm{O} \\
\mathrm{O}-\mathrm{C}=\mathrm{O}\end{array}$ \\
\hline $\operatorname{Ag} 3 d^{5 / 2}$ & $\begin{array}{l}367.4 \\
367.8\end{array}$ & $\begin{array}{c}\mathrm{Ag}^{+}\left(\mathrm{Ag}_{2} \mathrm{O}\right) \\
\mathrm{Ag}^{0}\end{array}$ \\
\hline $01 s$ & $\begin{array}{l}531.9 \\
532.7\end{array}$ & $\begin{array}{c}\mathrm{Ag}-\mathrm{O}, \mathrm{Ag}-\mathrm{OH} \\
\mathrm{O}-\mathrm{C} \text { y } \mathrm{O}=\mathrm{C}\end{array}$ \\
\hline N1s & 399.8 & C-N \\
\hline
\end{tabular}

Tabla 5.1 -Resultados arrojados de la deconvolucion de las señales XPS de las nanopartículas de Ag. 


\subsubsection{Nanopartículas de $\mathrm{Fe}_{3} \mathrm{O}_{4}$.}

A diferencia de lo que ocurre en la síntesis de la Nanopartículas de Ag, la participación del extracto de $\mathrm{YM}$ en la obtención de nanopartículas de $\mathrm{Fe}_{3} \mathrm{O}_{4}$ es solo la de estabilizante superficial. Ensayos preliminares donde se intentó utilizar el extracto de YM como agente precipitante de las partículas mostraron la obtención de sólidos sin propiedades magnéticas. Sin embargo, en la literatura se han empleado extracto de té como precipitantes en la síntesis de magnetita [24]

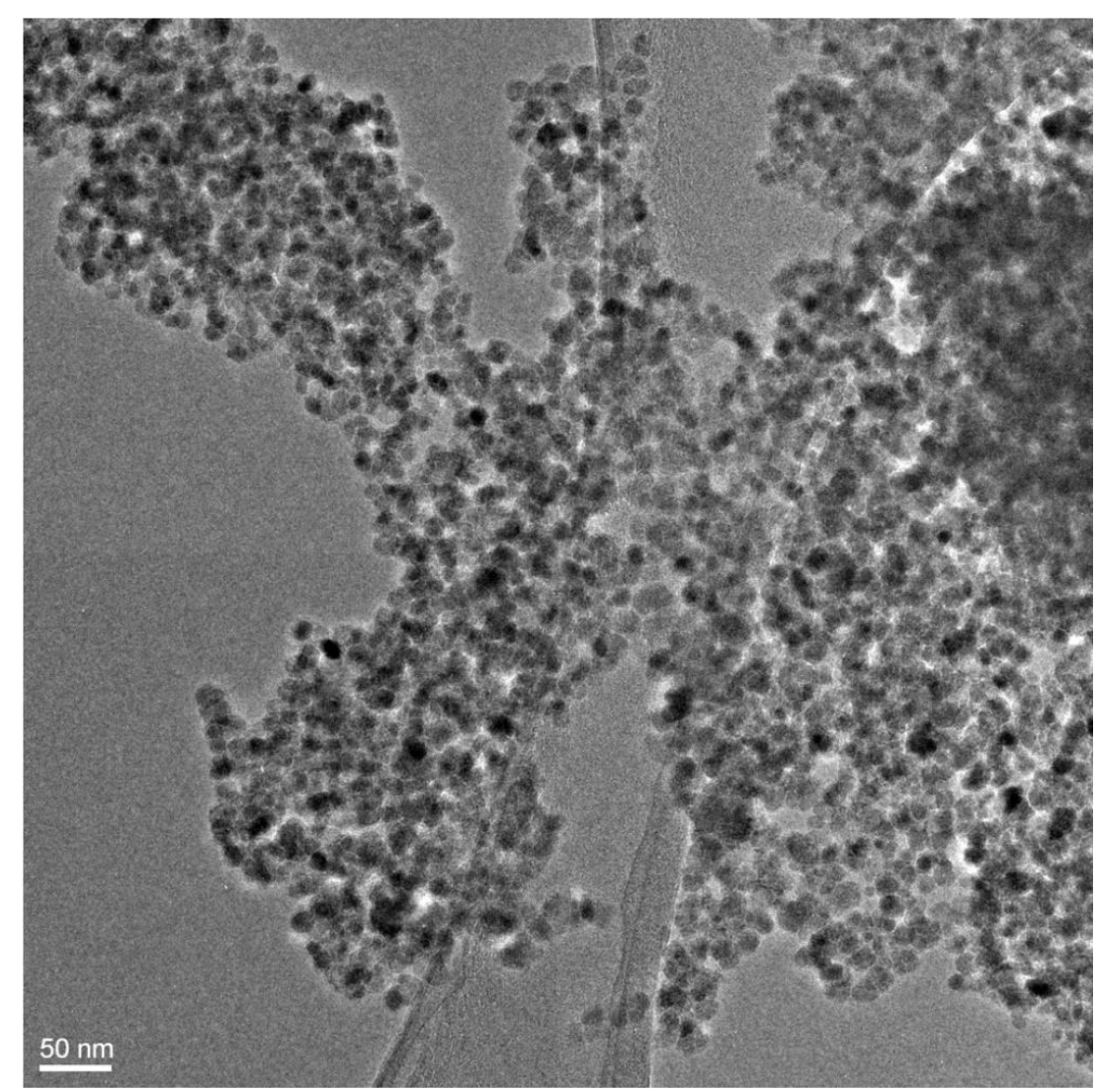

Fig. 5.9 - Imagen HRTEM de la muestra YMO.

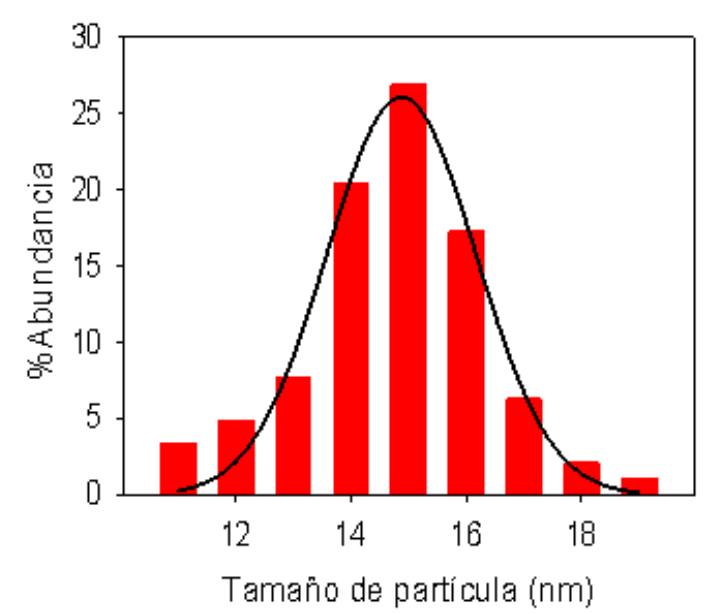

Los

ensayos

de caracterización realizados apuntan a elucidar el efecto del extracto de YM sobre las características y propiedades de las partículas de $\mathrm{Fe}_{3} \mathrm{O}_{4}$. En la figura 5.9 se muestra una imagen HRTEM obtenida para las partículas de YM0, en la cual se evidencia la formación de un sólido de forma esférica con un tamaño medio de partícula de $(15 \pm 2) \mathrm{nm}$ del orden esperado para estas partículas [8], [25].

Fig. 5.10 - Distribución de tamaño de partícula de la muestra YMO obtenida a partir de imagenes HRTEM. 
La distribución de tamaños de las nanopartículas YM0 muestra un comportamiento acotado, esto era esperable ya que ha sido comprobado que al utilizar $\mathrm{NH}_{4} \mathrm{OH}$ en lugar de $\mathrm{NaOH}$ como agente precipitante de nanopartículas se obtiene una distribución de tamaño monodispersa[25].

Para evidenciar si hay material orgánico remanente en las partículas, las mismas fueron sometidas a un ensayo de TGA bajo atmosfera de aire. De esta forma se espera comprobar la combustión de la materia orgánica y así calcular la masa orgánica que posee cada tipo de partícula.

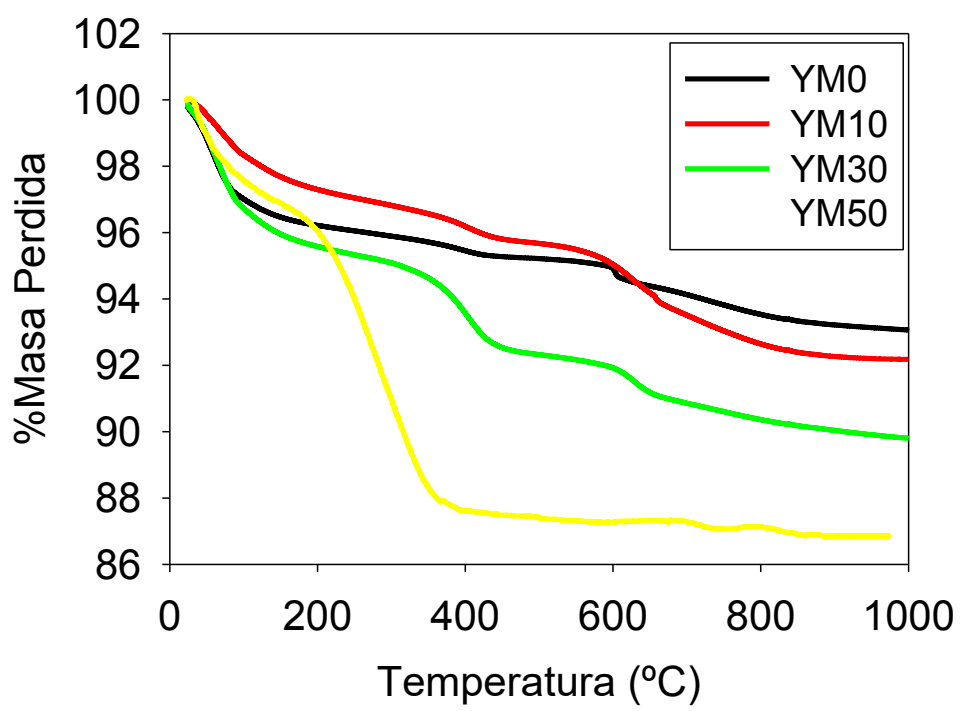

Fig. 5.11 - Curvas del ensayo Termogravimetrico de todas las nanopartículas mágneticas en atmosfera de aire.

Todas las curvas mostradas en la figura 5.11 presentan en esencia dos perdidas de masa en común, una aproximadamente hasta $150^{\circ} \mathrm{C}$ atribuida a agua fisisorbida sobre la superficie del material[8] y la segunda por encima de $200^{\circ} \mathrm{C}$ correspondiente a la descomposición térmica de materia orgánica [26]. Para el caso específico de la YM0 que no debería poseer material orgánico en la superficie debido a la forma en la que fueron sintetizadas, la descomposición térmica por encima a los $200^{\circ} \mathrm{C}$ presenta principalmente un pico entre $550 \mathrm{y}$ $650^{\circ} \mathrm{C}$ atribuible al cambio de fase de magnetita a otros óxidos de hierro [26]. Por lo anterior y considerando que la YM0 presenta $0 \%$ en masa de materia orgánica, las partículas YM10, YM30 y YM50 poseen $0.88,3.26$ y $6.23 \%$ respectivamente de materia orgánica como estabilizante superficial. Lo anterior fue calculado realizando la diferencia de \%Masa Perdida a $1000^{\circ} \mathrm{C}$ donde cualquier fracción orgánica presente en las muestras es volatilizada, entre la partícula de interés y la YM0.

Una vez calculada la cantidad de materia orgánica superficial que posee cada partícula, es de interés conocer las diferencias entre grupos funcionales mayoritarios presentes en las mismas y para ello se utilizó la espectroscopia FTIR. Los espectros resultantes para las muestras YM0 y YM50 se muestran en la figura 5.12. Se puede apreciar para ambos sólidos la aparición de dos señales importantes de absorción a $~ 564$ y $639 \mathrm{~cm}^{-1}$ atribuido a la extensión $\mathrm{Fe}-\mathrm{O}$ [27] lo que apunta a la formación exitosa de óxidos de hierro. Por su parte, la señal con 
máximo de absorción situado a $\sim 3440 \mathrm{~cm}^{-1}$ es correspondiente a vibraciones de grupos $\mathrm{O}-\mathrm{H}$.

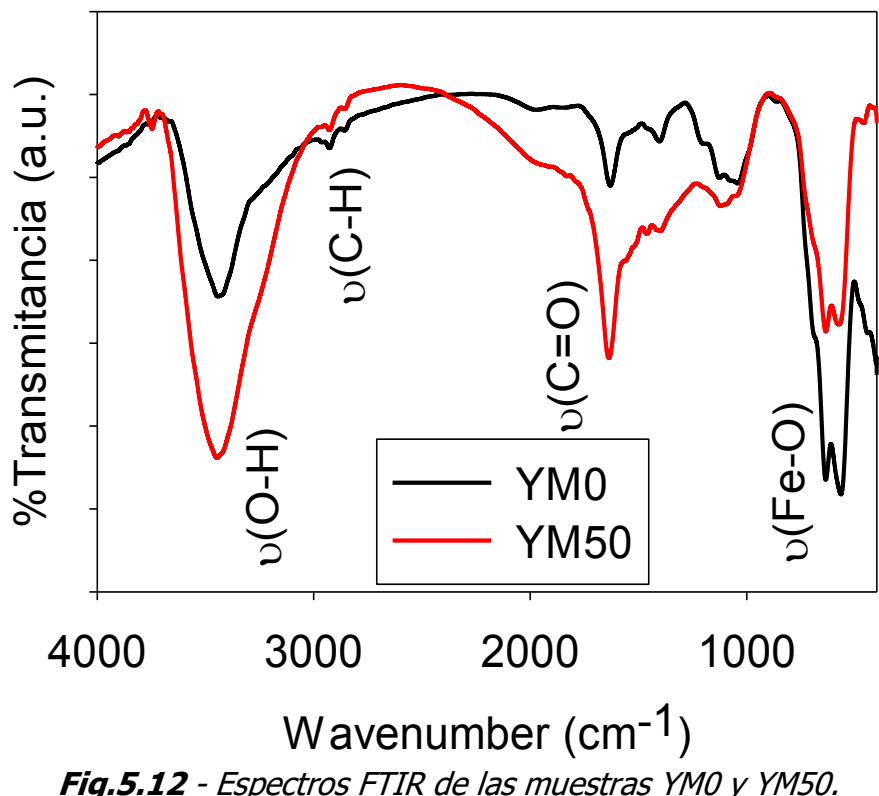

Para este estudio en particular resulta más relevante el análisis de las señales ubicadas a $\sim 1630 \mathrm{~cm}^{-1}$ correspondiente a modos vibracionales de grupos carboxílicos y a 2867 y $2934 \mathrm{~cm}^{-1}$ referentes a vibraciones de grupos $\mathrm{CH}_{2}$ [26] ya que ambas indican un aumento en la cantidad de materia rica en grupos orgánicos presentes en los materiales.

Debido a que la materia orgánica del extracto de YM se encontraría adsorbida sobre el material, resulta interesante evidenciar que justamente es en la superficie donde se aprecia la diferencia de grupos orgánicos, por lo que se realizaron análisis de ATR-IR. Los espectros obtenidos se muestran en la figura 5.13, en la cual se evidencia entre otras cosas el aumento significativo en las señales $\sim 1630 \mathrm{~cm}^{-1}$ y $\sim 3440 \mathrm{~cm}^{-1}$ atribuidas a grupos carboxílicos y amidas o hidroxilos respectivamente, sugiriendo un mayor recubrimiento de las partículas a medida que se incrementa la concentración de YM en la síntesis.

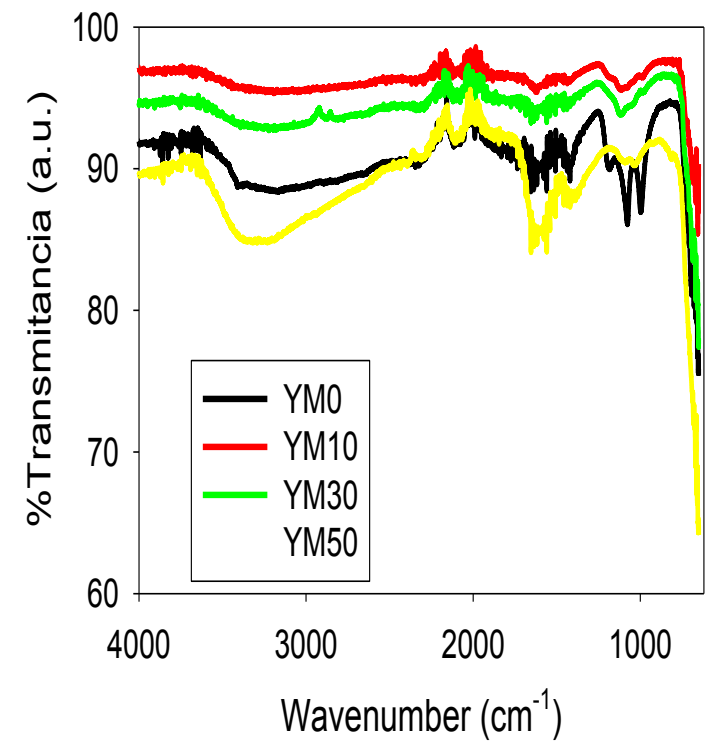

Fig.5.13 - Espectros ART-IR de las partículas

Es de esperar que con la introducción de la materia orgánica como estabilizante superficial de las nanopartículas cambien las propiedades fisicoquímicas de las mismas, tales como la agregación en suspensión acuosa. 
Uno de los parámetros más importantes de la estabilidad de los coloides es el Punto de Carga Cero $(p c z)$, que como su nombre lo indica es el pH en el cual un sólido en suspensión no presenta carga neta superficial y debido a ello es muy probable que las partículas presenten un alto de agregación[28]. Los datos obtenidos en los experimentos para el cálculo de $\mathrm{pH}_{\mathrm{PzC}}$ se muestran en la figura 5.14. En esta última figura no se muestra la curva resultante para la partícula YM10 debido a que no hay mucha diferencia respecto a la YM0.

Se puede apreciar fácilmente en la figura que las partículas presentan comportamientos diferentes en función de la cantidad de extracto de YM utilizado durante el proceso de síntesis, es decir, la introducción de los grupos orgánicos superficiales en las partículas modifica las propiedades superficiales de los materiales cuando estos son suspendidos en agua.

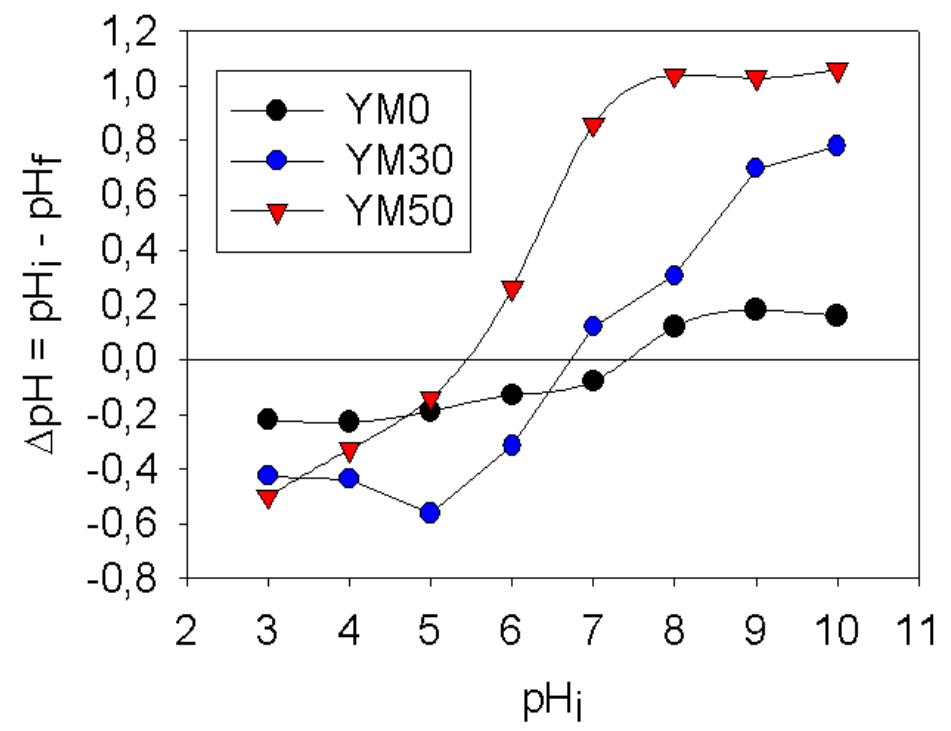

Fig. 5.14 - Curvas experimentales para el cálculo del pzc para las partículas YMO (Negro), YM30(Azul) y YM50(Rojo).

El pH PZc aproximado obtenido para la YM0 está alrededor de 7.4 cercano al reportado en la literatura [8]. Este valor indica la presencia mayoritaria de grupos $-\mathrm{OH}$ en la superficie de la misma. El valor experimental obtenido para la YM0 es de 7.3, para la YM30 es aproximadamente 6.7, mientras que para YM50es de 5.4. Lo anterior es indicativo de la formación de una capa orgánica en la superficie debido a interacciones electrostáticas entre la fracción orgánica y la superficie de la partícula[8]. Debido a la naturaleza química del extracto de YM rico en Vitaminas, aminoácidos, cafeína, entre otros [17], es posible que grupos funcionales con carga positiva queden expuestos al exterior de la partícula, lo que justificaría, en parte, la disminución del $\mathrm{pH}_{\mathrm{Pzc}}$ con el mayor agregado de YM.

Como parte de la caracterización de estas partículas, también se realizaron ensayos de XPS de las partículas YM0 y YM50. A continuación se muestran las señales obtenidas para la YMO luego de la corrección mediante la asignación del C1s espurio a $284.6 \mathrm{eV}$. La figura 5.15 muestra el espectro de la señal Fe2p y las curvas simuladas: 


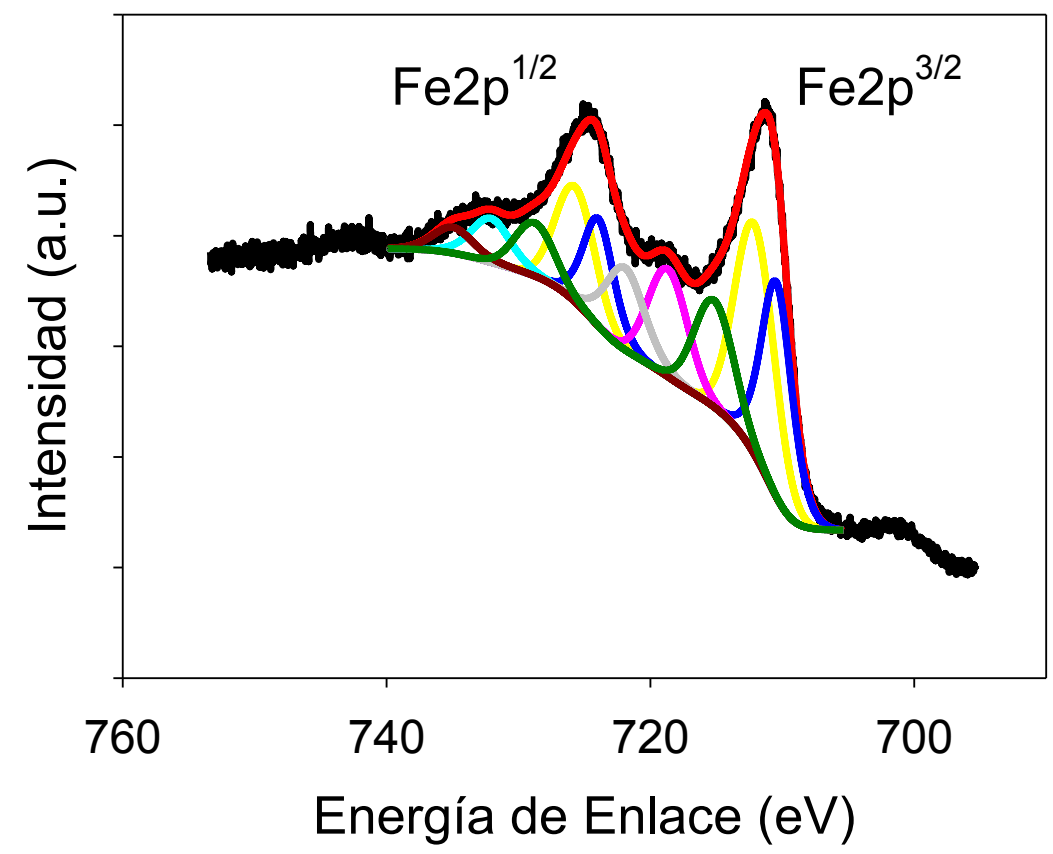

Fig. 5.15 - Señal XPS Fe2pde la muestra YMO (Curva Negra) y picos simulados (Curvas de Colores).

La simulación del pico Fe2p de la YM0 arrojó 3 curvas simuladas con una separación de $13.4 \mathrm{eV}$ que está dentro del orden de lo reportado para el Fe [31]y dos satélites. El primero de los picos ubicado en $710.4 \mathrm{eV}$ es atribuido a $\mathrm{Fe}^{+2}$ de la magnetita, los demás picos con máximos en 712.1 y 715.1 eV corresponden al $\mathrm{Fe}^{+3}$ octaédrico y tetraédrico respectivamente del mismo material[19], [23], [32]-[34]. Es interesante resaltar que estos valores presentan una desviación referente a los esperados para la magnetita de escala macrométrica, pero en el orden para los reportados para sistemas nanopartículados. Esta diferencia estaría indicando que la disminución del tamaño de las nanopartículas por debajo de los $\sim 15 \mathrm{~nm}$ resulta en mayores interacciones coulombicas, hibridación $\mathrm{p}-\mathrm{d}$ entre otros [23]. La relación $\mathrm{Fe}^{+2} / \mathrm{Fe}^{+3}$ para la magnetita cuya fórmula molecular es $\mathrm{Fe}_{3} \mathrm{O}_{4}$ o $\mathrm{FeO} \cdot \mathrm{Fe}_{2} \mathrm{O}_{3}$ es 0.5 , en este caso específico el valor experimental calculado a partir de las aéreas de los picos respectivos es de 0.52, que en el orden del error se encuentra acertado. De todas formas es esperable que exista una sobrevaloración de esta relación debido a la naturaleza del XPS ya que un haz de electrones bombardea la superficie de la muestra pudiendo dar lugar a una posible reducción de $\mathrm{Fe}^{+3} \mathrm{a} \mathrm{Fe}{ }^{+2}$.

Es importante mencionar que el análisis de la señal de C1s debe ser cauteloso, ya que la presencia de carbono espurio en todas las muestras es un interferente en el análisis. Por otro lado, esta señalsimulada satisfactoriamente mediante dos curvas. La primera a $284.6 \mathrm{eV}$ asignada al Carbono Espurio y la segunda $287.8 \mathrm{eV}$ correspondiente a $\mathrm{CO}_{3}{ }^{-2}$ formados durante la síntesis de las partículas dado que el $\mathrm{pH}$ al momento de agregar el $\mathrm{NH}_{4} \mathrm{OH}$ supera las 9 unidades facilitando así la disolución de $\mathrm{CO}_{2}$ atmosférico. La figura 5.16 muestra estos resultados. 


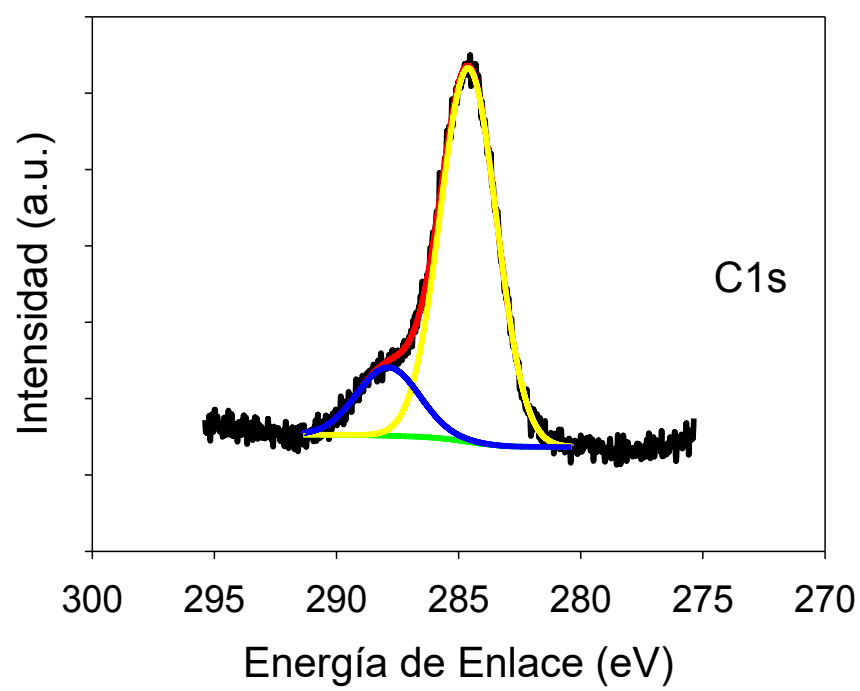

Fig. 5.16 - Señal XPS de C1s de la muestra YMO (Curva Negra) y picos simulados (Curvas de Colores).

Por su parte, el análisis de la señal de O1s arrojó la contribución de 2 especies, la primera ubicada a $530.2 \mathrm{eV}$ corresponde a óxidos de $\mathrm{Fe}$ [32], mientras que el segundo pico ubicado a $532.9 \mathrm{eV}$ es atribuido a grupos $-\mathrm{OH}$ superficiales propios de la nanopartícula 0 de agua fisisorbida sobre la superficie, cabe mencionar que el entorno químico de ${\mathrm{lo} \mathrm{CO}_{3}}^{-2}$ se solapa con esta zona.

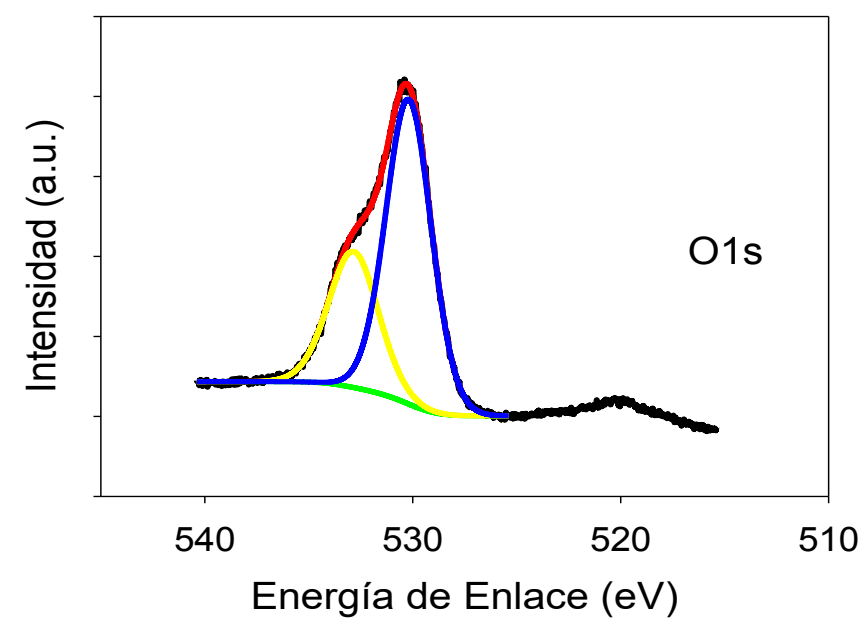

Fig. 5.17 - Señal XPS de O1s de la muestra YMO (Curva Negra) y picos simulados (Curvas de Colores).

La relación experimental Fe/O para esta muestra es de 0.55 considerando solo los oxígenos correspondientes a los Óxidos de Fe. Este valor se encuentra desviado del teórico de 0.75 calculado a partir de la magnetita cristalina, lo que es indicativo de defectos superficiales que modifican la relación estequiometrica entre los elementos considerados. Cabe mencionar que también se encontraron señales $\mathrm{Cl} 2 \mathrm{p}$ y N1s asociadas a la adsorción los iones $\mathrm{Cl}^{-}$y $\mathrm{NH}_{4}{ }^{+}$utilizados durante la síntesis de las partículas. La fórmula empírica representativa de la superficie de estas partículas obtenida sin considerar el C es: $\mathrm{N}_{0.23} \mathrm{Cl}_{0.30} \mathrm{Fe}_{1} \mathrm{O}_{2.77}$.

Por su parte, los resultados obtenidos a partir del análisis de las señales XPS de la región correspondiente a Fe2p de la muestra YM50, indican que las especies de Fe involucrados son los mismos que en la YM0, sin embargo hay un cambio en cuanto la abundancia relativa de cada uno. Las señales obtenidas a partir de la deconvolución se encuentran centradas en $710.4,712.5$ y $715.5 \mathrm{eV}$ correspondientes a $\mathrm{Fe}^{+2}, \mathrm{Fe}^{+3}$ octaédrico y tetraédrico respectivamente. En cuanto a la relación $\mathrm{Fe}^{+2} / \mathrm{Fe}^{+3}$ es de 1.2 , muy alejado del 0.52 obtenido para la YM0, esto es indicativo que el extracto de YM utilizado en la síntesis 
efectivamente funciona como estabilizante superficial de las nanopartículas evitando así la posible oxidación de $\mathrm{Fe}^{+2}$ a $\mathrm{Fe}^{+3}$. Este comportamiento también se observó en el trabajo con SBO y la hidroxiapatita dopada con iones Fe descrito en esta tesis.

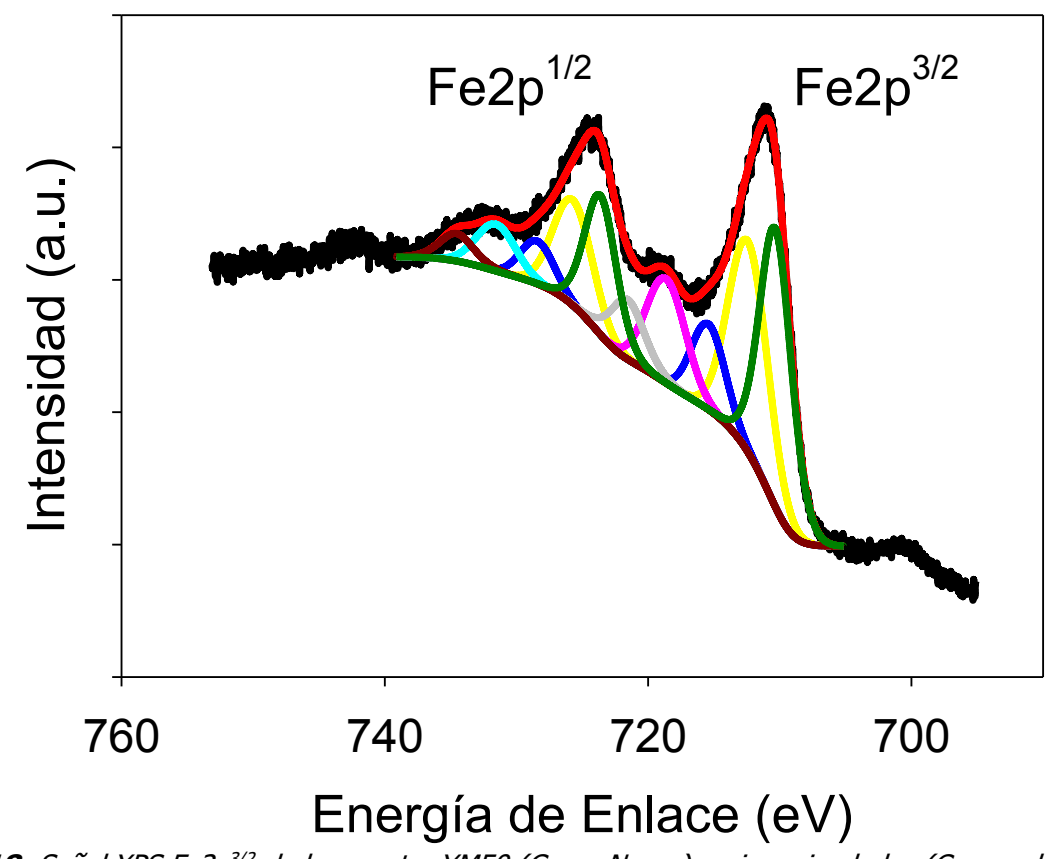

Fig. 5.18- Señal XPS Fe2p $p^{3 / 2}$ de la muestra YM50 (Curva Negra) y picos simulados (Curvas de Colores).

Como se mencionó anteriormente, el análisis de la señal C1s, aporta también información. Sin embargo su análisis debe de ser cuidadoso, ya que debido a la presencia de carbono espurio en las muestras, este puede enmascarar todas las observaciones. Si bien se aprecia la señal de Carbono espurio ubicada en $284.6 \mathrm{eV}$ las otras dos señales centradas en 286.6 y 288.6 eV podrían deberse a la contribución de los grupos orgánicos $\mathrm{C}-\mathrm{N}, \mathrm{C}-\mathrm{O}$ y $\mathrm{O}-\mathrm{C}=\mathrm{O}$ adsorbidos sobre la superficie de las nanopartículas, en concordancia con los espectros de IR-ATR. Esta señal XPS se muestra en la figura 5.19 .

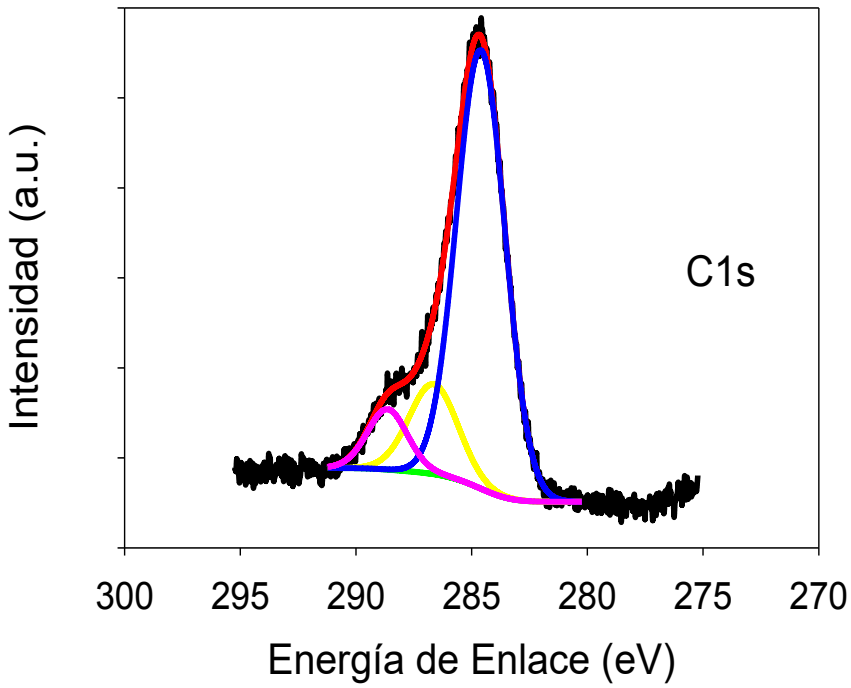

Fig. 5.19 - Señal XPS de C1s de la muestra YM50 (Curva Negra) y picos simulados (Curvas de Colores). 
Un análisis cuantitativo considerando solamente los oxígenos correspondientes a óxidos de hierro permite obtener la relación experimental $\mathrm{Fe} / \mathrm{O}$ para esta muestra arrojando un valor de 0.57 en el orden del obtenido para la YM0, sin embargo este también se encuentra por debajo del valor teórico para la magnetita.

Por su lado, la señal de O1s se simuló con tres contribuciones, dos de las cuales son idénticas a las observadas para la YM0, ubicadas a 529.8 y $531.5 \mathrm{eV}$ correspondientes a óxidos de $\mathrm{Fe}$ y grupos $-\mathrm{OH}$ superficiales debido a la nanopartícula como tal o de agua adsorbida sobre la superficie de la misma.

La tercera señal que aparece ubicada en $533.3 \mathrm{eV}$ corresponde a señales $\mathrm{O}=\mathrm{C}$ y/o O-C, lo cual está en concordancia con el aumento de la banda $\sim 1620 \mathrm{~cm}^{-1}$ observada en el espectro FTIR de la muestra YM50 en comparación con la YM0. Es importante recalcar que en esta muestra también se aprecian la contribución de iones $\mathrm{NH}_{4}^{+}$y Cl $\mathrm{Cl}^{-}$adsorbidos. La figura 5.20 muestra estos resultados.

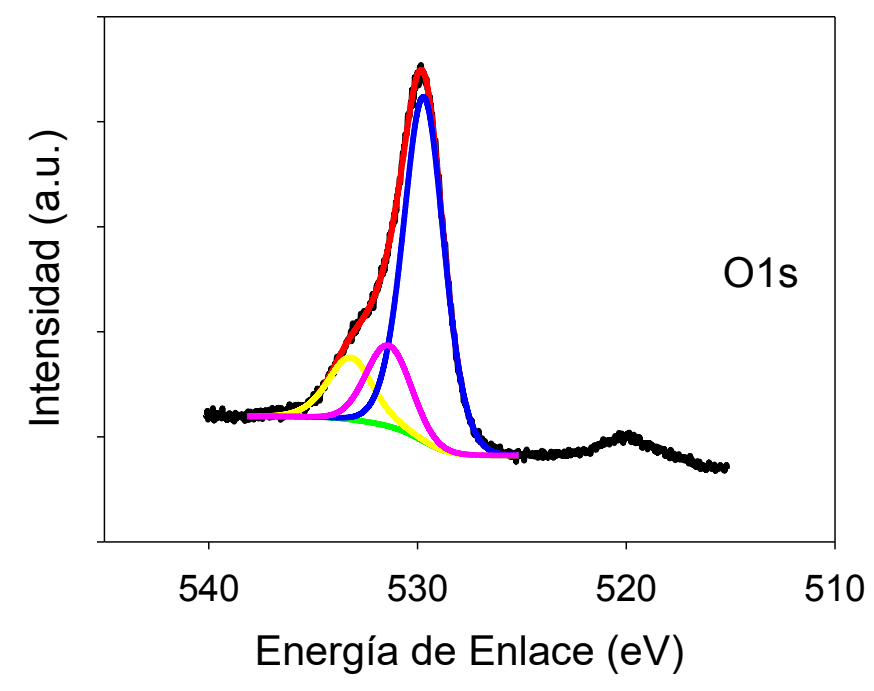

Fig. 5.20 - Señal XPS de O1s de la muestra YM50 (Curva Negra) y picos simulados (Curvas de Colores).

La fórmula empírica experimental obtenida de un análisis cuantitativo de las señales XPS para la muestra YM50 es: $\mathrm{N}_{0.6} \mathrm{Cl}_{0.42} \mathrm{Fe}_{1} \mathrm{O}_{2.4}$. Es importante recalcar que si bien la relación O/Fe se mantiene invariable en comparación con la misma para la muestra YM0, la relación total del N aumenta un $100 \%$.

Es también de interés elucidar si el uso del extracto de YM en la síntesis modifica la forma de las nanopartículas y la forma en la que interaccionan entre sí cuando se encuentran en suspensión acuosa, por este motivo se realizaron ensayos de SAXS de todas las nanopartículas suspendidas en agua cuyos resultados se muestran en la figura 5.21 y los ajustes realizados en la tabla 5.2. Cabe mencionar que el signo * en los datos mostrados en esta tabla indica que el parámetro se mantuvo constante durante el ajuste.

El análisis de datos pone en evidencia la existencia de agregados de algo más de $\mathrm{Rg} \approx 25 \mathrm{~nm}$ con una superficie con características fractales $(\mathrm{N}<4)(\mathrm{Rg} 2$ y N2 respectivamente), el otro nivel presente está representado por partículas globulares de $\mathrm{Rg} \approx 5.3 \mathrm{~nm}$ con una superficie suave bien definida $(\mathrm{N}<4)$. 


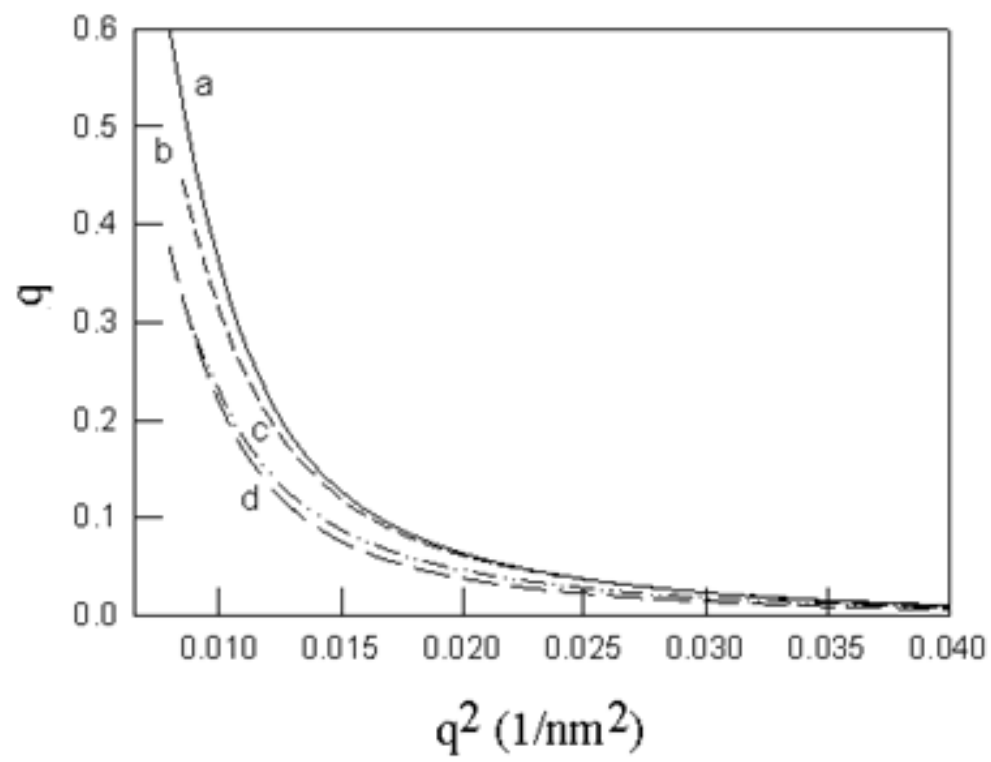

Fig. 5.21-Curvas SAXS de suspensiones de las Np. A - D corresponden a YMO - YM50 respectivamente.

\begin{tabular}{|c|c|c|c|c|}
\hline Parámetro & YM0 & YM10 & YM30 & YM50 \\
\hline Rg1(nm) & $5.67 \pm 0.03$ & $5.60 \pm 0.04$ & $5.28 \pm 0.04$ & $5.47 \pm 0.08$ \\
\hline N1 & $3.33 \pm 0.03$ & $3.94 \pm 0.02$ & $4 *$ & $4 *$ \\
\hline Rg2 (nm) & $27.6 \pm 0.30$ & $25.8 \pm 0.30$ & $24.9 \pm 0.30$ & $26.0 \pm 0.50$ \\
\hline N2 & $3.07 \pm 0.04$ & $2.86 \pm 0.05$ & $2.84 \pm 0.04$ & $2.80 \pm 0.07$ \\
\hline Diámetro de Partícula (nm) & $14.64 \pm 0.06$ & $14.46 \pm 0.08$ & $13.63 \pm 0.08$ & $14.12 \pm 0.16$ \\
\hline
\end{tabular}

Tabla 5.2 -Resultados del análisis del SAXS de nanopartículas en suspensión acuosa.

Es remarcable mencionar que para el caso de la partículas YM0 el tamaño de partícula obtenido por SAXS $(14.64 \mathrm{~nm})$ se encuentra dentro del rango de diámetros arrojado por la distribución de tamaño medio de partícula en imágenes HRTEM $(15 \pm 2) \mathrm{nm}$. Los ensayos de SAXS confirman la forma esférica de las partículas.

Los resultados anteriores denotan que bajo las condiciones experimentales no se evidencian cambios apreciables en el tamaño y forma de las distintas partículas, ni en el de los agregados (que se encuentran dentro del rango de medición experimental) ni en la forma que estos últimos toman.

Se realizaron ensayos de DRX para todas las partículas consideradas. Los difractogramas se muestran en la figura 5.22. Un análisis detallado de esta permite concluir que efectivamente la fase presente en el sólido es magnetita/maghemita ya que esta técnica no permite diferenciar entre estas fases. Sin embargo los datos de XPS confirman la predominancia de la fase de magnetita.

Se calculó el tamaño del dominio magnético siguiendo la ecuación de Scherrer y el diámetro del cristal obtenido para las partículas YM0 a YM50 toma valores de 14.8, 12.2, 11.6 y $11.3 \mathrm{~nm}$ respectivamente. Estos valores están de 
acuerdo con los resultados obtenidos para las partículas de Fe-nAp (Cap. 4), donde la introducción de materia orgánica al material conlleva a la disminución de la cristalinidad y del tamaño del cristal obtenido.

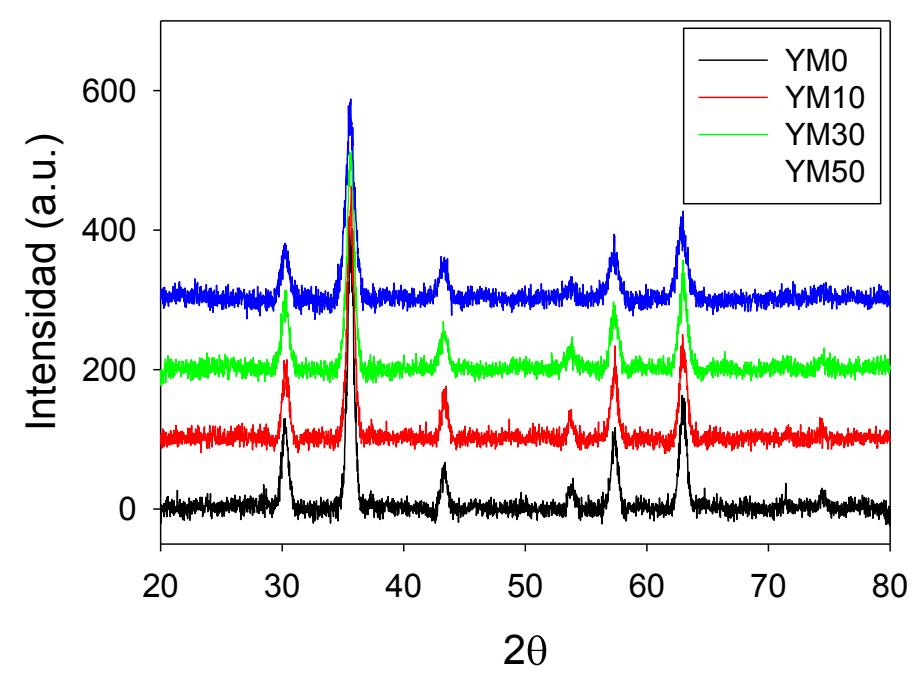

Fig. 5.22 - Difractogramas obtenidos para todas las partículas.

\subsubsection{Nanopartículas de C.}

La nanopartículas de $\mathrm{C}$ se mencionaron en este capítulo debido a que se obtienen siguiendo la ruta sintética mostrada en la figura 5.1 sin embargo se analizarán en detalle en el capítulo 6 ya que se compararán sus propiedades fotoquímicas con otras nanopartículas de C obtenidas por otras vías. Aquí describiremos solo algunas generalidades.

Las suspensiones acuosas de $\mathrm{NpC}$ presentan una coloración ámbar que al ser irradiada con luz ultravioleta $(\lambda \sim 350 \mathrm{~nm})$ se aprecia a simple vista que presentan luminiscencia de acuerdo con lo reportado para estas, en la figura 5.23 se muestra la luminiscencia de las mismas.

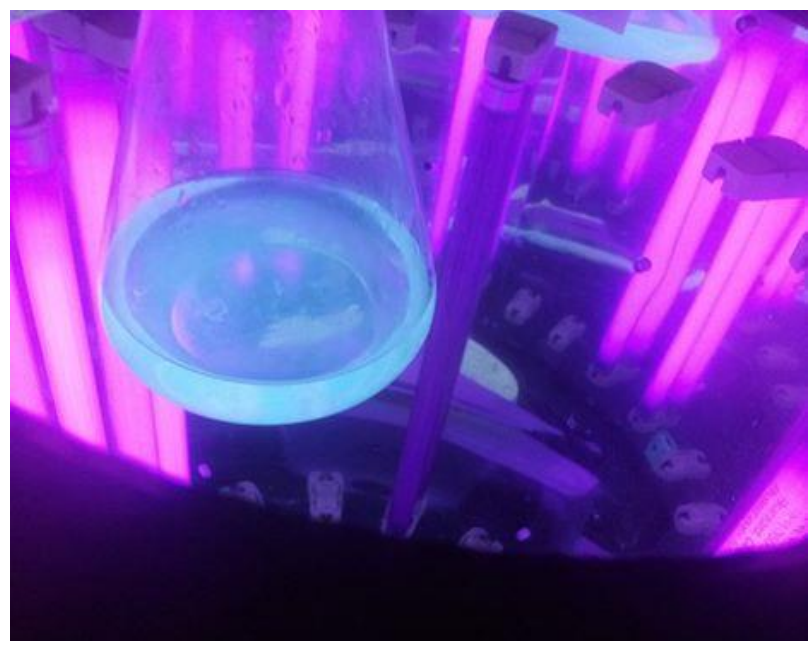

Fig. 5.23- Luminiscencia de una suspensión de NpC sometida a 350 nm de excitación 
Se tomaron imágenes TEM de todas las nanopartículas obtenidas durante los procesos de síntesis mencionadas anteriormente, la imagen 5.24 muestra los resultados obtenidos.

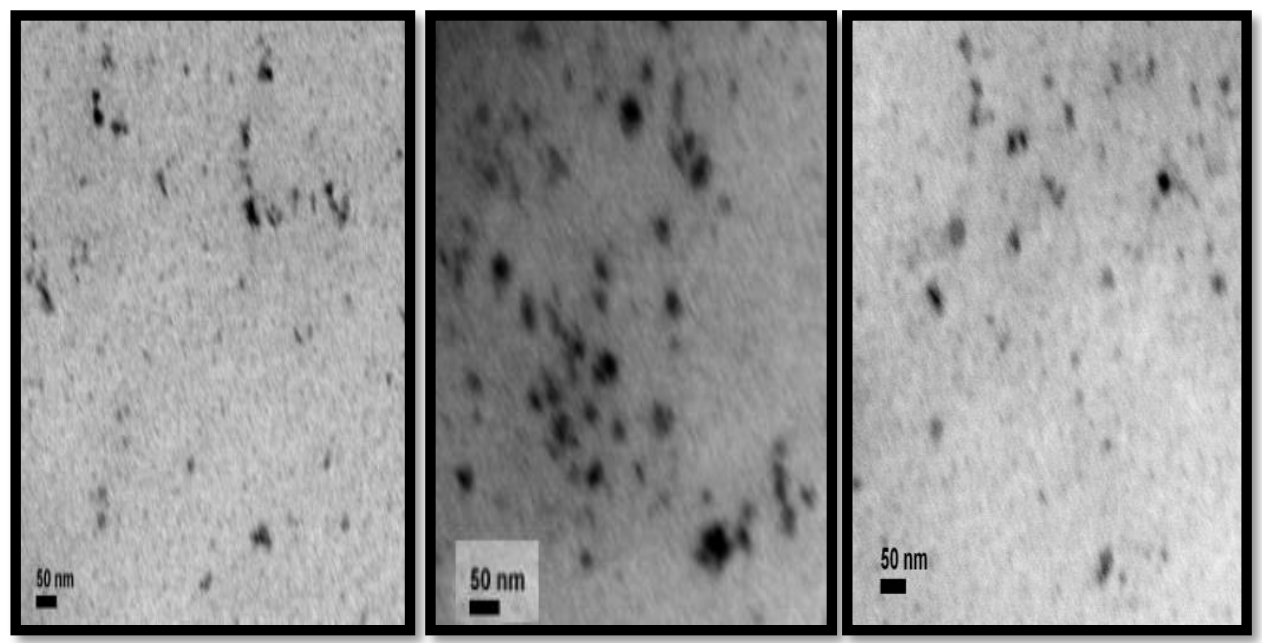

Fig. 5.24 - Imágenes TEM de Izquierda: NpC YM 400 -Medio: NpC CN 300 y Derecha: NpC CN Mw.

En las imágenes anteriores se evidencia la formación de material nanoparticulado por los 3 métodos de síntesis. No se pudo obtener una distribución de tamaño de estos debido a que la resolución del equipo utilizado no lo permite. El tamaño observado para estos materiales se encuentra en concordancia con lo reportado para otras $\mathrm{NpC}$ obtenidas por diferentes métodos y utilizando otras fuentes como materia prima, tanto reactivos de grado HPLC como desechos orgánicos como en este caso.

Se tomaron espectros de FTIR de las suspensiones acuosas de estas nanopartículas, los cuales se muestran en la figura 5.25. Los espectros evidencian que hay distinciones en la abundancia relativa de los grupos funcionales superficiales presentes en las partículas.

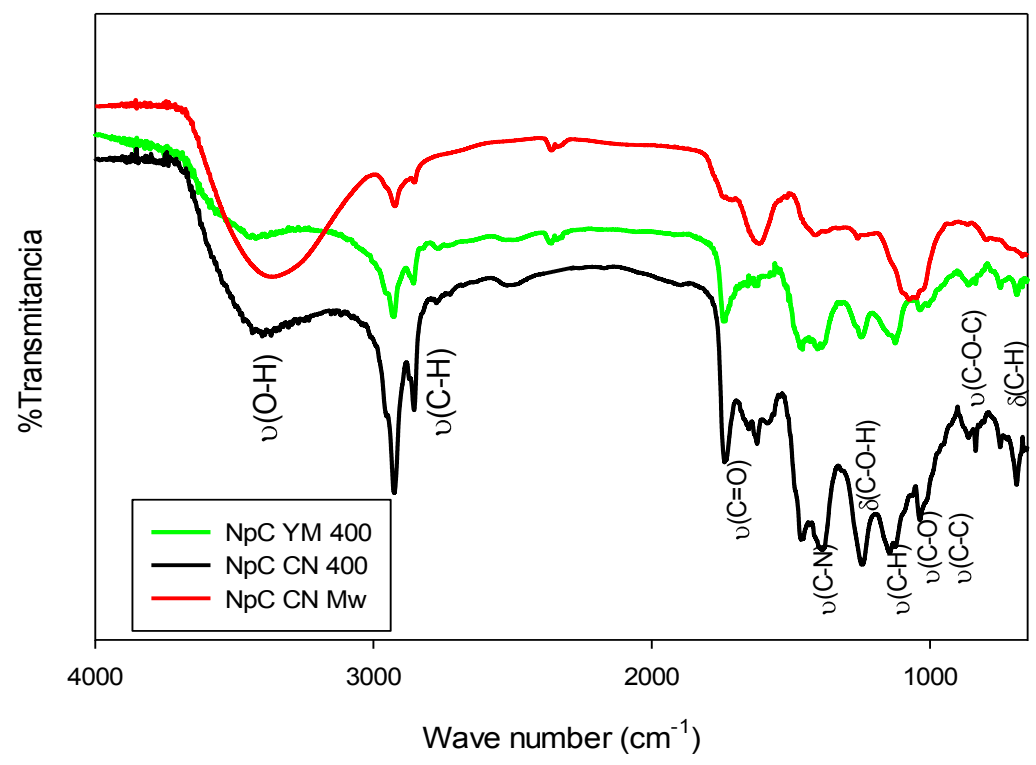

Fig. 5.25 - Espectros FTIR de las NpC sintetizadas. 
El análisis de estos espectros denota que las partículas NpC CN400 son las que presentan mayor número de grupos funcionales diferentes entre sí, es decir, la superficie de estas sería la más heterogénea. Además, estas partículas presentan mayor abundancia relativa de enlaces $\mathrm{C}-\mathrm{H}$ y $\mathrm{C}=\mathrm{O}$ cuando se comparan con las otras. Las NpC YM400 serían las que menos grupos $\mathrm{O}-\mathrm{H}$ presentan e incluso se podría proponer la presencia de enlaces $\mathrm{N}-\mathrm{H}$.

\subsubsection{Nanopartículas de $\mathrm{SiO}_{2}$ "}

Las nanopartículas de $\mathrm{SiO}_{2}$ fueron sintetizadas a partir de las cenizas obtenidas de calcinar el sólido carbonoso residual de las nanopartículas de C.

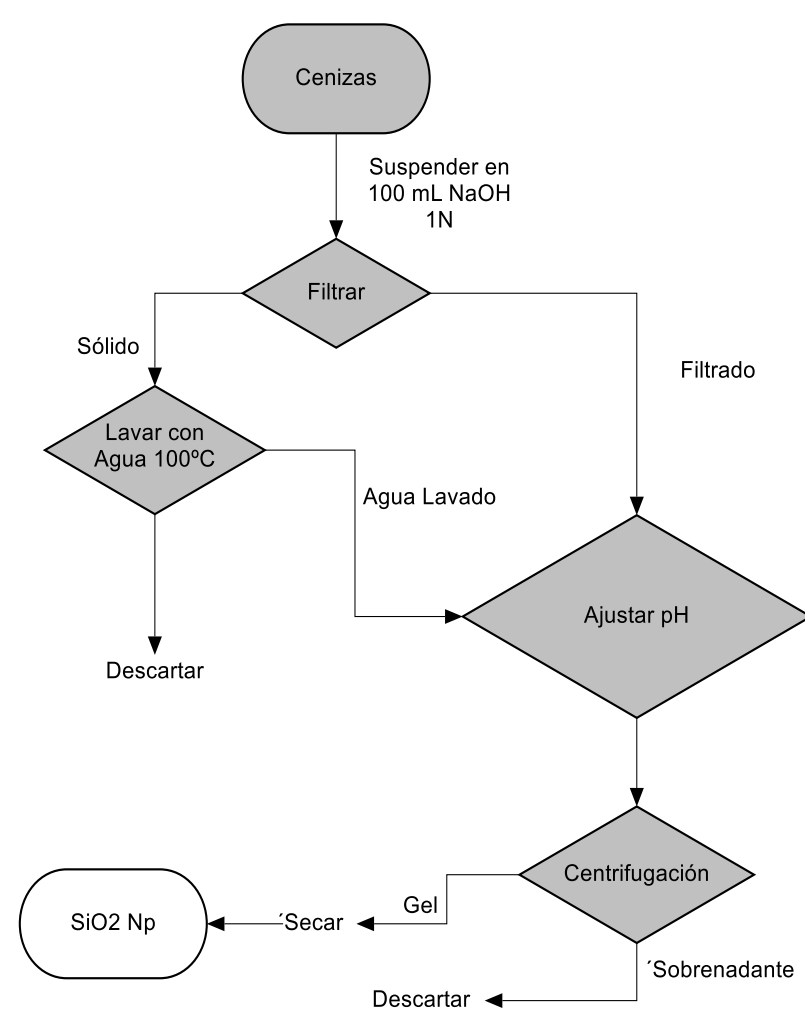

Fig.5.26- Diagrama de flujo de la ruta sintética de las nanopartículas de $\mathrm{SiO}_{2}$.
La figura 5.26 muestra el diagrama de flujo de la ruta sintética para la obtención de las nanopartículas de $\mathrm{SiO}_{2}$ adoptado de varios estudios [14]. La primera parte de esta ruta sintética tiene como objetivo la eliminación de sales inorgánicas presentes en las cenizas que puedan contaminar las futuras nanopartículas. Posterior a ello se procede a un proceso de cristalización donde el pH inicial juega un papel importante en las propiedades superficiales del material obtenido. En nuestro caso el pH de cristalización utilizado es de 7.0

El sólido obtenido de color blanco se caracterizó por TEM para evidenciar su tamaño. La fig. 5.27 muestra algunas de las imágenes obtenidas. De la figura se puede apreciar un grado de aglomeración considerable de las partículas, lo que no permite la obtención de una distribución de tamaño adecuada. Pareciera además que existe material poroso y de gran superficie. 

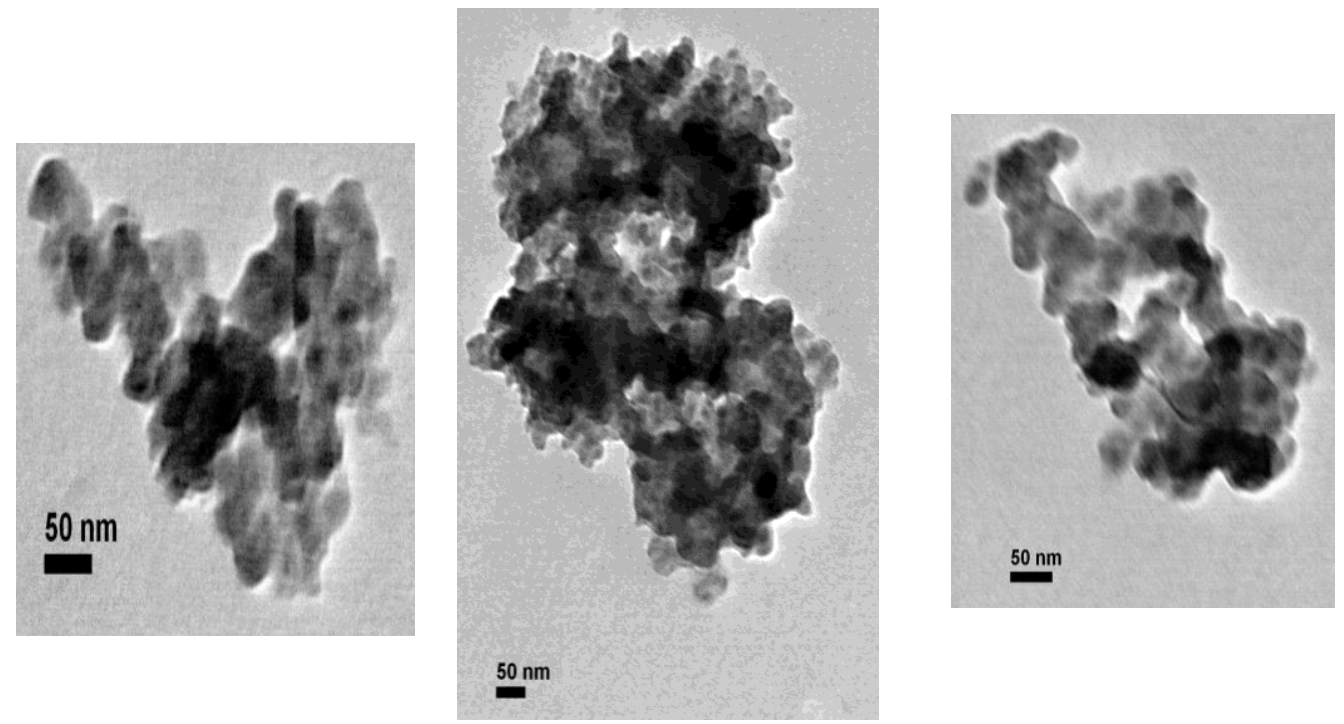

Fig.5.27-Imágenes TEM obtenidas para las nanopartículas de $\mathrm{SiO}_{2}$ obtenidas.

El espectro FTIR de las nanopartículas de $\mathrm{SiO}_{2}$ obtenidas se muestra en la figura 5.28. En él se evidencian mayoritariamentelos modos vibracionales correspondientes a enlaces Si-O [36]. En $3427 \mathrm{~cm}^{-1}$ se aprecia la flexión correspondiente a grupos $\mathrm{O}-\mathrm{H}$, en $1089 \mathrm{~cm}^{-1}$ el estiramiento del enlace $\mathrm{Si}-\mathrm{O}-\mathrm{Si}$, en $793 \mathrm{~cm}^{-1}$ la flexión del grupo tetraédrico $\mathrm{SiO}_{4}$ y por último en $487 \mathrm{~cm}^{-1}$ la flexión del grupo Si-O-Si. Se puede apreciar en grandes rasgos que

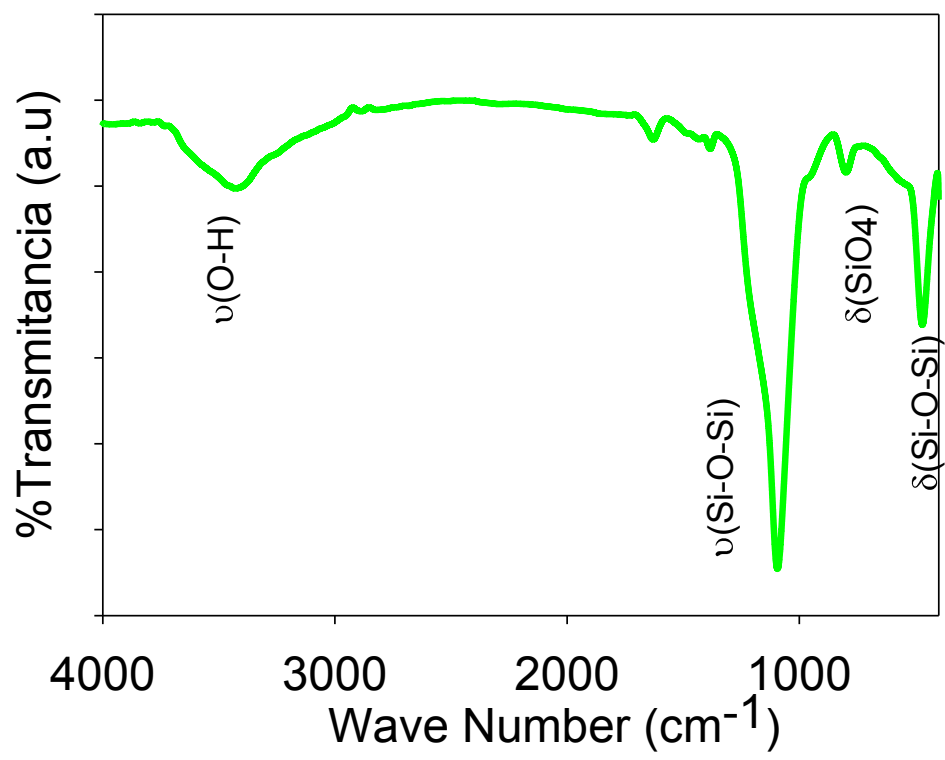
macroscópicamente no existe contaminación por parte de grupos orgánicos debido a que al alcanzar la temperatura de $700^{\circ} \mathrm{C}$ durante la síntesis, gran parte de la materia orgánica del residuo sólido de la YM es eliminado por combustión (se puede evidenciar claramente en el TGA de la YM mostrado en el capítulo 6)

Fig.5.28 - Espectro FTIR obtenido para las nanopartículas de $\mathrm{SiO}_{2}$.

Al igual que con las otras nanopartículas, a estas se le realizaron ensayos de XPS para la caracterización de la superficie. En la figura 5.29 se muestran las señales Si2p y Si2s de estas nanopartículas y como se puede apreciar ambas señales fueron simuladas adecuadamente con el uso de dos curvas que indican la presencia de Si con dos entornos diferentes. 
La señal Si2p presenta dos contribuciones ubicadas en 101.9 eV y 103.1 eV. Por su lado la señal Si2s presenta dos curvas con máximos en 152.9 eV y $154.1 \mathrm{eV}$. Las anteriores señales soportan la presencia de $\mathrm{SiO}_{2}$ en la muestra, pero además es indicativo de la existencia de una red no totalmente oxidada de $\mathrm{Si}-\mathrm{Si}(-\mathrm{O}-)_{3}[36]$.

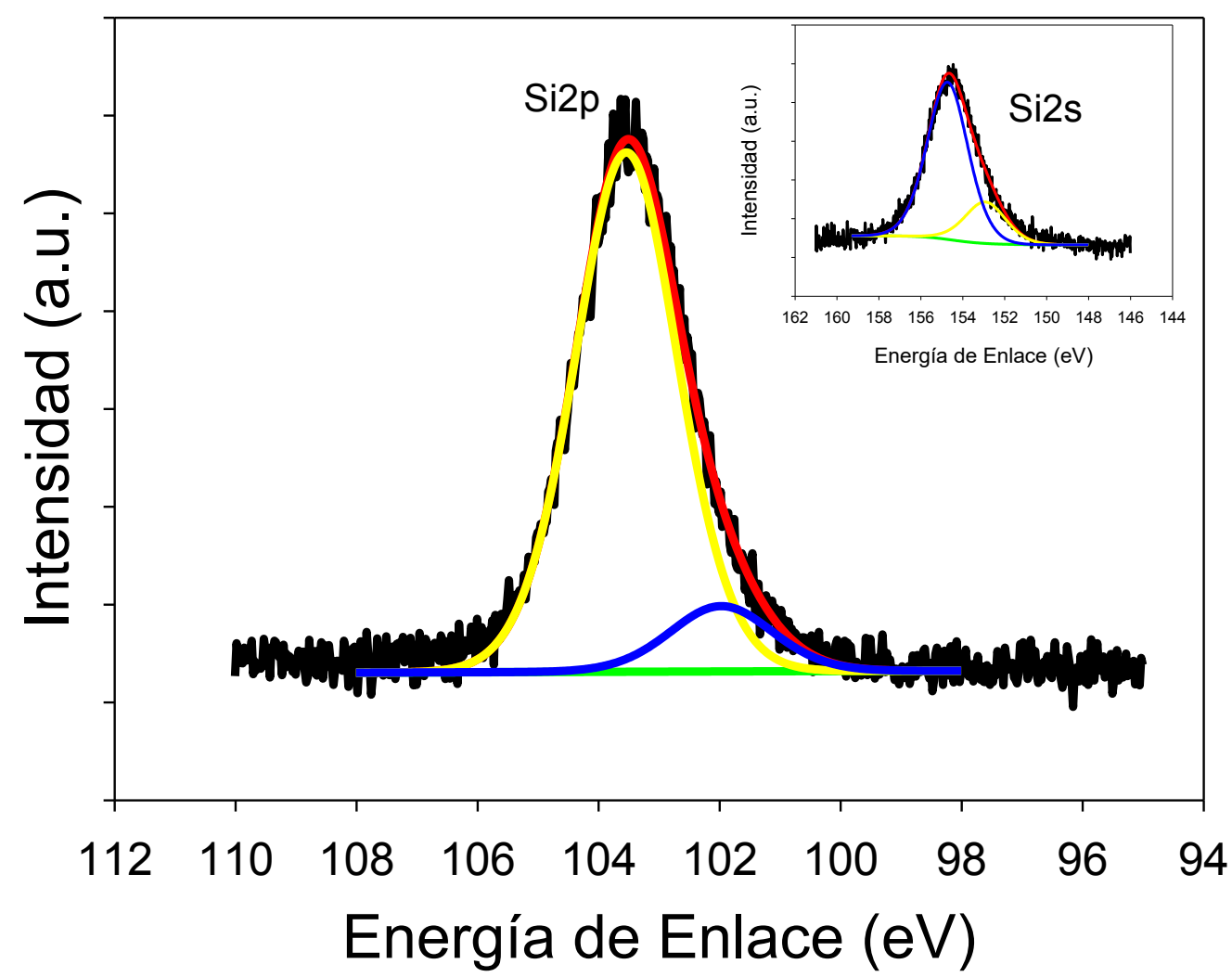

Figura 5.29- Señal XPS de Sizp de la muestra $\mathrm{SiO}_{2}$ (Curva Negra) y picos simulados (Curvas de Colores). Inset: Señal XPS de Sizs de la misma muestra y picos simulados (Curvas de Colores).

Por su parte la señal O1s se pudo simular con la participación de 2 contribuciones, la primera ubicada en $532.1 \mathrm{eV}$ atribuible a entornos del tipo $\mathrm{SiO}_{2}$. La relación experimental $\mathrm{Si} / \mathrm{O}$ considerando solamente los oxígenos del $\mathrm{SiO}_{2}$ y utilizando la señal de Si2p, es de 1.7 indicando así una sobreabundancia de $\mathrm{Si}$ ya que se encuentra muy por encima de la relación teórica 0.5 . Lo anterior soporta aún más la presencia de estructuras tipo $\mathrm{Si}-\mathrm{Si}(-\mathrm{O}-)_{3}$ en la muestra.

La segunda banda de la señal O1s presentó un máximo en 532.7 eV en concordancia para señales típicas para $\mathrm{CO}_{3}{ }^{-2}$, además se evidencia una señal de C1s (no mostrada) en $288.4 \mathrm{eV}$ indicativa de presencia de carbonatos. Esto último se puede explicar debido a la disolución de $\mathrm{CO}_{2}$ en el agua de lavado de las cenizas de YM en el paso de alcalinización con $\mathrm{NaOH}$. 


\subsection{Conclusiones.}

Los ensayos descriptos en este capítulo nos permiten concluir que es posible utilizar el extracto hidrosoluble de la Yerba Mate como agente reductor y estabilizante superficial para la obtención de nanopartículas de Ag con geometría semiesférica.

Por otro lado, en la síntesis de nanopartículas de $\mathrm{Fe}_{3} \mathrm{O}_{4}$ el extracto hidrosoluble de la Yerba Mate no funcionó como agente precipitante de este óxido magnético de hierro, ya que en ese caso, los sólidos obtenidos no presentan propiedades magnéticas. Sin embargo, al hacer uso de $\mathrm{NaOH}$ como agente precipitante de la síntesis y usar el extracto de YM se puede proteger la superficie de los materiales de una posible oxidación. Como describiremos más adelante, la adsorción del extracto de YM en la superficie es capaz de modificar las propiedades magnéticas de las partículas.

Es posible la obtención de nanopartículas de $\mathrm{C}$ con propiedades luminiscentes utilizando el sólido residual de la YM y de la Cascara de Naranja mediante pirolisis por vía térmica o para la última materia prima por irradiación con microondas.

Las nanopartículas de $\mathrm{SiO}_{2}$ obtenidas no presentan capa orgánica superficial. Se postula en la literatura, que la obtención de $\mathrm{SiO}_{2}$ a partir de extractos de vegetales es adecuada para el uso de estos materiales en preparaciones medicinales[35]. 


\subsection{Referencias bibliográficas.}

[1] S. Patra, S. Mukherjee, A. K. Barui, A. Ganguly, B. Sreedhar, and C. R. Patra, "Green synthesis, characterization of gold and silver nanoparticles and their potential application for cancer therapeutics," Mater. Sci. Eng. C, vol. 53, pp. 298309, 2015.

[2] J. K. Sharma, M. S. Akhtar, S. Ameen, P. Srivastava, and G. Singh, "Green synthesis of $\mathrm{CuO}$ nanoparticles with leaf extract of Calotropis gigantea and its dyesensitized solar cells applications," J. Alloys Compd., vol. 632, pp. 321-325, 2015.

[3] G. Sangeetha, S. Rajeshwari, and R. Venckatesh, "Green synthesis of zinc oxide nanoparticles by aloe barbadensis miller leaf extract: Structure and optical properties," Mater. Res. Bull., vol. 46, no. 12, pp. 2560-2566, 2011.

[4] Q. Liang, W. Ma, Y. Shi, Z. Li, and X. Yang, "Easy synthesis of highly fluorescent carbon quantum dots from gelatin and their luminescent properties and applications," Carbon N. Y., vol. 60, pp. 421-428, 2013.

[5] Q. Sun, X. Cai, J. Li, M. Zheng, Z. Chen, and C. P. Yu, "Green synthesis of silver nanoparticles using tea leaf extract and evaluation of their stability and antibacterial activity," Colloids Surfaces A Physicochem. Eng. Asp., vol. 444, pp. 226-231, 2014.

[6] S. a Wohlgemuth, R. J. White, and M. M. Titirici, "Fluorescent Carbon Nanoparticles From," pp. 1-4.

[7] M. P. Sk, A. Jaiswal, A. Paul, S. S. Ghosh, and A. Chattopadhyay, "Presence of Amorphous Carbon Nanoparticles in Food Caramels," Sci. Rep., vol. 2, 2012.

[8] G. Magnacca, A. Allera, E. Montoneri, L. Celi, D. E. Benito, L. G. Gagliardi, L. Carlos, and J. Accepted, "Novel magnetite nanoparticles coated with waste sourced bio- based substances as sustainable and renewable adsorbing materials," 2014.

[9] H. Li, F. Li, G. Wang, and H. Sun, "One-step synthesis of fluorescent carbon nanoparticles for degradation of naphthol green under visible light," J. Lumin., vol. 156, pp. 36-40, 2014.

[10] R. Vikneswaran, S. Ramesh, and R. Yahya, "Green synthesized carbon nanodots as a fluorescent probe for selective and sensitive detection of iron(III) ions," Mater. Lett., vol. 136, pp. 179-182, 2014.

[11] Y. Wang and A. Hu, "Carbon quantum dots: synthesis, properties and applications," J. Mater. Chem. C, vol. 2, pp. 6921-6939, 2014.

[12] R. Rajan, K. Chandran, S. L. Harper, S.-I. Yun, and P. T. Kalaichelvan, "Plant extract synthesized silver nanoparticles: An ongoing source of novel biocompatible materials," Ind. Crops Prod., vol. 70, pp. 356-373, 2015.

[13] U. Kalapathy, a. Proctor, and J. Shultz, "An improved method for production of silica from rice hull ash," Bioresour. Technol., vol. 85, no. 3, pp. 285-289, 2002.

[14] U. Kalapathy, A. Proctor, and J. Shultz, "A simple method for production of pure silica from rice hull ash," Fuel Energy Abstr., vol. 42, no. 1, p. 45, 2001.

[15] M. Wu, Y. Wang, W. Wu, C. Hu, X. Wang, J. Zheng, Z. Li, B. Jiang, and J. Qiu, "Preparation of functionalized water-soluble photoluminescent carbon quantum dots from petroleum coke," Carbon N. Y., vol. 78, pp. 480-489, 2014.

[16] J. Zhang, W. Shen, D. Pan, Z. Zhang, Y. Fang, and M. Wu, "Controlled synthesis of green and blue luminescent carbon nanoparticles with high yields by the carbonization of sucrose," New J. Chem., vol. 34, no. 4, p. 591, 2010.

[17] M. C. Esmelindro, G. Toniazzo, A. Waczuk, C. Dariva, and D. De Oliveira, "Caracterização físico-química da erva mate: influência das etapas do processamento industrial," Ciência e Tecnol. Aliment., vol. 22, no. 2, pp. 199-204, 2002.

[18] M. R. El-Zahry, A. Mahmoud, I. H. Refaat, H. A. Mohamed, H. Bohlmann, and B. Lendl, "Antibacterial effect of various shapes of silver nanoparticles monitored by SERS," Talanta, vol. 138, pp. 183-189, 2015.

[19] P. Prieto, V. Nistor, K. Nouneh, M. Oyama, M. Abd-Lefdil, and R. D??az, "XPS 
study of silver, nickel and bimetallic silver-nickel nanoparticles prepared by seedmediated growth," Appl. Surf. Sci., vol. 258, no. 22, pp. 8807-8813, 2012.

[20] O. Ivashchenko, M. Lewandowski, B. Pepli??ska, M. Jarek, G. Nowaczyk, M. Wiesner, K. Za????ski, T. Babutina, A. Warowicka, and S. Jurga, "Synthesis and characterization of magnetite/silver/antibiotic nanocomposites for targeted antimicrobial therapy," Mater. Sci. Eng. C, vol. 55, pp. 343-359, 2015.

[21] S. Calderon V, A. Cavaleiro, and S. Carvalho, "Chemical and structural characterization of Zr-C-N-Ag coatings: XPS, XRD and Raman spectroscopy," Appl. Surf. Sci., vol. 346, pp. 240-247, 2015.

[22] NIST, "NIST X-ray Photoelectron Spectroscopy Database; Version 4.1," 2012. [Online]. Available: http://srdata.nist.gov/xps/.

[23] D. Wilson and M. A. Langell, "XPS analysis of oleylamine/oleic acid capped Fe3O4 nanoparticles as a function of temperature," Appl. Surf. Sci., vol. 303, pp. 6-13, 2014.

[24] L. Huang, X. Weng, Z. Chen, M. Megharaj, and R. Naidu, "Synthesis of iron-based nanoparticles using oolong tea extract for the degradation of malachite green," Spectrochim. Acta - Part A Mol. Biomol. Spectrosc., vol. 117, pp. 801-804, 2014.

[25] W. S. Peternele, V. Monge Fuentes, M. L. Fascineli, J. Rodrigues Da Silva, R. C. Silva, C. M. Lucci, and R. Bentes De Azevedo, "Experimental investigation of the coprecipitation method: An approach to obtain magnetite and maghemite nanoparticles with improved properties," J. Nanomater., vol. 2014, no. 1, pp. 110, 2014.

[26] M. Rudolph, J. Erler, and U. A. Peuker, "A TGA-FTIR perspective of fatty acid adsorbed on magnetite nanoparticles-Decomposition steps and magnetite reduction," Colloids Surfaces A Physicochem. Eng. Asp., vol. 397, pp. 16-23, 2012.

[27] Y.-S. LI, J. S. CHURCH, and A. L. WOODHEAD, "Infrared and Raman spectroscopic studies on iron oxide magnetic nano-particles and their surface modifications," $J$. Magn. Magn. Mater., vol. 324, no. 8, pp. 1543-1550.

[28] L. Ai, C. Zhang, F. Liao, Y. Wang, M. Li, L. Meng, and J. Jiang, "Removal of methylene blue from aqueous solution with magnetite loaded multi-wall carbon nanotube: Kinetic, isotherm and mechanism analysis," J. Hazard. Mater., vol. 198, pp. 282-290, 2011.

[29] J. Gomis, R. F. Vercher, A. M. Amat, D. O. Mártire, M. C. González, A. Bianco Prevot, E. Montoneri, A. Arques, and L. Carlos, "Application of soluble bio-organic substances (SBO) as photocatalysts for wastewater treatment: Sensitizing effect and photo-Fenton-like process," Catal. Today, vol. 209, pp. 176-180, 2013.

[30] G. Magnacca, A. Allera, E. Montoneri, L. Celi, D. E. Benito, L. G. Gagliardi, and L. Carlos, "Novel magnetite nanoparticles coated with waste sourced bio- based substances as sustainable and renewable adsorbing materials," ACS Sustain. Chem. Eng., vol. in press, 2014.

[31] M. C. Biesinger, B. P. Payne, A. P. Grosvenor, L. W. M. Lau, A. R. Gerson, and R. S. C. Smart, "Resolving surface chemical states in XPS analysis of first row transition metals, oxides and hydroxides: $\mathrm{Cr}, \mathrm{Mn}, \mathrm{Fe}$, $\mathrm{Co}$ and Ni," Appl. Surf. Sci., vol. 257, no. 7, pp. 2717-2730, 2011.

[32] S. Sitthichai, C. Pilapong, T. Thongtem, and S. Thongtem, "CMC-coated Fe3O4 nanoparticles as new MRI probes for hepatocellular carcinoma," Appl. Surf. Sci., vol. 356, pp. 972-977, 2015.

[33] A. P. Grosvenor, B. A. Kobe, M. C. Biesinger, and N. S. McIntyre, "Investigation of multiplet splitting of Fe 2p XPS spectra and bonding in iron compounds," Surf. Interface Anal., vol. 36, no. 12, pp. 1564-1574, 2004.

[34] T. Yamashita and P. Hayes, "Analysis of XPS spectra of Fe2+ and Fe3+ ions in oxide materials," Appl. Surf. Sci., vol. 254, no. 8, pp. 2441-2449, 2008.

[35] Y. C. Lin, L. Y. Lin, M. Y. Gao, and Y. P. Fang, "Mesoporous silica nanoparticles synthesized from liquid crystal display manufacturing extracts as a potential 
candidate for a drug delivery carrier: Evaluation of their safety and biocompatibility," Int. J. Nanomedicine, vol. 8, pp. 3833-3842, 2013.

[36] J.J. Romero, M.J. Llansola-Portoles, M. L. Dell'Arciprete, H. B. Rodríguez, A. L. Moore and M. C. Gonzalez, "Photoluminiscent 1-2 nm size silicon nanoparticles: A surface-dependent system," Chem. Mater., vol 25, no. 17, pp. 3488-3498. 


\section{(6) \\ Estudio de las propiedades y aplicaciones de algunos nanomateriales obtenidos usando residuos domiciliarios.}

Nanomateriales magnéticos tales como algunos óxidos de hierro, de cobalto, entre otros, han sido objeto de múltiples estudios debido a sus posibles aplicaciones en medicina, transporte controlado de drogas, hipertermia magnética, remediación de cuerpos de aguas contaminados, etcétera, debido a su fácil direccionamiento bajo la aplicación de un campo magnético.

Por su lado, las nanopartículas de Carbono ( $\mathrm{NpC}$ ), las cuales fueron descubiertas en 2004, poseen propiedades ópticas y electrónicas asociadas a su estructura en la nanoescala. Entre las propiedades especiales que les otorga potencial uso tecnológico podemos citar su capacidad fotoluminiscente por excitación mono y multifotónica. El espectro de emisión suele ser ancho y variable frente a cambios de las condiciones de síntesis y presencia de iones metálicos. Debido a estas propiedades y a los procedimientos de síntesis sencillos y de bajo costo, algunos autores han vaticinado que las $\mathrm{NpC}$ reemplazarían en varias aplicaciones a los puntos cuánticos de metales de transición[1]-[4].

En este capítulo nos centramos en el estudio de algunas propiedades de las nanopartículas de $\mathrm{Fe}_{3} \mathrm{O}_{4}$ y $\mathrm{NpC}$ obtenidas por la ruta sintética estudiada en el capítulo 5. Sobre las nanopartículas de $\mathrm{Fe}_{3} \mathrm{O}_{4}$ se hizo hincapié en el efecto del extracto hidrosoluble de YM utilizado durante la síntesis sobre algunas propiedades magnéticas de los nanomateriales y su capacidad de adsorción del colorante azul de metileno. Además se estudió la degradación catalizada por $\mathrm{SO}_{4}$ del azul de metileno usando estas nanopartículas en función de su recubrimiento orgánico.

Por otro lado se investigó la fotoquímica de las NpC obtenidas por los tres métodos antes mencionados que permitieron calcular entre otras cosas el rendimiento cuántico de fluorescencia, tiempos de decaimientos de fluorescencia y una primera aproximación para elucidar la identidad de los estados excitados de las NpC. Estos estudios son necesarios para usos tecnológicos posteriores de las nanopartículas como sensores fotoluminiscentes y fotosensibilizadores, no cubiertos en este trabajo de tesis. 


\subsection{Caracterización magnética de las nanopartículas de} $\mathrm{Fe}_{3} \mathrm{O}_{4}$ con diferentes recubrimientos de extracto de $\mathrm{YM}$.

\subsubsection{Materiales y Métodos}

Las curvas de magnetización de las partículas en función del campo aplicado se obtuvieron a temperatura ambiente. La magnetización específica de cada material se obtuvo a partir de la relación entre el momento específico respectivo y la masa magnética de cada partícula. La magnetización volumétrica del núcleo de cada material se obtuvo dividiendo la magnetización especifica por la densidad del spine/ del óxido de Hierro $\left(5.210^{3} \mathrm{~kg} / \mathrm{m}^{3}\right)$.

\subsubsection{Resultados y análisis.}

Debido a las propiedades magnéticas que poseen las nanopartículas sintetizadas, se obtuvieron las curvas de magnetización del material (M) en función del campo aplicado $(\mathrm{H})$ a temperatura ambiente para los polvos de estos materiales. La figura 6.1 muestra las curvas de magnetización de las partículas: YM0, YM10, YM30 y YM50.

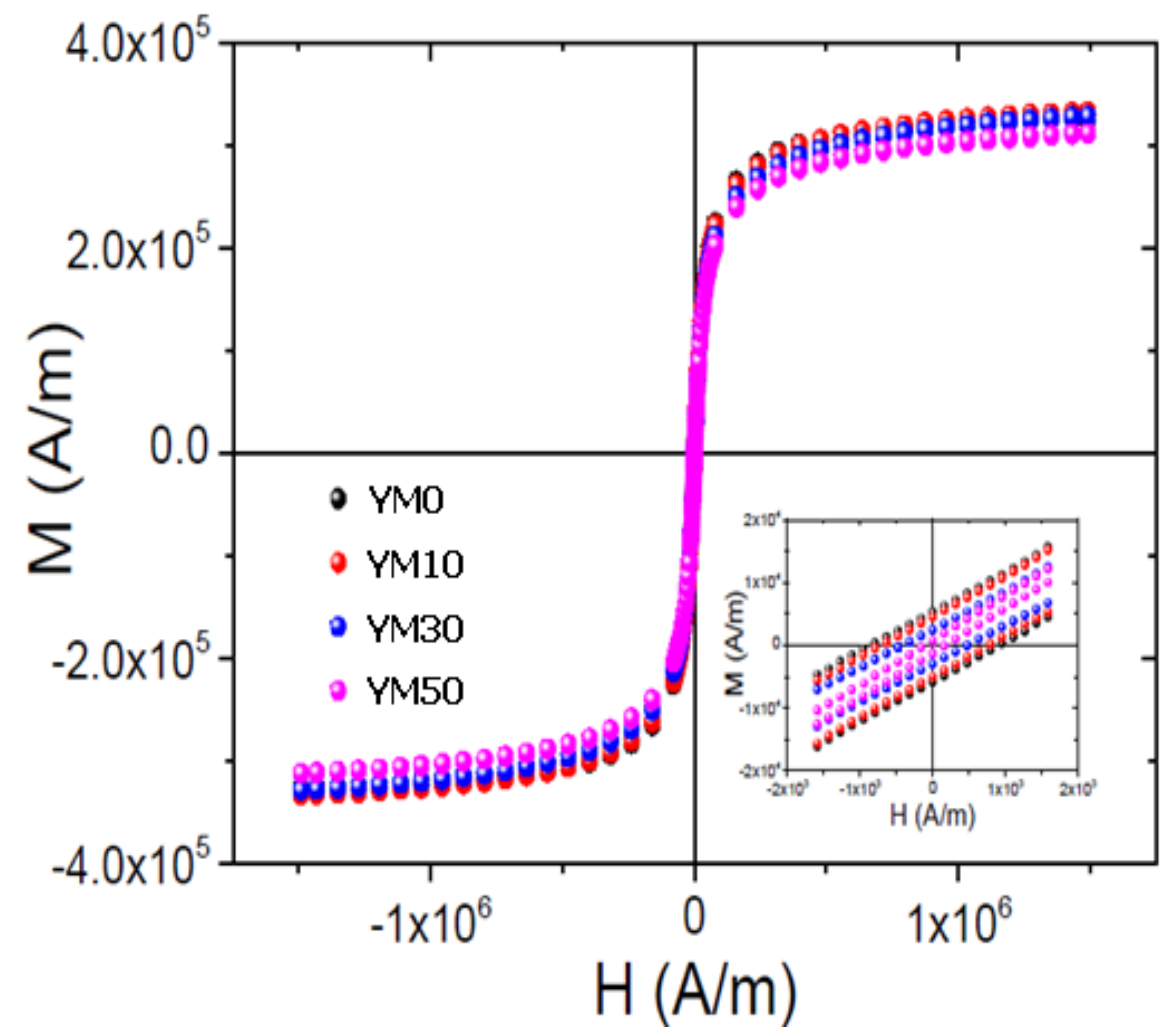

Fig. 6.1 - Curvas de Magnetización de las partículas en función del campo aplicado. Inset Inferior: Zoom de la zona a bajos campos.

Se observa de estas curvas que ninguna de las partículas posee coercitividad cero, por lo que se descarta que presenten comportamiento superparamagnético.

Sin embargo, la fig. 6.2 muestra que si bien la coercitividad no es cero, la tendencia de estos valores es a disminuir a medida que se utilizó mayor cantidad de extracto hidrosoluble de YM. Este último parámetro es representado por la relación \% $m_{\text {recubrimiento }} / \mathrm{m}_{\text {núcleo }}$ tomando como mrecubrimiento la materia orgánica 
superficial de cada partícula calculado por TGA (Capítulo 5, sección 2.2 mostrado, figura 5.11) y muúcleo la masa correspondiente a los óxidos de hierro. Todo lo anterior es indicativo que el uso de las diferentes cantidades de YM modifica el comportamiento magnético de los materiales y que a medida que se utilizó mayor cantidad de YM durante el proceso de síntesis, el material obtenido tiende a un comportamiento superparamagnético.

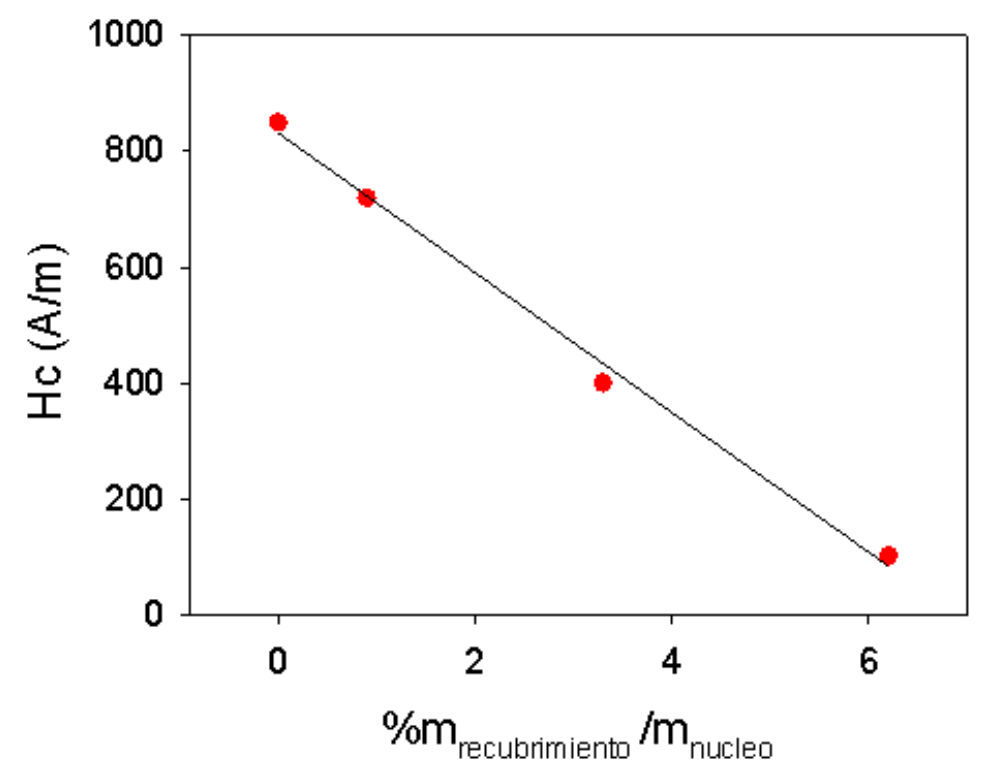

Fig. 6.2 -Relación experimental entre la Hc y la relación \% $m_{\text {recubrimiento }} / m_{\text {núcleo. }}$

A partir de las curvas mostradas en la figura 6.1 es posible obtener curvas M vs $\mathrm{H}$ que no presenten histéresis[5]. Para ello en la región histerética se promediaron los dos aportes $\mathrm{M}$ de estas curvas para un mismo campo aplicado. Se utilizó la siguiente ecuación para tal fin:

$M(H)=\left(M_{\text {up }}(H)+M_{\text {low }}(H)\right) / 2$, donde $M_{\text {up }}$ y $M_{\text {low }}$ son la banda superior e inferior de la región histerética permitiendo así la obtención de una curva sin histéresis.

La figura 6.3 muestra las curvas sin histéresis resultante de este tratamiento para todas las partículas. En la parte superior de la misma, se evidencian los datos experimentales tratados y un ajuste de los mismos siguiendo la siguiente ecuación:

$$
M(H, T)=N \int \mu\left(\operatorname{coth}\left(\frac{\mu_{0} \mu H}{k T}\right)-\frac{k T}{\mu_{0} \mu H}\right) f(\mu) d \mu+\chi_{l}(T) H ;
$$

Donde $\chi$ es la susceptibilidad lineal a altos campos que combina contribuciones negativas debido a la posible respuesta diamagnética del recubrimiento de las nanopartículas con contribuciones positivas debido a la posible existencia de capas magnéticas frustradas en la superficie del núcleo de las nanopartículas. Por su lado, $f(\mu) d \mu$ es el número de momentos magnéticos normalizado en el intervalo $\mu y \mu+d \mu$. Para el análisis, se utilizó una distribución de tamaños lognormal. En la parte inferior de la figura 6.3 se muestra la susceptibilidad aparente $\kappa$ obtenido del análisis de la región lineal central de estas curvas. 


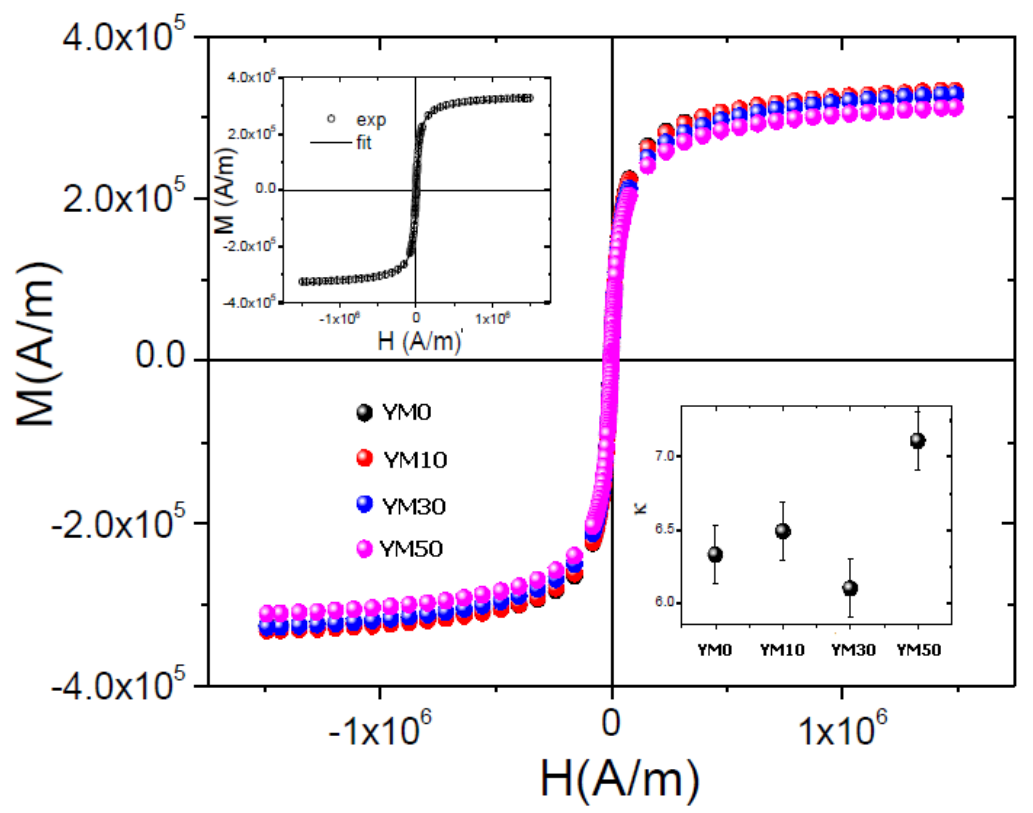

Fig. 6.3 - Curvas de Magnetización modificadas. Inset Superior: Datos experimentales y ajuste superparamagnético. Inset Inferior: Susceptibilidad magnética aparente.

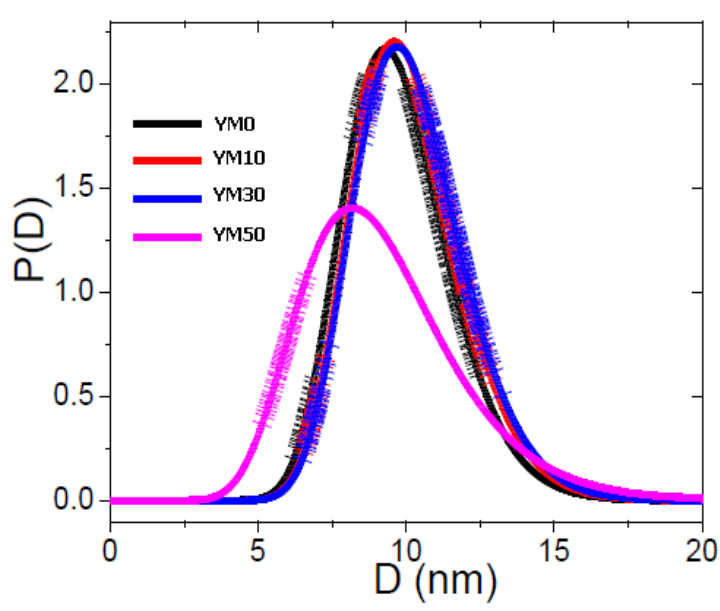

La figura 6.4 muestra la distribución lognormal obtenida mediante el ajuste de los valores experimentales. Los estudios de magnetización sugieren que la introducción de la YM en la síntesis a bajas cantidades no modifica sustancialmente el tamaño de las partículas. Se observa sin embargo, que la distribución de tamaños se ve modificada hacia menores diámetros para la concentración más alta de YM utilizada.

Fig. 6.4 - Distribución de tamaños de las Nanopartículas.

La tabla 6.1 muestra los valores de saturación de magnetización $\mathrm{M}_{\mathrm{s}}$ el número promedio de nanopartículas por unidad de volumen $\mathrm{N}$, el promedio de los momentos $\langle\mu\rangle$, el diámetro promedio de las nanopartículas $\left\langle D_{p}\right\rangle$, y las desviaciones estándar $\sigma_{\mu}$ y $\sigma_{D} d e \ln (\mu)$ y $\ln \left(D_{p}\right)$ respectivamente.

\begin{tabular}{|c|c|c|c|c|c|c|c|}
\hline Material & \%mrec & $<\mu>\left(\mu_{\mathrm{B}}\right)$ & $\sigma_{\mu}$ & $\begin{array}{c}\mathbf{N} \\
\left(\mathbf{1} / \mathbf{m}^{\mathbf{3}}\right)\end{array}$ & $\begin{array}{c}\mathbf{D}_{\mathbf{p}} \\
(\mathbf{n m})\end{array}$ & $\sigma_{\mathrm{P}}$ & $\begin{array}{c}\mathbf{M}_{\mathbf{s}} \\
(\mathbf{A} / \mathbf{m})\end{array}$ \\
\hline YM0 & 0.0 & $1.62 \times 10^{4}$ & 0.55 & $2.05 \times 10^{24}$ & 9.8 & 0.18 & $3.07 \times 10^{5}$ \\
\hline YM10 & 0.9 & $1.73 \times 10^{4}$ & 0.54 & $1.87 \times 10^{24}$ & 10.1 & 0.18 & $2.98 \times 10^{5}$ \\
\hline YM30 & 3.3 & $1.71 \times 10^{4}$ & 0.55 & $1.80 \times 10^{24}$ & 10.2 & 0.18 & $2.85 \times 10^{5}$ \\
\hline YM50 & 6.2 & $1.28 \times 10^{4}$ & 0.85 & $2.42 \times 10^{24}$ & 9.2 & 0.28 & $2.88 \times 10^{5}$ \\
\hline
\end{tabular}

Tabla 6.1 - Resumen de las propiedades - \%mreci: Porcentaje de materia del recubrimiento en relación de la materia del núcleo magnético, $\langle\mu\rangle$ : Momento magnético aparente promedio, $\sigma_{\mu}$ : desviación lognormal asociada a la distribución de tamaños, N: número de partículas por unidad de volumen, Dp: Tamaño magnético aparente, бp: desviación lognormal a la distribución de tamaños magnéticos. Ms: Magnetización de saturación. 
Los resultados obtenidos para los polvos se comparan con los obtenidos para suspensiones acuosas de $10 \mathrm{~g} / \mathrm{L}$ de las nanopartículas (ferrofluidos). La fig. 6.5 muestra en la parte superior, la curva de magnetización $\mathrm{M}$ vs $\mathrm{H}$ del ferrofluido de YM50 comparado al del sólido del mismo material. La figura evidencia una diferencia entre ambas curvas a bajos campos indicando que existen diferencias en la susceptibilidad aparente del mismo material dependiendo de la fase en la que se encuentre.

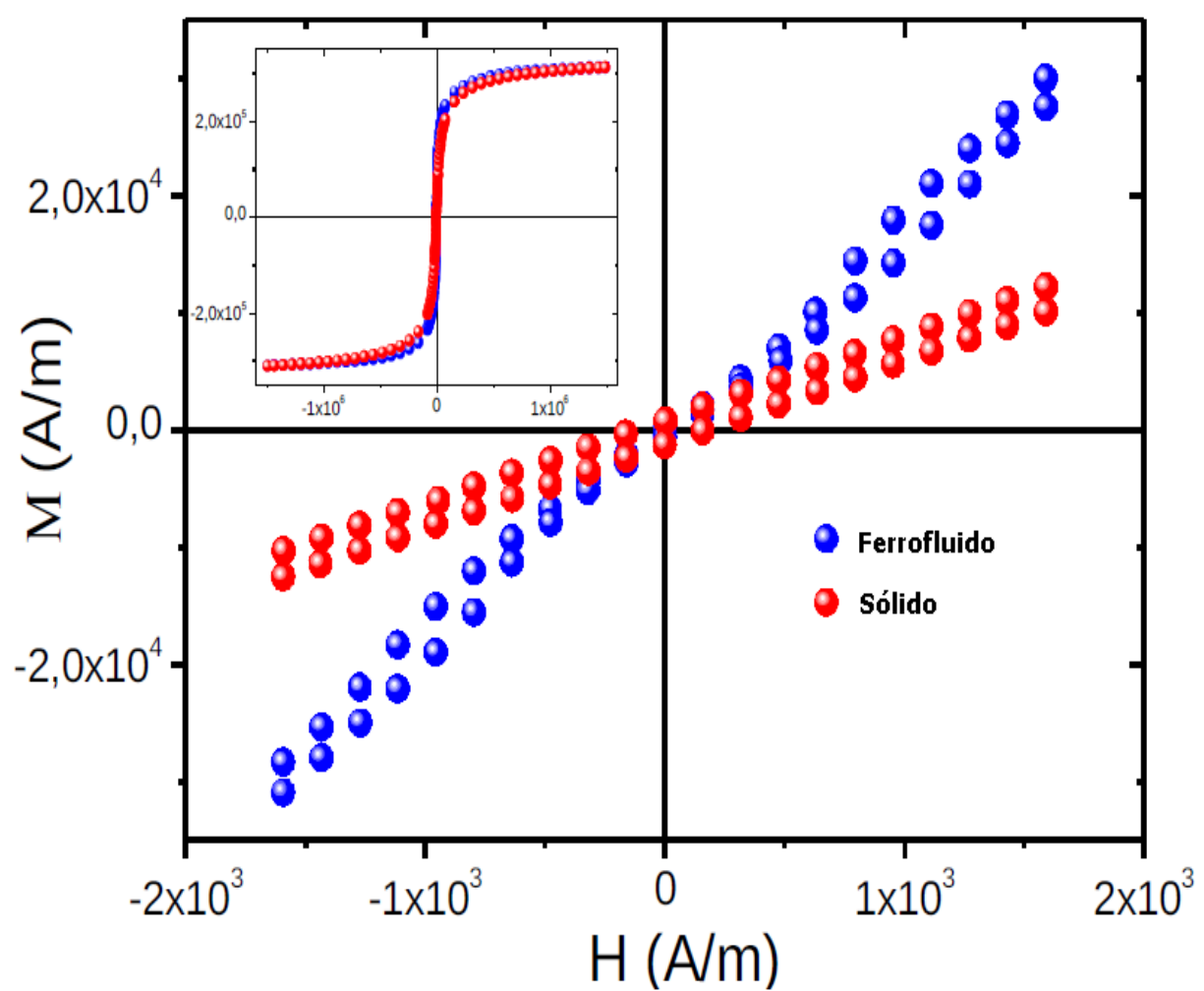

Fig. 6.5 - Curva de magnetización a bajos campos del ferrofluido y del sólido YM50. Inset: Curva de magnetización en todo el espectro de campos estudiado.

La susceptibilidad aparente para el sólido y el ferrofluido son $\kappa_{\mathrm{s}}=7.1 \mathrm{y}$ $\kappa_{\mathrm{f}}=17.7$, respectivamente. Esta diferencia será discutida más adelante. Además, medidas de susceptibilidad obtenidas con un campo magnético alterno confirman esta diferencia tal como se describe a continuación.

Las componentes de $\kappa$ para todo el rango de temperaturas analizado muestran que $\kappa_{s}<\kappa_{f}$, en concordancia con los experimentos anteriores. En el análisis de la fase real (izquierda) se evidencia para el ferrofluido un cambio drástico en la respuesta magnética del coloide cerca al punto de congelamiento del agua. En esta misma fase, la susceptibilidad aparente $\kappa^{\prime}$ toma valores de $\kappa_{\mathrm{f}}^{\prime} \approx$ 11.5 y $\kappa^{\prime} \approx 5.7$ para el ferrofluido y el sólido a $273 \mathrm{~K}$, respectivamente. A $300 \mathrm{~K}$ la susceptibilidad del sólido $\left(\kappa_{s}^{\prime} \approx 6\right)$ coincide dentro del error experimental, con el obtenido mediante las curvas $\mathrm{M}$ vs. $\mathrm{H}$ a la misma temperatura $\left(\kappa_{s} \approx 7.1\right)$. En cambio, para el ferrofluido $\left(\kappa_{f}^{\prime} \approx 7.4\right)$ es diferente al obtenido mediante las medidas de $\mathrm{M}$ vs $\mathrm{H}\left(\kappa_{\mathrm{f}} \approx 17.7\right)$. 

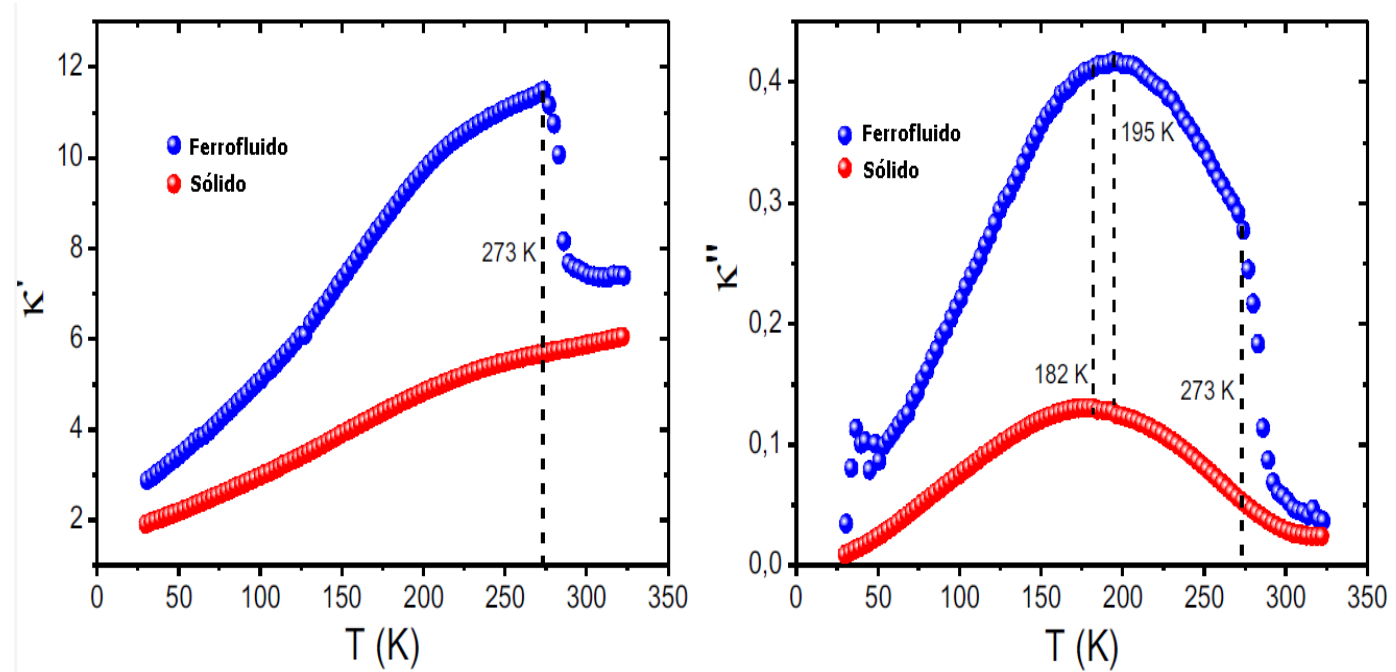

Fig. 6.6 - Curva de susceptibilidad ac de la YM50 para izquierda: fase real, derecha: fase imaginaria.

Por otro lado, la disminución drástica de la susceptibilidad del ferrofluido por encima del punto de fusión es consecuencia de la existencia de dos fracciones de partículas, unas persistentes en suspensión y otras en el fondo del recipiente. Las distancias interpartícula en la fracción precipitada sería comparable a la de los ensayos para polvos. Por ello, la susceptibilidad del ferrofluido por encima a $273 \mathrm{~K}$ tiende a los valores de susceptibilidad obtenido para el polvo $\left(\kappa_{f}^{\prime} / \kappa_{s}^{\prime} \approx 1.2\right)$.

En las medidas en fase imaginaria la susceptibilidad $\kappa "$ presenta máximos entre 180 y $200 \mathrm{~K}$ que pueden ser atribuidos a los procesos de bloqueo del momento magnético de las nanopartículas. Las temperaturas donde $\kappa "$ es máximo puede ser tomado como una medida cuasi directa de la temperatura de bloqueo $T_{B}[6]$. Se puede apreciar en la figura, que existe una diferencia de $13 \mathrm{~K}$ entre las temperaturas de bloqueo para el ferrofluido y del sólido aun estando ambas muestras en estado sólido $\left(\mathrm{T}_{\mathrm{B}}^{\mathrm{f}} \approx 195 \mathrm{~K}>\mathrm{T}_{\mathrm{B}} \approx 182 \mathrm{~K}\right)$. Con estas temperaturas es posible calcular la densidad efectiva de anisotropía Kef. Para estos valores de $T$ de bloqueo, $K_{\text {ef }}$ son del orden de $5.8 \times 10^{4}$ y $6.3 \times 10^{4} \mathrm{~J} / \mathrm{m}^{3}$. Estos valores son aproximadamente 5 veces mayores que el esperado para la energía magnetocristalina de la magnetita $\left(1.1 \times 10^{4}-1.25 \times 10^{4} \mathrm{~J} / \mathrm{m}^{3}\right.$ para 200 $\mathrm{K}<\mathrm{T}<300 \mathrm{~K}$ ) [15], pero se encuentran en concordancia con nanopartículas de magnetita de ese tamaño o menores [16].

Existen evidencias que las interacciones dipolares pueden modificar el tiempo de relajación y la coercitividad de nanopartículas con monodominio magnético[7], [8]. En la mayoría de los casos se propone que las interacciones dipolares incrementan la energía de barrera para las fluctuaciones de momento y consecuentemente incrementan la coercitividad[9]. En el presente estudio la coercitividad disminuye con el aumento de la relación másica $m_{\text {recubrimiento }} / \mathrm{m}_{\text {núcleo }}$ desde YM0 a YM50, como se mostró en la figura 6.2. El aumento de la relación $\mathrm{m}_{\text {recubrimiento }} / \mathrm{m}_{\text {núcleo }}$ implica un aumento del espesor de la capa de recubrimiento $d$, y con ello un aumento en las distancias entre los núcleos de las partículas en estado sólido. Para las partículas en contacto, la distancia entre los centros de 2 partículas sería del orden de $2\left(\mathrm{~d}_{\mathrm{YM}}+\mathrm{R}_{\mathrm{S}}\right)$ con $\mathrm{R}_{\mathrm{S}}$ el radio del núcleo de óxidos de hierro determinado por SAXS y $d_{Y M}$ el espesor del recubrimiento orgánico. Asumiendo que la coercitividad $H_{c}$ posee un origen en las interacciones 
dipolares[10] es posible suponer que estas dependen de $d_{Y M}$ y $R_{S}$ como $\left(d_{Y M}+R_{S}\right)^{-3}$ que para valores $X=d_{Y M} / R_{S}$ bajos, puede ser aproximado $a$ :

$$
H_{C} \propto\left(d_{Y M}+R_{S}\right)^{-3} \propto\left(1+\frac{d_{Y M}}{R_{S}}\right)^{-3} \approx b(1-3 x) / R_{S}^{3}
$$

Por otro lado, es posible establecer una relación entre $\mathrm{m}_{\text {recubrimiento }} / \mathrm{m}_{\text {núcleo }} \mathrm{Y}$ $x$.

$$
\frac{m_{\text {recubrimiento }}}{m_{\text {núcleo }}}=\frac{\rho_{\text {rec }} V_{\text {rec }}}{\rho_{\text {núcleo }} V_{\text {núcleo }}}=\frac{\rho_{\text {rec }}}{\rho_{\text {núcleo }}}\left[\left(1+\frac{d_{Y M}}{R_{S}}\right)^{3}-1\right] \approx 3 \frac{\rho_{\text {rec }}}{\rho_{\text {núcleo }}} \mathrm{x}
$$

Donde $\mathrm{V}_{\text {rec }} \mathrm{y} \mathrm{V}_{\text {núcleo }}$ son los volúmenes de la capa de recubrimiento y el núcleo, respectivamente, y $\rho_{\text {rec }}$ y $\rho_{\text {núcleo }}$ sus respectivas densidades.

Con las expresiones anteriores es posible obtener la siguiente relación:

$$
H_{C} \approx b / R_{S}^{3}\left(1-\frac{\rho_{\text {rec }} V_{\text {rec }}}{\rho_{\text {núcleo }} V_{\text {núcleo }}}\right)
$$

Con la cual $\rho_{\text {rec }}$ puede ser estimada. Considerando $\rho_{\text {núcleo }}=370 \mathrm{~kg} / \mathrm{m}^{3}[11]$, resulta $\rho_{\text {rec }} \approx 1 \times 10^{3} \mathrm{~kg} / \mathrm{m}^{3}$. Esta densidad corresponde a la masa de materia orgánica que ocupa el volumen del recubrimiento con ancho $\mathrm{d}$ y dado que existen espacios vacíos entre las moléculas adsorbidas, esta densidad es menor a la densidad del sustrato de YM en estado líquido.

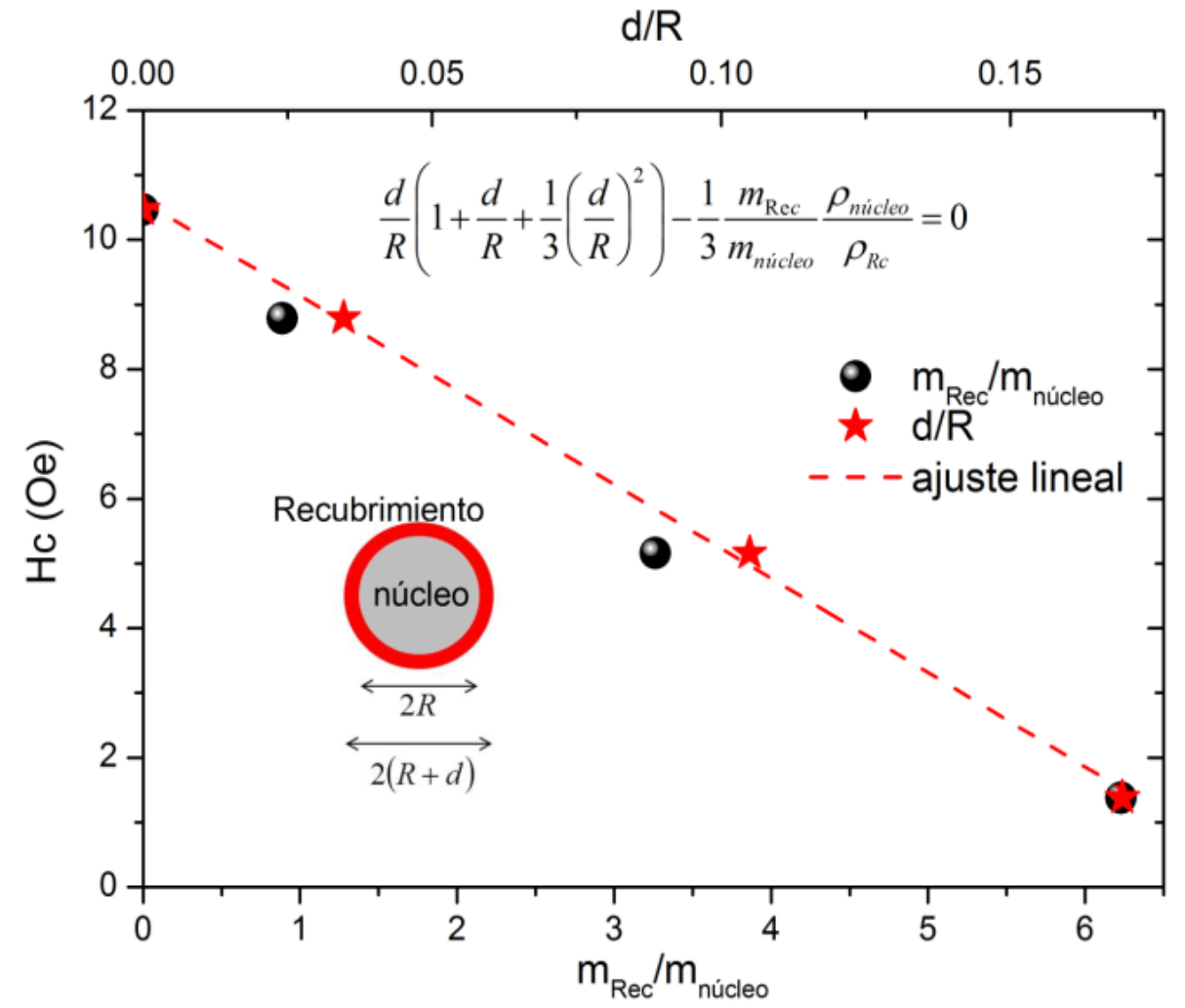

Fig. 6.7 - Ajustes experimentales $H c(x)$ siendo $x d / R$ o $m_{\text {red }} / m_{\text {núdeo. }}$ 
Las diferencias observadas entre los valores de la susceptibilidad ac inicial aparente obtenidas para el sólido y para el ferrofluido de la YM50 (mostrados en las figuras 6.5 y 6.6) son sorprendentes. El hecho que $\kappa_{f}>\kappa_{s}$ para la muestra YM50, resalta la importancia de las interacciones intermoleculares en el ferrofluído. Se conoce de la literatura, que las interacciones entre coloides capaces de inducir arreglos lineales de varias nanopartículas, producen un aumento en el campo efectivo de las nanopartículas que se traduce en un aumento de la susceptibilidad aparente, la que resulta diferente de la susceptibilidad propia de la partícula sin interacciones[13]. Efectivamente, los ensayos de SAXS mostraron la presencia de estos arreglos para las partículas en suspensión.

La existencia de interacciones dipolares no despreciables indica que la medida de susceptibilidad debe ser considerada como "aparente" en el sentido que estas no son intrínsecas a las nanopartículas individuales. En el caso de dispersiones aleatorias de partículas en sólidos y polvos, las interacciones dipolares poseen carácter desmagnetizante y con ello se evidencia una disminución de la susceptibilidad[12]. Un criterio que permite diferenciar si existen efectos magnetizantes 0 desmagnetizantes presentes en las nanopartículas es comparar el tamaño magnético aparente con el tamaño de las mismas medido por TEM, SAXS o incluso el tamaño de la cristalita del óxido de hierro determinado mediante DRX. En la figura 6.8 se muestran los radios de las partículas determinados por diferentes técnicas y el espesor $d_{Y M}$ del recubrimiento orgánico.

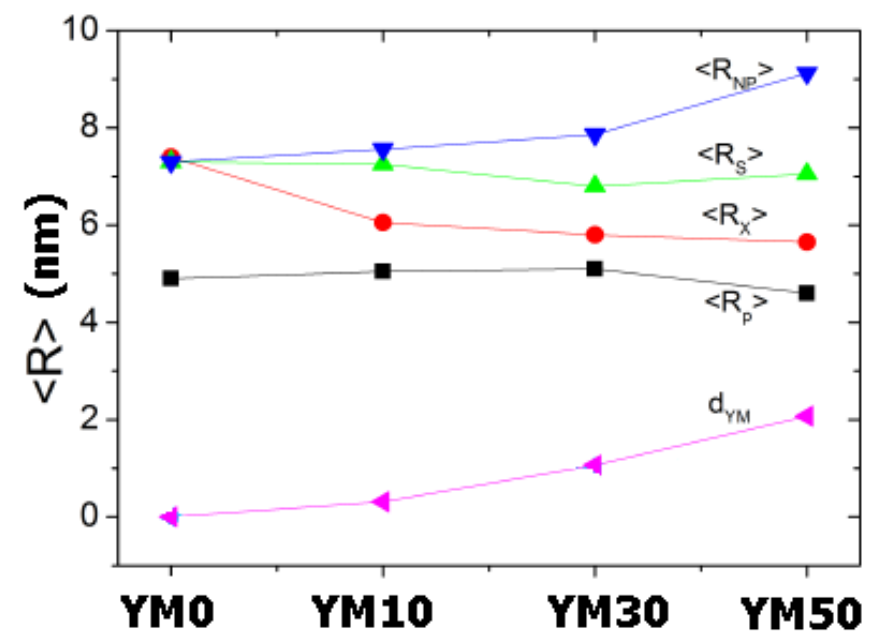

Fig. 6.8 - Radio de las partículas determinados por diferentes técnicas. $\left\langle R_{N p}\right\rangle=\left\langle R_{S}\right\rangle+d_{Y M},\left\langle R_{S}\right\rangle: S A X S$, $\left\langle R_{X}\right\rangle: X R D,\left\langle R_{p}\right\rangle$ : Tamaño magnético proveniente de la fig. 6.4 y $d_{Y M}$ es el espesor de la capa orgánica.

Como se puede apreciar en la figura, el radio de partícula determinado por las medidas magnéticas es menor que los obtenidos por todas las otras técnicas. Lo anterior permite concluir que las interacciones entre los momentos dipolares de las nanopartículas en polvo conllevan a un aumento de la susceptibilidad medida (aparente). El menor tamaño aparente obtenido por medidas magnéticas comparado con los determinados por otras técnicas indica que las interacciones desmagnetizantes se encuentran también presentes en el polvo. 


\subsection{Adsorción de Azul de Metileno sobre las nanopartículas de $\mathrm{Fe}_{3} \mathrm{O}_{4}$ recubiertas con extracto de $\mathrm{YM}$.}

\subsubsection{Materiales y Métodos}

Con el objetivo de evaluar la capacidad de adsorción de azul de metileno sobre las nanopartículas sintetizadas se realizaron una serie de experimentos de

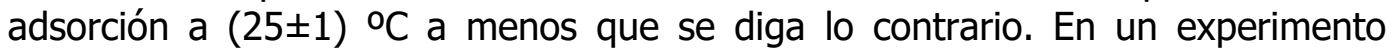
típico a $50 \mathrm{~mL}$ de solución de Azul de Metileno (AM) con concentración conocida se le agrega una cantidad tal de la nanopartículas de estudio de tal forma de obtener 600 ppm de concentración partículas. El pH fue ajustado usando $\mathrm{NaOH}$ o $\mathrm{HCl}$ de ser necesario. La solución fue sometida a agitación en frascos cerrados color caramelo durante 2 horas. La separación de las partículas luego de concluido el ensayo, se llevó a cabo por la aplicación de un campo magnético. La concentración residual de AM fue monitoreada por medidas de absorbancia. La concentración máxima de AM utilizada en estos ensayos fue de 40 ppm.

Los cálculos realizados para la obtención de las isotermas son los mismos realizados para la adsorción de metales sobre materiales en base a la Hidroxiapatita (Capitulo 3).

\subsubsection{Resultados y análisis}

Entre las potenciales aplicaciones de las nanopartículas de $\mathrm{Fe}_{3} \mathrm{O}_{4}$ recubiertas con extracto de YM se procedió a evaluar su capacidad como adsorbente y catalizador de la remoción de Azul de Metileno (AM) en solución. Los resultados obtenidos se discuten a continuación.

Los ensayos cinéticos preliminares (no mostrados) indican que la adsorción de $40 \mathrm{ppm}$ de AM sobre $1 \mathrm{~g} / \mathrm{L}$ de partículas alcanza el equilibrio aproximadamente en 50 min., por ende en los experimentos de absorción se mantuvo la solución de AM en contacto con las nanopartículas durante 2 horas para garantizar se alcance un estado de equilibrio.

La capacidad de adsorción de las partículas fue evaluada a $\mathrm{pH} 7.0$, los resultados se muestran en la figura 6.9.

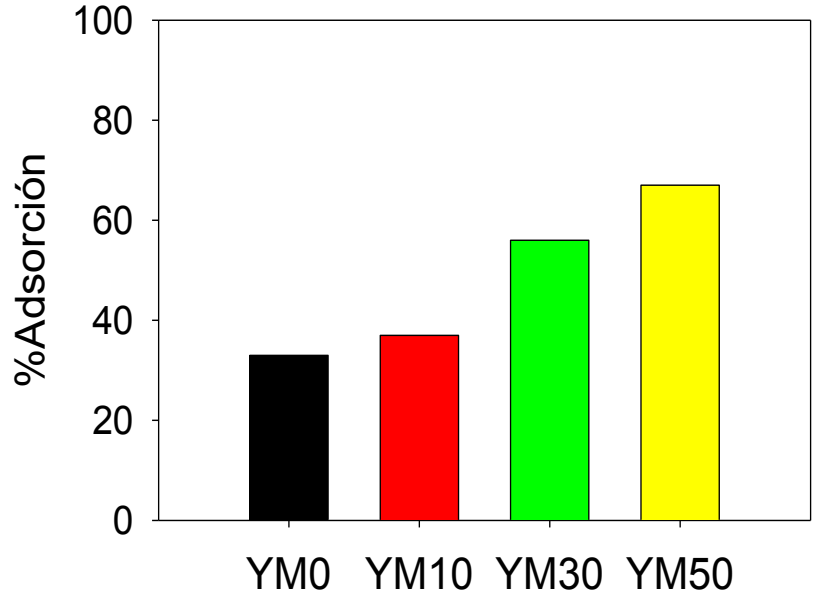

Fig. 6.9 - \%Adsorción AM de las diferentes partículas. $[A M]_{0}=40 p p m,[N P]=600 \mathrm{mg} \mathrm{L}^{-1}, \mathrm{pH}=7,0$.

La muestra con mayor capacidad de adsorción fue la YM50 ( 67\%), seguida por un la YM30 ( 56\%), y por último la YM10 ( 37\%) y YMO( 32\%). Estos valores se resumen en la tabla 6.2 junto con los valores de $\mathrm{pH}_{\mathrm{pzc}}$ obtenidos para cada partícula (Cap. 5 Fig 5.14). 


\begin{tabular}{|c|c|c|}
\hline Partícula & pH $_{\text {PZC }}$ & \%Ads AM* \\
\hline YM0 & 7,4 & 32 \\
\hline YM10 & -- & 37 \\
\hline YM30 & 6,7 & 56 \\
\hline YM50 & 5,4 & 67 \\
\hline
\end{tabular}

Tabla 6.2 - Valores de pHpzc de cada partícula y el \%Ads de AM alcanzado por las mismas. El símbolo * denota que las condiciones experimentales corresponden a las de la Fig 6.8.

Como se discutió en el capítulo anterior, la introducción de diferentes cantidades de extracto de $\mathrm{YM}$ en la síntesis modifica el $\mathrm{pH}_{\mathrm{PzC}}$ de las partículas. Este valor se desplaza a $\mathrm{pH}$ más bajos a medida que se utiliza más extracto de YM. En las condiciones de los experimentos de adsorción, las partículas YM0 y YM30 poseen un $\mathrm{pH}_{\mathrm{PZC}} \approx \mathrm{pH}_{\mathrm{Exp}}$ (al pH del experimento igual a 7.0). Por ello, la diferencia en el \%Ads entre estas partículas inicialmente no se debería solamente a diferencias en la carga neta superficial de las mismas.

En los ensayos que se discuten a continuación no se han considerado las partículas YM10 debido a que el aumento en la eficiencia del proceso de adsorción es, dentro del error experimental, comparable a la de YM0.

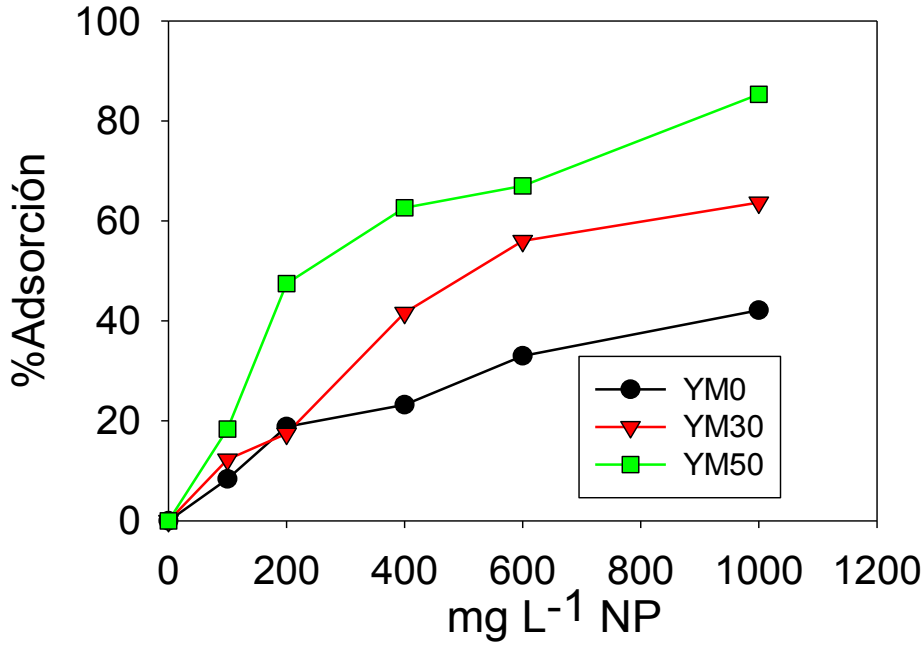

Ensayos variando la concentración de partículas utilizadas (Fig 6.10) permitieron apreciar que a una concentración de $1 \mathrm{~g} / \mathrm{L}$ de YM50 se alcanza casi un $90 \%$ de adsorción del colorante, muy superior al $40 \%$ obtenido para YM0. Por su lado la YM30 presentó un comportamiento intermedio.

Fig. 6.10- \%Adsorción AM en función de la concentración de partículas utilizada. $[A M]_{0}=40 p p m$ y $\mathrm{pH}=7,0$.

Dado que el $\mathrm{pH}$ PzC de las partículas difiere entre ellas, diferencias en las cargas superficiales pueden afectar severamente la interacción electrostática entre la superficie de las partículas y AM así como la aglomeración de las partículas. Dado que estos dos factores son esenciales al proceso de adsorción, resulta necesario investigar la eficiencia del proceso en función del $\mathrm{pH}$.

En la figura 6.11 se aprecia una fuerte dependencia de la adsorción con el $\mathrm{pH}$. Al aumentar el $\mathrm{pH}$, aumenta la eficiencia del proceso de adsorción, lo que se podría explicar mediante la desprotonación de los grupos orgánicos carboxilo y amino superficiales de la partícula y grupos $\mathrm{OH}$ sobre la magnetita capaces de interactuar electrostáticamente con el adsorbato AM. 


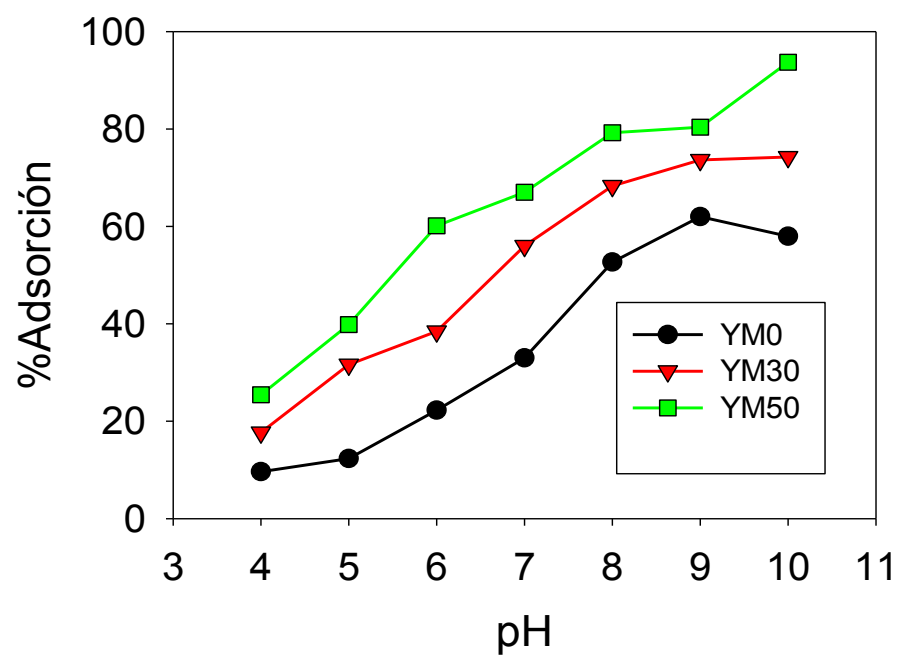

Fig. 6.11 - \%Adsorción AM en función del pH.[AM]o=40ppm y $[\mathrm{NP}]=600 \mathrm{mg} L^{1}$.

La Fig. 6.12 muestra las isotermas de adsorción a $(25 \pm 2)^{\circ} \mathrm{C}$ de AM sobre las partículas. Para ello se utilizó un intervalo de concentraciones de 5 $\mathrm{ppm}<[\mathrm{AM}]_{0}<40 \mathrm{ppm}$ y $[\mathrm{NP}]=600 \mathrm{mg} \mathrm{L}^{-1}$ a $\mathrm{pH}=7,0$. Los datos obtenidos se ajustaron a los modelos matemáticos de las isotermas de Freundlich y Langmuir, de entre los cuales el modelo de Langmuir fue el que mejor representó el comportamiento del sistema. Comportamientos similares se encontraron en la literatura para la adsorción del mismo colorante sobre nanopartículas cubiertas con ácidos húmicos [17], [18].

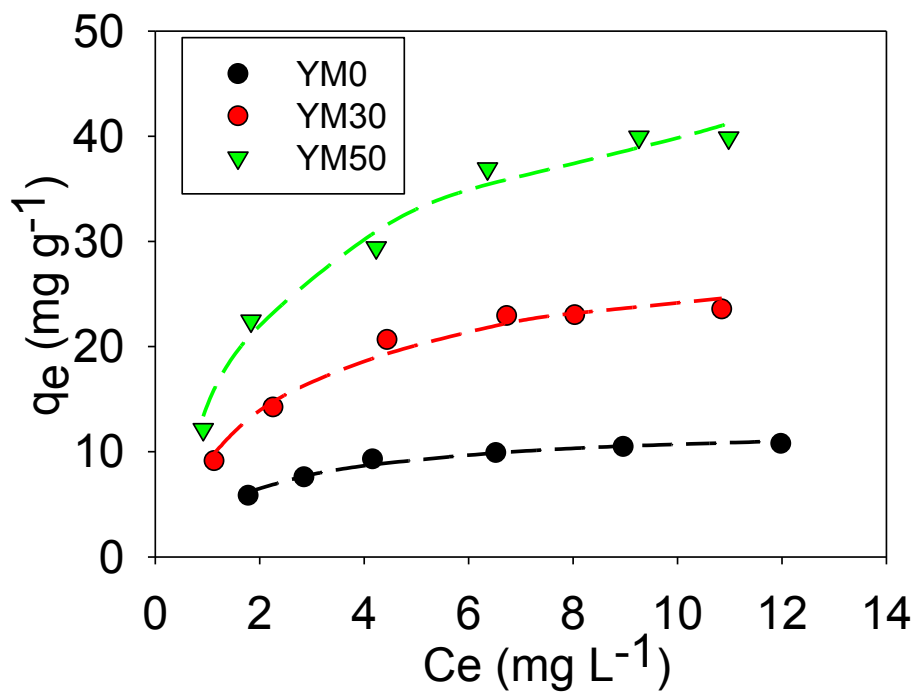

Fig. 6.12 - Isotermas de adsorción de AM sobre las diferentes partículas a (25 \pm 2$)^{\circ} \mathrm{C}[\mathrm{AM}]_{0}=40 \mathrm{ppm}$ $[N P]=600 \mathrm{mg} \mathrm{L}^{-1}, \mathrm{pH}=7,0$. Las líneas punteadas son el ajuste del modelo de Langmuir.

La capacidad de adsorción de una monocapa $b\left[\mathrm{mg} \mathrm{g}^{-1}\right]$ de AM, depende fuertemente de la cantidad de extracto de YM utilizado en la síntesis. Un comportamiento similar se observa para, la constante de afinidad adsorbente adsorbato, $\mathrm{K}_{\mathrm{L}}$. La tabla 6.2 resume los resultados obtenidos. 


\begin{tabular}{|c|c|c|c|}
\hline Partícula & $\begin{array}{c}\mathbf{b} \\
\text { [ } \mathbf{m g ~ g}^{-\mathbf{1}} \text { ] }\end{array}$ & $\begin{array}{c}\mathbf{K} \mathbf{L} \\
{\left[\mathbf{L} \mathbf{~ m g}^{-\mathbf{1}}\right]}\end{array}$ & $\mathbf{r}^{\mathbf{2}}$ \\
\hline YM0 & $14,35 \pm 1,84$ & $0,88 \pm 0,06$ & 09745 \\
\hline YM30 & $29,80 \pm 2,49$ & $1,30 \pm 0,04$ & 0,9767 \\
\hline YM50 & $49,82 \pm 6,31$ & $1,51 \pm 0,04$ & 0,9827 \\
\hline
\end{tabular}

Tabla 6.2 - Parámetros del ajuste modelo de Langmuir.

En general se puede mencionar que la adición del extracto de YM en la síntesis de nanopartículas de $\mathrm{Fe}_{3} \mathrm{O}_{4}$ aumenta la eficiencia del proceso de adsorción de AM. En la figura 6.13 se evidencia una relación lineal entre la capacidad de adsorción y el porcentaje de materia orgánica de cada partícula bajo las condiciones estudiadas.

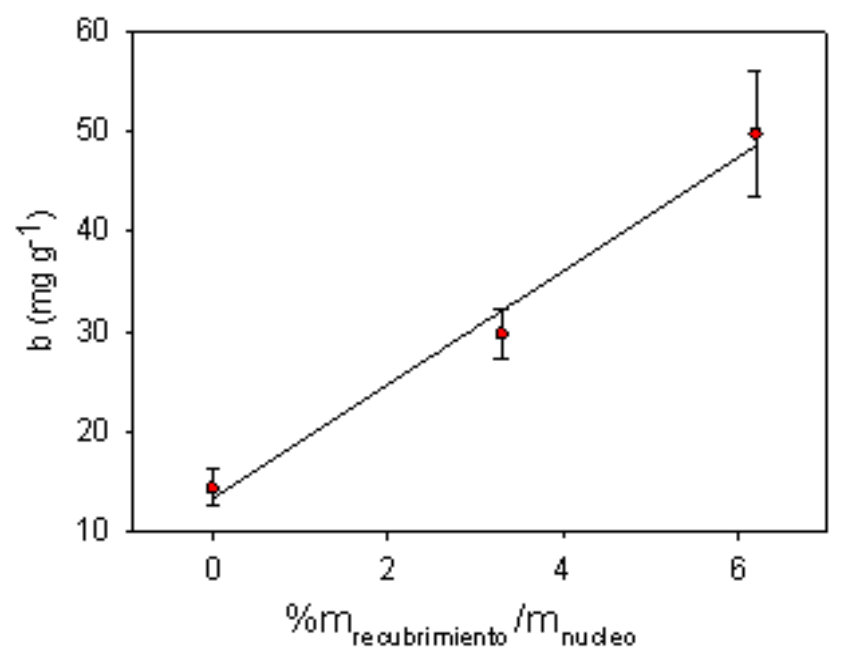

Fig. 6.13 - Relación lineal entre el \% $m_{\text {red }} / m_{\text {núcleo }} y b\left(m g g^{1}\right)$.

El parámetro $\mathrm{K}_{\mathrm{L}}$, relacionado con la naturaleza de la interacción partícula - AMen el caso de que se cumplan las condiciones impuestas por el modelo de Langmuir, también aumenta con el incremento de la cantidad de agente orgánico en la superficie de las nanopartículas. Esto indicaría que en la muestra YM0 la interacción entre adsorbente-adsorbato es más débil que para las otras partículas YM30 y YM50.

En el sistema YM0-AM la interacción más importante sería la del colorante con los grupos $\sim \mathrm{O}-\mathrm{H}$ y $\sim \mathrm{Fe}-\mathrm{O}$ superficiales de la magnetita. Estos grupos se evidenciaron mediante la caracterización por XPS (Cap. 5 - Fig. 5.17). Por su parte, en el sistema YM30-AM estas interacciones estarían presentes de igual forma, pero a la vez surge una nueva posibilidad de interacción, debido a la presencia de los grupos orgánicos superficiales $\sim \mathrm{C}(=\mathrm{O}) \mathrm{O}-\mathrm{y} \sim \mathrm{N}-\mathrm{H}$ (Cap. 5 - Fig. 5.13). En el sistema YM50-AM estos últimos grupos predominarían ya que se encuentran en mayor proporción, lo que favorece aún más la adsorción.

En efecto, la diferencia observada en la eficiencia del proceso de adsorción entre la YM30 y YM50 estaría soportada por una mayor concentración superficial de grupos orgánicos presentes en la YM50 disponibles para la interacción. Esto explicaría la razón por la cual, para estas dos partículas, el parámetro $\mathrm{K}_{\mathrm{L}}$ está dentro del mismo rango mientras que para el parámetro b hay un aumento significativo al cambiar de partícula. [20], [21]. Los valores de b obtenidos para estas partículas son comparables para los reportados para la adsorción de AM sobre otros materiales [18], [20], [21]mostrados en la tabla 6.3: 


\begin{tabular}{|c|c|}
\hline Material & b [ $\left.\mathbf{m g ~ g}^{-1}\right]$ \\
\hline $\mathbf{F e}_{3} \mathbf{O}_{\mathbf{4}}$-Ácidos Húmicos & 93,07 \\
\hline Este Trabajo & 49,82 \\
\hline $\mathbf{F e}_{3} \mathbf{O}_{\mathbf{4}} / \mathbf{C N T}$ & 48,06 \\
\hline $\mathbf{F e}_{\mathbf{2}} \mathbf{O}_{\mathbf{3}} / \mathbf{C N T}$ & 42,30 \\
\hline Cascarilla de naranja & 40,59 \\
\hline CNT & 35,00 \\
\hline Cascara de naranja calcinada & 25,50 \\
\hline
\end{tabular}

Tabla 6.3 -Comparación de la capacidad de adsorción de AM de varios materiales a 250C.

Es oportuno resaltar que la capacidad de adsorción de la YM50 se encuentra por encima de compositos de magnetita/nanotubos de carbono (CNT), pero aun así es menor que la de nanopartículas de $\mathrm{Fe}_{3} \mathrm{O}_{4}$ recubiertas con Ácidos Húmicos comerciales.

\subsection{Ensayos de degradación de azul de metilleno mediante la formación catalizada de $\mathrm{SO}_{4}$ - $^{-}$por las nanopartículas de $\mathrm{Fe}_{3} \mathrm{O}_{4}$.}

\subsubsection{Métodos experimentales}

Los ensayos de laser flash fotolisis fueron realizados bajo las mismas condiciones experimentales que los realizados en el capítulo 3 para la determinación del mecanismo de reacción del Flusilasol con este radical. La concentración máxima de nanopartículas fue de $1000 \mathrm{ppm}$ y la $\left[\mathrm{S}_{2} \mathrm{O}_{8}{ }^{-2}\right]=$ $1.0 \times 10^{-2} \mathrm{M}$ a $25^{\circ} \mathrm{C}$. El seguimiento de los decaimientos se hizo a $450 \mathrm{~nm}$.

\subsubsection{Resultados}

La técnica de oxidación de contaminantes orgánicos en fase acuosa usando el anión radical sulfato está ganando interés debido a que esta técnica no presenta la problemática de disminución de su eficiencia en cuerpos de aguas con $\mathrm{pH}>5$ que presentan los sistemas de tratamiento tipo Fenton convencionales. El anión radical $\mathrm{SO}_{4}{ }^{-}\left(\varepsilon^{0}=2.6 \mathrm{~V}\right)$ se forma mediante la activación del anión peroxodisulfato $\mathrm{S}_{2} \mathrm{O}_{8}{ }^{-2}$. Esta activación puede ser por vía térmica, redox o fotoquímica. La reacciones (1), (2) y (3), muestran estos procesos respectivamente [22]-[24].

(1) $\mathrm{S}_{2} \mathrm{O}_{8}{ }^{-2} \underset{\Delta}{\rightarrow} 2 \mathrm{SO}_{4}^{-\cdot}\left(35^{\circ} \mathrm{C}<\mathrm{T}<90^{\circ} \mathrm{C}\right)$

(2) $\mathrm{S}_{2} \mathrm{O}_{8}^{-2}+\mathrm{Fe}^{+2} \rightarrow \mathrm{SO}_{4}{ }^{-}+\mathrm{SO}_{4}^{-}+\mathrm{Fe}^{+3}$

(3) $\mathrm{S}_{2} \mathrm{O}_{8}^{-2} \stackrel{h v}{\rightarrow} 2 \mathrm{SO}_{4}^{--}$

Este radical puede reaccionar con aniones hidroxilos produciendo $\mathrm{HO}$ - en medio alcalino. La reacción 4 muestra esta situación:

(4) $\mathrm{SO}_{4}^{--}+\mathrm{OH}^{-} \rightarrow \mathrm{OH}+\mathrm{SO}_{4}^{-2}$

Debido a lo anterior, controlando el $\mathrm{pH}$ es posible establecer la predominancia del $\mathrm{SO}_{4}{ }^{-}$en soluciones ácidas y del HO-en soluciones alcalinas. Ambos radicales pueden reaccionar con el anión peroxodisulfato disminuyendo 
así la eficiencia global del proceso de degradación de algún contaminante. La reacciones químicas entre estos radicales y el anión peroxodisulfato se muestran a continuación:

$$
\begin{aligned}
& \text { (5) } \mathrm{HO}+\mathrm{S}_{2} \mathrm{O}_{8}^{-2} \rightarrow \mathrm{HSO}_{5}^{-}+\mathrm{SO}_{4}^{4^{-}} \\
& \text {(6) } \mathrm{HO}+\mathrm{S}_{2} \mathrm{O}_{8}^{-2} \rightarrow \mathrm{S}_{2} \mathrm{O}_{8}^{-\cdot}+\mathrm{OH}^{-} \\
& \text {(7) } \mathrm{SO}_{4}^{--}+\mathrm{S}_{2} \mathrm{O}_{8}^{-2} \rightarrow \mathrm{S}_{2} \mathrm{O}_{8}^{--}+\mathrm{SO}_{4}^{-2}
\end{aligned}
$$

También es válido mencionar que el anión radical $\mathrm{SO}_{4}-$ puede reaccionar con metales presentes en el medio por vía reacciones de óxido reducción. La ecuación (8) muestra este caso:

$$
\text { (8) } \mathrm{Fe}^{+2}+\mathrm{SO}_{4}^{--} \rightarrow \mathrm{Fe}^{+3}+\mathrm{SO}_{4}^{-2}
$$

Por lo que se hace necesario trabajar en la relación inicial óptima entre $\left[\mathrm{Fe}^{+2}\right] /\left[\mathrm{S}_{2} \mathrm{O}_{8}{ }^{-}\right]$. Por otro lado, se ha demostrado que las nanopartículas de magnetita son capaces de producir $\mathrm{SO}_{4}-$ por vía redox aprovechando el $\mathrm{Fe}^{+2}$ superficial que estas poseen [22], [25], [26]. La reacción (9) muestra este proceso, en el cual el ión $\mathrm{Fe}^{+2}$ se encuentra en la superficie de la partícula:

$$
\text { (9) } \sim \mathrm{Fe}^{+2}+\mathrm{S}_{2} \mathrm{O}_{8}^{-} \rightarrow \sim \mathrm{Fe}^{+3}+\mathrm{SO}_{4}^{-}+\mathrm{SO}_{4}^{--}
$$

Además, en la literatura existe evidencia de que el $\mathrm{SO}_{4}{ }^{--}$es capaz de promover la degradación del AM llegando, en condiciones adecuadas, hasta la mineralización total del colorante [23]. Por ello, en el estudio realizado en este trabajo se evaluó la eficiencia de la degradación de azul de metileno mediante el radical $\mathrm{SO}_{4} \cdot-$ activado por vía redox utilizando el $\mathrm{Fe}^{+2}$ superficial de las diferentes nanopartículas de magnetita sintetizadas con recubrimiento proveniente de la YM. Estos ensayos se hicieron a $\mathrm{pH}=7.0$.

Debido a las diferentes capacidades de adsorción de AM que presentan las nanopartículas, los ensayos de degradación se realizaron una vez alcanzado el equilibrio de este proceso, es decir después de las 2 horas de mezclado. Posterior a ello se agregó el $\mathrm{Na}_{2} \mathrm{~S}_{2} \mathrm{O}_{8}$. Las condiciones experimentales son las mismas a las que se realizaron los estudios de adsorción y se detallan a continuación: $\mathrm{T}=(25 \pm 2)^{\circ} \mathrm{C},[\mathrm{AM}]_{0}=40 \mathrm{ppm},[\mathrm{NP}]=600 \mathrm{mgL}^{-1}, \mathrm{pH}=7 \mathrm{y}$ $\left[\mathrm{S}_{2} \mathrm{O}_{8}{ }^{-2}\right]_{0}=1.0 \times 10^{-2} \mathrm{M}$, además estos ensayos se hicieron en frascos color ámbar para evitar la formación por vía fotoquímica del $\mathrm{SO}_{4}{ }^{-}$.

La figura 6.14 muestra las curvas de disminución de la concentración de AM durante el proceso de degradación. En un ensayo preliminar (no mostrado) bajo las mismas condiciones experimentales, pero sin presencia de nanopartículas, no se evidenció degradación significativa de AM $(<2 \%)$ durante 4 horas.

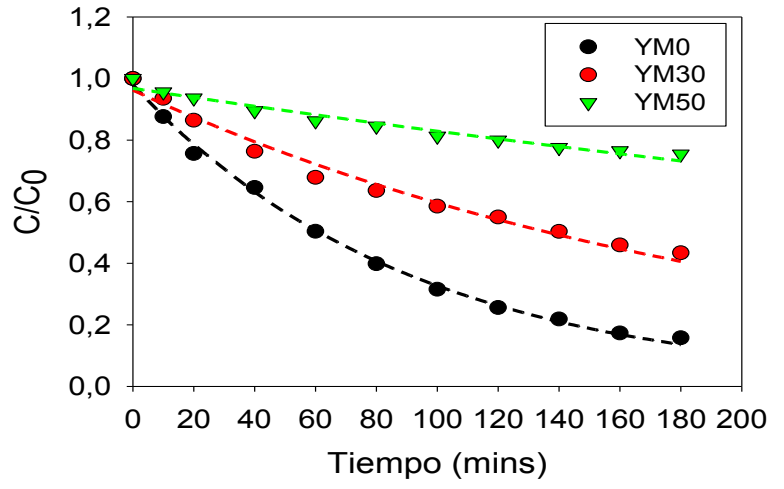

Fig. 6.14 - Variación de la concentración de $A M$ en función del tiempo de degradación mediante $\mathrm{SO}_{4} \cdot(25 \pm 2)^{\circ} \mathrm{C}$, $[\mathrm{AM}]_{0}=40 \mathrm{ppm},[\mathrm{NP}]=600 \mathrm{mg} \mathrm{L}^{-1},\left[\mathrm{NaS}_{2} \mathrm{O}_{8}\right]=10 \mathrm{mM}$ y $\mathrm{pH}=7.0$. 
En la figura 6.15 se muestra el ajuste de los datos obtenidos a un modelo cinético de primer orden $\left(r^{2}>0.9\right)$.

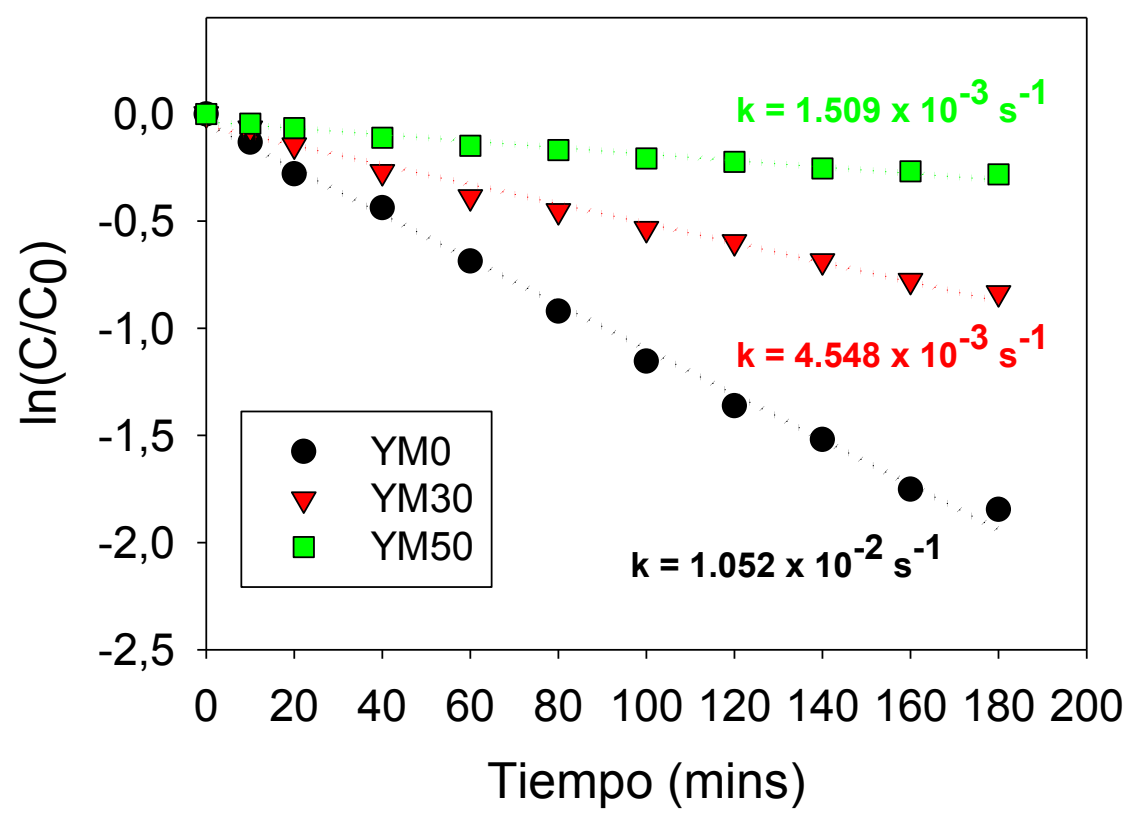

Fig. 6.15 - Ajuste del modelo cinético de primer orden para la degradación del AM bajo las condiciones utilizadas.

Claramente se puede apreciar que las nanopartículas utilizadas presentan diferente capacidad para promover la degradación catalizada del AM, de hecho la eficiencia de este proceso sigue un orden inverso al observado para el proceso de adsorción del mismo colorante, es decir que el uso del extracto de YM en la síntesis de las nanopartículas tiene un efecto adverso sobre la eficiencia de la degradación de AM mediante la reacción catalizada con $\mathrm{SO}_{4}{ }^{-}$. observado:

Existen varias razones que permitirían explicar el comportamiento

1. Es posible que las nanopartículas liberen una fracción de $\mathrm{Fe}^{+2}$ al medio y así este se encuentre disponible para dar formación al $\mathrm{SO}_{4}{ }^{--}$por vía redox homogénea. Para corroborar si este escenario jugaba un papel importante en los sistemas estudiados, se realizaron ensayos en los cuales luego de alcanzar el equilibrio del proceso de adsorción ( 2 horas) se retiran las nanopartículas y se agrega el $\mathrm{Na}_{2} \mathrm{~S}_{2} \mathrm{O}_{8}$ a la solución de AM. En estos ensayos (resultados no mostrados) no se apreció una disminución de más del $4 \%$ de la concentración de AM para ninguna de las partículas. Esto indicaría que si bien el escenario considerado es posible, este no sería el mecanismo predominante para promover la degradación del colorante en los sistemas considerados.

2. La reacción del $\mathrm{Na}_{2} \mathrm{~S}_{2} \mathrm{O}_{8}$ con el $\mathrm{Fe}^{+2}$ es heterogénea, es decir ocurre solo en la superficie de la partícula. En este caso, el recubrimiento superficial con YM inhibirá la reacción superficial.

3. $\mathrm{El} \mathrm{SO}_{4}-$ podría reaccionar con el material orgánico superficial de las nanopartículas, es decir, con los componentes provenientes del extracto de la YM y con el AM adsorbido. 


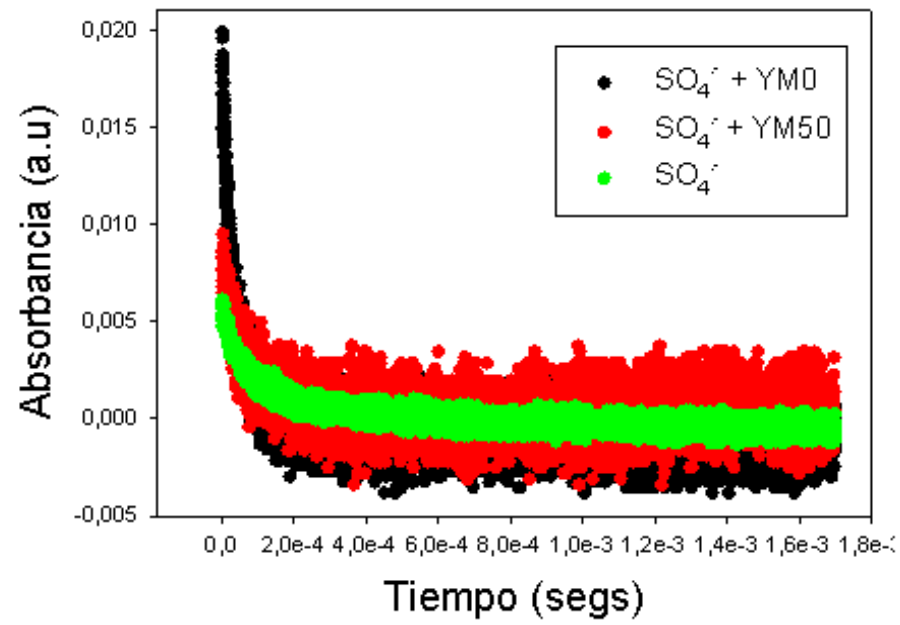

Fig. 6.16 - Curvas de decaimiento de especies reactivas seguidas a $450 \mathrm{~nm}$ en presencia y ausencia de las nanopartículas $Y M O$ y YM5O $[\mathrm{NP}]=600 \mathrm{mg} \mathrm{L}^{-1}, \mathrm{pH}=7,0$ y $\left[\mathrm{S}_{2} \mathrm{O}_{8}^{-}\right]_{0}=1.0 \times 10^{-2} \mathrm{M}$.

Para corroborar esta última posibilidad, se realizaron ensayos de laser flash fotolisis con $2.5 \times 10^{-2} \mathrm{M}$ de $\mathrm{S}_{2} \mathrm{O}_{8}{ }^{-2}, 600 \mathrm{ppm}$ de partículas a una longitud de onda de seguimiento de $450 \mathrm{~nm}$, en la cual el radical anión $\mathrm{SO}_{4}{ }^{-}$presenta su máximo de absorción. Es importante recalcar que durante los experimentos de degradación del AM mostrados con anterioridad, el $\mathrm{SO}_{4} \cdot-$ es producido por vía redox al reaccionar con el $\mathrm{Fe}^{2+}$ superficial de las partículas, mientras que en los ensayos de laser flash fotolisis la producción de $\mathrm{SO}_{4}$ - $^{-}$mayoritariamente se dará por vía fotoquímica con un pulso de $\lambda=266 \mathrm{~nm}$, tal como se describió para los experimentos con el Flusilasol. La fig. 6.16 muestra los decaimientos obtenidos mientras que en la fig. 6.17 se muestran los ajustes cinéticos de orden mixto.
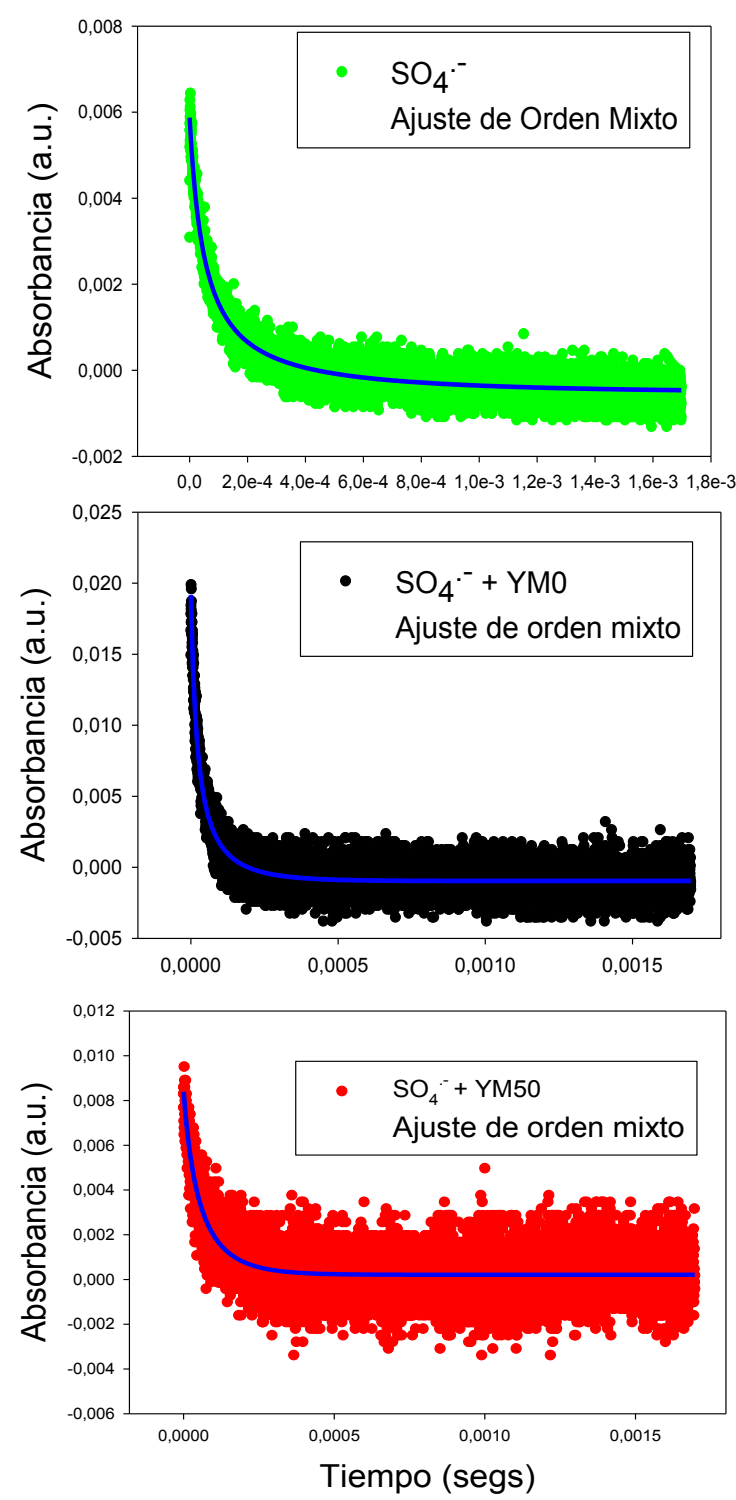

Fig. 6.17- Curvas de ajustes de orden mixto para cada uno de los sistemas estudiados. 
La curva de decaimiento del $\mathrm{SO}_{4}{ }^{-}$presenta una cinética de orden mixto, con una constante de primer orden igual a $(3.2 \pm 0.1) \times 10^{3} \mathrm{~s}^{-1}$ y una constante de orden dos que se correlaciona con la reacción de recombinación de este radical para generar su precursor $\mathrm{S}_{2} \mathrm{O}_{8}{ }^{-2}$, lo que está en concordancia con lo reportado para esta especie reactiva[27]. Dado que la constante de primer orden es del orden de la esperada para sistemas acuosos en ausencia de iones $\mathrm{Fe}^{+2}$, la posibilidad que este radical reaccione con iones $\mathrm{Fe}^{+2}$ en solución liberados por la partícula no posee significancia.

Todos los decaimientos observados a $450 \mathrm{~nm}$ en presencia de las nanopartículas se ajustan a una cinética de orden mixto. Si bien la contribución del decaimiento de orden dos se correlaciona con el observado para la recombinación de los radicales aniones $\mathrm{SO}_{4}{ }^{--}$como se describió antes, se aprecia un aumento en la componente de primer orden. Lasconstantes cinéticas determinadas para los ensayos en presencia de YM0 y YM50 son de $(7.45 \pm 0.40) \times 10^{3} \mathrm{~s}^{-1}$ y $(1.01 \pm 0.08) \times 10^{4} \mathrm{~s}^{-1}$, respectivamente. Esto indica que efectivamente el $\mathrm{SO}_{4}^{-}$reacciona con la superficie de las nanopartículas. La tabla 6.4 resume estos resultados.

\begin{tabular}{|c|c|}
\hline Sistema & $\mathbf{k}_{\mathbf{1}}\left[\mathbf{s}^{-1}\right]$ \\
\hline $\mathrm{SO}_{4}{ }^{-}$ & $(3.20 \pm 0.10) \times 10^{3}$ \\
\hline $\mathrm{SO}_{4}:^{-}+\mathrm{YMO}$ & $(7.45 \pm 0.40) \times 10^{3}$ \\
\hline $\mathrm{SO}_{4} 4^{-}+$YM50 & $(1.01 \pm 0.08) \times 10^{4}$ \\
\hline
\end{tabular}

Tabla 6.4 -Constantes de primer orden para cada sistema estudiado.

De la diferencia entre las constantes de velocidad para la reacción del radical sulfato con YM0 y YM50 y ladiferencia respectiva en la concentración de materia orgánica de cada sistema, se estima una constante absoluta de reacción para el radical sulfato con la materia orgánica aportada por la YM del orden de $71,24 \mathrm{gr}^{-1} \mathrm{~s}^{-1}$.

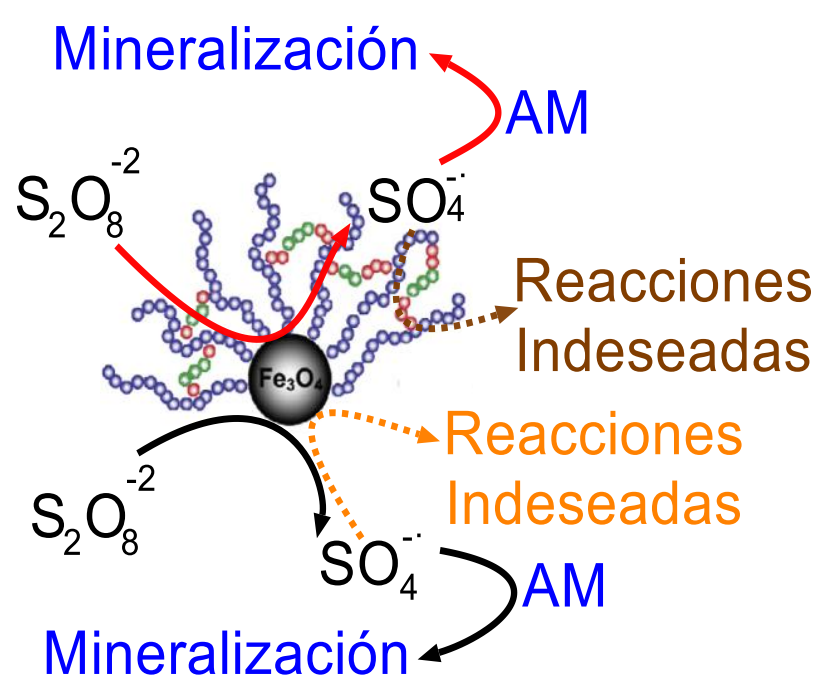
La figura 6.18 representa un modelo básico propuesto para el comportamiento observado en los ensayos anteriores. En ella se evidencia una región de una partícula hipotética sin recubrimiento orgánico (análoga a lo que sería la YM0) y una región con alto contenido de cadenas carbonadas (YM50).

Fig. 6.18- Mecanismo propuesto para la degradación catalítica de $A M$ estudiado.

En la parte inferior de esta figura se visualiza la activación del $\mathrm{S}_{2} \mathrm{O}_{8}{ }^{-2}$ por vía redox mediante la reacción con $\mathrm{Fe}^{+2}$, a partir de allí el $\mathrm{SO}_{4}^{--}$puede difundir 
hasta reaccionar con el AM y conllevar a la mineralización del colorante. Pero además este radical puede reaccionar con los componentes que se encuentran en la cobertura de las nanopartículas ( $\mathrm{Fe}^{+2}$ y $\mathrm{AM}$ adsorbido). Este modelo es el propuesto para la YM0.

En la parte superior de la fig. 6.18 se representaría el modelo propuesto para el sistema de la YM50. En este el $\mathrm{S}_{2} \mathrm{O}_{8}{ }^{-2}$ se formaría siguiendo el mismo mecanismo anterior, solo que ahora la cantidad de materia orgánica superficial sobre la partícula es mayor que en el sistema de la YM0 debido a la presencia de la capa orgánica de la YM y del AM adsorbido.

Cabe mencionar que para que la degradación del AM tenga lugar, se requiere que el $\mathrm{S}_{2} \mathrm{O}_{8}{ }^{-2}$ difunda desde el seno de la solución hasta la superficie de las nanopartículas y reaccione con el $\mathrm{Fe}^{+2}$ para formar el $\mathrm{SO}_{4} \cdot$. Pero debido que al aumentar la cantidad de materia orgánica superficial, se estaría apantallando el $\mathrm{Fe}^{+2}$ superficial disminuyendo así la velocidad del proceso. Además, una vez formado el $\mathrm{SO}_{4}{ }^{-}$, este debería estar cerca de la zona de adsorción del $\mathrm{AM}$, de lo contrario reaccionará con los componentes de la YM.

\subsection{Caracterización Fotoquímica de las diferentes NpC.}

\subsubsection{Métodos de síntesis}

La temperatura a la que se induce la pirolisis durante la síntesis de las $\mathrm{NpC}$ es un factor de suma importancia sobre sus propiedades luminiscentes [28]. Por ello, es necesario conocer el comportamiento ante una descomposición termogravimétrica del material de partida para seleccionar la temperatura de síntesis de los materiales. Si bien no se conoce con certeza el mecanismo de luminiscencia de estas partículas [29], se ha planteado que su química superficial es la razón principal de su luminiscencia, por lo que la manipulación de los grupos funcionales superficiales jugaría un papel importante en el comportamiento fotoquímico de estas novedosas nanopartículas[29]-[32].

En la figura 6.19 se pueden apreciar las curvas TGA para la YM y CN utilizadas como materia prima para la obtención de las NpC. Estas curvas presentan el comportamiento típico de descomposición térmica de biomasa vegetal[33] presentando dos picos característicos DTA alrededor de $300^{\circ} \mathrm{C}$ y $475^{\circ} \mathrm{C}$. La ubicación exacta de los mismos y la intensidad de flujo de calor liberado por la muestra depende de la composición química de la misma. Alrededor del primer pico ocurre la combustión de la porción de hemicelulosa, acompañado de la carbonización parcial de lignina y celulosa. En la región comprendida entre los dos picos mencionados anteriormente se inicia la formación de monóxido de carbono, además de hidrocarburos, fenoles y cresoles. Por encima del segundo pico, se promueve la degradación total de la materia orgánica remanente para dar lugar al residuo de cenizas. [28] Por ello la síntesis de $\mathrm{NpC}$ se llevó a cabo a $400{ }^{\circ} \mathrm{C}$, tanto a partir de la YM como de la CN. Los nombres utilizados para identificar a los materiales sintetizados por pirolisis térmica son: YM400 y CN400. Además, las NpC sintetizadas utilizando microonda se identificó como CN Mw. 

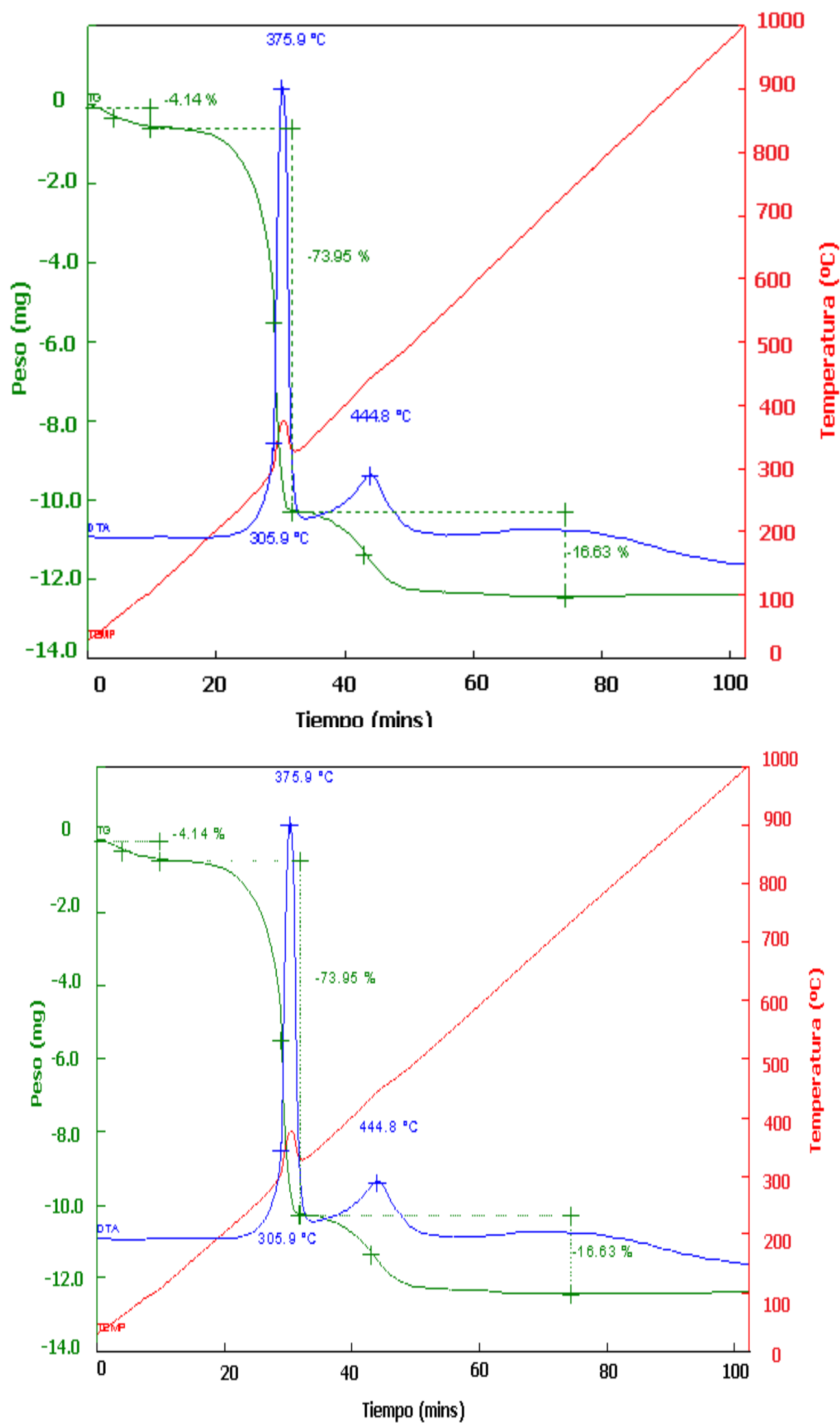

Fig. 6.19 - Curvas de degradación termogravimétrica de Superior: YM. Inferior: CN. 
Con respecto a la síntesis por irradiación de Microondas, no se evidenció la formación de NpC utilizando como materia prima la Yerba Mate, mientras que si se logró la síntesis a partir de la Cascara de Naranja. Durante la síntesis se realizó un seguimiento por espectroscopia Uv/Vis y fluorescencia midiendo el espectro de absorción y la matriz excitación/emisión de las suspensiones a distintos tiempos. Estos últimos resultados se muestran en la figura 6.20 a 6.22.

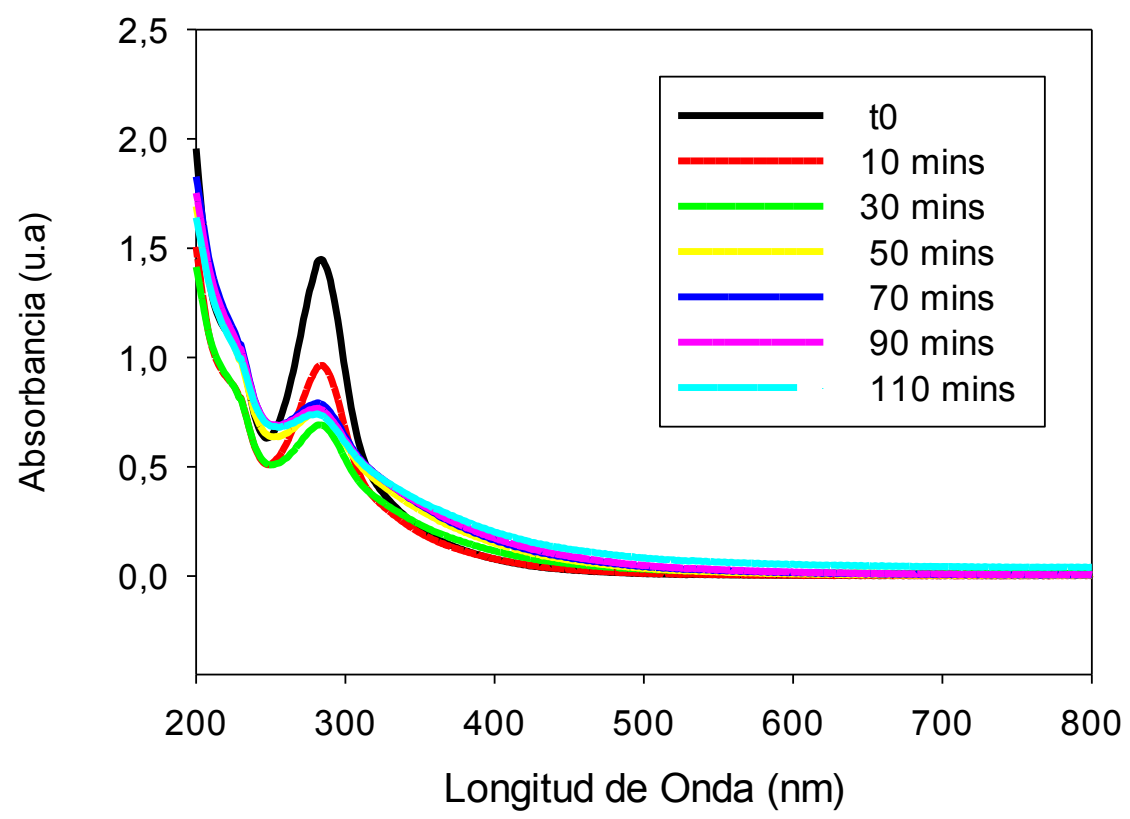

Fig. 6.20 - Variación del espectro de absorción UV/Vis de la suspensión de NpC obtenidas mediante irradiación Microondas de Cascara de Naranja.

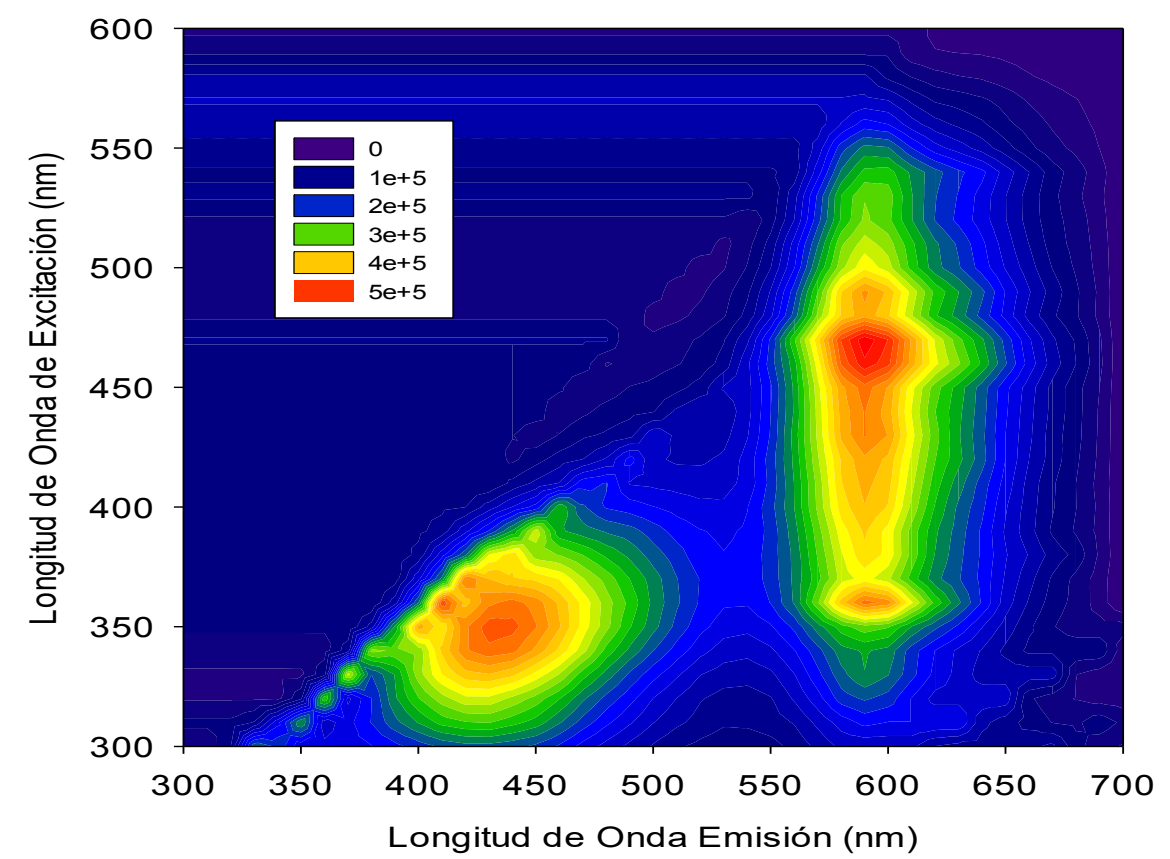

Fig. 6.21 -Matriz excitación-emisión de las NPC CN Mw luego de 10mins de irradiación con Microondas. 


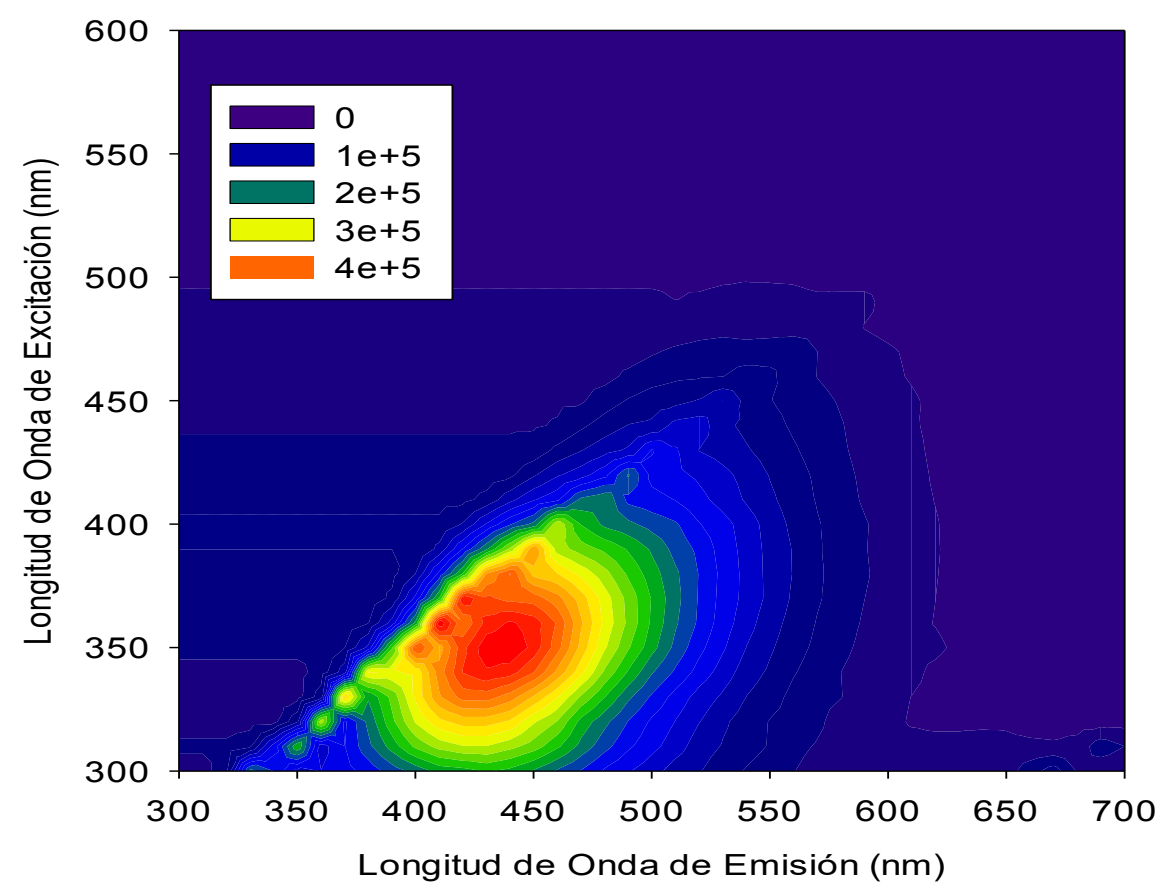

Fig. 6.22 - Matriz emisión-excitación posterior a la síntesis por irradiación Microondas de 110mins.

Ambas muestras evidencian la degradación del precursor orgánico al ser irradiado con microondas para dar lugar a la formación de compuestos fluorescentes y a las NpC. Por su parte, los ensayos de absorción Uv/Vis muestran la disminución de un pico fuerte a 300nm aproximadamente hasta los 70 minutos, pasado este tiempo no se evidencian cambios drásticos en la intensidad de absorción a esa longitud de onda. Por su parte, la matriz de excitación-emisión muestra dos regiones bien diferenciadas, la primera centrada aproximadamente a $425 \mathrm{~nm}$ de emisión con la misma estructura que la obtenida para las NpC YM 400 (ver Figura 6.23) y otra a $600 \mathrm{~nm}$ aproximadamente atribuida al precursor orgánico de las NpC. Una vez terminado el proceso de síntesis, esta última región desaparece totalmente permaneciendo solo la luminiscencia proveniente de las $\mathrm{NpC}$, tal como se muestra en la figura 6.22.

\subsubsection{Estudios fotoluminiscentes}

Las matrices correspondientes a las NpC YM400 y CN400 mostradas en la figura 6.23 y las de NpC CN Mw presentan algunas pequeñas diferencias, tal como es de esperar debido a las distintas materia primas y rutas de síntesis empleadas para su obtención [28]-[30], [32], [34]-[37]. Para visualizar estos cambios se analizaron las matrices de excitación-emisión mediante un programa bilineal capaz de identificar el número de distintas especies contribuyentes a la emisión y sus espectros de excitación y emisión individuales.

En la figura 6.24 pueden verse los resultados obtenidos de este análisis para cada tipo de partícula sintetizada. Las líneas del mismo color representan a una misma especie, las líneas continuas representan el espectro de excitación y las discontinuas el de emisión. Al comparar los resultados para cada material, se puede apreciar como los componentes obtenidos por la simulación se asemejan entre sí, lo que indicaría que los estados emisores de las muestras son similares, lo cual nos habla de que pese a la diferencia en el esquema de síntesis, el 
producto final presenta transiciones ópticas similares, al menos las que implican emisión.
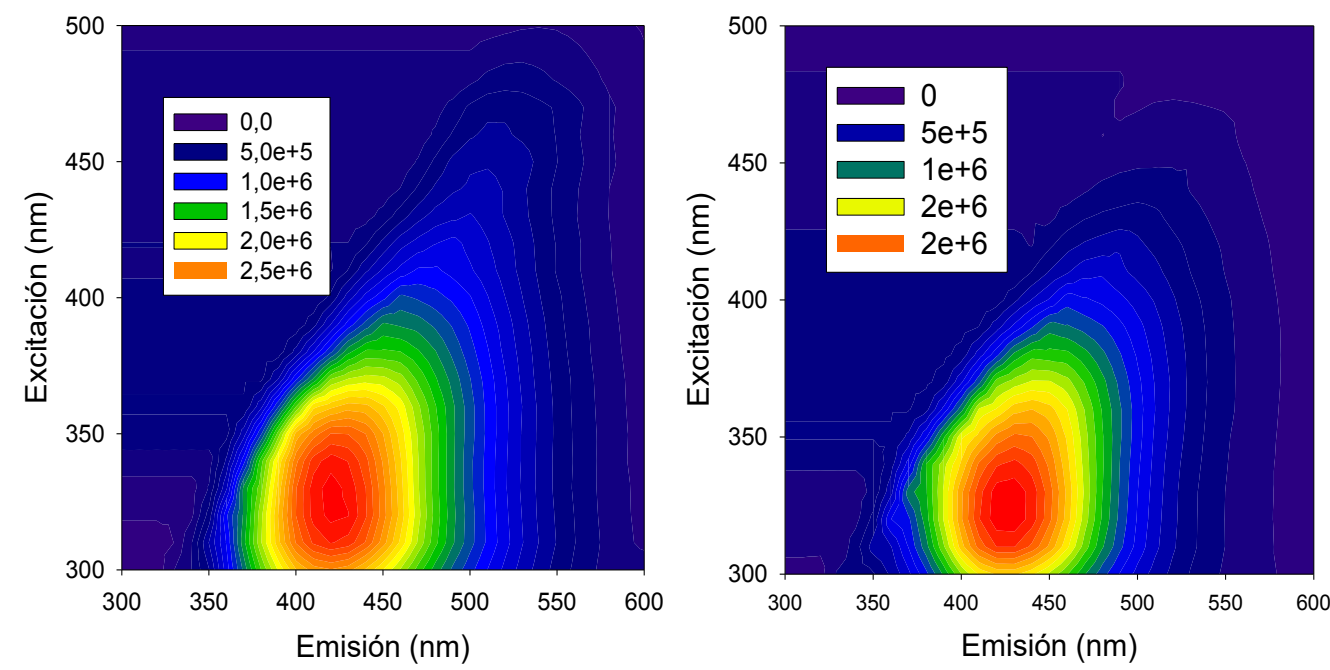

Fig. 6.23 - Matrices excitación-emisión de las Izquierda: NpC YM400. Derecha: NpC CN 400.

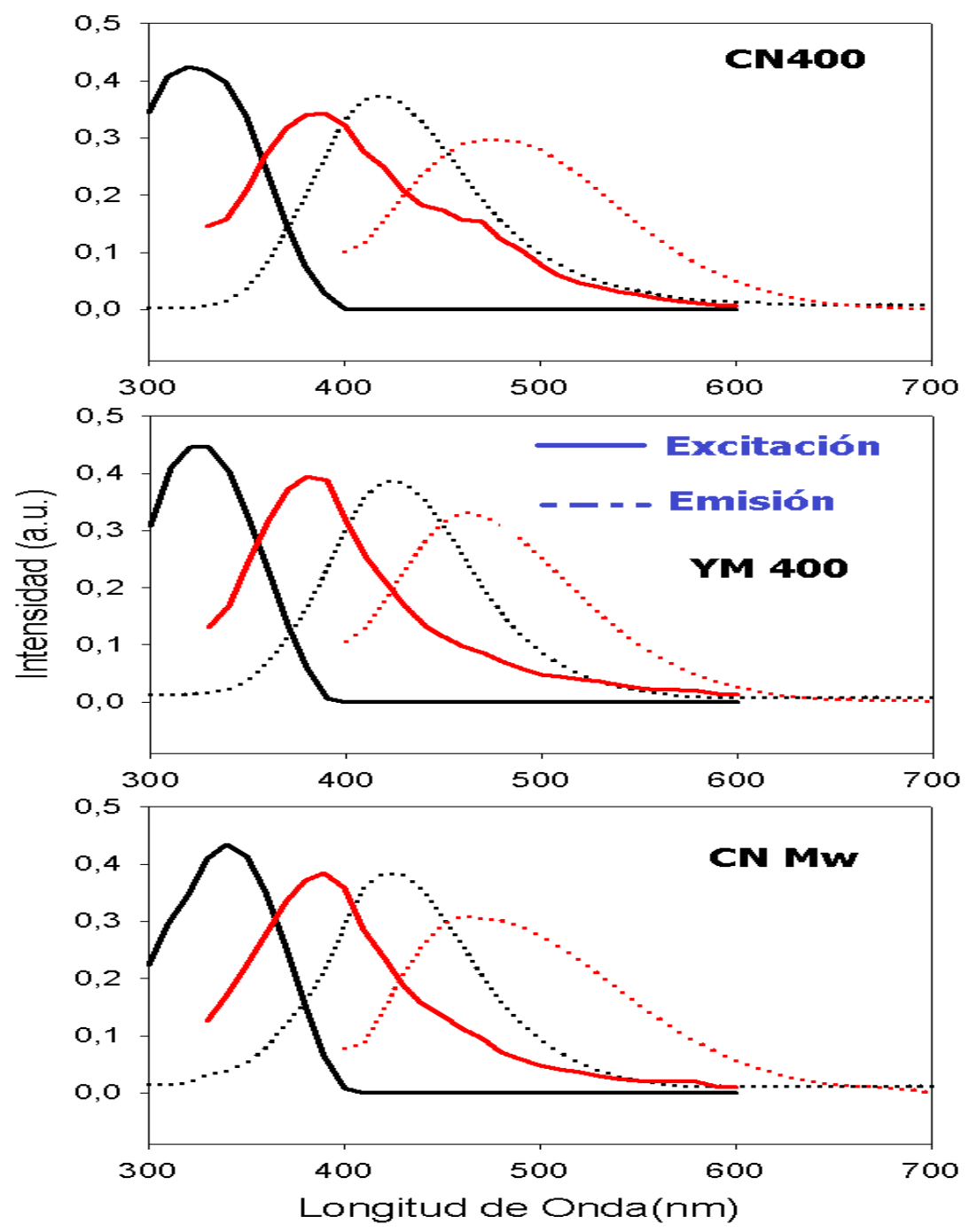

Fig. 6.24 - Deconvolución de las matrices de excitación-emisión de las distintas NpC obtenidas. 
En la tabla 6.5 se muestra la ubicación de los máximos de excitación/emisión de las curvas deconvolucionadas y mostradas en la figura 6.24. Del análisis de la tabla se puede concluir que la componente $\boldsymbol{a}$ en los tres tipos de partículas presenta, dentro del error experimental del análisis, espectros de emisión y excitación muy similares, lo que implicaría que la especie responsable de dicha emisión se encuentra presente en las tres partículas. En cambio, la segunda especie que contribuye a la emisión de las partículas parece depender de la materia prima de partida, ya que las mayores diferencias se observan para la YM400.

\begin{tabular}{|c|c|c|c|}
\hline Material & & Especie a & Especie b \\
\hline \multirow{2}{*}{ NpC YM400 } & Excitación (nm) & 325 & 423 \\
\cline { 2 - 4 } & Emisión (nm) & 423 & 477 \\
\hline \multirow{2}{*}{ NpC CN400 } & Excitación (nm) & 326 & 382 \\
\cline { 2 - 4 } & Emisión (nm) & 425 & 464 \\
\hline \multirow{2}{*}{ NpC CN Mw } & Excitación (nm) & 340 & 391 \\
\cline { 2 - 4 } & Emisión (nm) & 424 & 465 \\
\hline
\end{tabular}

Tabla 6.5 -Picos máximos de las curvas deconvoluciondas para la matriz emisión/excitación de las NpC.

Los rendimientos cuánticos de emisión con $\lambda_{\text {exc }}=350 \mathrm{~nm}$ en aire y a pH 7 fueron determinados utilizando sulfato de quinina $(Q=0.546 \pm 0.020)$ en una solución $0.5 \mathrm{M}$ de $\mathrm{H}_{2} \mathrm{SO}_{4}$ como estándar en la región de emisión de interés[38], [39]. Los resultados obtenidos se muestran en la tabla 6.6

\begin{tabular}{|c|c|c|c|}
\hline Material & Intensidad de emisión & $\begin{array}{c}\text { Abs a } \\
\mathbf{3 5 0} \mathbf{~ n m}\end{array}$ & Qemi \\
\hline NpC YM400 & 143760658 & 0.06915 & $0.36 \pm 0.04$ \\
\hline NpC CN400 & 377304208 & 0.08124 & $0.82 \pm 0.10$ \\
\hline NpC CN Mw & 133591364 & 0.09787 & $0.24 \pm 0.05$ \\
\hline
\end{tabular}

Tabla 6.6 -Rendimientos cuánticos de emisión de suspensiones saturadas en Aire a pH = 7 de las NpC.

Los rendimientos cuánticos de emisión de las nanopartículas YM400 y CN Mw excitando a $350 \mathrm{~nm}$ se encuentran dentro de los valores publicados en la literatura para $\mathrm{NpC}$ obtenidas a partir de otros materiales y por otra ruta sintética[29], sin embargo el valor de la CN400 se encuentra muy por encima de lo encontrado en la literatura. Los rendimientos cuánticos observados para estos materiales son de interés en aplicaciones como sensores fotoluminiscentes.

Se investigó el efecto del $\mathrm{pH}$ en el espectro fotoluminiscente de forma de evidenciar si este parámetro afectaba de manera diferente a las propiedades fotofísicas de las NpC. Los resultados de estos experimentos se muestran en la figura 6.25. La forma del espectro de emisión de las NpC CN nw no se ve modificado por los cambios en el pH de las suspensiones, aunque si se observa una gran variación en las intensidades de emisión. En cambio, las NpC sintetizadas por vía térmica muestran pequeños corrimientos de $2-4 \mathrm{~nm}$ del máximo de emisión y cambios en la intensidad de emisión que no siguen una tendencia clara con el pH. En efecto, el rendimiento cuántico de emisión obtenido por excitación a $350 \mathrm{~nm}$, muestra una tendencia diferente para cada nanomaterial considerado, además que no se monitorean cambios significativos 
en los espectros de absorción de los mismos. La tabla 6.7 muestra los valores calculados a los pH considerados.
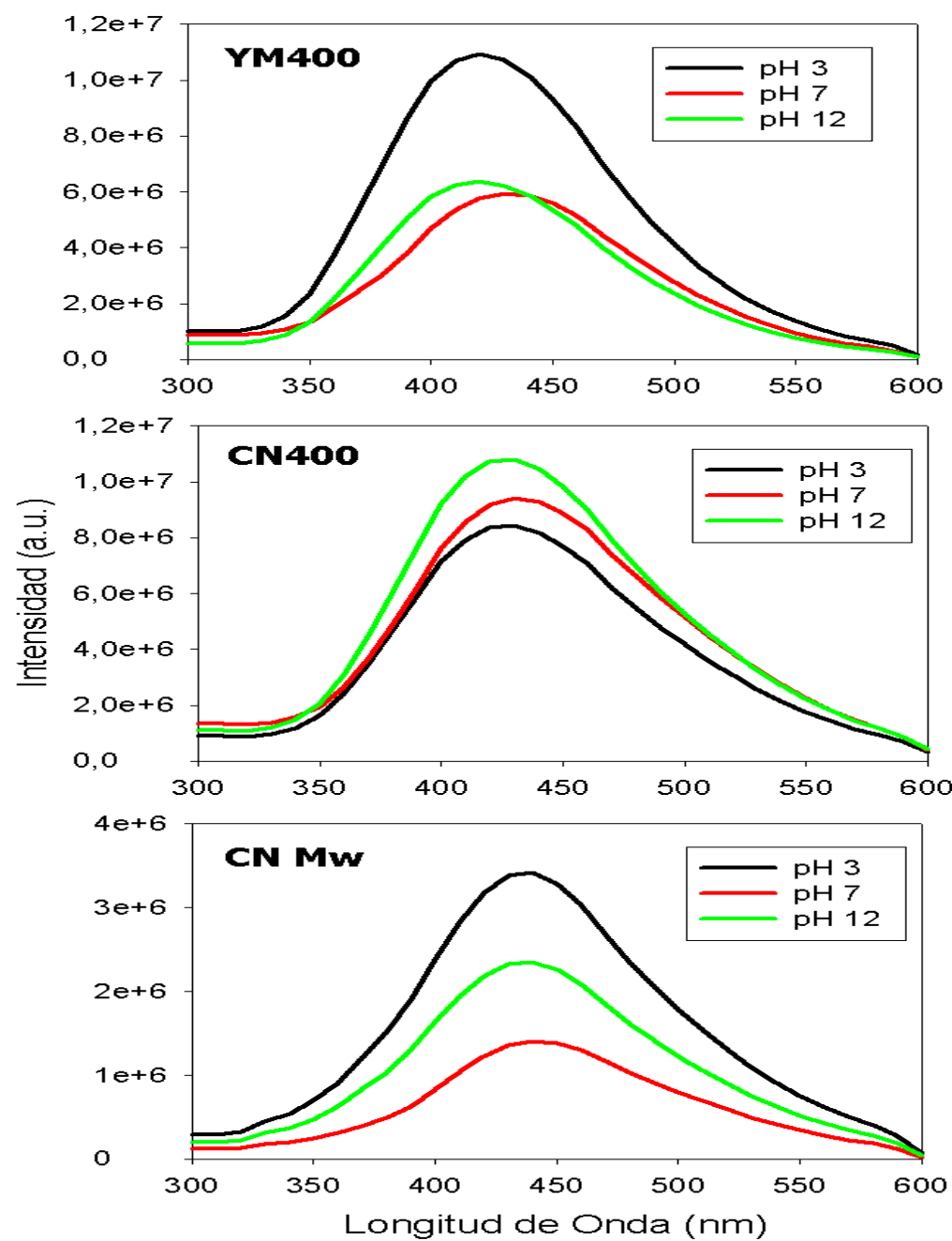

Fig. 6.25 - Curvas de emisión $\left(\lambda_{\mathrm{exc}}=350 \mathrm{~nm}\right.$ ) de suspensiones de las $\mathrm{NpC}$ a diferentes $\mathrm{pH}$.

\begin{tabular}{|c|c|c|c|c|c|}
\hline \multicolumn{2}{|c|}{ CN400 } & \multicolumn{2}{c|}{ YM400 } & \multicolumn{2}{c|}{ CN Mw } \\
\hline pH & Qemi & pH & Qemi & pH & Qemi \\
\hline $\mathbf{2 . 7 9}$ & $0.56 \pm 0.07$ & $\mathbf{2 . 8 7}$ & $0.75 \pm 0.09$ & $\mathbf{2 . 6 8}$ & $0.54 \pm 0.08$ \\
\hline $\mathbf{7 . 0 0}$ & $0.82 \pm 0.10$ & $\mathbf{7 . 0 0}$ & $0.36 \pm 0.04$ & $\mathbf{7 . 0 0}$ & $0.24 \pm 0.05$ \\
\hline $\mathbf{1 1 . 7 5}$ & $0.91 \pm 0.10$ & $\mathbf{1 1 . 8 7}$ & $0.39 \pm 0.05$ & $\mathbf{1 1 . 8 7}$ & $0.43 \pm 0.07$ \\
\hline
\end{tabular}

Tabla 6.7 -Rendimientos cuánticos de emisión de suspensiones saturadas en Aire de las NpC consideradas a diferente $\mathrm{pH}$.

En la bibliografía también se observa una disparidad en los resultados publicados, encontrándose $\mathrm{NpC}$ que presentan diferentes comportamientos ante los cambios de $\mathrm{pH}$, en algunos casos presentando máximos de emisión a $\mathrm{pH}$ neutro, otros a pH ácidos, otros a $\mathrm{pH}$ alcalinos e incluso se reportaron $\mathrm{NpC}$ que son insensibles a cambios en este parámetro[28]-[30], [32], [35], [37]. Por lo expuesto, toda explicación de estos resultados requiere de un conocimiento 
detallado de la naturaleza química de los grupos superficiales y composición interna de las $\mathrm{NpC}$ que escapa a los objetivos de este trabajo de tesis.

Por otro lado se investigó el efecto de la presencia de oxígeno molecular sobre la fotoluminiscencia de las $\mathrm{NpC}$. Para ello se realizaron ensayos en el estado estacionario con suspensiones acuosas de las $\mathrm{NpC}$, saturadas en diferentes atmosferas a $\mathrm{pH}=7$. Los espectros obtenidos, mostrados en la figura 6.26, indican que el oxígeno molecular no modifica el espectro de fluorescencia ni su intensidad. Estas observaciones nos permiten afirmar que el oxígeno molecular no interacciona con los estados excitados de las $\mathrm{NpC}$.
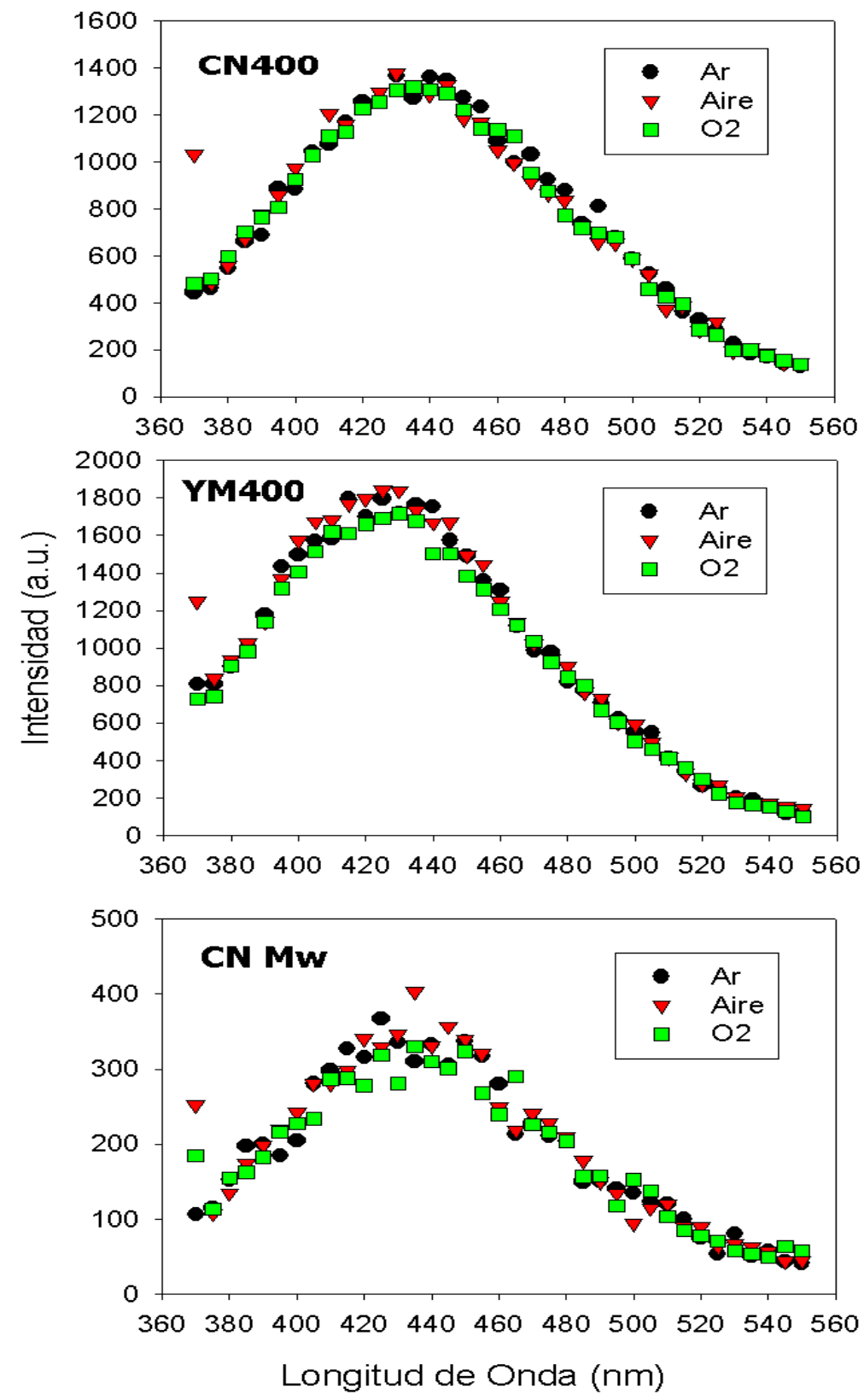

Fig. 6.26 - Curvas de emisión $\left(\lambda_{e x c}=350 \mathrm{~nm}\right)$ de suspensiones de las diferentes NpCsaturadas en atmosfera de oxígeno, aire y argón. 
Los ensayos de decaimiento de fluorescencia resueltos en el tiempo fueron evaluados inicialmente bajo $\mathrm{pH}=7$ y en una atmosfera saturada de Aire. La figura 6.27 muestra en el lado izquierdo los decaimientos obtenidos de los 3 nanomateriales considerados, por su parte la figura de la derecha muestra el ajuste cinético resultante para la NpC YM400. Cabe mencionar que todas las curvas fueron simuladas mediante funciones triexponenciales de la forma:

$$
I_{t}=A+B_{1} e^{\left(-t / \tau_{1}\right)}+B_{2} e^{\left(-t / \tau_{2}\right)}+B_{3} e^{\left(-t / \tau_{3}\right)}
$$

Donde $\boldsymbol{\tau}_{\mathrm{i}}$ es el tiempo de vida media de la especie i. Los ensayos anteriores se realizaron también a diferentes $\mathrm{pH}$. La tabla 6.8 muestra los tiempos de vida calculados para cada especie en los diferentes $\mathrm{pH}$ considerados.
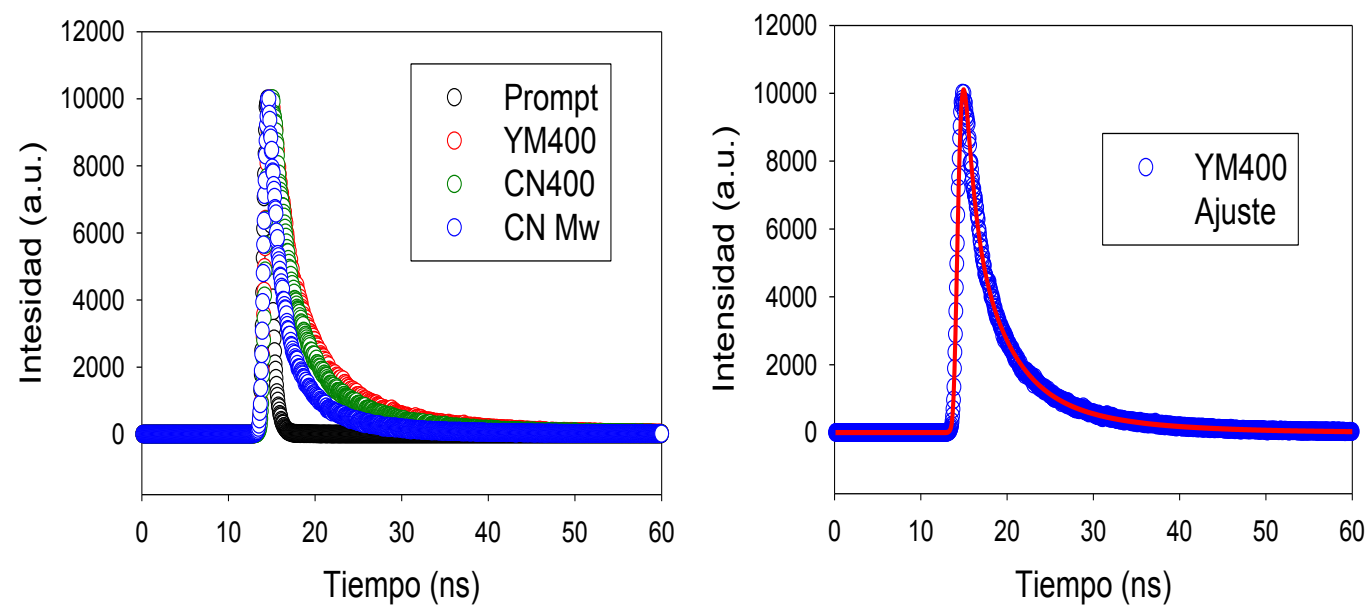

Fig. 6.27 - Curvas de decaimiento de fluorescencia a pH $=7$ en atmosfera de Aire $\left(\lambda_{e x c}=341 \mathrm{~nm}\right.$ y $\lambda_{\text {emisión }}=$ $425 \mathrm{~nm}$ )Izquierda:Todas las NpC y el prompt utilizado. Derecha: Ajuste de la curva de decaimiento de la NpC Y400.

\begin{tabular}{|c|c|c|c|c|}
\hline \multirow{2}{*}{ Material } & \multicolumn{4}{|c|}{ Parámetros } \\
\hline & pH & $\tau_{1}(\mathrm{~ns})-(\%$ L. e.) & $\tau_{2}(\mathrm{~ns})-(\%$ L. e.) & $\tau_{3}(\mathrm{~ns})-(\%$ L. e.) \\
\hline \multirow{3}{*}{ NpC YM400 } & 3 & $4.0 \pm 0.2-(53 \%)$ & $0.8 \pm 0.4-(18 \%)$ & $10.6 \pm 0.5-(29 \%)$ \\
\hline & 7 & $4.0 \pm 0.2-(50 \%)$ & $0.8 \pm 0.1-(15 \%)$ & $11.0 \pm 0.6-(35 \%)$ \\
\hline & 12 & $3.7 \pm 0.2-(42 \%)$ & $0.8 \pm 0.1-(14 \%)$ & $10.2 \pm 0.5-(44 \%)$ \\
\hline \multirow{3}{*}{ NpC CN400 } & 3 & $3.1 \pm 0.2-(46 \%)$ & $0.7 \pm 0.1-(23 \%)$ & $8.5 \pm 0.4-(31 \%)$ \\
\hline & 7 & $3.8 \pm 0.2-(51 \%)$ & $0.9 \pm 0.1-(21 \%)$ & $11.6 \pm 0.6-(28 \%)$ \\
\hline & 12 & $4.0 \pm 0.2-(48 \%)$ & $1.0 \pm 0.1-(23 \%)$ & $11.4 \pm 0.6-(29 \%)$ \\
\hline \multirow{3}{*}{ NpC CN Mw } & 3 & $2.7 \pm 0.1-(51 \%)$ & $0.4 \pm 0.1-(25 \%)$ & $10.4 \pm 0.5-(24 \%)$ \\
\hline & 7 & $2.5 \pm 0.1-(49 \%)$ & $0.3 \pm 0.1-(27 \%)$ & $9.3 \pm 0.5-(24 \%)$ \\
\hline & 11 & $2.6 \pm 0.1-(50 \%)$ & $0.4 \pm 0.1-(21 \%)$ & $9.4 \pm 0.5-(29 \%)$ \\
\hline
\end{tabular}

Tabla 6.8-Tiempos de vida medio y \% de Luz Emitida obtenidos para cada especie emisora en suspensiones de la NpC a diferentes $\mathrm{pH}$.

El ajuste de los decaimientos de la fluorescencia de la NpC realizado por una función triexponencial también ha sido publicado[29]para nanopartículas obtenidas a partir del tratamiento hidrotérmico de Gelatina arrojando tiempos de vida $\boldsymbol{\tau}_{1}=4.15, \boldsymbol{\tau}_{2}=0.81$ y $\boldsymbol{\tau}_{3}=10.68$ ns. Los anteriores valores están dentro del orden de los obtenidos en este trabajo experimental. Es probable que los valores relativamente bajos obtenidos para el tiempo $\boldsymbol{\tau}_{2}$ (particularmente los 
valores cercanos a 0.3 ns) se deban a una contribución importante debido al scattering que sufren los fotones emitidos por las mismas nanopartículas.

De la Tabla 6.8 se puede concluir que, dentro del error experimental no se evidencian cambios en los tiempos de vidade las componentes que contribuyen a la fluorescencia total a pesar de las variaciones importantes en el $\mathrm{pH}$ de las suspensiones. Salvo para la NpC YM400, tampoco se observan diferencias apreciables en el porcentaje de contribución a la fluorescencia total de cada tiempo de reacción en función del pH. La NpC YM400 solo muestra variaciones del $10 \%$ en el intervalo de $\mathrm{pH}$ entre 3 y 12 . Considerando que, para la longitud de onda de excitación de $341 \mathrm{~nm}$ se estaría excitando principalmente a la población de partículas identificada como especie $\boldsymbol{a}$, se puede concluir de estos ensayos que esta población no ve afectada su fotoluminiscencia por cambios en el $\mathrm{pH}$, y por ende cambios en la carga superficial de las partículas.

Se realizaron luego experimentos a $\mathrm{pH}=7$ bajo atmósferas con cantidades diferentes de oxígeno para evidenciar si la presencia de oxígeno molecular modifica los tiempos de vida de alguna de estas especies. Los resultados de estos experimentos se encuentran resumidos en la tabla 6.9.

\begin{tabular}{|c|c|c|c|c|}
\hline \multirow{2}{*}{ Material } & \multicolumn{4}{|c|}{ Parámetros } \\
\cline { 2 - 5 } & Atmosfera & $\tau_{1}(\mathbf{n s})-(\% L . ~ e)$. & $\tau_{2}(\mathbf{n s})-(\% L . ~ e)$. & $\tau_{3}(\mathbf{n s})-(\% L . ~ e)$. \\
\hline \multirow{3}{*}{ NpC YM400 } & Argón & $4.6 \pm 0.2-(52 \%)$ & $1.1 \pm 0.1-(19 \%)$ & $12.3 \pm 0.5-(29 \%)$ \\
\cline { 2 - 5 } & Aire & $4.0 \pm 0.2-(50 \%)$ & $0.8 \pm 0.1-(15 \%)$ & $11.0 \pm 0.5-(35 \%)$ \\
\cline { 2 - 5 } & Oxígeno & $4.3 \pm 0.2-(50 \%)$ & $1.1 \pm 0.1-(19 \%)$ & $11.0 \pm 0.4-(31 \%)$ \\
\hline \multirow{3}{*}{ NpC CN400 } & Argón & $3.6 \pm 0.2-(46 \%)$ & $0.9 \pm 0.1-(24 \%)$ & $11.7 \pm 0.5-(30 \%)$ \\
\cline { 2 - 5 } & Aire & $3.8 \pm 0.2-(51 \%)$ & $0.9 \pm 0.1-(21 \%)$ & $11.6 \pm 0.6-(28 \%)$ \\
\cline { 2 - 5 } & Oxígeno & $3.2 \pm 0.1-(48 \%)$ & $0.8 \pm 0.1-(20 \%)$ & $10.3 \pm 0.3-(32 \%)$ \\
\hline \multirow{3}{*}{ NpC CN Mw } & Argón & $2.8 \pm 0.1-(51 \%)$ & $0.5 \pm 0.1-(25 \%)$ & $9.8 \pm 0.4-(24 \%)$ \\
\cline { 2 - 5 } & Aire & $2.5 \pm 0.1-(49 \%)$ & $0.3 \pm 0.1-(27 \%)$ & $9.3 \pm 0.5-(24 \%)$ \\
\cline { 2 - 5 } & Oxígeno & $2.5 \pm 0.1-(50 \%)$ & $0.4 \pm 0.1-(25 \%)$ & $8.7 \pm 0.4-(25 \%)$ \\
\hline
\end{tabular}

Tabla 6.9-Tiempos de vida medio y \% de Luz Emitida obtenidos para cada especie emisora en las suspensiones de la $\mathrm{NpC}$ saturadas en diferentes atmosferas a $\mathrm{pH}=7$.

De los datos de la tabla se puede concluir que el quenching difusional de las NpC por el oxígeno molecular es muy pequeño y solo se evidencia para el tiempo de decaimiento $\boldsymbol{\tau}_{3}$. Cabe destacar que los ensayos estacionarios (Figura 6.25) no muestran variaciones importantes en la intensidad de fluorescencia por la presencia de oxígeno molecular por lo que se descarta un mecanismo estático de quenching de la luminiscencia provocado por la adsorción de oxígeno sobre la superficie de la partícula.

De forma de poder identificar si los tiempos de decaimiento obtenidos se deben a la presencia de poblaciones de partículas con diferentes espectros de emisión, se realizaron ensayos mediante el método de espectroscopia de emisión resuelta en el tiempo (TRES de sus siglas en inglés Time Resolved Emission Spectroscopy) con $\lambda_{E X C}=341 \mathrm{~nm}$ de suspensiones acuosas de las nanopartículas a pH 7 y saturadas en atmosfera de aire. Es de notar que por excitación a 341 estaríamos excitando mayormente a la especie contribuyente $\boldsymbol{a}$ (ver Figura 6.24). 
La figura 6.28 muestra el resultado de este análisis para la muestra NpC YM400. Los resultados obtenidos para las otras dos partículas si bien no se muestran presentan un comportamiento similar.

El espectro obtenido a un tiempo de emisión de 0.05 ns se corresponde claramente con un espectro típico de procesos asociados al scattering o dispersión de fotones. En cambio, el espectro observado a 2.96 ns es coincidente con el observado para el fluoroforo $\boldsymbol{a}$ (ver Figura 6.23), tal como era de esperar para una longitud de onda de excitación de $341 \mathrm{~nm}$. Por otro lado, el espectro observado a 9.51 ns con máximo de emisión a $430 \mathrm{~nm}$ es muy similar y coincide en gran parte con el observado a 2.96 ns. Es muy probable que estos dos decaimientos se deban al mismo fluoroforo pero en diferentes entornos dieléctricos o bajo formas ácido-base diferente. En este último caso estaría avalado por los espectros de emisión obtenidos a distintos $\mathrm{pH}$ que muestran modificaciones mínimas (corrimientos de pocos $\mathrm{nm}$ ) en el máximo de emisión por cambios abruptos en el pH (Figura 6.24). Sin embargo, no debe descartarse que estas diferencias podrían deberse a poblaciones de nanopartículas con diferentes tamaños.

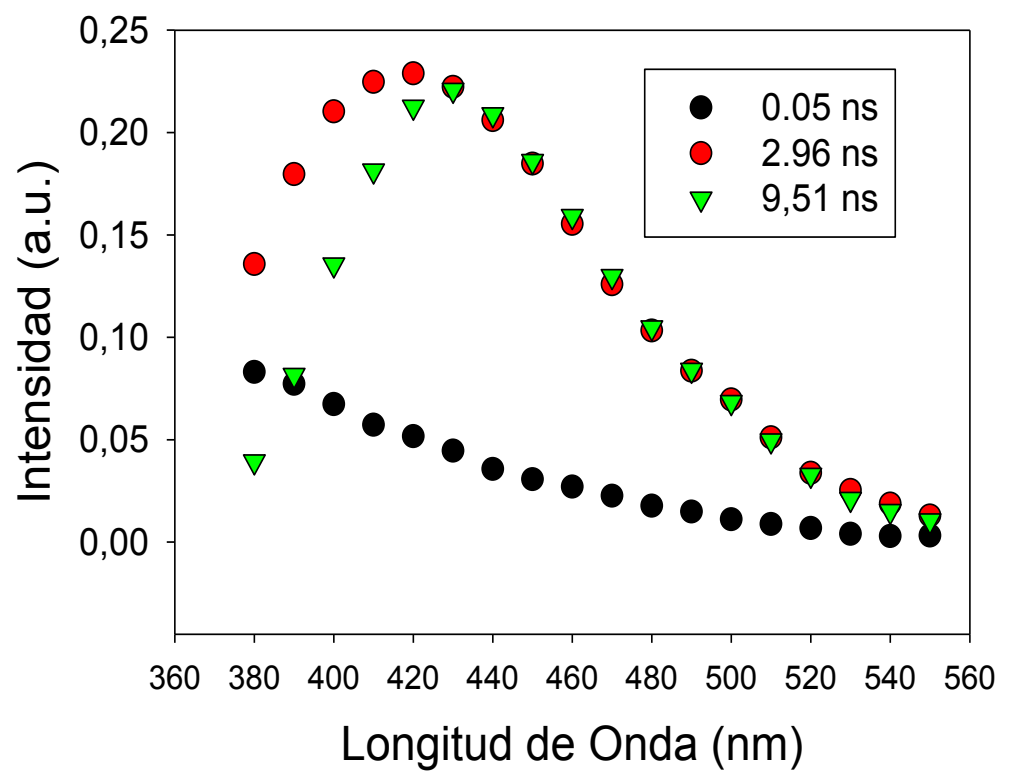

Fig. 6.28- Espectros de emisión resultante del ajuste TRES con $\lambda_{E X C}=341 \mathrm{~nm}$ para distintos tipos de decaimiento.

Se realizaron ensayos con luz polarizada, para estudiar la naturaleza de las transiciones involucradas en la emisión y absorción, y los mecanismos de despolarización involucrados. La medida de anisotropía resuelta en el tiempo está relacionada con las orientaciones relativas de los momentos dipolares de las partículas tanto en estado basal como en estado excitado. Estos experimentos permiten obtener el tiempo de rotación Browniana $(\theta)$ y la anisotropía a tiempo cero $\left(\mathbf{r}_{\mathrm{o}}\right)$. Esta relación sigue el siguiente modelo:

$$
r(t)=r_{0} e^{t / \theta}
$$

La figura 6.29 muestra los resultados obtenidos para la YM400, si bien no se muestran los resultados de las otras partículas, son similares a los que se muestran a continuación. 


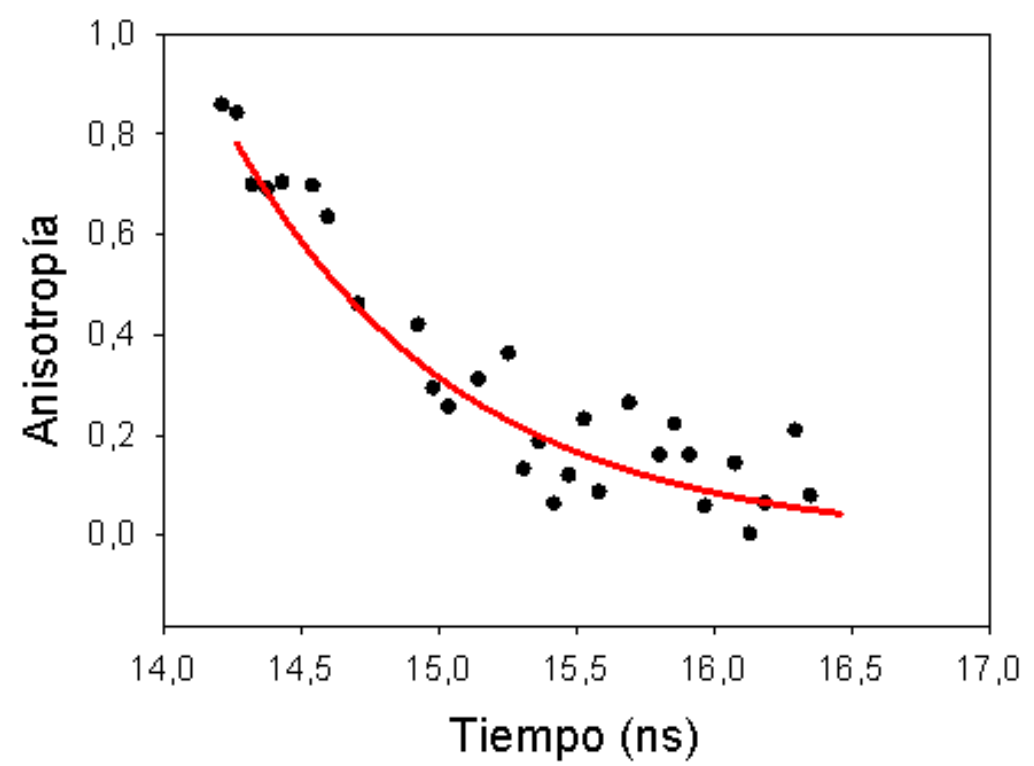

Fig. 6.29 - Curva de anisotropía (Exc 341 nm y Ems 425nm) obtenida para una suspensión acuosa de la YM400 (Puntos negros) y curva simulada.

Todos los ajustes utilizados para simular los decaimientos fueron monoexponenciales. Lo anterior permite concluir que la emisión se origina principalmente a partir de una población de partículas con tres ejes de rotación perpendiculares e idénticos entre sí, lo que sugiere una forma esférica para estas partículas. Si bien no se han encontrado reportes de estudios similares para estos materiales, si se han logrado evidenciar por HRTEM que esta es la geometría de esta clase de material[30], [32].

Los resultados obtenidos a partir del ajuste de estas curvas se muestran en la Tabla 6.7. Las NpC despolarizan la radiación mayormente por difusión rotacional. A su vez, la orientación entre los vectores momento de transición para la emisión y la absorción es diferente para las tres partículas, pero el cambio más notorio se observa para CN400. Esto indica que si bien los estados involucrados comparten ciertas características como tiempos de decaimiento y espectros de excitación y emisión, se diferencian bien según sus momentos de transición.

\begin{tabular}{|c|c|c|c|}
\hline Material & $\boldsymbol{\Theta}(\mathbf{n s})$ & ro & D $_{\text {AN }}(\mathbf{n m})$ \\
\hline NpC YM400 & 0.83 & 0.34 & 2.8 \\
\hline NpC CN400 & 0.98 & 0.20 & 3.3 \\
\hline NpC CN Mw & 1.32 & 0.37 & 4.5 \\
\hline
\end{tabular}

Tabla 6.7 - Valores de tiempo de rotación Browniano $(\theta)$, Anisotropía a tiempo cero (ro) y diámetro hidrodinámico $\left(D_{A N}\right)$ obtenidos por medidas de anisotropía para las suspensiones acuosas de $\mathrm{NpC}$ a $\mathrm{pH}=7$.

Conociendo los datos del tiempo de rotación de las partículas se puede obtener el valor del radio hidrodinámico de las mismas, ya que la dependencia del tiempo de rotación Browniano $(\Theta)$ con el volumen de las partículas (V) para partículas esféricas está dada por la teoría hidrodinámica de la difusión rotacional para esferas:

$$
\Theta=\frac{\eta V}{k_{B} T}
$$


Donde $\mathrm{k}_{\mathrm{B}}$ es la constante de Boltzman y $\eta$ es la viscosidad del solvente a la temperatura experimental. En este caso $\eta=1.00 \mathrm{mPa} \cdot \mathrm{S}$ (298K)[39]. Cabe resaltar además, que los $D_{A N}$ obtenidos para estar partículas está en concordancia con lo reportado por HRTEM para esta clase de nanomateriales[30], [32].

En la literatura existe discrepancia respecto a la explicación que se le atribuye al origen de la fluorescencia que presentan estas partículas. Algunos autores afirman que se deben al efecto de confinamiento cuántico, motivo por el cual se les denominan en algunos casos a estos materiales como Carbon Quantum Dots, sin embargo otros apuntan a que se debe a la fluorescencia de los grupos orgánicos superficiales presentes en los materiales [1].Los resultados aquí presentados muestran que partículas obtenidas a partir de diversos precursores y un mismo proceso de síntesis, así como partículas sintetizadas a partir de un mismo precursor pero a partir de distintos métodos, poseen en común un mismo cromóforo (especie $\boldsymbol{a}$ ) y otro a mayores longitudes de onda de emisión (especie $\boldsymbol{b}$ ), dependiente del precursor. Dado que el $\mathrm{pH}$ afecta la fluorescencia, es de esperar alguna contribución de los grupos superficiales a la luminiscencia. Estas observaciones sugieren la coexistencia de ambos tipos de emisión, donde la emisión asociada a la especie $\boldsymbol{a}$ se deba al efecto del confinamiento cuántico, tal como se sugirió al observar dos tiempos de decaimiento diferentes con espectros de emisión muy similares por excitación a $341 \mathrm{~nm}$. Por otro lado, la especie $\boldsymbol{b}$ podría estar asociada al decaimiento de estados excitados superficiales originados por la presencia de diferentes grupos funcionales.

\subsubsection{Ensayos de generación de especies reactivas.}

Las Nanopartículas fueron sometidas a ensayos de irradiación $\left(\lambda_{\text {exc }}=350\right.$ $\mathrm{nm}$ ) en estado estacionario para evidenciar si estas eran capaces de generar mediante fotosensibilización Oxígeno Molecular Singulete. Los resultados de estos ensayos se muestran en la figura 6.30.

Para la CN 400 se observa que no hay consumo de Oxígeno molecular cuando solo se encuentran las nanopartículas en suspensión (puntos negros). Luego de agregar Alcohol furfurílico (puntos verdes) se evidencia que hay una disminución un poco más rápida del $\mathrm{O}_{2}$, sin embargo al estar presente la $\mathrm{NaN}_{3}$ (puntos rojos) la concentración de $\mathrm{O}_{2}$ sigue disminuyendo con la misma velocidad.

La YM400 por su parte, no presenta consumo de $\mathrm{O}_{2}$ al estar solo las partículas en suspensión, pero al agregar $\mathrm{AF}$ al sistema se evidencia una disminución marcada de la concentración de $\mathrm{O}_{2}$. Al agregar $\mathrm{NaN}_{3}$ este consumo persiste pero con una velocidad más baja.

Los ensayos para la $\mathrm{CN}$ Mw indican que incluso cuando las partículas se encuentran solas en suspensión hay consumo de $\mathrm{O}_{2}$. Dicha velocidad de consumo no se ve afectada al introducir el $\mathrm{AF}$ ni $\mathrm{NaN}_{3}$ en el sistema. 


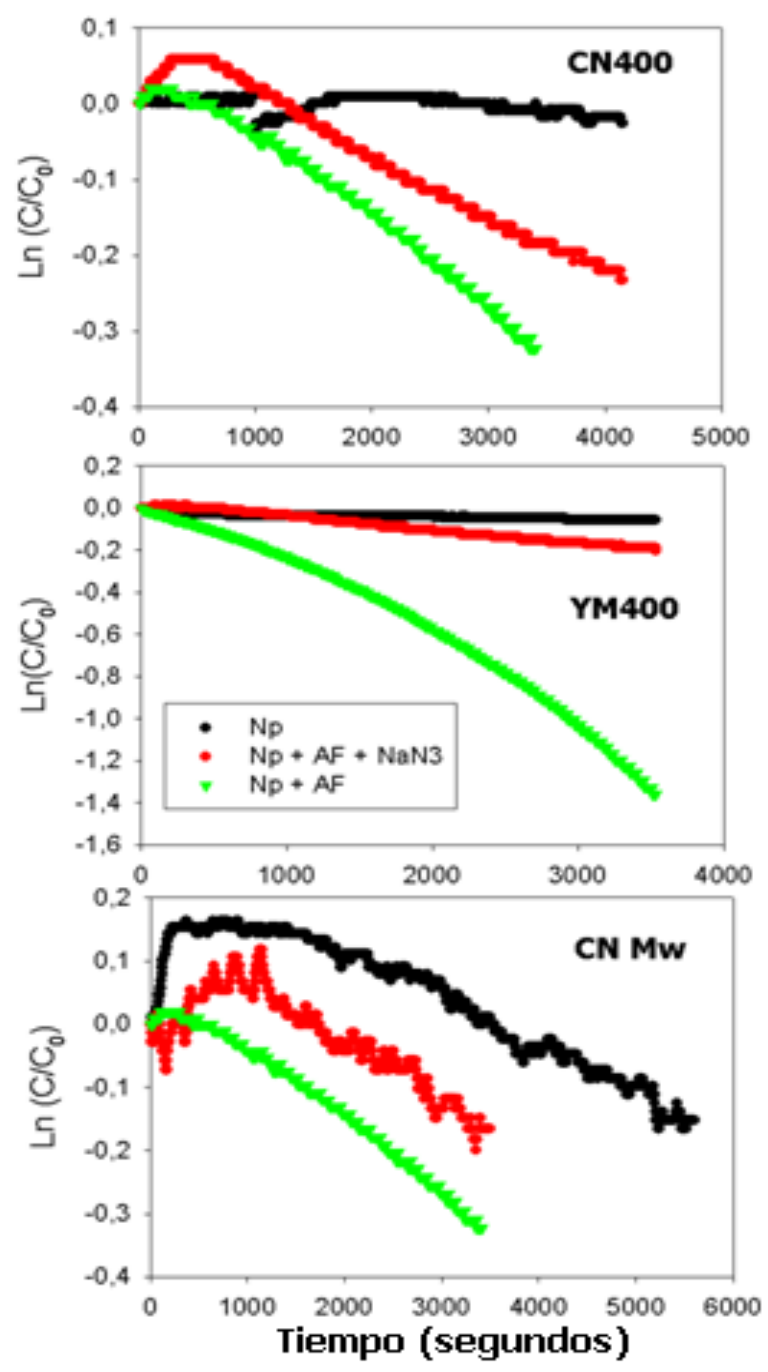

Fig. 6.30 - Curvas de Consumo de O2desuspensiones de las diferentes NpC obtenidas.

En la tabla 6.8 se muestran las pendientes de los ajustes lineales que simulan las curvas anteriores con el fin de analizar el comportamiento observado.

\begin{tabular}{|c|c|c|c|}
\hline \multirow{2}{*}{ Material } & Np & Sistema \\
\cline { 2 - 4 } & Np AF & Np $+\mathbf{A F}+\mathbf{N a N}_{\mathbf{3}}$ \\
\hline NpC CN400 & $(-3.5 \pm 0.3) \times 10^{-6}$ & $(-7.5 \pm 0.5) \times 10^{-5}$ & $(-8.0 \pm 0.5) \times 10^{-5}$ \\
\hline NpC YM400 & $(-1.07 \pm 0.2) \times 10^{-5}$ & $(-6.31 \pm 0.22) \times 10^{-5}$ & $(-3.75 \pm 0.20) \times 10^{-4}$ \\
\hline NpC CN Mw & $(-5.81 \pm 0.65) \times 10^{-5}$ & $(-6.00 \pm 0.16) \times 10^{-5}$ & $(-6.09 \pm 0.53) \times 10^{-5}$ \\
\hline
\end{tabular}

Tabla 6.8- Pendientes de las curvas de consumo de $\mathrm{O}_{2}$ mostradas en la Fig. 6.26

Los resultados anterioresdenotan un comportamiento diferente para cada tipo de nanopartícula. La CN400 no reacciona por vía fotoquímica con el $\mathrm{O}_{2}$, por ello cuando estas nanopartículas se encuentran solas en suspensión no hay consumo de la concentración de $\mathrm{O}_{2}$. Si bien al introducir AF al sistema hay disminución de la concentración de Oxígeno, en el tercer sistema esta 
disminución persiste y con la misma velocidad, por lo que se descarta la producción de Oxígeno Singlete. Este consumo por su lado, podría deberse a la formación de radicales del oxígeno capaces de reaccionar con el AF, pero no con al azida.

Por su lado, el sistema de la YM400 muestra el comportamiento típico de las partículas que producen Oxígeno Singulete. Las nanopartículas solas no producen consumo de $\mathrm{O}_{2}$. Al introducir $\mathrm{AF}$ al sistema hay un consumo más rápido de oxígeno y al agregar $\mathrm{NaN}_{3}$ si bien el consumo persiste es más lento debido al apagamiento del oxígeno singulete por vía física por reacción con la azida. Por todo lo anterior se puede concluir que estas partículas producen Oxígeno Singulete y que además, este no reacciona con la superficie de la nanopartícula.

Un caso contrario se evidenció para las nanopartículas CN Mw. En este sistema hay un consumo de oxígeno fijo para todos los casos. Esto es indicador de una reacción fotoquímica entre la superficie de la nanopartículas y el $\mathrm{O}_{2}$ presente en el medio.

Estas observaciones indican que las diferentes nanopartículas presentan diferencias superficiales que afectan su fotoreactividad, lo cual es razonable considerando que vienen de materias primas o métodos de síntesis diferentes. Tal como se discutió anteriormente, los respectivos espectros FTIR (Figura 5.25) muestran diferencias notables en los picos correspondientes a diferentes grupos orgánicos. Es de esperar que superficies tan diversas y heterogéneas muestren diferente reactividad frente a las reacciones del oxígeno.

Se intentó cuantificar el rendimiento cuántico de la producción de $\mathrm{O}_{2}\left({ }^{1} \Delta_{G}\right)$ por ensayos con luz pulsada, pero no fue posible debido a las suspensiones de estos materiales en acetonitrilo no son estables, presentando precipitación de un sólido de color verdoso.

Por último, se realizaron ensayos cualitativos para evidenciar la generación del radical anión superóxido. Para fines comparativos, en estos ensayos se utilizaron suspensiones con idéntica absorbancia a $350 \mathrm{~nm}$. La tabla 6.9 muestra los resultados obtenidos:

\begin{tabular}{|c|c|c|}
\hline Material & Abs $350 \mathbf{~ n m}$ & {$\left[\mathbf{H}_{\mathbf{2}} \mathbf{O}_{\mathbf{2}}\right] \mathbf{\mu M}$} \\
\hline YM400 & 0.0937 & $4.71 \pm 0.51$ \\
\hline CN400 & 0.0945 & $27.16 \pm 0.09$ \\
\hline CN Mw & 0.0902 & $23.15 \pm 0.10$ \\
\hline
\end{tabular}

Tabla 6.9 - $\left[\mathrm{H}_{2} \mathrm{O}_{2}\right]$ producida por una suspensión de las $\mathrm{Np}$ luego de ser irradiadas.

De la tabla 6.9 se concluye que la concentración de $\mathrm{O}_{2} \cdot-$ generado por las partículas de YM400 es muy pequeña y menor que la generada por las NpC obtenidas de la cascara de naranja.

La diferente producción de $\mathrm{O}_{2}$-puede deberse a dos factores: diferente capacidad de producción de $\mathrm{O}_{2}$-intrínseca de cada tipo de partícula o debido al consumo de $\mathrm{O}_{2}{ }^{--}$por reacción con la superficie. Esta última reacción compite con la generación de $\mathrm{H}_{2} \mathrm{O}_{2}$ que es el producto detectado por el kit comercial, y por lo tanto se estimarían valores menores a los generados. 
D. Fabio Mercado

Es interesante notar que la YM400 es la partícula menos eficiente en la producción de $\mathrm{O}_{2}$-pero la única a la que se le pudo probar la generación de oxígeno singulete. 


\subsection{Conclusiones.}

El efecto del extracto de Yerba Mate sobre la síntesis de nanopartículas de $\mathrm{Fe}_{3} \mathrm{O}_{4}$ modifica las propiedades magnéticas de las mismas, dado que el recubrimiento de las partículas con materia orgánica conlleva a la disminución de la coercitividad magnética que presentan las muestras. Además, se evidenció que las interacciones interpartículas de los nanomateriales recubiertos con extractos de YM poseen un efecto desmagnetizante para todos los sistemas estudiados.

Por otro lado, se demostró que el uso del extracto de yerba mate aumenta la adsorción de Azul de Metileno en fase acuosa respecto de la magnetita sin recubrir. El análisis de los parámetros obtenidos a partir del ajuste de las isotermas mediante el modelo de Langmuir sugiere que las interacciones adsorbato-adsorbente en las partículas recubiertas con materia orgánica son más estables que las interacciones con la superficie del óxido. Por otro lado, a pesar de la mayor adsorción de colorante en las nanopartículas recubiertas con extracto de yerba mate, la degradación de AM por especies reactivas oxidantes se ve inhibida respecto del mismo sistema en ausencia de materia orgánica. Se atribuyó esta última inhibición a varias razones, entre ellas, destaca la ocurrencia de reacciones competitivas entre las especies oxidantes y la materia orgánica, tal como se demostró para la degradación de AM por activación del radical $\mathrm{SO}_{4}{ }^{-}$.

Por su lado, utilizando Yerba Mate residual y Cascara de Naranja se pudieron obtener nanopartículas de Carbono que poseen altos rendimientos cuánticos de fluorescencia. A pesar de provenir de diferentes materias primas y de métodos de síntesis variados, se obtuvieron partículas con propiedades luminiscentes similares. Sin embargo, la generación de oxígeno singulete y anión radical superóxido parece ser muy dependiente de la naturaleza del precursor y del método de síntesis. Estas observaciones permitieron obtener algunas primeras aproximaciones al conocimiento de la naturaleza de las propiedades ópticas de estas partículas.

Todo lo anterior permite vislumbrar algunos campos de aplicación posibles para los residuos considerados. En el caso de la Yerba Mate, el uso de un mismo residuo en procesos en serie conllevaría por un lado a la obtención de nanopartículas magnéticas recubiertas con propiedades interesantes como absorbentes de colorantes en fase acuosa. Por el otro, permite obtener nanomateriales de última generación con propiedades luminiscentes interesantes para usos en tecnologías ópticas, como por ejemplo sensores fotoluminiscentes. 


\subsection{Referencias bibliográficas.}

[1] Y. Wang and A. Hu, "Carbon quantum dots: synthesis, properties and applications," J. Mater. Chem. C, vol. 2, no. 34, p. 6921, 2014.

[2] S. De, A. M. Balu, J. C. Van Der Waal, and R. Luque, "Biomass-derived porous carbon materials: Synthesis and catalytic applications," ChemCatChem, vol. 7, no. 11, pp. 1608-1629, 2015.

[3] S. N. Baker and G. A. Baker, "Luminescent carbon nanodots: Emergent nanolights," Angew. Chemie - Int. Ed., vol. 49, no. 38, pp. 6726-6744, 2010.

[4] P. Roy, P.-C. Chen, A. P. Periasamy, Y.-N. Chen, and H.-T. Chang, "Photoluminescent carbon nanodots: synthesis, physicochemical properties and analytical applications," Mater. Today, vol. 00, no. 00, pp. 1-12, 2015.

[5] P. Allia, M. Coisson, P. Tiberto, and F. Vinai, "Hysteretic magnetisation curves in the granular Cu 100-x Co x system," Nanostructured Mater., vol. 11, no. 6, pp. 757-767, 1999.

[6] T. Jonsson, J. Mattsson, P. Nordblad, and P. Svedlindh, "Energy barrier distribution of a noninteracting nano-sized magnetic particle system," vol. 53, no. 8607739, pp. 404-407, 1986.

[7] S. Morup and E. Tronc, "Superparamagnetic relaxation of weakly interacting particles," Phys. Rev. Lett., vol. 72, no. 20, pp. 3278-3281, 1994.

[8] G. T. Landi, "Role of dipolar interaction in magnetic hyperthermia," Phys. Rev. B Condens. Matter Mater. Phys., vol. 89, no. 1, pp. 1-6, 2014.

[9] J. L. Dormann, L. Bessais, and D. Fiorani, "A dynamic study of small interacting particles: superparamagnetic model and spin-glass laws," J. Phys. C Solid State Phys., vol. 21, no. 10, p. 2015, 1988.

[10] P. Allia, M. Coisson, M. Knobel, P. Tiberto, and F. Vinai, "Magnetic hysteresis based on dipolar interactions in granular magnetic systems," Phys. Rev. B, vol. 60, no. 17 , pp. 12207-12218, 1999.

[11] Hudson Institute of Mineralogy, "Mineral Data," 2016. [Online]. Available: http://www.mindat.org/.

[12] F. H. Sánchez, P. Mendoza Zélis, M. L. Arciniegas, G. A. Pasquevich, and M. B. F. van Raap, "Dipolar interaction and demagnetizing effects in magnetic nanoparticle dispersions: introducing the Mean Field Interacting Superparamagnet Model (MFISP Model)," p. 32, 2015.

[13] G. Mériguet, E. Dubois, M. Jardat, A. Bourdon, G. Demouchy, V. Dupuis, B. Farago, R. Perzynski, and P. Turq, "Understanding the structure and the dynamics of magnetic fluids: coupling of experiment and simulation," J. Phys. Condens. Matter, vol. 18, pp. S2685-S2696, 2006.

[14] S. Nakamae, C. . Crauste-Thibierge, K. Komatsu, D. L. Hôte, E. Vincent, and E. Dubois, "Anisotropy-axis orientation effect on the magnitization of," J. Phys. $D$ Appl. Phys., vol. 43, 2010.

[15] R. Reznícek, V. Chlan, H. Stepánkova, P. Povák, and M. Marysko, "Magnetocrystalline anisotropy of magnetite," J. Magn. Magn. Mater., vol. 31-34, no. PART 2, pp. 813-814, 1983.

[16] Y. Sunghyun, "Determination of the Temperature Dependence of the Magnetic Anisotropy Constant in Magnetite Nanoparticles," J. Korean Phys. Soc., vol. 59, no. 5, p. 3069, 2011.

[17] G. Magnacca, A. Allera, E. Montoneri, L. Celi, D. E. Benito, L. G. Gagliardi, and L. Carlos, "Novel magnetite nanoparticles coated with waste sourced bio- based substances as sustainable and renewable adsorbing materials," ACS Sustain. Chem. Eng., vol. in press, 2014.

[18] X. Zhang, P. Zhang, Z. Wu, L. Zhang, G. Zeng, and C. Zhou, "Adsorption of methylene blue onto humic acid-coated Fe3O4 nanoparticles," Colloids Surfaces $A$ Physicochem. Eng. Asp., vol. 435, pp. 85-90, 2013.

[19] G. Magnacca, A. Allera, E. Montoneri, L. Celi, D. E. Benito, L. G. Gagliardi, L. Carlos, and J. Accepted, "Novel magnetite nanoparticles coated with waste 
sourced bio- based substances as sustainable and renewable adsorbing materials," 2014.

[20] J. Fu, Z. Chen, M. Wang, S. Liu, J. Zhang, J. Zhang, R. Han, and Q. Xu, "Adsorption of methylene blue by a high-efficiency adsorbent (polydopamine microspheres): Kinetics, isotherm, thermodynamics and mechanism analysis," Chem. Eng. J., vol. 259, pp. 53-61, 2015.

[21] A. . Dada, A. . Olalekan, A. . Olatunya, and O. Dada, "Langmuir , Freundlich , Temkin and Dubinin - Radushkevich Isotherms Studies of Equilibrium Sorption of Zn 2 + Unto Phosphoric Acid Modified Rice Husk," IOSR J. Appl. Chem., vol. 3, no. 1, pp. 38-45, 2012.

[22] P. Avetta, A. Pensato, M. Minella, M. Malandrino, V. Maurino, C. Minero, K. Hanna, and D. Vione, "Activation of Persulfate by Irradiated Magnetite: Implications for the Degradation of Phenol under Heterogeneous Photo-Fenton-Like Conditions," Environ. Sci. Technol., vol. 49, no. 2, pp. 1043-1050, 2015.

[23] A. Ghauch, A. M. Tuqan, N. Kibbi, and S. Geryes, "Methylene blue discoloration by heated persulfate in aqueous solution," Chem. Eng. J., vol. 213, pp. 259-271, 2012.

[24] W. J. Mcelroy and S. J. Waygood, "Kinetics of the Reactions of the Radical SO4.with SO4-, S2O8-, H2O and Fe2+," vol. 86, no. 14, pp. 2557-2564, 1990.

[25] C. Tan, N. Gao, Y. Deng, J. Deng, S. Zhou, J. Li, and X. Xin, "Radical induced degradation of acetaminophen with $\mathrm{Fe} 3 \mathrm{O} 4$ magnetic nanoparticles as heterogeneous activator of peroxymonosulfate," J. Hazard. Mater., vol. 276, pp. 452-460, 2014.

[26] Y. S. Zhao, C. Sun, J. Q. Sun, and R. Zhou, "Kinetic modeling and efficiency of sulfate radical-based oxidation to remove $\mathrm{p}$-nitroaniline from wastewater by persulfate / Fe 304 nanoparticles process," Sep. Purif. Technol., vol. 142, pp. 182-188, 2015.

[27] M. C. GONZALEZ, D. O. MARTIRE, and A. M. BRAUN, "Aqueous phase kinetic studies involving highly reactive species of environmental interest," Recent Res. Dev. Photochem. Photobiol., pp. 25-45.

[28] X. W. Tan, A. N. B. Romainor, S. F. Chin, and S. M. Ng, "Carbon dots production via pyrolysis of sago waste as potential probe for metal ions sensing," J. Anal. Appl. Pyrolysis, vol. 105, pp. 157-165, 2014.

[29] Q. Liang, W. Ma, Y. Shi, Z. Li, and X. Yang, "Easy synthesis of highly fluorescent carbon quantum dots from gelatin and their luminescent properties and applications," Carbon N. Y., vol. 60, pp. 421-428, 2013.

[30] M. Wu, Y. Wang, W. Wu, C. Hu, X. Wang, J. Zheng, Z. Li, B. Jiang, and J. Qiu, "Preparation of functionalized water-soluble photoluminescent carbon quantum dots from petroleum coke," Carbon N. Y., vol. 78, pp. 480-489, 2014.

[31] Y. Wang and A. Hu, "Carbon quantum dots: synthesis, properties and applications," J. Mater. Chem. C, vol. 2, pp. 6921-6939, 2014.

[32] Y. Hu, J. Yang, J. Tian, L. Jia, and J. S. Yu, "Waste frying oil as a precursor for one-step synthesis of sulfur-doped carbon dots with $\mathrm{pH}$-sensitive photoluminescence," Carbon N. Y., vol. 77, pp. 775-782, 2014.

[33] D. Ciolkosz and R. Wallace, "A review of torrefraction for bioenegy feedstock production," Biofuels, Bioprod. Biorefining, vol. 5, no. 3, pp. 317-329, 2011.

[34] M. P. Sk, A. Jaiswal, A. Paul, S. S. Ghosh, and A. Chattopadhyay, "Presence of Amorphous Carbon Nanoparticles in Food Caramels," Sci. Rep., vol. 2, 2012.

[35] J. Zhang, W. Shen, D. Pan, Z. Zhang, Y. Fang, and M. Wu, "Controlled synthesis of green and blue luminescent carbon nanoparticles with high yields by the carbonization of sucrose," New J. Chem., vol. 34, no. 4, p. 591, 2010.

[36] Y. Q. Zhang, D. K. Ma, Y. G. Zhang, W. Chen, and S. M. Huang, "N-doped carbon quantum dots for TiO2-based photocatalysts and dye-sensitized solar cells," Nano Energy, vol. 2, no. 5, pp. 545-552, 2013.

[37] R. Vikneswaran, S. Ramesh, and R. Yahya, "Green synthesized carbon nanodots 
as a fluorescent probe for selective and sensitive detection of iron(III) ions," Mater. Lett., vol. 136, pp. 179-182, 2014.

[38] B. Valeur, Molecular Fluorescence. Principles and Applications. New York: Wiley $\mathrm{VCH}, 2002$.

[39] J. R. Lakowicz, Principles of Fluorescence Spectroscopy, 3rd ed. Baltimore: Plenum Press, 1999. 


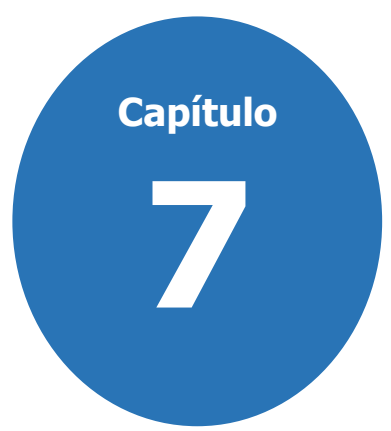

\section{Conclusiones Generales.}

En esta tesis se plantearon algunos objetivos iniciales que nos permitieron ahondar en el conocimiento del uso de residuos domiciliarios en diversos procesos para el tratamiento de contaminantes y en la obtención de nanomateriales de interés tecnológico.

A continuación, se describen los objetivos secundarios considerados en el marco de este trabajo y sus resultados.

- Estudiar la capacidad de los SBO de actuar como agentes fotosensibilizadores. Se emplearán al Azul de Metileno y el Pireno en solución acuosa como compuestos prueba.

La degradación fotoquímica de Azul de Metileno y Pireno asistida por los SBO demostró que los SBO no poseen propiedades prometedoras como fotosensibilizadores de especies reactivas capaces de iniciar la degradación de estos contaminantes. De hecho se evidenció que por irradiación en la zona del UV, estos compuestos actúan como filtros internos evitando la fotolisis directa de los contaminantes. Por otro lado se evidenció que los SBO interaccionan de forma débil con el pireno pero de forma fuerte con el Azul de Metileno.

- Investigar el efecto de la presencia de los SBO en el rendimiento de la degradación por vía tipo Fenton. Se estudiará la degradación del Flusilasol a pH 5.0como caso prueba. Postular el mecanismo de degradación inicial del Flusilasol.

La reacción fenton es un proceso muy eficiente para la degradación de muchos contaminantes en solución acuosa, y en particular a pH 3.0. En efecto, se evidenció que el Flusilasol se degrada por vía Fenton a pH 3.0 casi en su totalidad a los 15 minutos. Sin embargo, la reacción Fenton disminuye su eficiencia a pH mayores debido a la insolubilidad de los iones hierro a pH más altos. De hecho, la degradación del Flusilasol a pH 5.0 no alcanza el $40 \%$ incluso después de los 30 minutos de irradiación. En este aspecto, el agregado de los SBO a la mezcla de reacción a pH 5.0 aumenta la eficiencia de la degradación del fungicida. Se propone, que el mecanismo operante de esta mejora en el tratamiento se debe a la complejación de los iones Fe de forma de mejorar la solubilidad de los mismos a este $\mathrm{pH}$. No obstante,el uso de SBO en las condiciones óptimas de $\mathrm{pH}$ típicas de los procesos Fenton (cerca de $\mathrm{pH}$ 3.0) tiene un efecto adverso sobre la eficiencia de la degradación. 
Por otro lado,los estudios fotoquímicos estacionarios y resueltos en el tiempo evidenciaron que el mecanismo de degradación inicial del Flusilasol con los agentes oxidantes como $\mathrm{SO}_{4}{ }^{-} / \mathrm{HO}$ tiene lugar por una transferencia de carga desde el $\mathrm{N}$ cabeza del grupo triazol hacia estos radicales. La constante de reacción absoluta determinada para la reacción entre el $\mathrm{SO}_{4} 4^{-}$y el fungicida es (4.6 \pm 0.4$) \times 10^{8} \mathrm{M}^{-1} \mathrm{~s}^{-1}$, indicando que el Flusilasol es en efecto un insecticida de fácil degradación por especies oxidantes reactivas.

- Utilizar los SBO como plantillas en la síntesis de nanomateriales. Caso de la síntesis de nanocompositos de Hidroxiapatita/Óxido de hierro que presenten propiedades magnéticas. Aplicación de los nanomateriales obtenidos en la adsorción de metales, $\mathrm{Cu}^{+2}$ y $\mathrm{Pb}^{+2}$

El uso de los SBO como plantilla en la síntesis de nanocompositos de hidroxiapatita/óxidos de Hierro introduce cambios importantes en la morfología y química superficial de estos materiales. A mayor cantidad de SBO en la síntesis se observa una disminución de la cristalinidad del material, un mayor contenido orgánico superficial, pero sobre todo, una disminución del tamaño de los aglomerados que forman estas partículas en suspensión acuosa. Todo lo anterior conlleva a un aumento en la eficiencia del proceso de adsorción de $\mathrm{Cu}^{+2} \mathrm{a}$ medida que se utiliza mayor cantidad de SBO en la síntesis de los materiales. Sin embargo, los estudios sobre la adsorción de $\mathrm{Pb}^{2+}$ indican que la presencia de los SBO aumenta la adsorción respecto de la hidroxiapatita sintética, pero esta absorción es menor que la observada para los híbridos hidroxiapatita/óxidos de hierro.

La adsorción en sistemas bi-metálicos depende fuertemente del material utilizado. Por su parte la nanohidroxiapatita sintética muestra una adsorción selectiva de $\mathrm{Pb}^{+2}$ sobre $\mathrm{Cu}^{+2}$, las nanopartículas híbridas hidroxiapatita/óxidos de hierro muestran selectividad fuertemente dependiente de la relación $[\mathrm{Pb}] /[\mathrm{Cu}]$ mientras que por su parte las nanopartículas híbridas hidroxiapatita/óxidos de hierro con SBO muestran igual afinidad por ambos metales.

- $\quad$ Sintetizar y caracterizar diferentes nanopartículas utilizando la Yerba Mate como materia prima. Obtención y evaluación de propiedades de nanopartículas de carbono. Uso de la cáscara de naranja en la obtención de NPs de C y en la variación de sus propiedades.

El uso de Yerba mate para la obtención de nanopartículas de $\mathrm{Ag}, \mathrm{Fe}_{3} \mathrm{O}_{4}, \mathrm{C}$ y $\mathrm{SiO}_{2}$ arrojó resultados interesantes. Se evidenció que el uso del extracto de esta planta permite la obtención de nanopartículas de $\mathrm{Ag} \mathrm{y} \mathrm{Fe}_{3} \mathrm{O}_{4}$. Las nanopartículas de $\mathrm{C}$ y $\mathrm{SiO}_{2}$ se obtuvieron en procesos en serie a partir del sólido remanente del extracto.

Por otro lado, la síntesis de Nanopartículas de Carbono también se llevó a cabo utilizando Cascara de Naranja como precursor. Es importante mencionar, que todas las Nanopartículas de Carbono obtenidas presentaron propiedades luminiscentes similares y un alto rendimiento cuántico de fluorescencia.

- $\quad$ Elucidar el efecto del uso del extracto hidrosoluble de la Yerba Mate como estabilizante superficial en la síntesis de nanopartículas de magnetita y sobre sus 
propiedades y en la eficiencia de adsorción. Aplicaciones de estas partículas en la degradación catalizada mediante el anión radical $\mathrm{SO}_{4}{ }^{-}$de azul de metileno.

La introducción de cantidades crecientes de extracto de yerba mate en la síntesis de las nanopartículas de $\mathrm{Fe}_{3} \mathrm{O}_{4}$ conlleva a un aumento del espesor de la capa orgánica superficial de las partículas. Esto introduce efectos desmagnetizantes en los materiales y disminuye su coercitividad magnética.

Por otra parte, se evidenció que el aumento del espesor de la capa orgánica de las nanopartículas de magnetita aumenta la eficiencia de adsorción de Azul de Metileno a partir de soluciones acuosas. Sin embargo, la eficiencia del proceso de degradación de este colorante por $\mathrm{SO}_{4}{ }^{-}$producido catalíticamente por los iones $\mathrm{Fe}^{2+}$ en la superficie de las partículas disminuye con el espesor.

Del conjunto de los resultados obtenidos, podemos resaltar las ventajas del uso de los SBO como agentes auxiliares para la degradación por vía fenton del Flusilasol a pH 5.0. Además, su uso como plantilla para la síntesis de nanopartículas hidroxiapatita/óxidos de hierro aumenta considerablemente la eficiencia del proceso de adsorción de $\mathrm{Cu}^{+2}$.

Sin embargo, entre las desventajas del uso de los SBO en procesos de remediación ambiental está la poca capacidad fotosensibilizadora de estos para la degradación de Azul de Metileno y de Pireno. Es importante mencionar queno se pudieron obtener nanopartículas de Carbono a partir de estos compuestos utilizando las mismas técnicas que para la yerba mate o la cascara de naranja. Analizando el proceso de síntesis de los SBO, la biomasa resultante como subproducto de la degradación de diversos contaminantes es sometida a un tratamiento alcalino y posteriormente ácido. En este último paso se utiliza $\mathrm{HNO}_{3}$ o $\mathrm{H}_{2} \mathrm{SO}_{4}$ concentrado por más de 4 horas en condiciones adecuadas para la carbonización del material. Esto último seguramente lleva a la formación de NpC que se estarían evacuando en el momento de centrifugar el sólido.

Como se mencionó oportunamente, los SBO son el producto del tratamiento de la Biomasa resultante de la degradación biológica de diversos residuos orgánicos. Las propiedades fisicoquímicas y químicas de estos materiales están sujetas a variaciones estacionales y su obtención requiere de la instalación de plantas de tratamiento de residuos verdes especiales. Los resultados de este trabajo y una búsqueda de bibliografía acertada permiten un replanteamiento en el proceso de los SBO hacia la implementación de procesos enmarcados en la temática de las Biorefinerias. Para ello, se requiere del diseño de un programa de recolección y clasificación de materia orgánica residual para la obtención de compuestos específicos. Casos similares han empezado a surgir en Alemania. El centro de investigación de agricultura de este país publicó un informe en el que se detalla la obtención de polímeros y carbohidratos, entre otros, a partir de residuos verdes clasificados. Esta clase de procesos conduce a una menor variabilidad en las propiedades fisicoquímicas de los precursores manteniendo la eficiencia de los procesos en los que se emplean y calidad de los materiales que de ellos se obtienen. 
D. Fabio Mercado

En términos generales se puede resumir las conclusiones de este trabajo en la frase "residuos para limpiar residuos". 